\title{
ON THE ABILITY OF ROCKS TO CONDUCT HEAT IN THE \\ LITHOSPHERE
}

\author{
A Dissertation \\ presented to \\ the Faculty of the Graduate School \\ at the University of Missouri-Columbia \\ In Partial Fulfillment \\ of the Requirements for the Degree \\ Doctor of Philosophy \\ by \\ JESSE MERRIMAN \\ Dr. Alan Whittington, Dissertation Supervisor \\ MAY 2019
}


The undersigned, appointed by the dean of the Graduate School, have examined the dissertation entitled

ON THE ABILITY OF ROCKS TO CONDUCT HEAT IN THE LITHOSPHERE presented by Jesse Merriman, a candidate for the degree of doctor of philosophy, and hereby certify that, in their opinion, it is worthy of acceptance.

\begin{tabular}{|c|}
\hline Professor Alan Whittington \\
\hline Professor Linda Godwin \\
\hline Professor Mian Liu \\
\\
\\
Professor Kevin Shelton \\
\hline
\end{tabular}


.......... for Paula, who gave me curiosity

......... for Larry, who defines resilience

........ for Brian, who gave me purpose

......... and for Thebe and Tethys, who really don't care 


\section{ACKNOWLEDGEMENTS}

Paul Carpenter assisted in electron microprobe, and X-Ray diffraction collection and sample preparation. Derick Roy provided competent and enthusiastic assistance during field work and performed additional XRD collection on samples. James Schiffbauer performed all SEM and EDS image collection on samples. Keith Benn provided early samples of rocks from the Superior province and advice for field work. Ed Van Hees, Wooter Bleeker, and John Percival provided GPS locations and advice for sample exposures, as well as administrative support for field work. Stuart Kenderes performed early data analysis for chapter 3 that was not included in the text. Nicholas Arndt provided komatiite samples, one of which was included in figure 3-1. Joy Branlund provided primary data points for the plagioclase model. Brian Evans provided sample Carrara, deformed. Peter Nabelek provided samples 17-4 and 33-1 and modified the Lithoheat software to accommodate time-dependent rundown of radioactive elements. Robert Bauer, Peter Nabelek, Mian Liu, Linda Godwin, and Kevin Shelton provided feedback at various stages as members of my dissertation committee. James Murrowchick provided feedback for XRD analysis. Anne Hofmeister collected much of the high-temperature LFA data in this work and has been an invaluable resource for all aspects of natural heat flow mechanisms and theory. Alan Whittington provided years of support, and feedback, and was instrumental in the grant, paper, and dissertation writing process, and gave me the unique opportunity to develop my own direction for my $\mathrm{PhD}$ research. 


\section{TABLE OF CONTENTS}

$\begin{array}{ll}\text { Acknowledgements } & \text { ii }\end{array}$

List of Illustrations $\quad$ iv

List of Tables vii

List of Equations viii

Abstract $x$

Chapter

1. Introduction to Thermal Transport Properties 1

2. Temperature-Dependent Thermal Transport Properties of Carbonate Minerals and Rocks

3. A Model for Temperature-Dependent Thermal Diffusivity of Crystalline Rocks, Part I: Samples, Characteristics, Methods, and Thermal Diffusivity Results

4. A Model for Temperature-Dependent Thermal Diffusivity of Crystalline Rocks, Part II: Ambient Temperatures and a New Model for Plagioclase

5. A Model for Temperature-Dependent Thermal Diffusivity of Crystalline Rocks, Part III: Modeling High-Temperature Thermal Diffusivity

6. Conclusions, Applications, and Suggestions for

Future Research 


\section{List of Illustrations}

Figure $\quad$ Page

Chapter 1

1-1. Thermal transport properties of common minerals 4

1-2. Diagram of the LFA 9

\section{Chapter 2}

2-1. Absoprtion spectra of common minerals at various temperatures 21

2-2. Tempeture-time curves for single-crystal and grainy calcite 24

2-3. Polarizing light photomicrographs of carbonate rock samples 40-45

2-4. Isobaric heat capacity measurements for carbonate rocks 47

2-5. Thermal diffusivity of carbonate minerals 51

2-6. Thermal diffusivity of limestones 54

2-7. Thermal diffusivity of metamorphic carbonate rocks 55

2-8. Repeat measurements of thermal diffusivity of the Carrara marble 58

2-9. Calculated thermal conductivity and heat capacity of carbonate minerals $\quad 59$

2-10. Calculated thermal conductivity of carbonate rocks 60

2-11. Thermal diffusivity versus cation mass and unit cell volume 62

2-12. $k_{e} / k_{m x}$ versus pore fraction of carbonate rocks 64

2-13 Comparison of models for calculating $k$ using ambient temperature measurements

2-14. Modeled geothermal gradients, variable $D$, variable $k$, and variable of the modeled basin

\section{Chapter 3}

3-1. Comparison of measured $D(T)$ for crustal rocks 92

3-2. Average $D(T)$, and anisotropy in $D(T)$ of select minerals 96

3-3. SEM, EDS, Binoscope, and composite images of sample 16-28 106

3-4. PLM images of samples 16-28, and 16-36 111

3-5. PLM images of sample 14-4D 113

3-6. PLM images of sample UP-3A 115 
Figure

Page

3-7. Ternary ACF, AKM, and AFM diagrams of the sample suite

3-8. Binocular microscope images of 5 disks of sample 16-28

3-9. New high temperature measurements and projected $D$

3-10. $D(T)$ versus quartz fraction of sample 16-36

3-11. $D(T)$ versus quartz fraction of sample 16-28

3-12. $D(T)$ versus quartz fraction of quartzo-feldspathic disks

3-13. Weighted plagioclase-subracted $D_{\text {meas }}$ versus quartz fraction of the suite

\section{Chapter 4}

4-1. Diagram of Parallel, Series, and random mineral mixing

4-2. Plagioclase phase diagram and relative $D$ by orientation

4-3. Averaged $D$ values for plagioclase from Branlund and Hofmeister (2012)

4-4. Comparison of $C_{P}$ from the literature

4-5. The plagioclase interpolation models for two orientations at $298 \mathrm{~K}$

4-6. The plagioclase interpolation models at select temperatures

4-7. $D_{\text {calc }}$ versus $D_{\text {meas }}$, uncorrected and corrected for samples $16-36 \& 16-28$

4-8. Comparative EDS maps of $\mathrm{Ca}$ and $\mathrm{Al}$ content of sample 16-28

4-9. $D_{\text {calc }}$ versus $D_{\text {meas }}$, of various subsuites and the full suite

4-10. Composite EDS and binocular microscope image of disk c2Ad1, 14-5B

4-11. Comparison of calculated and measured porosity of porous samples

\section{Chapter 5}

5-1. Theoretical mixture of 50-50 quartz and plagioclase

5-2. Theoretical mixture of 50-50 augite and halite

5-3. Theoretical mixture of equal parts quartz, plagioclase, and biotite

5-7. Measured and calculated $D$ compared to minerals in disk for 16-03 
Figure

Page

5-10. $D_{\text {calc }} / D_{\text {meas }}$ for sample AW20 Run \#1 228

5-11. $D_{\text {calc }} / D_{\text {meas }}$ for samples with high-temperature alteration 230

5-12. $D_{\text {calc }} / D_{\text {meas }}$ for samples KB09c, Acasta Run \#1, and UP-7B 232

\section{Chapter 6}

6-1. Calculated $D$ for different bulk compositions of migmatite 16-35 246 
Table

Chapter 2

3-1. Carbonate sample sources and characteristics 30

2-2. EMPA analysis of carbonate samples 34

2-3. ICP-OES of carbonate suite 35

2-4. Fitting parameters for $C_{P}, D$, and $k$ of carbonate samples $\quad 48-49$

2-5. $D$ results for carbonate samples 53

2-6. Input parameters for thermal models $\quad 71$

Chapter 3

3-1. Characteristics and sources for sample used in the rock model 101-102

3-2. Disk-specific characteristics for the full suite 117-120

3-3. ICP-OES results for bulk rock powders of samples in the suite 123

3-3. Disk-specific XRD results 126-127

\section{Chapter 4}

4-1. Fitting parameters for ambient- $T$ suites

\section{Chapter 6}

6-1. Weight percent oxides in samples of migmatite 16-35 245

6-2. XRD results for sediment and sandstones collected by the Curiosity Rover 248 


\section{List of Equations}

Equation

Chapter 1

$1-1$.

$1-2$.

$1-3$.

1-4.

Chapter 2

2-1.

2-2.

2-3.

2-4.

Chapter 3

3-1.

3-2.

3-3.

3-4.

3-5.

104

3-6.

137

3-7.

137

3-8.

137

3-9.

137

3-10.

144

3-11.

144

\section{Chapter 4}

4-1.

4-2.

4-3.

165

4-4. 
4-5.

4-6.

173

4-7.

177

4-8.

173 


\begin{abstract}
This work focuses on creating a model for the conductive thermal transport properties of rocks using measured thermal diffusivity $(D)$ with the Laser Flash Analysis (LFA) method, which eliminates common errors associated with physical contacts and spurious ballistic radiative transfer. Using a suite of 122 samples of 55 Rocks, we develop a new approach to understanding $D$ of rocks by direct, careful, and thorough characterization of the disks used in measurements, and improving our understanding of the minerals that compose samples.
\end{abstract}

Using a newly-developed plagioclase interpolation model, and new measurements for the $D$ of common carbonate minerals, we compare measured to calculated $D$ at ambient and elevated temperature $(T)$. For most samples, $D$ at all $T s$ is best reproduced using the geometric mixing model, but some samples with clear anisotropy mix according to the series or parallel models. However, many high-temperature measurements are clouded by previously unidentified experimental errors, which typically lower reported $D$.

For application in Earth science, we created a Microsoft Excel(C) spreadsheet which will automatically calculate $D(T)$ of rocks using inputs of temperature, and the relative abundances of phases. Given the random errors found in measurements of rock $D$, the cost and time required to directly measure thermal transport properties of rocks, and the complex and unpredictable variations in rock characteristics on the scale of samples used to measure $D$, we recommend using calculated $D$ rather than measured $D$ for modeling thermal conduction in the lithosphere. 


\section{Chapter 1: Introduction to thermal transport properties}

"(It) is the little causes, long continued, which are considered as bringing about the greatest changes of the earth." - James Hutton, Theory of the Earth, Volume 2.

Science has progressed, in part, by developing new tools with which to examine the universe. The telescope opened up the heavens and required new math to explain simple and familiar concepts such as the length of a day. The microscope magnified an entire new world of life, literally at our finger tips, and showed us there were natural causes for our previously assumed supernatural illnesses. The concept of atomic decay gave us a quantitative clock with which to measure natural processes, not only producing objective numbers for the age of the Earth, but also describing a new source of heat that drives the Earth's ability to reshape its own surface. We constantly seek to develop new tools, and refine the tools we already have, always eking out another hair of precision, and pushing limits of detection. New and better tools help to breach limits of detection, and new concepts arise as a result. This work is an attempt to develop one such new tool: the ability to calculate how the outer layers of the Earth conduct heat and, consequently, push our understanding of the processes driven by Earth's just a little bit further.

While unlikely to have the impact or fame of the telescope, or to become a nearuniversal object in the tool bag of scientists like the microscope, this thermal diffusivity (D) calculator is a necessary endeavor, nonetheless. The fundamental physical property thermal diffusivity $\left(\mathrm{m}^{2} \mathrm{~s}^{-1}\right)^{1}$ is the rate with which a thermal disturbance will propagate through a material. It is an intrinsic property of all matter: independent of the amount of

\footnotetext{
${ }^{1}$ Because rock $D$ is typically on the order of $10^{-6} \mathrm{~m}^{2} \mathrm{~s}^{-1}$, we report $D$ in $\mathrm{mm}^{2} \mathrm{~s}^{-1}$ to save space and make numbers more digestible.
} 
material present, and dependent upon the structure, chemistry and bonds of the atoms composing that material. It relates intimately to temperature, also intrinsic, but is necessary for understanding the change in extrinsic properties of matter like quantities and movement of heat. In the Earth, the outer rigid layer, the lithosphere ${ }^{2}$, is partially defined by the domination of conduction of heat over convection within it. Thermal diffusivity is essential in determining how quickly heat present at any given depth can be conducted towards the surface of the Earth. If conduction is insufficient, then temperature increases, and convection may be required to dissipate this bottled-up heat. Although other properties of materials are essential to these concepts, thermal diffusivity has, until recently, been poorly understood. A calculator for thermal diffusivity could aid in our understanding of these processes.

An effective calculator for the ability of rocks to conduct heat will give Earth scientists a new tool to explore the movement of heat involved in numerous Earth processes: location, sources, and mechanisms driving melting within the lithosphere (Whittington et al., 2009), durations and triggers of thermally-driven metamorphism of rocks (Nabelek et al., 2012), temporal variations in strength and stress fields in the lithosphere (McKenzie et al., 2005), causes of and processes involved in the growth of the first continents (Rozel et al., 2017), and sources and rates of hydrothermal mineralization (Davis and Streufert, 1990; Zheng et al., 2019). Furthermore, as we continue to explore our solar system, new data may become available on the composition and minerals making-up the crusts of other terrestrial bodies. A effective model for

\footnotetext{
${ }^{2}$ The lithosphere is the outer ridged (rocky) layer of Earth which in which conduction dominates over convection. This layer is capped by the crust, which is a part of the lithosphere, but compositionally distinct from the layers of lithosphere below it.
} 
thermal diffusivity of rocks would be an essential tool for further developing our understanding of how other planets and moons of the solar system cool (van Thienen et al., 2005), and why most terrestrial bodies in the solar system appear geologically inactive (e.g. Mars, the Moon) while geologically-active bodies are rare (e.g. Hartmann, 2005).

It is difficult to discuss thermal diffusivity without the more well-known, related property thermal conductivity $\left(k, \mathrm{~W} \mathrm{~m}^{-1} \mathrm{~K}^{-1}\right)$, which is the ability of a material to conduct heat. These two properties are related through the equation:

$$
k=\rho C_{p} D
$$

Equation 1-1.

where $\rho$ is density $\left(\mathrm{kg} \mathrm{m}^{-3}\right)$, and $C_{\mathrm{P}}$ is isobaric heat capacity $\left(\mathrm{J} \mathrm{kg}^{-1} \mathrm{~K}^{-1}\right)$. Indeed, as we shall see later in this work, understanding $k$ may be best approached by treating $D, C_{P}$ and $\rho$ as independent components. Furthermore, all these properties vary with temperature $(T)$ and pressure $(P)^{3}$. In the case of density, this variability is modest: typically, less than 5\% between extremes of temperature of the Earth's lithosphere ( $\sim 300$ $1600 \mathrm{~K}, \mathrm{Fei}, 1995)$. Heat capacity, or the heat required to raise the temperature of a material, is more variable over similar temperatures, changing by $\sim 40 \%$ for plagioclase feldspar (pure anorthite, Benisek et al., 2013), or as much as a factor of five (e.g. diamond, Robie and Hemingway, 1995).

Thermal diffusivity, however, appears to be the primary driver of a general decrease in $k$ with increasing temperature. Heat capacity increases with increasing

\footnotetext{
${ }^{3}$ Pressure effects on thermal transport properties of rocks and minerals are minor over typical lithospheric pressures and typically offset by thermal expansion associated with increasing temperature with depth. See Hofmeister, 2007 for more information
} 

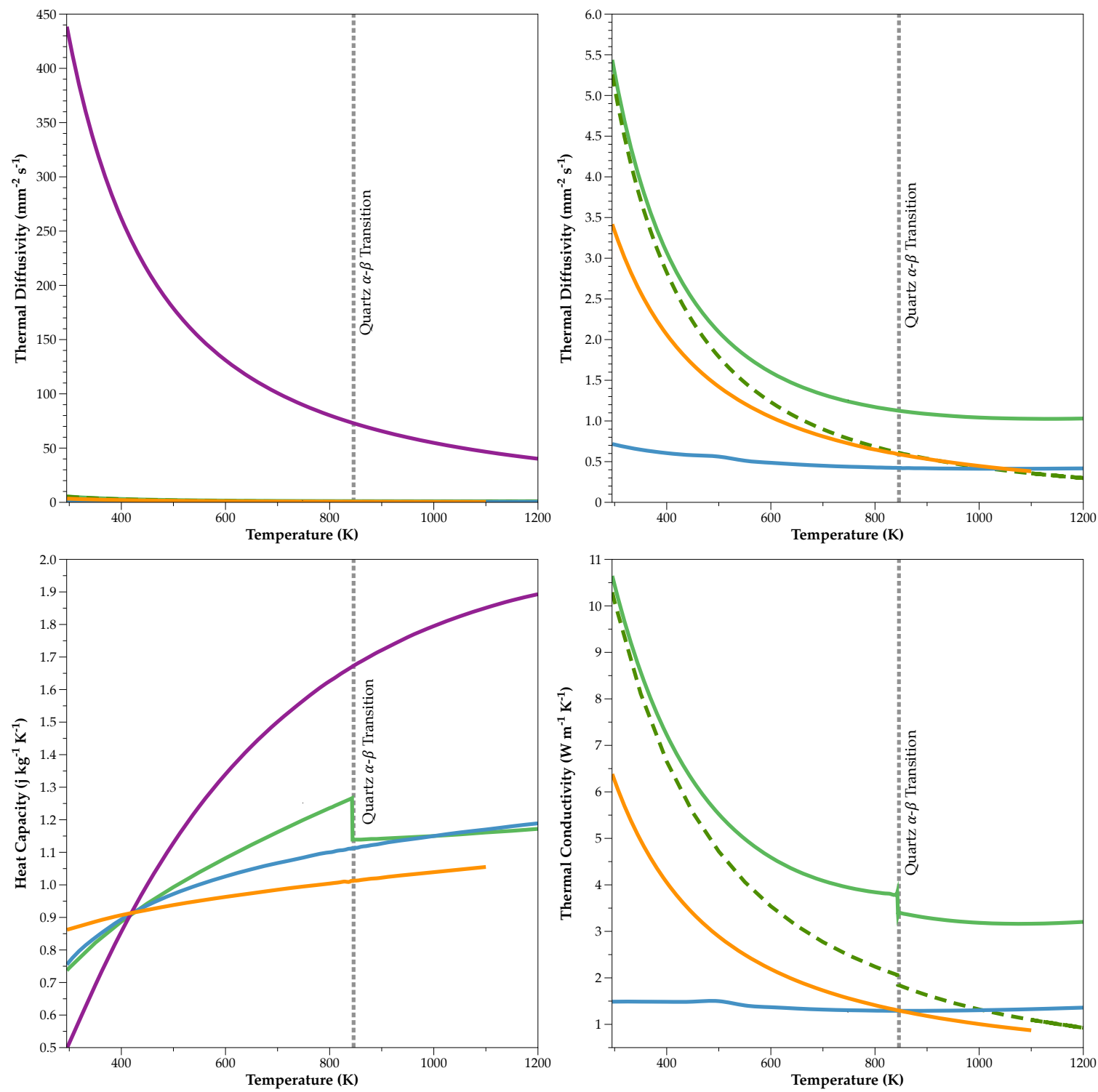

Figure 1-1) The temperature-dependence of thermal diffusivity (B), thermal conductivity (D) and isobaric heat capacity $(\mathrm{C})$ of the minerals quartz (solid light green line), halite (orange) and plagioclase ( $\mathrm{An}_{95}$, blue line). The dashed dark green line is an approximation of $D$ and $k$ for quartz if it had no diffusive radiative contribution at elevated temperature. The fit was generated by setting the radiative term of equation 2-3 to zero (see Hofmeister et al., 2014 for more information). (A) includes all the minerals in the top right as well as the $D$ of diamond, the most highlyconductive naturally-occurring material (Hofmeister, 2019). Note the change in scale. All data for $D$ are averages of orientations from the following sources: Quartz - Branlund and Hofmeister, 2007; Halite - Yu and Hofmeister, 2010; Anorthite - Branlund and Hofmeister, 2012. Heat capacity values are from Robie and Hemingway, 1995, except Anorthite, which was interpolated from endmember albite and anorthite presented by Benisek et al., 2013. 
temperature, but over the above temperatures, $k$ for most rock-forming minerals decreases. Minor decreases in density due to thermal expansion are unlikely to be the source, as the $\sim 5 \%$ increase in volume cited above is an extreme, and most minerals, or solid-solutions have volumes that increase by $\sim 2 \%$ (Fei, 1995). Thermal diffusivity, however, decreases by up to an order of magnitude (or more for rarer minerals) in this temperature range (Fig. 1-1A). For example, two of the most common minerals in the Earth's continental crust, quartz, and the solid-solution plagioclase have highly contrasting $D$ values (Fig 1-1B). Quartz, at ambient temperature, has a mean $D$ of 5.35 $\mathrm{mm}^{2} \mathrm{~s}^{-1}$ (Branlund and Hofmeister, 2007), compared to the $D$ of nearly pure anorthite (An95) of $0.71 \mathrm{~mm}^{2} \mathrm{~s}^{-1}$ (Branlund and Hofmeister, 2012). As temperature increases, $D$ decreases rapidly for quartz, but only modestly for Plagioclase: $3.14 \mathrm{~mm}^{2} \mathrm{~s}^{-1}$ and 0.61 $\mathrm{mm}^{2} \mathrm{~s}^{-1}$ at $400 \mathrm{~K}$ for quartz and plagioclase respectively. By $1000 \mathrm{~K}$, quartz $D$ has fallen $80 \%$ to $1.04 \mathrm{~mm}^{2} \mathrm{~s}^{-1}$ whereas plagioclase has decreased a more modest $40 \%$.

These highly variable thermal diffusivity values appear to translate to rocks as well. Whittington et al. (2009), and Merriman et al. (2013) studied thermal diffusivity across similar temperature ranges and found $D$ varied by a factor of four for rhyolite, granite, and schist (Whittington et al., 2009), and a factor of three for common amphibolite-facies rocks (Merriman et al., 2013), and a factor of two for supracrustal volcanic rocks. Of the rocks measured, lower-crustal granulites had the most modest variability across measured temperatures: on the order of a $40 \%$ decrease. However, as this work will show, common International Union of Geological Sciences (IUGS)- 
designated monikers for rocks are not good predictors of the ability of a rock to conduct heat.

\subsection{Thermal Transport Properties in the Context of the Solid}

\section{Earth}

The first-order controls on the conductive thermal structure of the lithosphere are the thickness of the lithosphere $(\Delta \mathrm{z})$, the boundary temperatures (typically reported as $298 \mathrm{~K}$ at the surface, and $\sim 1600 \mathrm{~K}$ at the base), and the rate of heat production ${ }^{4}$ within the lithosphere $\left(A_{\mathrm{rad}}\right)$. However, boundary temperatures do not fluctuate dramatically on Earth (e.g. Rollinson, 2007). Thus, it is likely that the temperature distribution within the lithosphere, the geothermal gradient, is primarily a result of the thickness of the lithosphere, and the heat produced within it.

For the simplest cases, the temperature at depth in the Earth can be found by rearranging Fourier's law:

$$
q=-k \frac{d T}{d z}
$$

Equation 1-2.

where $q$ is heat flux $\left(\mathrm{W} \mathrm{m}^{-2}\right)$. This equation, however, does not account for internal heat sources. Furthermore, most of the lithosphere is likely not at steady-state (e.g. Mareschal and Jaupart, 2006), and complex thermal processes operate within it. Therefore, we need an equation for a time-dependent geothermal gradient (in three dimensions):

\footnotetext{
${ }^{4}$ The primary source of heat production within the lithosphere is the decay of radioactive isotopes of the elements U, Th, and K. Additional sources of heat are typically location-specific and include such processes as latent heat of crystallization (the heat released by a liquid crystallizing), frictional heating along faults, and strain heating associated with plate flexure.
} 


$$
\frac{\partial T}{\partial t}=D(T) \nabla^{2} T+{\frac{A_{\text {rad }}}{\rho(T) C_{p}(T)}}^{5}
$$

Equation 1-3.

Note that both $C_{P}$ and $\rho$ are temperature-dependent. This equation uses $D$ rather than $k$. Because, until recently, it was thought that $D$ did not vary as strongly as the other components, $D$ was generally considered secondary to $A_{\text {rad }}$ and $\mathrm{d} T / \mathrm{dz}$ in influencing heat flow within the lithosphere. However, incremental development in the late 1990's of a tool first introduced by Parker et al. (1961), combined with recognition that results from traditional measurement techniques for $k$ are affected by imperfect physical contacts (Hofmeister and Branlund, 2015), has heightened the interest in $D$ as an important influence on the thermal state of the lithosphere.

\subsection{Phonons, Photons, and the Laser Flash Method}

Two components of heat transfer are present in conduction in varying amounts: a vibrational component, and a radiative component (Hofmeister and Branlund, 2015). Vibrational conduction is facilitated by the quasi-particle known as a phonon (e.g. Lowrie, 2011). All matter vibrates at different frequencies depending partially on temperature, and these "modes" of vibration vary by structure and composition (Hofmeister, 1999; Hofmeister, 2014; Hofmeister, 2019). Long wavelength vibrations are thought to be the source of sound waves, whereas quantized vibrations transport heat. As

\footnotetext{
${ }^{5} \nabla$ is the Laplacian Operator and in this case indicates partial derivative of temperature with respect to the Cartesian coordinates (x, y, z). See Appendix 1, pg. 616 of Fowler, 2005.
} 
temperature increases, the mean free path for a particular phonon decreases because the unit cell becomes saturated with phonons, and the ability of a material to transport heat is dampened. This is the source of most of the initial exponential decrease in $D$ displayed by quartz and halite in figure 1-1B.

So why then does this rate of decrease $(\mathrm{d} D / \mathrm{d} T)$ fall off at elevated temperatures? Warm bodies radiate heat in the infrared frequencies, and at low temperature, minerals are partially- to fully-transparent to this light. However, as temperature increases, IR intensity increases (see Fig. 2-1), and diffusive radiative transfer contributes more strongly to the $D$ of most minerals. However, not all minerals produce radiative transfer at elevated temperatures. Halite and diamond (Fig. 1-1B and A respectively) have fewer IR modes than other minerals and consequently have little radiative contribution at elevated temperatures. This means these minerals keep their high $\mathrm{d} D / \mathrm{d} T$ as they are heated to temperatures where IR intensity is orders of magnitude higher than at ambient temperatures. Conversely, quartz and plagioclase diffuse heat radiatively at high temperatures. Figure 1-1C shows an approximation of the radiative contribution to conduction in quartz (solid green line - measured $D$, dashed green line - approximate vibrational component of quartz). Without this diffusive radiative component, quartz, and likely much of the crust, would be more insulating at elevated temperatures.

The Laser Flash Analysis method (LFA), first developed by Parker et al. (1961) uses a laser to heat the bottom of a sample suspended within an atmosphere-controlled chamber (Fig 1-2). This eliminates the issue of imperfect physical contacts, as the light is absorbed by a graphite coating, and conducted into the sample. Heat flows across the sample to the opposite side, where a detector measures the change temperature over time. 
Thermal diffusivity is given by:

$$
D=0.1388 \frac{l^{2}}{t_{1 / 2}}
$$

Equation 1-4.

Figure removed due to copywrite restrictions

Figure 1-2) A schematic diagram of the LFA. An infrared laser heats the sample from below (left), which is suspended in an atmosphere-controlled chamber at the desired temperature. Light heats a graphite coating applied prior to insertion in the apparatus, which conducts into the sample, and then into the graphite coating on the opposite side of the disk (b). Emissions from a pre-defined area of the disk (controlled by the size of the aperture on the end cap) are measured by an IR detector on the opposite side of the laser pulse. The only physical contacts are between the graphite coating and the sample. Modified from Hofmeister et al., 2007.

Where $l$ is length $(\mathrm{mm})$ and $t_{1 / 2}$ is the half the time (s) required for the peak change in temperature measured on the opposite side of the sample. Application of this method was limited to opaque materials such as metals, until the algorithm of Mehling et al. (1998) 
facilitated the removal of an experimental form of radiative transfer termed "ballistic" or "direct" radiative transfer. This form of heat transfer occurs when light generated by the heat source travels through the sample without interacting with it (see Chapter 2, Introduction). The effect is to artificially elevate reported $D$ or $k$, particularly at high temperature. Consequently, experiments which did not control for ballistic radiative transfer often produced results with "U"-shaped curves, where the $D$ of the sample initially decreased, approached a minimum at intermediate temperatures, and returned to near-ambient values at very high temperatures (c.f. open symbols, no ballistic transfer, closed symbols ballistic transfer, Fig. 4, Pertermann et al., 2008).

Measurements of $D$ using the LFA method thus provide results which are free of contact losses at ambient temperatures, and spurious radiative transfer at elevated temperatures. Using the LFA method in this study provides the best opportunity to develop a first-order understanding of what controls both thermal diffusivity and thermal conductivity of rocks. The primary goal of this work was to develop such a model using an available database for the thermal diffusivity of minerals (Hofmeister, 2019), and a suite of 122 samples of common crustal rocks exhumed from paleodepths ranging from shallow, to near the Moho.

\subsection{Structure of this Dissertation}

Chapter 2 presents measurements for $D$ of carbonate minerals and rocks and provides a more detailed introduction to the LFA method, and the forms of error associated with common methods for measuring heat transfer properties. Chapter 3 
presents a new database for the thermal properties of rocks, including measurements of $D$ collected using the LFA technique, as well as detailed chemical, mineralogical and textural characterization. Chapter 4 compares calculated $D$ to measured $D$ for rocks at ambient temperature and discusses various methods for mixing the properties of constituent minerals, as well as presenting an interpolation model for the plagioclase feldspars. Chapter 5 examines calculated $D$ results at temperatures above ambient, evaluates the effectiveness of the plagioclase model at high- $T$, and suggests several new applications for the calculator. Finally, the main conclusions from this dissertation are summarized in Chapter 6, which also includes suggestions for future work.

\section{REFERENCES CITED}

Benisek, A., Dachs, E., and Carpenter, M.A., 2013, Heat capacity and entropy of low structural state plagioclases. Physics and Chemistry of Minerals: v. 40, p. 167-173, doi:10.1007/s00269-012-0556-2.

Branlund, J.M., and Hofmeister, A.M., 2007, Thermal diffusivity of quartz to $1,000^{\circ} \mathrm{C}$ : Effects of impurities and the $\alpha-\beta$ transition: Physics and Chemistry of Minerals, v. 34, p. 581-595, https://doi.org/10.1007/s00269-007-0173-7.

Branlund, J.M., and Hofmeister, A.M., 2012, Heat transfer in plagioclase feldspars: The American Mineralogist, v. 97, p. 1145-1154, https://doi.org/10.2138/am.2012.3986. 
Bräuer, H., Dusza, L., and Schulz, B., 1992, New laser flash equipment LFA 427:

Interceram, v. 41, p. 489-492.

Davis, M.W., and Streufert, R.K., 1990, Gold Occcurrences of Colorado: Colorado Geological Survey Department of Natural Resources, Denver, Colorado, $101 \mathrm{p}$.

Fei, Y., 1995, Thermal expansion, in Ahrens, T.J., ed., Mineral Physics and Crystallography: A Handbook of Physical Constants: Washington, DC, American Geophysical Union, p. 29-44, https://doi.org/10.1029/RF002p0029.

Fowler, C.M.R., 2005, The Solid Earth: An Introduction to Global Geophysics. $2^{\text {nd }}$ ed: Cambridge University Press, Cambridge, p. 1699-1706.

Hartmann, W.K., 2005, Moons and Planets. $5^{\text {th }}$ ed: Brooks/Cole-Thomson Learning, Belmont, CA, 428 p.

Hofmeister, A.M., 1999, Mantle Values of Thermal Conductivity and the Geotherm from Phonon Lifetimes: Science, v. 283, p. 1699-1706.

Hofmeister, A.M., 2007, Pressure dependence of thermal transport properties: Proceedings of the National Academy of Sciences of the United States of America, v. 104, p. 9192-9197, https:// doi.org/10.1073/pnas.0610734104. 
Hofmeister, A.M., 2014, Thermodynamic and optical thickness corrections to diffusive radiative transfer formulations with application to planetary interiors: Geophysical Research Letters, v. 41, p. 3074-3080, doi:10.1002/2014GL059833.

Hofmeister, A.M., 2019, Measurements, Mechanisms, and Models of Heat Transport. $1^{\text {st }}$ Ed., Elsevier, 440 p.

Hofmeister, A.M., and Branlund, J.M., 2015, Thermal conductivity of the Earth, in Schubert, G., Price, G.D., and Stixrude, L., eds., Treatise on Geophysics (second edition), Volume 2: Mineral Physics: Elsevier, Amsterdam, p. 583-608, https://doi.org/10.1016/B978-0-444-53802-4 .00047-6.

Hofmeister, A.M., Pertermann, MM. \& Branlund, J.M., 2007, Thermal conductivity of the Earth: In: Schubert, G. (ed.) Treatise in Geophysics: Mineral Physics, Amsterdam: Elsevier, p. 543-578.

Hofmeister, A.M., Dong, J., and Branlund, J.M., 2014, Thermal diffusivity of electrical insulators at high temperatures: Evidence for diffusion of bulk phonon-polaritons at infrared frequencies augmenting phonon heat conduction: Journal of Applied Physics, v. 115, 163517, https:// doi.org/10.1063/1.4873295.

Lowrie, W., 2011, A Student's Guide to Geophysical Equations. $1^{\text {st }}$ ed., Cambridge University Press, Cambridge, $281 \mathrm{p}$. 
McKenzie, D., Jackson, J., and Priestley, K., 2005, Thermal structure of oceanic and continental lithosphere: Earth and Planetary Science Letters, v. 233, p. 337-349, doi:10.1016/j.eps1.2005.02.005.

Mareschal, J-C., and Jaupart, C., 2006, Archean Thermal Regime and Stabilization of the Cratons: in: Archean Geodynamics and Environments, Geophysical Monograph Series 164, American Geophysical Union, Washington, p. 61-73, doi:10.1029/164GM06.

Merriman, J.D., Whittington, A.G., Hofmeister, A.M., Nabelek, P.I., and Benn, K., 2013, Thermal transport properties of major Archean rock types to high temperature and implications for cratonic geotherms: Precambrian Research, v. 233, p. 358-372, https://doi.org/10.1016/j .precamres.2013.05.009.

Nabelek, P.I., and Morgan, S.S., 2012, Metamorphism and fluid flow in the contact aureole of the Eureka Valley-Joshua Flat-Beer Creek pluton, California: Geological Society of America Bulletin, v. 124, p. 228-239, https://doi.org/10.1130/B30425.1

Parker, J.W., Jenkins, J.R., Butler, P.C., and Abbott, G.I., 1961, Flash method of determining thermal diffusivity, heat capacity, and thermal conductivity: Journal of Applied Physics, v. 32, p. 1679-1684, https://doi.org/10.1063/1.1728417. 
Pertermann, M., Whittington, A.G., Hofmeister, A.M., Spera, F.J., and Zayak, J., 2008, Transport properties of low-sanidine single-crystals, glasses and melts at high temperature: Contributions to Mineralogy and Petrology, v. 155, p. 689-702, https://doi.org/10.1007/s00410-007 -0265-X.

Robie, R.A., and Hemingway, B.S., 1995, Thermodynamic properties of minerals and related substances at $298.15 \mathrm{~K}$ and 1 bar (105 pascals) pressure and at higher temperature: U.S. Geological Survey Bulletin 2131, 470 p.

Rollinson, H., 2007, Early Earth Systems: A Geochemical Approach. Blackwell Publishing, Malden, MA, 285 p.

Rozel, A.B., Golabek, G.J., Jain, C., Tackley, P.J., and Gerya, T., 2017, Continental crust formation on early Earth controlled by intrusive magmatism: Nature, v. 545, p. 332-335, doi:10.1038/nature22042.

van Thienen, P., Vlaar, N.J., and van den Berg, A.P., 2005, Assessment of the cooling capacity of plate tectonics and flood volcanism in the evolution of Earth, Mars and Venus: Physics of the Earth and Planetary Interiors, v. 150, p. 287-315.

Whittington, A.G., Hofmeister, A.M., and Nabelek, P.I., 2009, Temperature-dependent thermal diffusivity of Earth's crust: Implications for crustal anataxis: Nature, v. 458, p. 319-321, https://doi.org/10.1038/nature07818. 
Yu, X. and Hofmeister, A.M., 2011, Thermal diffusivity of alkali and silver halide crystals as a function of temperature: Journal of Applied Physics, v. 109, 033516, doi: $10.1063 / 1.3544444$.

Zheng, Y., Mao, J., Chen, Y., Sun, W., Ni, P. and Yang, X., 2019, Hydrothermal ore deposits in collisional orogens: Science Bulletin, v. 64, p. 205-212. 


\title{
Chapter 2: Temperature-dependent thermal transport
}

\section{properties of carbonate minerals and rocks*}

\author{
*This chapter was first published in Geosphere as an open access article: \\ Merriman, J.D., Hofmeister, A.M., Roy, D.J., and Whittington, A.G., 2018. Temperature-dependent \\ thermal transport properties of carbonate minerals and rocks: Geosphere, v. 14, no. 4, \\ https://doi.org/10.1130/GES01581.1.
}

\subsection{ABSTRACT}

To address thermal processes involving carbonate rocks, we measured thermal diffusivity $(D)$ of a suite of carbonate minerals and rocks using laser flash analysis at temperatures from $\sim 300 \mathrm{~K}$ up to $\sim 1000 \mathrm{~K}$. For different minerals, $D$ was governed by density or unit cell size. Near room temperature, for example, $D$ ranged from $4.36 \mathrm{~mm}^{2} \mathrm{~s}^{-}$

${ }^{1}$ for magnesite to $1.61 \mathrm{~mm}^{2} \mathrm{~s}^{-1}$ for calcite. At any given temperature, $D$ decreases from magnesite to dolomite to rhodochrosite to calcite. As temperature increases, $D$ decreases for all samples, with the strongest drop occurring in the interval $\sim 300-500 \mathrm{~K}$. For rocks, mineralogy and porosity were also strong controls on rock $D$. Calcitic limestones showed proportionally lower $D$ than the mineral, scaling with measured pore fraction, whereas dolomitized rocks produced higher $D$ than calcitic rocks across the interval $300-600 \mathrm{~K}$. Measurements of heat capacity and density were used to calculate thermal conductivity (k) for the suite, and these results show a stronger temperature dependence for $k$ of 
carbonate rocks and minerals than previous studies, with $k$ decreasing by $\sim 50 \%$ between ambient and $\sim 600 \mathrm{~K}$.

These results can strongly affect models of the geothermal gradient. Because dolomite conducts heat more efficiently across all measured temperatures than calcite, regions with large proportions of dolomitized rocks may have lower temperatures at depth than those dominated by calcitic carbonates. Additionally, the strong temperature dependence of carbonate rocks introduces the potential for feedback relationships in high heat-producing or thin crust, suggesting that carbonate-dominated crust could have higher temperatures at depth than previously thought. This strong temperature dependence also has implications for the duration of metamorphic events such as metasomatism driving skarn mineralization, or contact metamorphism resulting from intrusion of an igneous body.

\subsection{INTRODUCTION}

Carbonate rocks are a significant component of the upper continental crust (Ronov and Yaroshevsky, 1976; Rudnick and Gao, 2003), and thus their thermal transport properties - thermal conductivity $(k)$ and thermal diffusivity $(D)$ influence important processes such as hydrocarbon maturation and the carbon cycle, in addition to geodynamic processes and geothermal energy potential (e.g., Bickle, 1996; Berner and Caldeira, 1997; Schütz et al., 2012). Because carbonate rocks blanket many platform regions of continental interiors, their role in moderating continental heat flow is potentially important, as thermal conductivity varies more at the low temperatures 
associated with shallow depths than at the high temperatures commonly found in the deeper interior (Whittington et al., 2009; Nabelek et al., 2010; Liu et al., 2011; Merriman et al., 2013). Despite the ubiquitous occurrence of carbonates, little is known about the effects of mineralogy and texture on their thermal properties above ambient temperatures. The remainder of this section briefly reviews heat transfer and methods for measuring the thermal transport properties of rocks and minerals to high temperature.

Thermal conductivity is the product of density $(\rho)$, heat capacity $\left(C_{P}\right)$, and thermal diffusivity:

$$
k=\rho C_{P} D
$$

Equation 2-1.

All of the above properties vary as functions of temperature $(T)$ and, to a lesser extent, pressure $(P)$ (reviewed by Hofmeister, 2007; Hofmeister et al., 2007). In the range of $\sim 300-600 \mathrm{~K}$, negative $d D / d T$ dominates over positive $d C_{P} / d T$ in rocks, and, because changes in $\rho$ are relatively small, $k$ decreases as temperature increases. Variations in $k$ with temperature can be large, because $D$ can decrease by as much as a factor of 10 for crustal rocks (e.g., Merriman et al., 2013; Hofmeister and Branlund, 2015), while $C_{P}$ typically increases by no more than a factor of two (e.g., Robie and Hemingway, 1995; Waples and Waples, 2004). The decrease in $D$ and $k$ as $T$ increases beyond ambient temperature is a consequence of stimulation of additional lattice vibrations as $T$ increases. More interactions occur as $T$ climbs, and so the mean free path decreases and so does $D$. In general, the mean free path is considered inversely dependent upon $T$ (see Hofmeister and Branlund (2015) for a review of the relevant literature).

Furthermore, decreases in $\rho$ with increasing $T$ are small because thermal expansivity of crystals is low, typically $\sim 1-3 \times 10^{-5} \mathrm{~K}^{-1}$ (Fei, 1995), and in the crust is 
offset by increasing $P$ with depth. Elevated $P$ typically increases $D$, but again the effect is small, on the order of 3\%-5\% per gigapascal (Hofmeister, 2007; Hofmeister and Pertermann, 2008). This increase in $D$ with increasing $P$ is primarily a result of increasing density, and these effects are negligible compared to those resulting from variations in mineralogy (Hofmeister et al., 2007). Many experimental methods used to measure $k$, such as the divided bar method, produce systematic errors (see Hofmeister et al., 2007). Physical contacts between the heat source and the sample are imperfect on a microscopic scale, leading to underestimates of $k$ by $\sim 10 \%$ per contact. In addition, radiative transfer can occur between the heat source and the sensor without interaction with the sample, resulting in measurements of $k$ that are artificially elevated (Mehling et al., 1998). This "ballistic" radiative transfer is an artifact of the experimental method and is not found in natural settings (Hofmeister, 2010). Contamination of measurements with spurious radiative transfer commonly goes unrecognized because the process is not well understood. Infrared spectroscopic data provide some insights. The effect of ballistic radiative transfer is strongest in minerals that are transparent in the near infrared (near IR) (Fig. 2-1). Although mineral transparency changes with temperature, many common rock-forming minerals are partially or fully transparent across the range of temperatures at which they are stable. Minerals with high concentrations of water or hydroxyl and high concentrations of $\mathrm{Fe}^{2+}$ in large sites are the only types that strongly absorb in this spectral region (Rossman, 1988a, 1988b). 


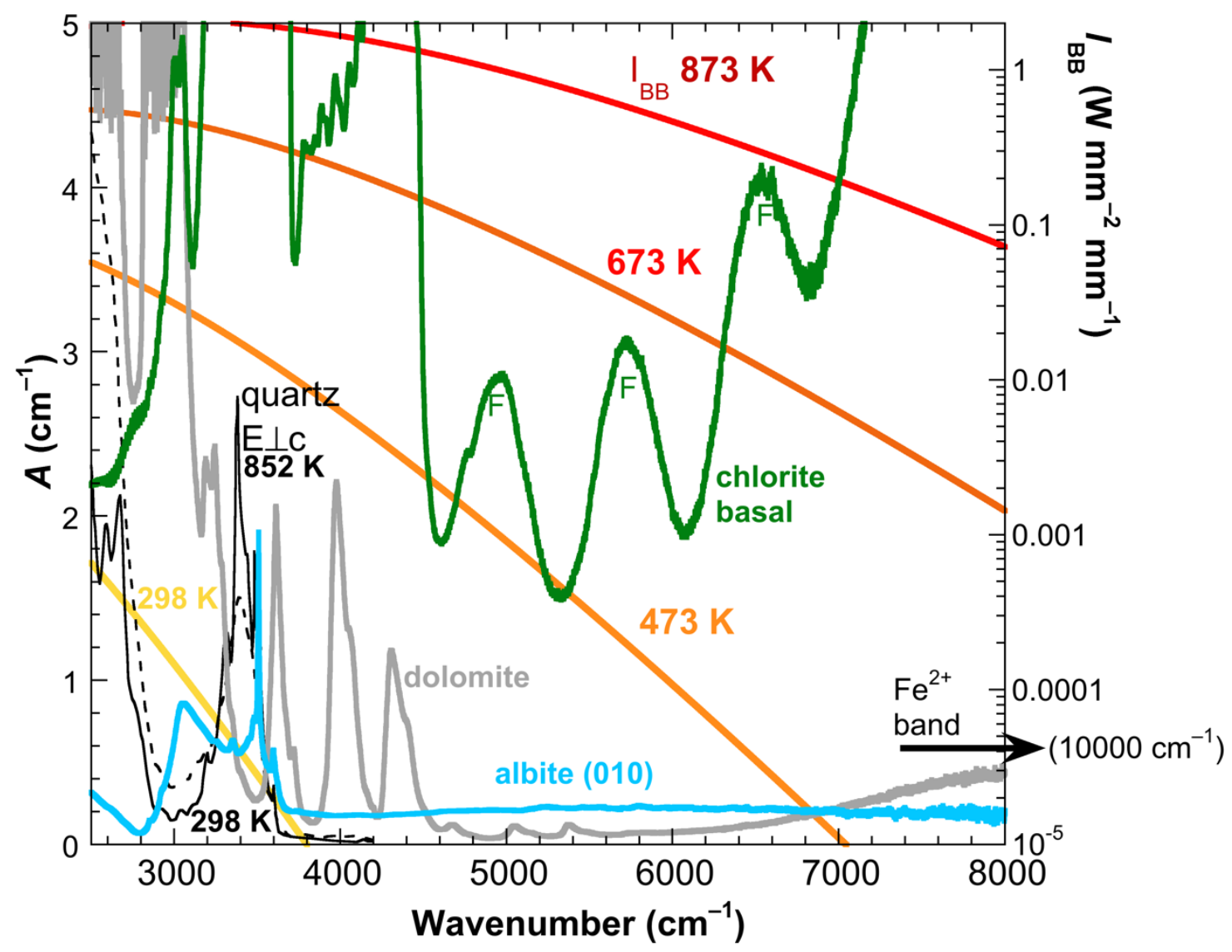

Figure 2-1) Comparison of near-infrared absorption spectra to ideal emissions of a blackbody for various minerals (warm colors, as labeled on a logarithmic scale). $A$ is the absorption coefficient and is defined as absorbance/sample thickness. Black lines are for quartz at room (solid line) and elevated (dashed line) temperature. $\mathrm{\perp} \perp \mathrm{c}$ indicates that polarized along the $c$ axis, from Aines and Rossman (1985); sample thickness was not reported but is estimated to be $\sim 1 \mathrm{~mm}$. Grey line is for a dolomite cleavage from a $6.73 \mathrm{~mm}$ sample with grey coloration. Blue line is for albite (variety cleavelandite) from a $4.8 \mathrm{~mm}$ cleavage. Green line is for chlorite (variety penninite) from a $0.25 \mathrm{~mm}$ basal flake. "F" indicates interference fringes due to internal layers, which contribute reflections and artificially high absorption coefficients. Bands for $\mathrm{OH}$ are off the scale. The rise of the dolomite and chlorite spectral curves as frequency increases is due to d-d electronic transitions of $\mathrm{Fe}^{2+}$ near $10,000 \mathrm{~cm}^{-1}$ (which occurs outside the scale of this graph). 
Because heat transfer data are typically collected on $\sim 3-5 \mathrm{~mm}$ thicknesses (note in Fig. 2-1 that absorbance ( $a$ ) is calculated from $a=-\log \left(I_{\text {trans }} / I_{0}\right)$, where $I_{\text {trans }}$ is the intensity of the transmitted light, and $I_{0}$ is the intensity of the incident light on the sample). $A=1$ describes optically thin conditions for a $1 \mathrm{~cm}$ sample. Light crosses typical sedimentary minerals with little attenuation in the near-IR region. Division by the measured thickness provides the absorption coefficient. Both effects reduce throughout. Near room temperature, the effect is small, resulting in scatter in measured values. At high $T$, however, ballistic transport results in excessive $D$, and sometimes in an incorrect sign for the temperature derivative, mostly because intensity of blackbody radiation grows as $T^{3}$. In rocks, scattering along grain boundaries limits this effect, but at the expense of reducing $D$ or $k$ due to thermal grain boundary resistance (Smith et al., 2003). These competing effects create a roughly correct answer for $D$ or $k$ near room $T$, but with substantial uncertainties.

Because the common sedimentary minerals quartz and feldspar are trans- parent in the near IR (Fig. 2-1), experimental methods for the measurement of $k$ of these minerals (and rocks dominated by them) are susceptible to ballistic radiative transfer, particularly above ambient $T$ (Branlund and Hofmeister, 2007). In the laser flash analysis (LFA) method, first developed by Parker et al. (1961), the effects of ballistic radiative transfer can be removed from the time- $T$ curve using the model of Mehling et al. (1998). The model fit is shown in Figure 2-2. Furthermore, this method avoids physical contact between the heat source and sample, eliminating this error source and thus isolating diffusive heat transfer. 
Consequently, the LFA method produces results for thermal diffusivity $(D)$ with errors of $\pm 5 \%$ at room temperature and $\pm<2 \%$ at elevated temperatures (Hofmeister, 2006). The effect of removing radiative transfer in quartz and the feldspars has been well documented (Branlund and Hofmeister, 2007, 2008, 2012; Pertermann et al., 2008; Hofmeister et al., 2009). Both show decreasing $D$ as temperature rises above ambient (Branlund and Hofmeister, 2007; Pertermann et al., 2008; Hofmeister et al., 2009), although $d D / d T$ is much higher for quartz than for the feldspars. This pattern extends to quartz- and feldspar-dominated rocks (e.g., Whittington et al., 2009; Miao et al., 2014), although other properties such as porosity $(\varphi)$ and pore contents become important (Branlund and Hofmeister, 2008).

The dominant minerals in carbonate rocks, calcite $\left(\mathrm{CaCO}_{3}\right)$ and dolomite $\left[\mathrm{CaMg}\left(\mathrm{CO}_{3}\right)_{2}\right]$, have not been examined using LFA. Note that we use the naming convention "dolomite" for the mineral, and "dolomite rock" for the sedimentary rock to avoid confusion, as both the mineral and rock appear in several of the same figures. Measurements of $k$ of both minerals exist in the literature (e.g., Birch and Clark, 1940; Horai, 1971), but these historical studies covered a limited temperature range and used methods that were subject to the experimental errors discussed above. More recently, $D$ of calcite was measured using a photoacoustic spectroscopic method (Ramachandran et al., 2006), but only at room temperature. Thermal diffusivity data for a suite of 11 carbonate minerals were collected across a wide range of temperatures using a modified 

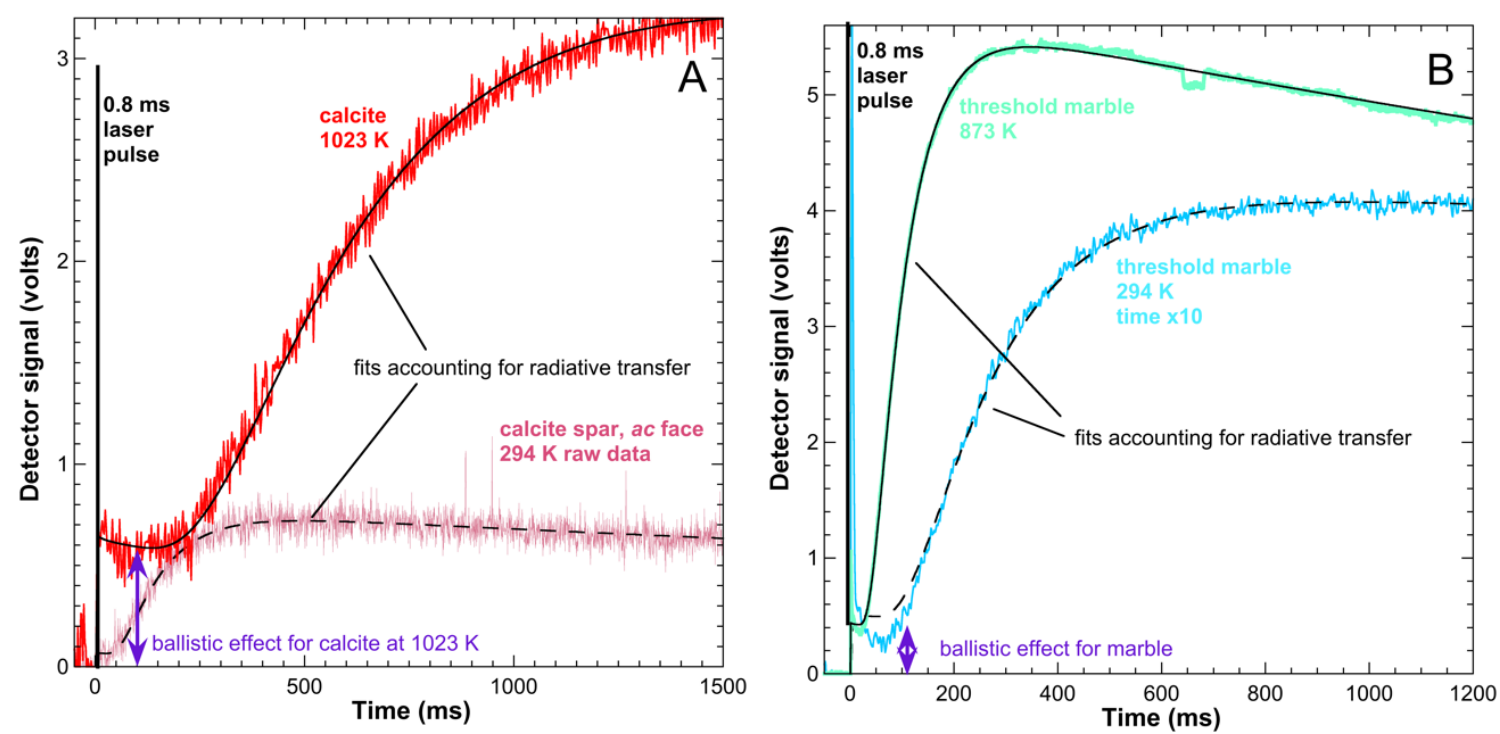

Figure 2-2) Time-temperature curves for single-crystal and grainy calcite samples. Colored curves show raw data for temperatures and samples as labeled; black curves show the model of Mehling et al. (1998). (A) Single-crystal calcite. Double purple arrow shows immediate jump in intensity following the firing of the laser at time $t=0 \mathrm{~ms}$ for the calcite at high temperature (T). The jump at room $T$ is small for the calcite, but non-negligible. (B) Threshold marble. Despite the fine grain size, the radiative response

transient technique (Gratz, 2006), but this method does not fully control radiative transfer and involves one physical contact which artificially reduces $D$ (Hofmeister et al., 2007). Similar to quartz and feldspar, absorption spectra of these minerals in the near IR show a strong potential for spurious radiative transfer in experiments (Fig. 2-1).

Moreover, there is a paucity of high-temperature $D$ and $k$ data for carbonate minerals and rocks, which can have widely varying textures and porosity depending on their mode of formation and degree of diagenesis or metamorphism. Although the mineralogy of limestones is relatively simple, considerable variety arises from packing of different biological detritus of highly variable shape and size, and, combined with chemical precipitation of calcite, leads to a spectrum of textural variation. Furthermore, recrystallization can occur at various stages of maturity post-diagenesis, with fossils 
acting as nucleation points or centers of replacement (Lippmann, 1973). Consequently, $\varphi$ in carbonate rocks varies widely. At near-surface $P$, calcitic limestone generally has higher $\varphi$ than dolomite rock, but the reverse is true when $P>\sim 50 \mathrm{MPa}$ in natural settings (Hantschel and Kauerauf, 2009).

Many workers have proposed models for the prediction of the temperature response of $k$ of rocks using measurements at room $T$ (Clauser and Huenges, 1995; Lee and Deming, 1998). These are based on results from contact methods, however, and do not incorporate mineralogical differences. Lee and Deming (1998) reviewed five such models for $T$-dependent $k$ based on single room- $T$ measurements of $k$. However, demonstrably more complex behavior occurs in minerals than can be captured by a single equation for different minerals, an observation that extends to measurements of rocks composed of more than one mineral (Whittington et al., 2009; Merriman et al., 2013), and thus a single equation is unlikely to reproduce the range of observed changes in thermal transport properties with $T$ across all rock types

We present new $D$ data on calcite, dolomite, magnesite $\left(\mathrm{MgCO}_{3}\right)$, and rhodochrosite $\left(\mathrm{MnCO}_{3}\right)$, and a suite of carbonate rocks, measured using the LFA method. We also measured ambient $\rho$ and the temperature dependence of $C_{P}$, from which we calculate $k$ as a function of $T$. We test existing models and explore the effects of porosity on the $T$-dependent thermal transport properties of these important rocks. 


\subsection{EXPERIMENTAL METHODS}

\subsubsection{Sample Selection}

Four different species of carbonate minerals were studied (Table 2-1), including two calcite samples (calcite spar and hexagonal calcite [calcite hex], both from the collection of the Department of Earth and Planetary Sciences at Washington University, St. Louis, Missouri, USA), a dolomite sample with both white and grey ends (white dolomite and grey dolomite, from Eugul, Navarre, Spain), magnesite (from Brumado, Bahia, Brazil), and rhodochrosite (from Wudong Mine, Wushuo Prefecture, Guangxi Zhuang, China). Magnesite was included to provide data on the Mg-bearing layers of dolomite. The addition of rhodochrosite permits examination of the effect of cation mass on mineral $D$. Rock samples include four calcite-dominated limestones from central Missouri: TF-001, a fossiliferous limestone from the Winterset Limestone; TF-002, an oolitic limestone from the Drum Limestone; MO-05, a boundstone from the Burlington Limestone; and MO-07, a micrite from the University of Missouri departmental collection. Additional rocks include: sample KS-002, a sedimentary dolomite rock from the Jefferson City Dolomite (Missouri), four calcite-dominated marbles, samples of Threshold marble (a building stone from a commercial retailer, Lowes, in Maplewood, Missouri, USA), Black marble (also from a commercial retailer, The Tile Store, in St. Anne, Missouri, USA), and Carrara Marble (Italy), including a marble deformed at ambient temperature under triaxial loading (Carrara deformed); sample AW-05, a marble with mixed calcite and dolomite phases (from Ross Lake near North Cascades National Park, Washington, USA); sample 17-4, a dolomitic marble (from the Eureka Valley- 
Joshua Flat-Beer Creek [EJB] aureole, White Mountains, California, USA; Nabelek and Morgan, 2012); sample 33-1, a forsterite- and chlorite-bearing calcite-dolomite marble (also from the EJB aureole); and a magnesite conglomerate (from the departmental collection at Washington University). The suite of rocks permits exploring effects of (1) depositional environments ranging from intertidal to shallow marine; (2) dolomitization; (3) porosities; and (4) contact and burial metamorphism involving variable mineralogy. We used polarized-light microscopy to describe mineralogy and textures and to measure grain sizes.

\subsubsection{X-Ray Diffraction}

Mineral proportions were determined using a Bruker D8 ADVANCE X-ray diffractometer (XRD). Weight-percent proportions were calculated from diffraction patterns with the Bruker software TOPAS (version 5), using the refinement method of Rietveld (1968). Results were converted to volume percent using published values of density for minerals (Deer et al., 1992), and using microprobe data to calculate endmember proportions of solid-solution minerals such as olivine.

\subsubsection{Electron Microprobe}

Mineral compositions were analyzed by wavelength-dispersive analysis with a JEOL JXA-8200 electron microprobe and using Probe for Windows software for data reduction (Probe Software, Inc., Eugene, Oregon, USA; http:// www.probesoftware.com/). The measured data were corrected with CITZAF software after Armstrong (1995). Oxide and silicate standards were used for calibration: Amelia 
albite for $\mathrm{Na}$ and $\mathrm{Si}$; microcline for $\mathrm{K}$; Gates wollastonite for $\mathrm{Ca}$; Alaska anorthite for $\mathrm{Al}$; synthetic fayalite for Fe; synthetic forsterite for $\mathrm{Mg}$; synthetic $\mathrm{TiO}_{2}$ for $\mathrm{Ti}$; synthetic $\mathrm{Mn}$ olivine for $\mathrm{Mn}$; and synthetic $\mathrm{Cr}_{2} \mathrm{O}_{3}$ for $\mathrm{Cr}$. Detection limits, calculated error, and calibration standards are available in Table A-1.

\subsubsection{Chemical Analysis}

Chemical analysis of rock samples was performed on limestones TF-001, TF-002, MO-05, MO-07, and KS-002 and marbles 33-1, 17-4, and Black marble by Activation Laboratories, Inc. (Ontario, Canada), using inductively coupled plasma-optical emission spectroscopy (ICP-OES) on lithium metaborate fusions for major oxide analysis, and combustion spectroscopy for total carbon and graphitic carbon analysis (through combustion and binding of carbon with oxygen to form $\mathrm{CO}$ and $\mathrm{CO}_{2}$ ). Calibration standards and duplicate measurements are available in Table A-2 [footnote 1].

\subsubsection{Infrared Spectroscopy}

We used an evacuated Bomem DA3.02 Fourier transform interferometer with an $\mathrm{SiC}$ source, an InSb detector, and a $\mathrm{CaF} 2$ beamsplitter for IR spectroscopy. Instrumental accuracy is $0.01 \mathrm{~cm}^{-1}$. About 1000 scans were collected at room temperature from $\sim 1200$ to $5000 \mathrm{~cm}^{-1}$ at a resolution of $2 \mathrm{~cm}^{-1}$. Data were collected from samples mounted on an $\sim 1 \mathrm{~mm}$ aperture, which served as the reference.

\subsubsection{Density}


Density was measured using three different methods. (1) Bulk density was determined using a geometric method, where the sample was cut into a regular shape (cube or cylinder) and then measured with a micrometer and weighed on an analytical balance. Longer cores $(1-3 \mathrm{~cm})$ were used to reduce errors associated with imperfections. Uncertainties are estimated at $2 \%$ based on variability between different cores of the same sample. (2) Density of the solid and its isolated pore spaces was ascertained using the Archimedean method. Samples were weighed in air and again while immersed in fluid (ethanol). The sample was soaked overnight to enable fluid penetration throughout connected pore space. (3) A Quantachrome multipycnometer was used to measure the bulk density of samples that were powered to $<150 \mu \mathrm{m}$ to allow helium to penetrate previously unconnected pore space. Sample powder was weighed in a sample chamber, which was then placed in a sealed chamber in the multipycnometer. Helium was added to a reference chamber to a measured pressure of $\sim 117 \mathrm{kPa}$ and opened to the sample chamber. With helium present in both the reference and sample chamber, the new pressure was re- corded, and the ratio of reference to sample plus reference chamber pressure was used to calculate the volume of the sample.

These three measurements were combined to calculate total porosity and connected porosity after Avard and Whittington (2012).

\subsubsection{Isobaric Heat Capacity}

The heat capacity of powdered rock samples was measured using a Perkin- Elmer DSC 8500 differential scanning calorimeter (DSC). Powdering was necessary to ensure uniformity given the small capacity of sample pans in the DSC (25-50 mg). All 


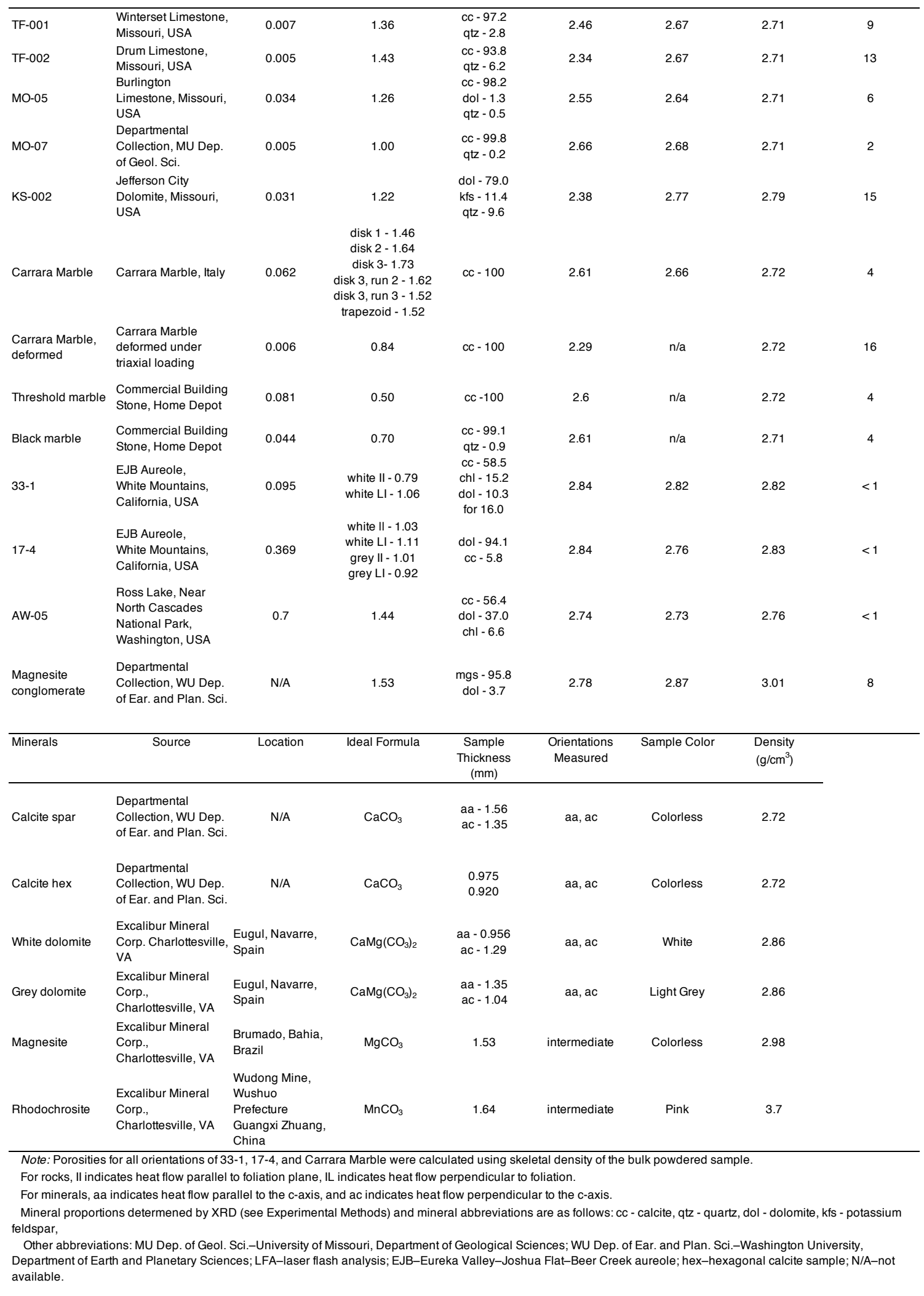

experiments were performed using gold sample pans and a sapphire reference standard. 
Our heat capacity measurements of single- crystal calcite varied $<2 \%$ from literature values across the temperature range $\sim 275-900 \mathrm{~K}$ (Jacobs et al., 1981). Heat capacity was measured at discrete intervals of $25 \mathrm{~K}$ across a range of temperatures from $\sim 275$ to $\sim 600$ $\mathrm{K}$ (limestones) or to $\sim 900 \mathrm{~K}$ (marbles). Experimental heat capacity results were fitted to the equation (Robie and Hemingway, 1995):

$$
C_{P}=a+b T+c T^{-2}
$$

Equation 2-2.

where $C_{\mathrm{P}}$ is in $\mathrm{J} \mathrm{kg}^{-1} \mathrm{~K}^{-1}, T$ is in Kelvin, and $a, b$, and $c$ are experimental fitting parameters.

For minerals, we used published $C_{P}$ data (calcite: Jacobs et al., 1981; dolomite: Krupka et al., 1985; magnesite: Robie and Hemingway, 1994; rhodochrosite: Moore, 1943). We combined these data for minerals with the modal mineralogy from XRD results to calculate ideal heat capacity for the rock samples to compare experimental results for powdered rock.

\subsubsection{Thermal Diffusivity}

We used a NETZSCH LFA 427, described by Bräuer et al. (1992), to measure thermal diffusivity. For a general description of this method, which is commonly used in industry and materials science, see Maglić and Taylor (1992), Vozár and Hohenauer (2003, 2005), and Criss and Hofmeister (2017). For procedural details regarding our laboratory, see Pertermann and Hofmeister (2006). 
In brief, samples were prepared as nearly circular disks between 0.75 and $2 \mathrm{~mm}$ thick, with a diameter of $\sim 10 \mathrm{~mm}$. All rock samples had grain sizes smaller than disk thickness, ensuring that measured $D$ reflects the bulk material rather than individual crystals. Samples were coated with one to two layers of graphite to aid in absorption of the laser pulse and emission of heat from the top side of the sample.

The method is contact free: A Nd:GGG laser is used to heat the bottom of the sample. As heat diffuses through the sample, an IR detector on the opposite side of the sample from the laser records the change in emissions with time, which is directly related to the change in temperature. Thermal diffusivity of the sample at the given temperature is obtained by fitting the time-temperature $(t-T)$ acquisitions using the model of Cowan (1963) at ambient temperature and Mehling et al. (1998) above $\sim 300 \mathrm{~K}$ to remove spurious effects of ballistic radiative transfer.

Maximum temperatures attained depended upon the sample maintaining physical integrity at elevated temperature without the presence of confining pressure. For each sample, $D$ is measured at discrete temperatures along a pre-programmed path. Each reported measurement is the average from $t-T$ curves of between two and six laser shots at that temperature, to ensure reproducibility. Measurement uncertainty is highest near room temperature (up to $5 \%$ ), decreasing to $\sim 2 \%$ at elevated temperatures, as ascertained by comparison with steel, iron, graphite, and Pyroceram standards reference materials from the National Institute of Standards and Technology and the manufacturer (Henderson et al., 1998a, 1998b). These standards are opaque and also soft, so they do not transmit light ballistically and adhere well to thermocouples, permitting calibration against results obtained from conventional methods, e.g., that of Hust and Lankford 
(1984). Temperatures were calibrated against the well-established Curie points of iron and cobalt.

\subsubsection{Sample Descriptions}

\subsubsection{Minerals}

Calcite spar is colorless and transparent, and microprobe analysis (Table 2-2) indicates a nearly pure calcite crystal with trace quantities $(<0.1 \mathrm{wt} \%)$ of magnesium, iron, and sodium. Calcite hex is a colorless, hexagonal calcite crystal (microprobe data unavailable).

The dolomite samples (white dolomite, grey dolomite) were cut from the same crystal. Both white and grey samples are nearly pure (Table 2-2) with small amounts of iron $(\mathrm{FeO}=0.18-0.42 \mathrm{wt} \%)$ and manganese $(\mathrm{MnO}=0.1 \mathrm{wt} \%)$, but total $\mathrm{CaO}+\mathrm{MgO}$ is low relative to ideal dolomite. Trace impurities $(<0.1 \mathrm{wt} \%$ oxide) include $\mathrm{Al}, \mathrm{Na}$, and $\mathrm{Ti}$. The color of grey dolomite likely results from a larger proportion of $\mathrm{FeO}$ compared to white dolomite.

The translucent magnesite crystal includes substitutions of $\mathrm{Mn}, \mathrm{Fe}$, and $\mathrm{Ca}$ for magnesium, with $\mathrm{Mg}$ composing $98 \%$ of cation mass within the crystal (Table 2-2). Additional trace elements include Na, Al, and K.

The rhodochrosite sample is pink in hand specimen. Microprobe analysis (Table 2-2) indicates $1.4 \mathrm{wt} \% \mathrm{FeO}$, with a smaller amount of $\mathrm{Mg}$ and trace quantities of $\mathrm{Al}, \mathrm{Ca}$, $\mathrm{Na}$, and $\mathrm{K}$. A solid solution exists between pure rhodochrosite and siderite $\left(\mathrm{FeCO}_{3}\right)$, and the mineral formula of this specimen is $\left(\mathrm{Mn}_{0.97} \mathrm{Fe}_{0.02} \mathrm{Mg}_{0.005}\right) \mathrm{CO}_{3}$. 
TABLE 2-2. MINERAL CHEMICAL ANALYSIS (ELECTRON MICROPROBE ANALYSIS)

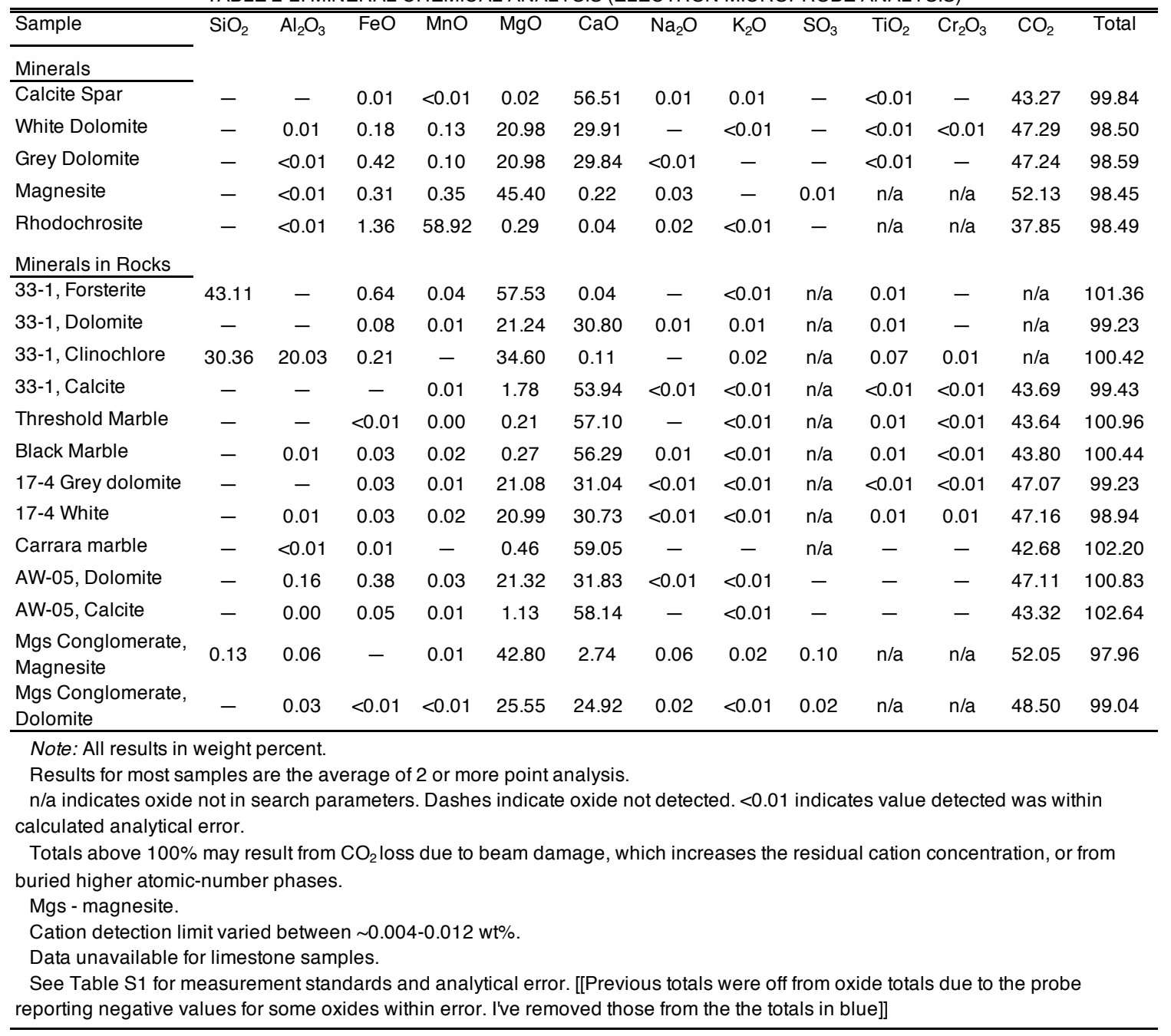

\subsubsection{Sedimentary Rocks}

Sample $T F-001$ is a fossiliferous limestone composed primarily of calcite with $\sim 3$ wt\% quartz (Table 2-1). The sample has a wide range of grain sizes, with the largest grains concentrated in the center of the matrix between fossils (Fig. 2-3A). Fine-grained material composed mostly of calcite with minor quartz occurs in the center of fossils and along the boundaries between clusters of smaller fossils. Pore space is estimated at $9 \%$, which is the difference between the measured density and the density calculated as the 
TABLE 2-3. MAJOR-ELEMENT CHEMICAL ANALYSIS OF ROCK SAMPLES

\begin{tabular}{|c|c|c|c|c|c|c|c|c|c|c|c|c|c|c|}
\hline Sample & $\begin{array}{c}\text { Total } \\
\text { Carbon }\end{array}$ & $\begin{array}{c}\text { Graphitic } \\
\text { Carbon }\end{array}$ & $\mathrm{SiO}_{2}$ & $\mathrm{Al}_{2} \mathrm{O}_{3}$ & $\begin{array}{c}\mathrm{Fe}_{2} \mathrm{O}_{3} \\
(\text { Total Fe) }\end{array}$ & $\mathrm{MnO}$ & $\mathrm{MgO}$ & $\mathrm{CaO}$ & $\mathrm{Na}_{2} \mathrm{O}$ & $\mathrm{K}_{2} \mathrm{O}$ & $\mathrm{TiO}_{2}$ & $\mathrm{P}_{2} \mathrm{O}_{5}$ & 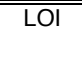 & Total \\
\hline $\begin{array}{l}\text { Detection } \\
\text { Limit (\%) }\end{array}$ & 0.01 & 0.05 & 0.01 & 0.01 & 0.01 & 0.00 & 0.01 & 0.01 & 0.01 & 0.01 & 0.01 & 0.01 & 0.01 & \\
\hline TF-001 & $\mathrm{n} / \mathrm{a}$ & $\mathrm{n} / \mathrm{a}$ & 2.72 & 0.09 & 0.74 & 0.06 & 0.44 & 53.38 & 0.02 & 0.03 & $<0.01$ & 0.08 & 41.66 & 99.22 \\
\hline TF-002 & $\mathrm{n} / \mathrm{a}$ & $\mathrm{n} / \mathrm{a}$ & 3.01 & 0.22 & 0.37 & 0.05 & 0.38 & 52.73 & 0.05 & 0.10 & 0.01 & 0.13 & 41.17 & 98.20 \\
\hline MO-05 & $\mathrm{n} / \mathrm{a}$ & $\mathrm{n} / \mathrm{a}$ & 0.41 & 0.08 & 0.19 & 0.04 & 0.17 & 55.75 & 0.01 & 0.03 & $<0.01$ & 0.02 & 42.41 & 99.10 \\
\hline MO-07 & 11.70 & 0.10 & 0.49 & 0.16 & 0.05 & 0.01 & 0.22 & 55.28 & 0.01 & 0.04 & 0.01 & $<0.01$ & 43.42 & 99.70 \\
\hline KS- 002 & $\mathrm{n} / \mathrm{a}$ & $\mathrm{n} / \mathrm{a}$ & 14.19 & 1.50 & 0.54 & 0.02 & 17.85 & 25.52 & 0.03 & 1.02 & 0.05 & 0.03 & 39.28 & 100.00 \\
\hline Black marble & 11.70 & 0.06 & 1.30 & 0.09 & 0.10 & 0.02 & 0.29 & 54.56 & 0.02 & $<0.01$ & 0.01 & 0.04 & 43.22 & 99.64 \\
\hline $33-1$ & 7.71 & 0.05 & 15.14 & 0.67 & 0.39 & 0.03 & 22.87 & 32.47 & $<0.01$ & $<0.01$ & 0.04 & 0.03 & 28.56 & 100.20 \\
\hline $17-4$ & 12.40 & 0.08 & 0.67 & 0.02 & 0.07 & 0.01 & 21.50 & 30.45 & 0.01 & $<0.01$ & $<0.01$ & 0.02 & 46.21 & 98.97 \\
\hline AW-05 & 11.00 & $\mathrm{n} / \mathrm{a}$ & 4.63 & 1.58 & 0.54 & 0.02 & 11.41 & 40.17 & 0.03 & 0.06 & 0.06 & 0.03 & 39.99 & 98.51 \\
\hline \multicolumn{15}{|c|}{$\begin{array}{l}\text { Note: See Experimental Methods in text for description of analytical methods, standards and analytical uncertainty (Table A-1). } \\
\text { Total does not include "Total Carbon" or "Graphitic Carbon". } \\
\text { n/a indicates analysis was not performed for sample. } \\
\text { All values are in mass \%. } \\
\text { LOI indicates Loss On Ignition. }\end{array}$} \\
\hline
\end{tabular}

weighted average of the constituent minerals. Bulk rock chemical analysis shows small amounts of Si as well as Fe and $\mathrm{Mg}$ (Table 2-3).

Sample TF-002 is a limestone dominated by ooids and rounded fossils. Ooids are fairly uniform in size, ranging from $\sim 0.25$ to $0.5 \mathrm{~mm}$ in diameter, and are composed of fine-grained bands radiating from a central point. Larger grains are concentrated in the matrix (Fig. 3B). This sample has the lowest amount of calcite of the four limestones $(93.8 \mathrm{wt} \%)$ and the highest $\varphi(13 \%)$. Chemical analysis suggests that either XRD analysis overestimates quartz content by several percent (Table 2-3) or some heterogeneity exists within the sample, and also indicates that the sample has small amounts of Fe, Al, and $\mathrm{Mg}$.

Sample MO-05 (boundstone) is nearly pure calcite (Table 2-1) with small amounts of dolomite and quartz in a highly variable matrix, which lacks immediately recognizable fossils (Fig. 2-3C). Porosity (6\%) is low compared to that of the above limestones, and not apparent in thin section. Bulk rock chemistry confirms a calcite-dominated mineralogy with small amounts of silica and magnesium (Table 2-3). 
Sample $\mathrm{MO}-07$ (micrite) is nearly $100 \%$ calcite (Table $2-1$ ), with a very small average grain size $(\sim 0.005 \mathrm{~mm})$ and very low $\varphi(\sim 2 \%)$. Most of the sample is composed of indistinguishable small grains; however, clusters of larger grains of calcite occur randomly throughout (Fig. 2-3D). Chemical analysis confirms the nearly pure calcite makeup of this sample (Table 2-3).

Sample KS-002 (dolomite rock) is largely dolomite (79\%), but also contains $\sim 11 \%$ potassium feldspar and $10 \%$ quartz (Table $2-1$ ). Bulk chemical analysis shows that a small amount of $\mathrm{Fe}$ is present, but only trace quantities of $\mathrm{Na}$, suggesting that feldspar is dominated by $\mathrm{K}$. This sample is also typified by a high $\varphi(15 \%)$, with an overall finegrained matrix broken by larger detrital quartz and feldspar grains (Fig. 2-3E).

\subsubsection{Metamorphic Rocks}

White Carrara Marble from Tuscany, Italy, has been quarried since the time of the Roman Empire. XRD revealed calcite as the only mineral phase, and microprobe analysis shows small amounts of $\mathrm{Mg}$ and only trace amounts of Fe and $\mathrm{Al}$ (Table 2-2). Two different samples of Carrara were used in this study: a fresh sample and an experimentally deformed sample. The fresh sample shows mostly interlocking grains of calcite with occasional fine-grained inter- faces between larger grains (Fig. 2-3F). In hand specimen, the outer layers of the fresh sample are brittle, but the interior remains relatively coherent. A sample deformed at room temperature by George Dresden was provided by Brian Evans (Xu and Evans, 2010), with deformation resulting in an orderof-magnitude decrease in average grain size (Table 2-1; Fig. 2-3G), as well as a fourfold increase in $\varphi$ ( $4 \%$ fresh, $16 \%$ deformed). 
Threshold marble is a commercial tile. This sample is also a pure calcite marble with $\sim 4 \%$ porosity, but has a slightly larger average grain size than Carrara Marble (0.08 $\mathrm{mm}$ versus $0.06 \mathrm{~mm}$ ). Threshold marble contains calcite crystals with strong twinning and cleaner grain boundaries than Carrara (Fig. 3H). Microprobe analysis indicates calcite crystals with minor Mg substitution (Table 2-1).

Black marble is $99 \%$ calcite, containing $\sim 1 \%$ of grey quartz veins. Like Carrara Mable and Threshold marble, Black marble contains small amounts of magnesium (Table 2-3) but lower amounts of total $\mathrm{CaO}$ (Table 2-3), and some quartz (Table 2-1) which the others lack. In thin section, this sample has what appears to be cloudy veins of graphite (Fig. 2-3I), but chemical analysis by combustion revealed only small amounts $(0.06$ wt\%). In addition to quartz and (possibly) graphite veins, bands of large, interlocking calcite crystals crisscross the sample (Fig. 2-3I). Porosity of this marble is relatively low $(4 \%)$.

Sample 33- 1 is a calcitic marble (calcite $=58.5 \%$ ) with high contents of dolomite (10.3\%), forsteritic olivine (16.0\%), and chlorite $(15.2 \%)$ as indicated by XRD (Table 21). In hand specimen, the sample has alternating white and grey layers of thicknesses between 0.5 and $2 \mathrm{~cm}$ which are not apparent in thin section (Fig. 2-3J), but may result from variable amounts of olivine or chlorite. Both olivine and chlorite are nearly pure Mg end members (Table 2-2). Dolomite crystals are modestly deficient in $\mathrm{Mg}$, whereas calcite contains up to $1.8 \mathrm{wt} \% \mathrm{MgO}$. Bulk rock chemical analysis (Table 23) suggests there is insufficient alumina present to support the $15 \mathrm{wt} \%$ chlorite indicated by XRD. This may be a scale effect due to compositional heterogeneity between white and grey layers. In thin section (Fig. 2-3J), large grains of calcite surround rounded to 
subrounded grains of olivine and dolomite, and no porosity is evident, which is

confirmed by density measurements (Table 2-1). Average grain size is larger than that of all other rock samples except 17-4.

Sample $17-4$ is a dolomite-dominated marble from the same metamorphic aureole as sample $33-1$, and contains $\sim 6 \%$ calcite. Like $33-1$, this sample has white and grey layers in hand specimen, which may result from variable proportions of calcite and dolomite (Fig. 2-3K). The composition of dolomite is homogeneous throughout (Table 22). Bulk rock chemical analysis found $<1 \%$ of silica that was not detected by the XRD. 17-4 has the largest grain size of any of our samples $(0.4 \mathrm{~mm})$, but no measurable $\varphi$ (Table 2-1).

Sample $A W-05$ is a foliated and lineated calcitic marble $($ calcite $=56 \%)$ accompanied by a substantial proportion of dolomite $(\sim 37 \%)$ and some chlorite $(\sim 7 \%)$ (Table 2-1). Like for the other marbles, microprobe analysis indicated that dolomite in this sample is somewhat deficient in $\mathrm{Mg}$. The hand specimen is white with thin foliation planes (1-2 mm). In thin section (Fig. 2-3L), large calcite crystals form foliation planes of moderately sized interlocking grains surrounded by microcrystalline dolomite. Dolomite grains are highly altered near large calcite crystals, but fresh where large calcite crystals are absent. Average grain size of dolomite matrix is $\sim 0.1 \mathrm{~mm}$, whereas calcite crystals are as large as $2.0 \mathrm{~mm}$. The bimodal distribution of grain sizes results in an average grain size of $\sim 0.7 \mathrm{~mm}$. Porosity is minimal $(<1 \%)$.

The magnesite conglomerate sample is largely magnesite with a small amount of accessory dolomite and $\sim 8 \%$ porosity (Table $2-1$ ). The magnesite is deficient in $\mathrm{Mg}$ and contains large amounts of $\mathrm{Ca}$, with smaller amounts of $\mathrm{Si}, \mathrm{Al}, \mathrm{Na}$, and $\mathrm{K}$; the dolomite has excess $\mathrm{Mg}$ and is deficient in $\mathrm{Ca}$ (Table 2-2). 


\subsection{RESULTS}

\subsubsection{Heat Capacity}

Experimental $C_{P}$ results on the rocks studied here agree reasonably well with $C_{P}$ calculated using literature data on mineral components and modal mineral proportions from XRD analysis (Fig. 2-4). Measurements of sedimentary samples were limited to $<\sim 600 \mathrm{~K}$.

Metamorphic carbonate rocks heated to higher $T$ depart significantly from calculated $C_{P}$. Powders for samples heated to high $T$ showed signs of significant alteration: typically, the powder darkened, and mass of the sample dropped by $1 \%-2 \%$, consistent with the onset of decarbonation reactions. Thus, fits of experimental $C_{P}$ to Equation 2-2 (Table 2-4A) do not include measurements above $600 \mathrm{~K}$.

Because initial $C_{P}$ measurements on rock samples TF-001, 17-4, and 33-1 and the magnesite conglomerate sample differed from calculated $C_{P}$ by $>3 \%$, duplicate experiments were performed on these samples, and all were within $2 \%$ of calculated $C_{P}$. All final results were consistent to $<2 \%$ at temperatures between 360 and $600 \mathrm{~K}$. In the temperature range $280-360 \mathrm{~K}$, all repeat experiments were within $3 \%$ of $C_{P}$ calculated with literature data except that for the magnesite conglomerate, which differed by $<4 \%$ in this temperature range. This may be due to adsorbed water on the powder used for measurement, as water has a heat capacity $>4000 \mathrm{~J} \mathrm{~kg}^{-1} \mathrm{~K}^{-}$

${ }^{1}$ at room $T$ (e.g., He et al., 2015). The powder for the second run (but not the first) was dried in an oven at $\sim 400 \mathrm{~K}$

for $24 \mathrm{~h}$. Variations of $1 \%-3 \%$ are reasonable given the experimental uncertainty and uncertainty in modal mineral proportions. 

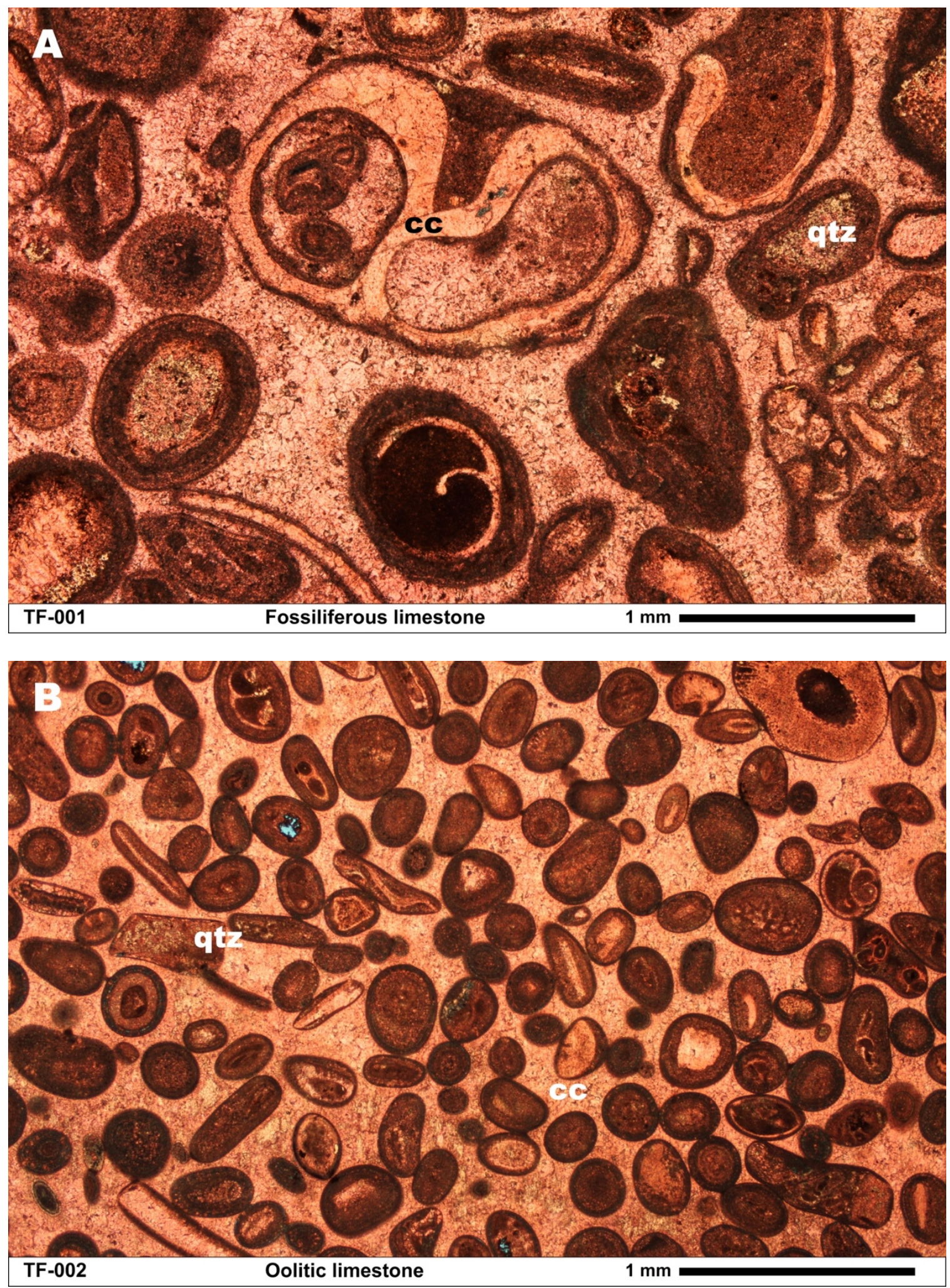

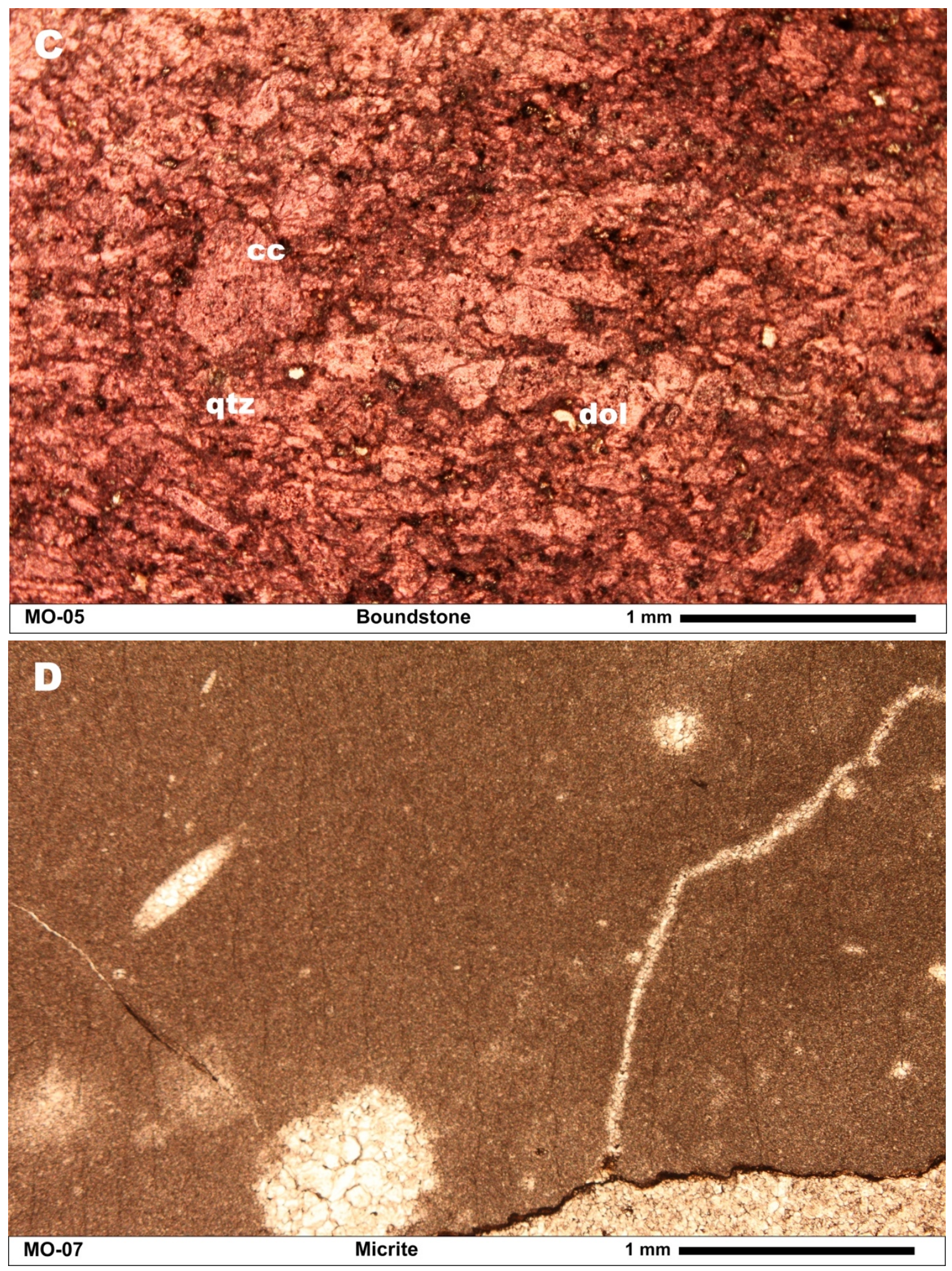

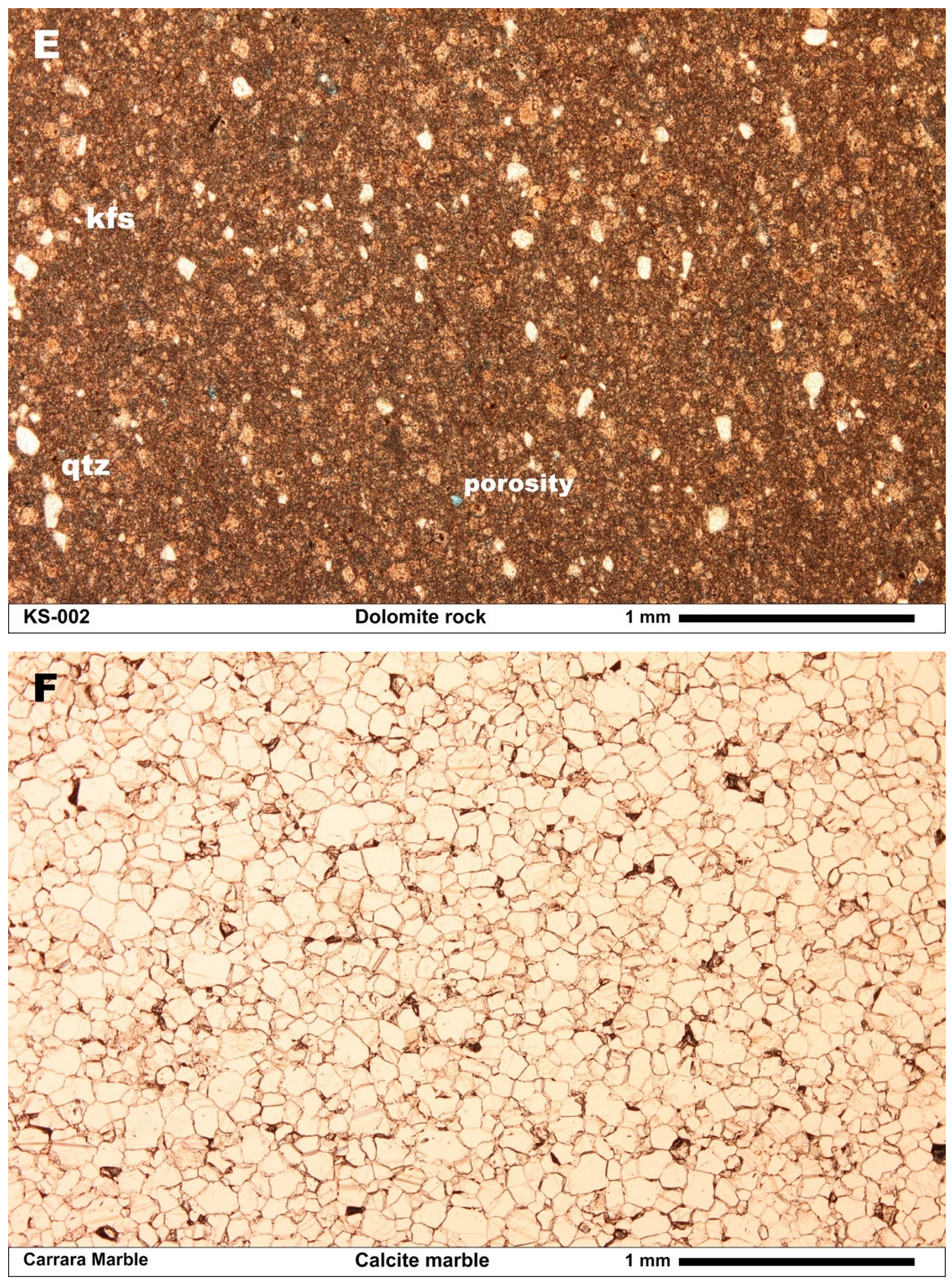

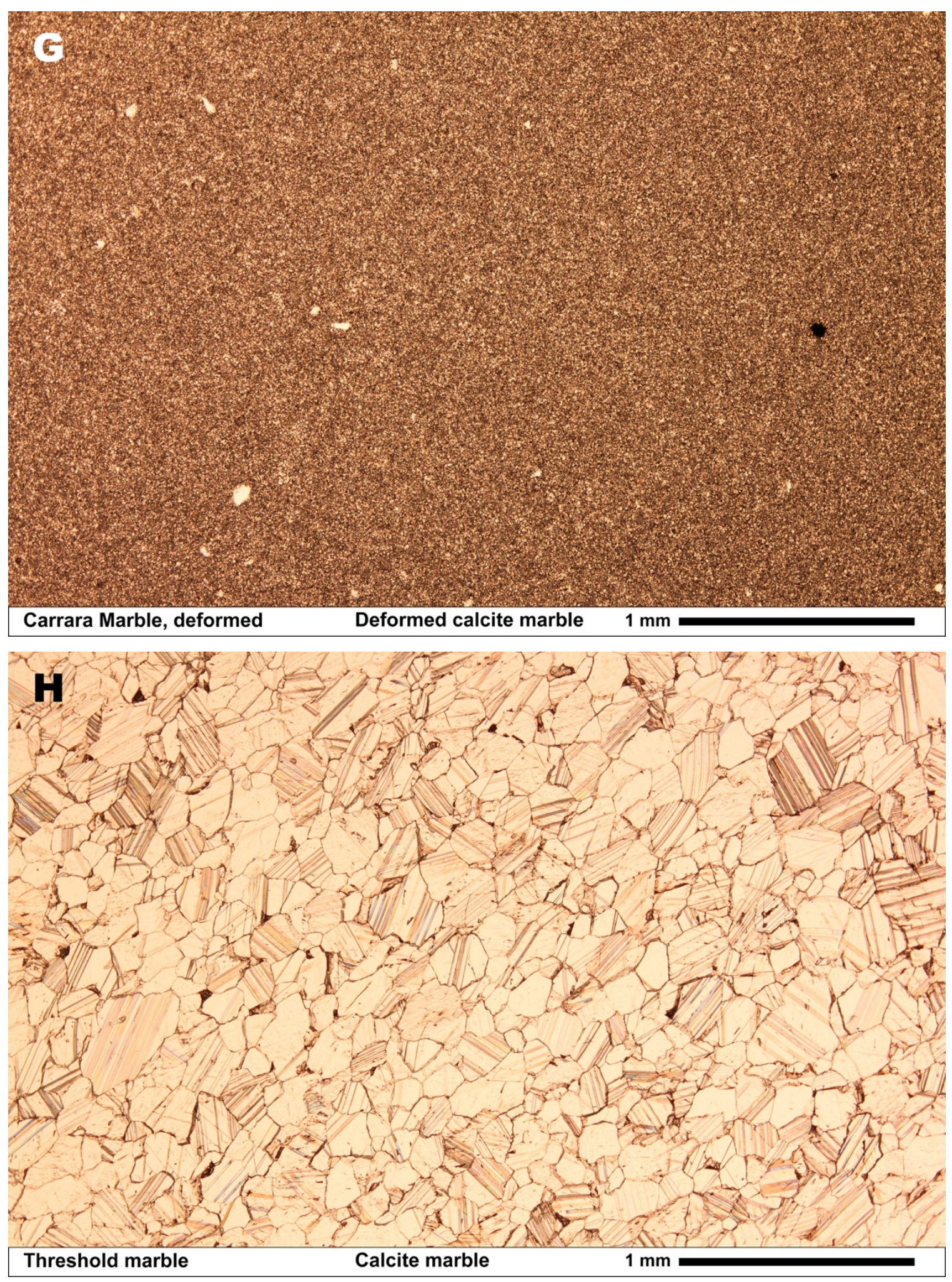

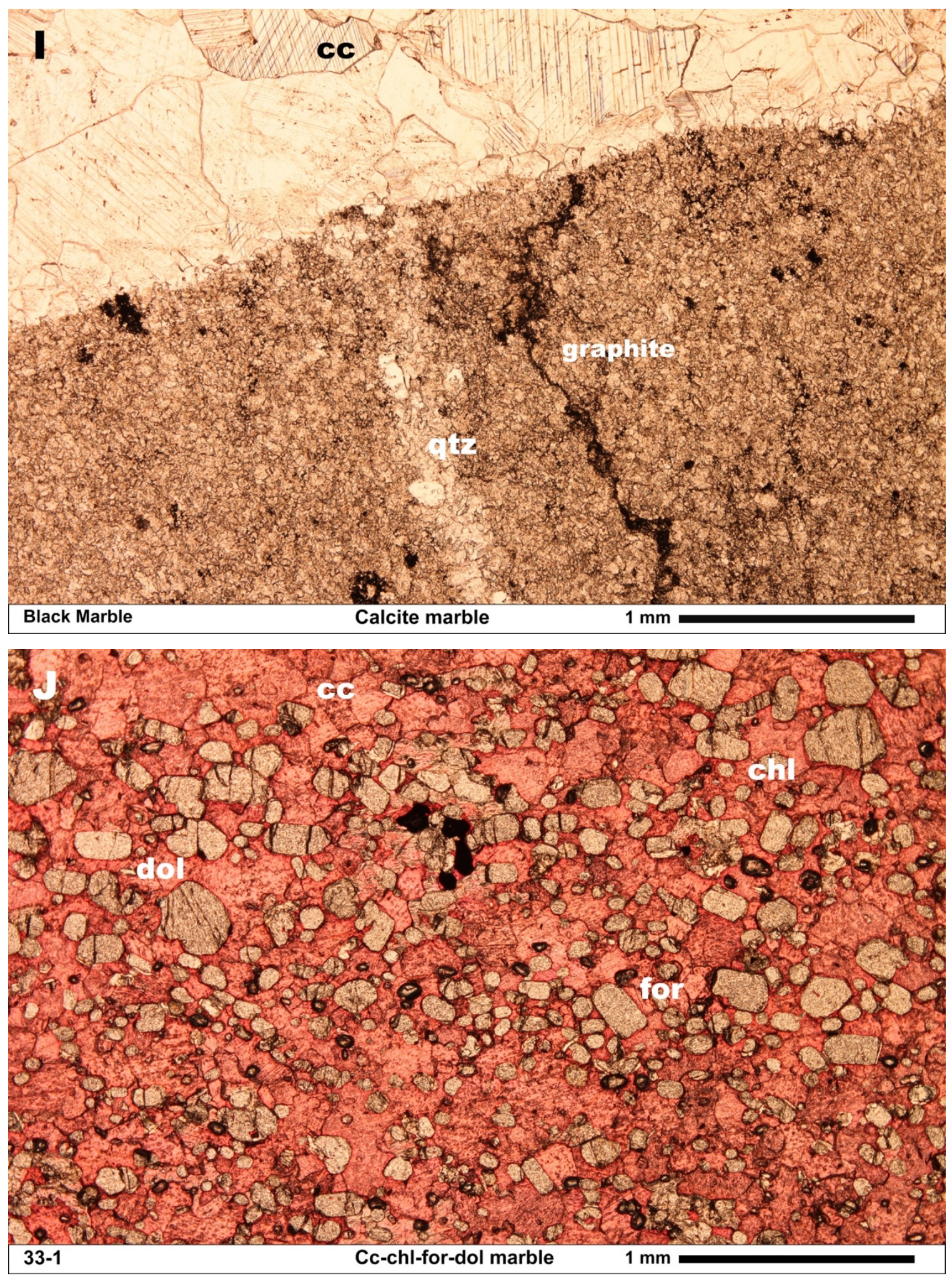

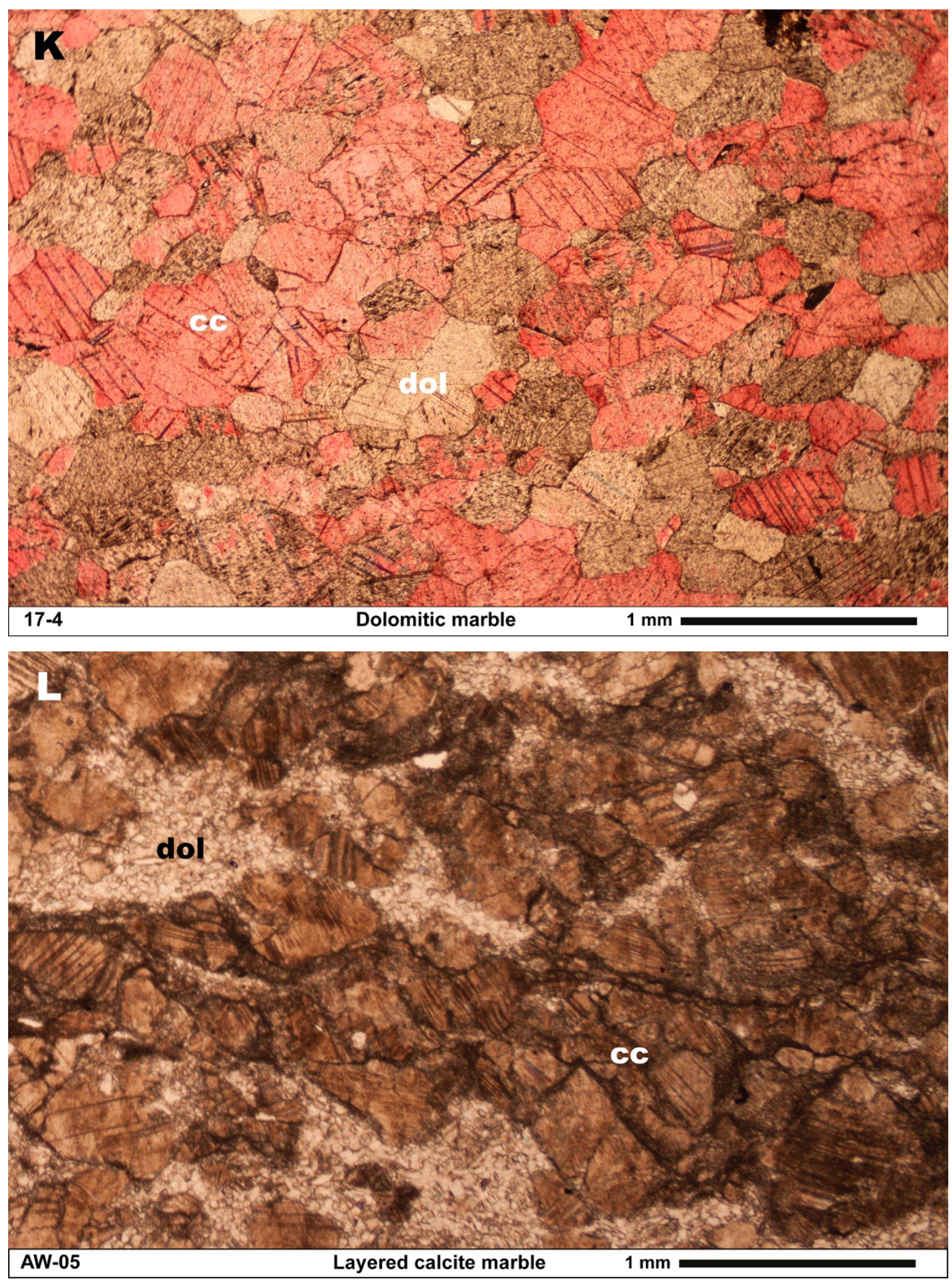
...above: Figure 2-3) Photomicrographs of rock samples (Table 2-1) in plane-polarized light. See text for sample descriptions. Samples TF-001, TF-002, MO-05, KS-002 , 33-1, and 17-4 were treated with alizarin to highlight calcite where present (red tint). All images are at the same scale. Polymineralic samples have example phases marked according to mineralogy: qtz—quartz; cc—calcite; dol—dolomite; for—forsterite; kfs — potassium feldspar; chl—chlorite. (A) Sample TF-001, fossiliferous limestone, with minor qtz in ooids and some fossils. (B) Sample TF-002, oolitic limestone, with minor qtz in ooids and fossils; large pore space (pale blue) in two upper left ooids is likely a result of sample preparation. (C) Sample MO-05, boundstone. (D) Sample MO-07, micrite, consisting of nearly pure cc; rare qtz is not visible at this scale.

(E) Sample KS-002, dolomite rock; matrix is cc, and larger grains are qtz or kfs; porosity is visible as pale blue. (F) Carrara Marble; pure calcite. (G) Carrara Marble, experimentally deformed; pure calcite. (H) Threshold marble; pure calcite marble; note larger average grain size than Carrara Marble (F).

(I) Black marble; calcite marble with minor (0.9 wt\%) qtz; black veins and spots may be graphite. (J) Sample 33-1, cc-chl-for-dol marble; cc is stained red; for appears as high-relief translucent grains, dol as lower-relief translucent grains; chl is visible as alteration between grains. (K) Sample 17-4, dolomitic marble; abundant cc (red) and dol (translucent) compared to X-ray diffraction results (Table 1; 94\% dol versus $\sim 6 \% \mathrm{cc}$ ) suggests mineralogical heterogeneity in the sample (see text for discussion). (L) Sample AW-05, layered cc marble; matrix is fine-grained dol; chl is visible as alteration along cc grains (brown); sample layering and textural variation are not visible at this scale.

\subsubsection{Thermal Diffusivity of Minerals}

The thermal diffusivity of calcite spar was measured from $\sim 300$ to $900 \mathrm{~K}$ in two orientations: with heat flowing parallel to the $c$-axis $(a a)$, and with heat flowing 

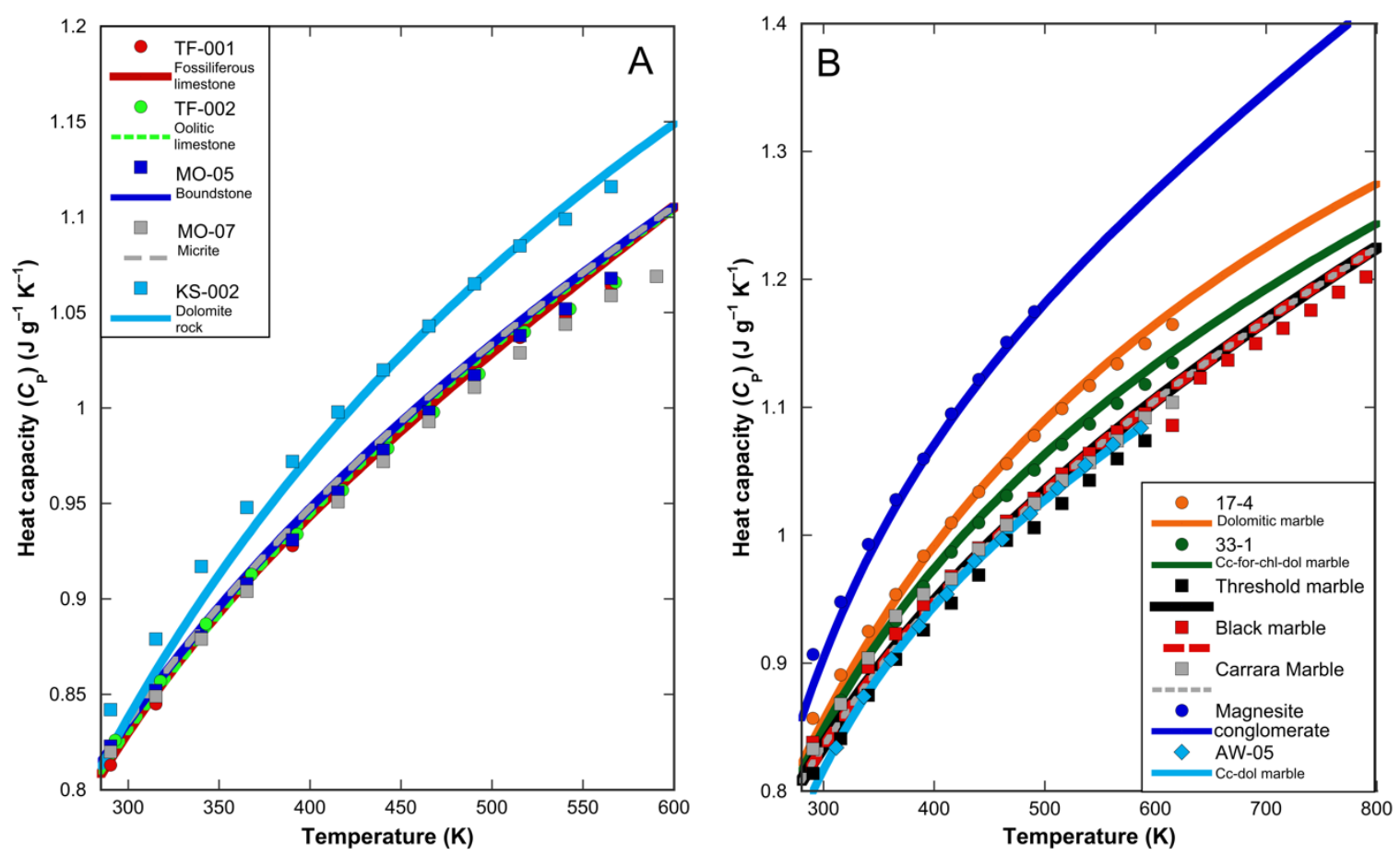

Figure 2-4) Isobaric heat capacity $\left(C_{P}\right)$ of limestone (A) and marble (B) samples. Lines show $C_{P}$ calculated from modal mineralogy (Table 2-1) after Robie and Hemingway (1995). Filled symbols are direct measurements of $C_{P}$ using powdered rock samples.

perpendicular to the $c$-axis $(a c)$. At room temperature $(296 \mathrm{~K}), D$ for calcite was very similar for both orientations: $1.66 \mathrm{~mm}^{2} \mathrm{~s}^{-1}$ for $a a$ and $1.63 \mathrm{~mm}^{2} \mathrm{~s}^{-1}$ for $a c$ (Fig. 5). $D$ decreased rapidly on heating to $\sim 500 \mathrm{~K}$, then decreased more slowly at higher temperatures. For the $a c$ orientation, $D$ decreased more rapidly and was $\sim 3 \%-10 \%$ lower than for $a a$. By $888 \mathrm{~K}, D$ was $\sim 0.47 \mathrm{~mm}^{2} \mathrm{~s}^{-1}$ for $a a$ and $\sim 0.43 \mathrm{~mm}^{2} \mathrm{~s}^{-1}(886 \mathrm{~K})$ for $a c$.

Dolomite had consistently higher $D$ than calcite, varying between $2.82 \mathrm{~mm}^{2} \mathrm{~s}^{-1}$ for white dolomite in the $a c$ orientation at $298 \mathrm{~K}$ and $2.46 \mathrm{~mm}^{2} \mathrm{~s}^{-1}$ for grey dolomite $(a c)$ at $297 \mathrm{~K}$. As with calcite, $D$ again decreased rapidly in the range 300-500 K, and more 
TABLE 2-4A. HEAT CAPACITY FITTING PARAMETERS

\begin{tabular}{|c|c|c|c|c|c|}
\hline Sample & $\mathrm{a}$ & $\mathrm{b}$ & $\begin{array}{c}C \\
\left(\times 10^{6}\right)\end{array}$ & $\mathrm{R}^{2}$ & $\begin{array}{c}\text { Measured } \\
\text { Temperature } \\
\text { Range }\end{array}$ \\
\hline TF-001 & 776.98 & 0.574 & -10.80 & 0.9995 & $265-565$ \\
\hline TF-002 & 760.16 & 0.598 & -8.82 & 0.9996 & $268-568$ \\
\hline MO-05 & 735.24 & 0.641 & -8.16 & 0.9996 & $265-565$ \\
\hline MO-07 & 780.60 & 0.548 & -9.89 & 0.9994 & $265-665$ \\
\hline KS-002 & 833.60 & 0.578 & -13.10 & 0.9996 & $265-565$ \\
\hline Carrara marble & 846.54 & 0.470 & -12.14 & 0.9991 & $265-615$ \\
\hline Threshold marble & 767.66 & 0.567 & -9.60 & 0.9989 & $265-615$ \\
\hline Black marble & 828.97 & 0.499 & -11.29 & 0.9995 & $265-790$ \\
\hline $17-4$ & 839.40 & 0.587 & -12.71 & 0.9993 & $265-615$ \\
\hline 33-1 & 850.60 & 0.522 & -13.85 & 0.9994 & $265-765$ \\
\hline AW-05 & 850.24 & 0.476 & -15.47 & 0.9997 & $261-661$ \\
\hline $\begin{array}{l}\text { Magnesite } \\
\text { conglomerate }\end{array}$ & 800.55 & 0.870 & -12.12 & 0.9998 & $265-515$ \\
\hline Calcite & 828.22 & 0.517 & -13.11 & 0.9994 & $285-870$ \\
\hline Dolomite & 955.42 & 0.449 & -21.43 & 0.9996 & $285-870$ \\
\hline Magnesite & 962.12 & 0.620 & -21.73 & 1.0000 & $298-1000$ \\
\hline Rhodochrosite & 669.87 & 0.496 & -10.27 & 0.9999 & $298-600$ \\
\hline
\end{tabular}

Note: Fitting parameters for equation 2-2 (see text). Mineral data is from the literature (see Experimental Methods in text for references).

\begin{tabular}{|c|c|c|c|c|c|}
\hline Sample & e & $f$ & $\begin{array}{c}g \\
\left(10^{-4}\right)\end{array}$ & $\mathrm{R}^{2}$ & $\begin{array}{c}\text { Measured } \\
\text { Temperature } \\
\text { Range (K) }\end{array}$ \\
\hline TF-002 & 10123 & 1.625 & 1.62 & 0.998 & $293-478$ \\
\hline MO-05 & 11746 & 1.599 & -1.26 & 0.998 & $295-529$ \\
\hline MO-07 & 10861 & 1.573 & 0.37 & 0.997 & $296-531$ \\
\hline KS-002 & 10773 & 1.564 & 1.37 & 0.994 & $293-597$ \\
\hline Carrara Marble (run 1) & 472 & 1.118 & 0.29 & 1.000 & $294-702$ \\
\hline $\begin{array}{l}\text { Carrara Marble ("trapezoid" } \\
\text { run) }\end{array}$ & 574 & 1.083 & -4.36 & 0.993 & $297-599$ \\
\hline Carrara Marble (deformed) & 9392 & 1.602 & 1.28 & 0.999 & $294-870$ \\
\hline Threshold marble & 3188 & 1.370 & 0.72 & 0.997 & $295-877$ \\
\hline Black marble & 15382 & 1.638 & 0.64 & 0.995 & $294-880$ \\
\hline $17-4$ grey dolomite, parallel & 6150 & 1.363 & - & 1.000 & $299-964$ \\
\hline $\begin{array}{l}17-4 \text { grey dolomite, } \\
\text { perpendicular }\end{array}$ & 5813 & 1.373 & - & 0.999 & 297-1013 \\
\hline $17-4$ white dolomite, parallel & 3051 & 1.287 & - & 1.000 & $300-1013$ \\
\hline $\begin{array}{l}\text { 17-4 white dolomite, } \\
\text { perpendicular }\end{array}$ & 11032 & 1.503 & - & 0.997 & $298-1013$ \\
\hline 33-1 White, Parallel & 1130 & 1.206 & -0.11 & 0.997 & $294-774$ \\
\hline 33-1 White, perpendicular & 5182 & 1.439 & 0.00 & 0.998 & $293-681$ \\
\hline AW-05 & 3282 & 1.364 & 1.94 & 1.000 & $295-777$ \\
\hline Magnesite conglomerate & 4035 & 1.366 & 6.87 & 0.987 & $295-574$ \\
\hline Calcite spar, aa & 3708 & 1.360 & 1.30 & 1.000 & $296-888$ \\
\hline Calcite spar, $a c$ & 4270 & 1.393 & 0.90 & 0.999 & $296-1008$ \\
\hline Dolomite grey, aa & 6569 & 1.371 & - & 1.000 & $294-898$ \\
\hline Dolomite grey, $a c$ & 3278 & 1.264 & - & 1.000 & $297-766$ \\
\hline Dolomite white, aa & 6770 & 1.380 & - & 0.990 & $295-483$ \\
\hline Dolomite white, $a c$ & 12007 & 1.467 & - & 1.000 & $298-547$ \\
\hline Magnesite & 8525 & 1.334 & - & 0.999 & $296-615$ \\
\hline Rhodochrosite & 6023 & 1.396 & - & 0.998 & $296-634$ \\
\hline \multicolumn{6}{|c|}{$\begin{array}{l}\text { Note: All samples fit to equation } 2-3 . \text { aa \& ac refer to heat flow parallel and } \\
\text { perpendicular to the c-axis of the mineral respectively. Parallel and perpendicular refer to } \\
\text { sample cut such that heat flow is parallel or perpendicular to bedding. }\end{array}$} \\
\hline
\end{tabular}


TABLE 2-4C. THERMAL CONDUCTIVITY FITTING PARAMETERS

\begin{tabular}{|c|c|c|c|c|c|c|}
\hline Sample & $\mathrm{h}$ & $\begin{array}{c}\mathrm{i} \\
\left(\times 10^{-3}\right)\end{array}$ & $\begin{array}{c}\mathrm{j} \\
\left(\times 10^{4}\right)\end{array}$ & $\mathrm{n}$ & $\mathrm{R}^{2}$ & $\begin{array}{l}\text { Measured } \\
\text { Temperature } \\
\text { Range } \\
\text { (K) }\end{array}$ \\
\hline TF-002 & -18.14 & 9.41 & -26.50 & 350.10 & 0.9998 & $293-565$ \\
\hline MO-05 & -17.59 & 9.91 & -12.40 & 323.54 & 1.0000 & $295-529$ \\
\hline MO-07 & 0.40 & -1.75 & 5.90 & 42.57 & 1.0000 & $296-531$ \\
\hline KS-002 & -7.18 & 2.79 & -8.30 & 176.52 & 0.9998 & $293-565$ \\
\hline Carrara (Run 1) & -1.31 & 0.43 & -0.99 & 53.64 & 0.9991 & $294-615$ \\
\hline Carrara (Trapezoid) & -3.32 & 1.15 & 2.19 & 87.93 & 0.9998 & $297-615$ \\
\hline Carrara (Deformed) & 0.40 & -0.06 & 9.85 & 10.13 & 0.9989 & $294-615$ \\
\hline Threshold marble & -8.55 & 2.96 & -18.50 & 215.73 & 0.9995 & $295-615$ \\
\hline Black marble & -17.11 & 7.10 & -27.50 & 364.38 & 0.9978 & $294-790$ \\
\hline 17-4 Average & -4.75 & 0.96 & -4.34 & 177.74 & 1.0000 & $295-640$ \\
\hline 33-1 Average & -3.84 & 1.22 & -1.59 & 118.03 & 1.0000 & $295-615$ \\
\hline AW-05 & -11.71 & 5.32 & -20.30 & 269.17 & 0.9997 & $295-587$ \\
\hline $\begin{array}{l}\text { Magnesite } \\
\text { Conglomerate }\end{array}$ & -13.49 & 8.10 & -22.50 & 315.51 & 0.9990 & $295-515$ \\
\hline Calcite Spar aa & -1.22 & 0.47 & 6.53 & 69.88 & 0.9990 & $296-870$ \\
\hline Calcite Spar ac & 2.28 & -0.76 & 20.30 & -11.93 & 0.9987 & $296-870$ \\
\hline Dolomite Grey, aa & -11.96 & 3.87 & -15.60 & 330.02 & 0.9999 & $294-870$ \\
\hline Dolomite Grey, ac & -7.01 & 1.79 & -10.40 & 234.94 & 0.9995 & $297-870$ \\
\hline Dolomite White, aa & -1.83 & -1.26 & 1.32 & 143.56 & 1.0000 & $295-483$ \\
\hline Dolomite White, ac & -37.78 & 19.69 & -46.60 & 759.75 & 1.0000 & $298-483$ \\
\hline Magnesite & 15.07 & -10.45 & 41.60 & -85.25 & 0.9996 & $296-634$ \\
\hline Rhodochrosite & -6.92 & 2.12 & -2.07 & 207.46 & 1.0000 & 296-600 \\
\hline \multicolumn{7}{|c|}{$\begin{array}{l}\text { Note: All samples fit to equation 2-4. aa \& ac refer to heat flow parallel and perpendicular to the } \\
\text { c-axis of the mineral respectively. Parallel and perpendicular refer to sample cut such that heat } \\
\text { flow is parallel or perpendicular to bedding. } \\
\text { Results should not be extrapolated beyond the reported temperature range. }\end{array}$} \\
\hline
\end{tabular}

slowly above $\sim 700 \mathrm{~K}$. Thermal diffusivity reached $\sim 0.74 \mathrm{~mm}^{2} \mathrm{~s}^{-1}$ at $766 \mathrm{~K}$ for grey

dolomite in both orientations.

Magnesite and rhodochrosite form a solid solution, and given the lack of

anisotropy in heat flow for calcite and low anisotropy in dolomite, an orientation between [001] and [100] was measured for both minerals. The Mg end-member magnesite had the highest $D$ of any carbonate sample across the range of temperatures measured, decreasing from $4.36 \mathrm{~mm}^{2} \mathrm{~s}^{-1}$ at $296 \mathrm{~K}$ to $1.64 \mathrm{~mm}^{2} \mathrm{~s}^{-1}$ at $615 \mathrm{~K} . D$ for the Mn end-member rhodochrosite was between that of dolomite and that of calcite, decreasing from 2.16 $\mathrm{mm}^{2} \mathrm{~s}^{-1}$ at $296 \mathrm{~K}$ to $0.71 \mathrm{~mm}^{2} \mathrm{~s}^{-1}$ at $634 \mathrm{~K}$. 
Data for all thermal diffusivity results (Table 2-5) were fit to the equation (see Table 4B):

$$
D\left(\mathrm{~mm}^{2} \mathrm{~s}^{-1}\right)=e T^{\mathrm{f}}+g T
$$

Equation 2-3.

where $T$ is in Kelvin. The form of this equation was proposed by Hofmeister et al. (2014) to reproduce $d D / d T$ for minerals with diverse structures and chemical compositions, but applies to rocks as well (see the following sections). The terms $e$ and $f$ describe the reduction in $D$ over the temperature range of $\sim 300-600 \mathrm{~K}$, and the $g$ term corresponds to an increasing diffusive radiative contribution at higher temperatures. This form also fits various glasses, alkali halides, and semi-conductors, and some 200 species follow Equation 3. Hofmeister et al. (2014) argued that the form represents the sum of phonon scattering and diffusion of IR radiation (polaritons).

\subsubsection{Thermal Diffusivity of Limestones}

Dolomitic limestone KS-002 reflects the higher diffusivity of the mineral dolomite when compared to more calcitic limestones (Fig. 6). KS-002 has a $D$ of 1.48 $\mathrm{mm}^{2} \mathrm{~s}^{-1}$ at $293 \mathrm{~K}$, which decreases to $0.55 \mathrm{~mm}^{2} \mathrm{~s}^{-1}$ at $597 \mathrm{~K}$. At similar temperatures, micrite MO-07 produced a $D$ of $1.38 \mathrm{~mm}^{2} \mathrm{~s}^{-1}$ at $296 \mathrm{~K}$, decreasing to $0.55 \mathrm{~mm}^{2} \mathrm{~s}^{-1}$ at 531 $\mathrm{K}$. The samples with large fossil fragments or ooids produce the lowest $D$ for limestones across the range of temperatures. Boundstone MO-05 had a $D$ of $1.30 \mathrm{~mm}^{2} \mathrm{~s}^{-1}$ at $295 \mathrm{~K}$, decreasing rapidly to $0.48 \mathrm{~mm}^{2} \mathrm{~s}^{-1}$ at $529 \mathrm{~K}$. Sample TF-001, a fossiliferous limestone, was only measured at $294 \mathrm{~K}$, and produced a $D$ of $1.04 \mathrm{~mm}^{2} \mathrm{~s}^{-1}$, similar to sample TF- 


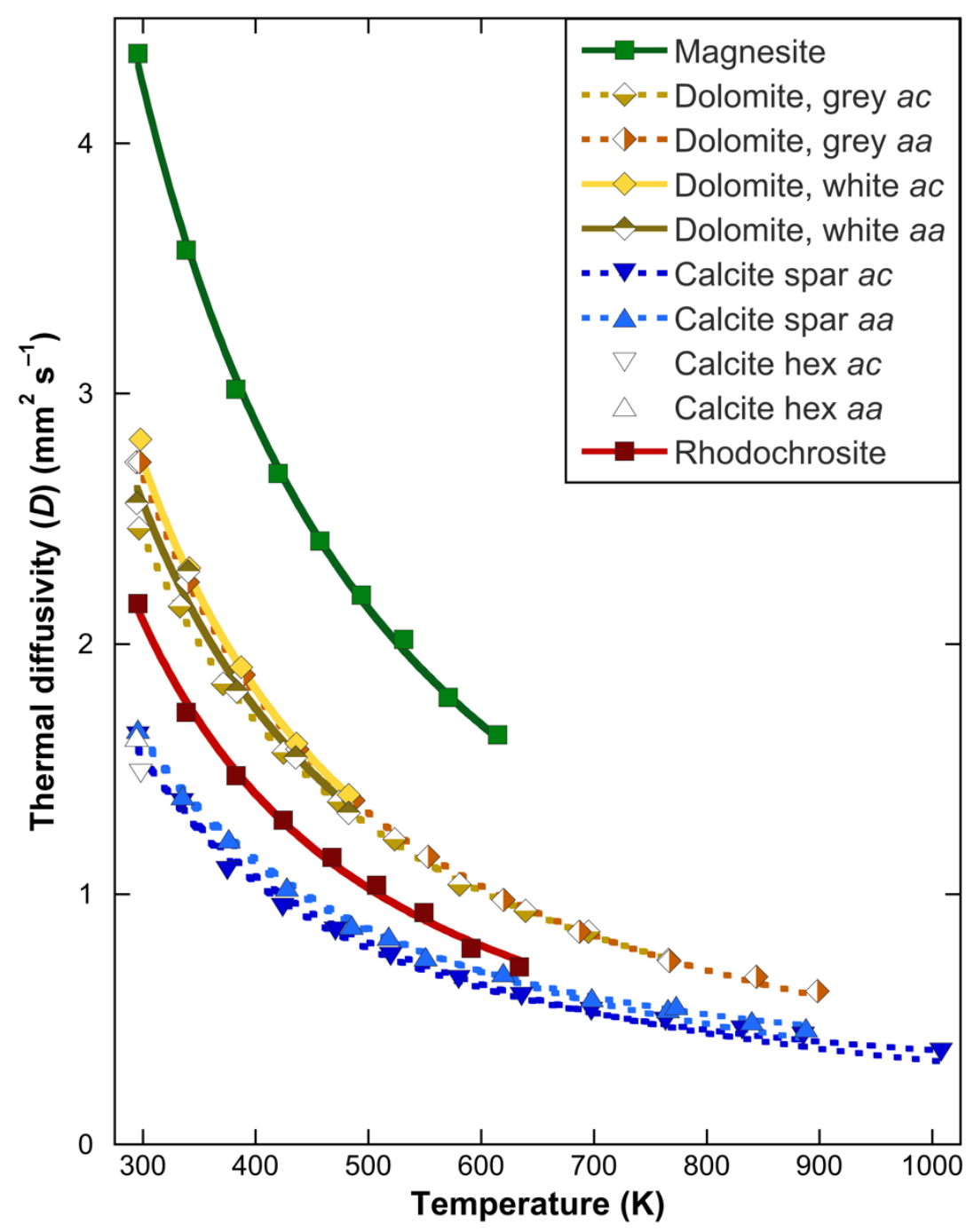

Figure 2-5) Thermal diffusivity $(D)$ of minerals measured for this study. For minerals measured in multiple orientations, $a a$ indicates heat flow parallel to the $c$-axis, and $a c$ heat flow perpendicular to the $c$-axis ( $c=$ [100]) Note that "calcite hex" is a hexagonal-shaped sample of calcite. Crystal orientation has only a small influence on $D$ at low temperature, and negligible influence at temperatures above $\sim 500 \mathrm{~K}$.

002, an oolitic limestone with a $D$ of $1.03 \mathrm{~mm}^{2} \mathrm{~s}^{-1}$ at $293 \mathrm{~K}$. TF-002 was heated to $478 \mathrm{~K}$, however, where $D$ was $0.52 \mathrm{~mm}^{2} \mathrm{~s}^{-1}$.

Experimental data for limestones were fit to Equation 2-3 (Table 2-4B). 


\subsubsection{Thermal Diffusivity of Marbles}

The thermal diffusivity of the marble samples varied more than that of the limestones, depending primarily on dolomite content (Fig. 2-7). Whereas roomtemperature $D$ for the AW-05, Black marble, and Threshold marble samples was comparable to that of limestone, at $1.45 \mathrm{~mm}^{2} \mathrm{~s}^{-1}, 1.37 \mathrm{~mm}^{2} \mathrm{~s}^{-1}$, and $1.29 \mathrm{~mm}^{2} \mathrm{~s}^{-1}$, respectively, $D$ dropped more rapidly on heating to $0.48 \mathrm{~mm}^{2} \mathrm{~s}^{-1}$ at $555 \mathrm{~K}$ for the Black marble and $0.60 \mathrm{~mm}^{2} \mathrm{~s}^{-1}$ at $561 \mathrm{~K}$ for the Threshold marble. Thermal diffusivity of sample AW-05, however, remained elevated at higher temperatures $\left(0.73 \mathrm{~mm}^{2} \mathrm{~s}^{-1}\right.$ at 523 $\mathrm{K})$, where its $D$ is similar to that of the dolomitic marbles. The marbles were measured to higher temperatures than the limestones, with $D$ values approaching $0.3 \mathrm{~mm}^{2} \mathrm{~s}^{-1}$ for Black marble $\left(0.31 \mathrm{~mm}^{2} \mathrm{~s}^{-1}\right.$ at $\left.880 \mathrm{~K}\right)$, calcite marble $33-1\left(0.33 \mathrm{~mm}^{2} \mathrm{~s}^{-1}\right.$ at $\left.870 \mathrm{~K}\right)$, and Threshold marble $\left(0.35 \mathrm{~mm}^{2} \mathrm{~s}^{-1}\right.$ at $\left.877 \mathrm{~K}\right)$. At room temperature $(294 \mathrm{~K}), D$ for sample 33-1 was $1.49 \mathrm{~mm}^{2} \mathrm{~s}^{-1}$ perpendicular to layering and $1.24 \mathrm{~mm}^{2} \mathrm{~s}^{-1}$ parallel to layering, but this difference disappeared at high temperature. Dolomitic marble 17-4 had the greatest anisotropy at ambient temperature, from $2.00 \mathrm{~mm}^{2} \mathrm{~s}^{-1}$ (parallel, $300 \mathrm{~K}$ ) to $2.01 \mathrm{~mm}^{2} \mathrm{~s}^{-1}$ (perpendicular, $298 \mathrm{~K}$ ) for the white sample, and from $2.64 \mathrm{~mm}^{2} \mathrm{~s}^{-1}$ (parallel, $299 \mathrm{~K}$ ) to $2.25 \mathrm{~mm}^{2} \mathrm{~s}^{-1}$ (perpendicular, $297 \mathrm{~K}$ ) for the grey sample. These differences were reduced at higher temperatures.

The first disk of Carrara Marble had the lowest $D$ of all samples measured at ambient temperature $\left(0.82 \mathrm{~mm}^{2} \mathrm{~s}^{-1}\right.$ at $\left.294 \mathrm{~K}\right)$, falling to $0.33 \mathrm{~mm}^{2} \mathrm{~s}^{-1}$ at $702 \mathrm{~K}$. The 


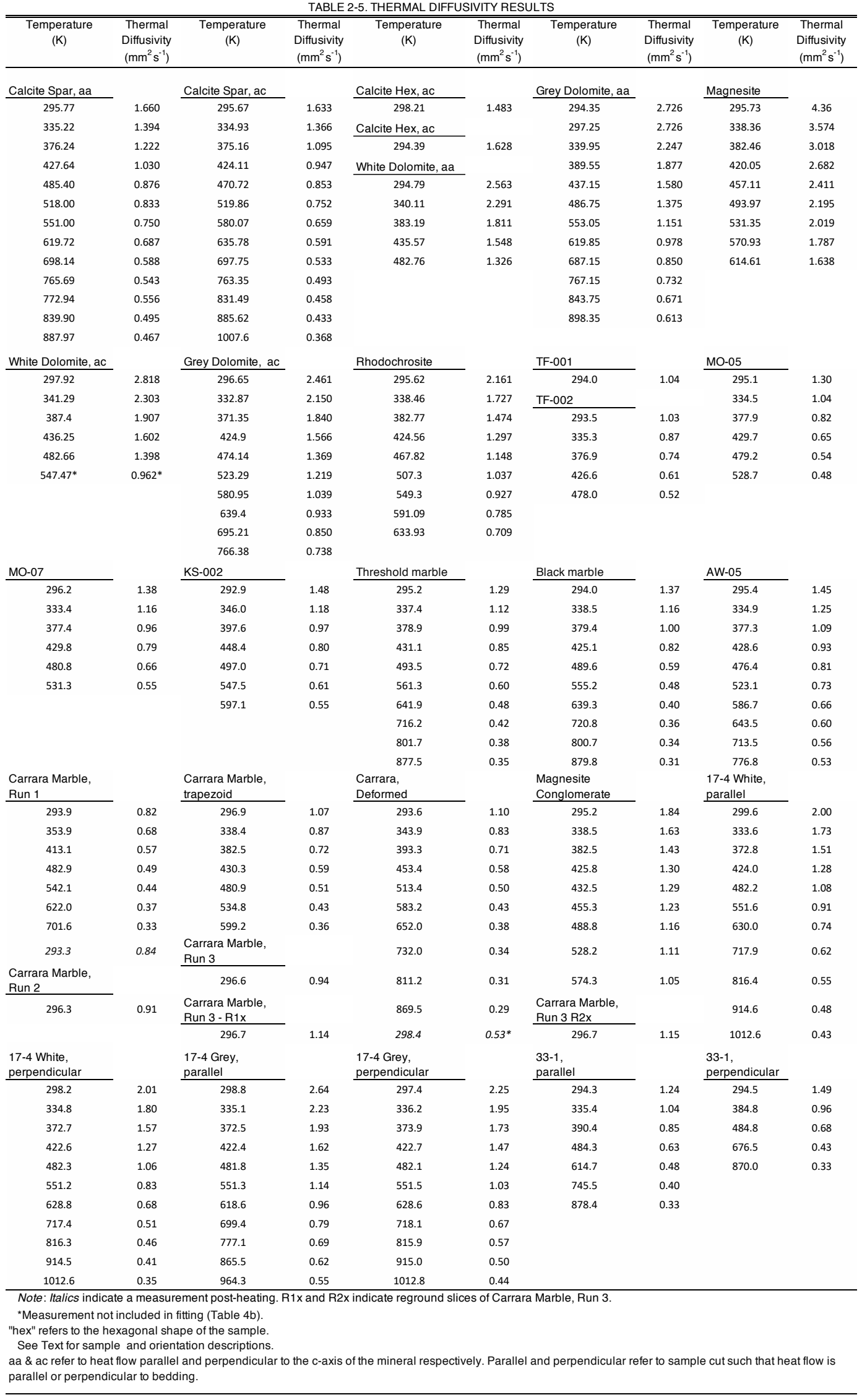


experimentally deformed sample had a higher $D$ at room temperature $(294 \mathrm{~K}), 1.10 \mathrm{~mm}^{2}$ $\mathrm{s}^{-1}$, but similar high-temperature values of $0.34 \mathrm{~mm}^{2} \mathrm{~s}^{-1}$ at $732 \mathrm{~K}$ and $0.29 \mathrm{~mm}^{2} \mathrm{~s}^{-1}$ at 870

K. A subsequent measurement of the same sample at room temperature (298 K) was only $0.53 \mathrm{~mm}^{2} \mathrm{~s}^{-1}$, suggesting that irreversible structural changes occurred in the sample during heating. As the sample is heated, grains within the disk expand differentially, opening new pore space, which remains upon cooling. The result is a more porous, friable sample whose intergrain thermal resistance is much higher.

Three additional disks of fresh Carrara were measured to assess reproducibility and explore the cause of low $D$ in the first disk (Fig. 2-8, run 2, run 3, and trapezoid). Room-temperature $D$ measurements were moderately higher at $0.91 \mathrm{~mm}^{2} \mathrm{~s}^{-1}(296 \mathrm{~K})$, $0.94 \mathrm{~mm}^{2} \mathrm{~s}^{-1}(297 \mathrm{~K})$, and $1.07 \mathrm{~mm}^{2} \mathrm{~s}^{-1}(297 \mathrm{~K})$. In hand specimen, the sample was brittle

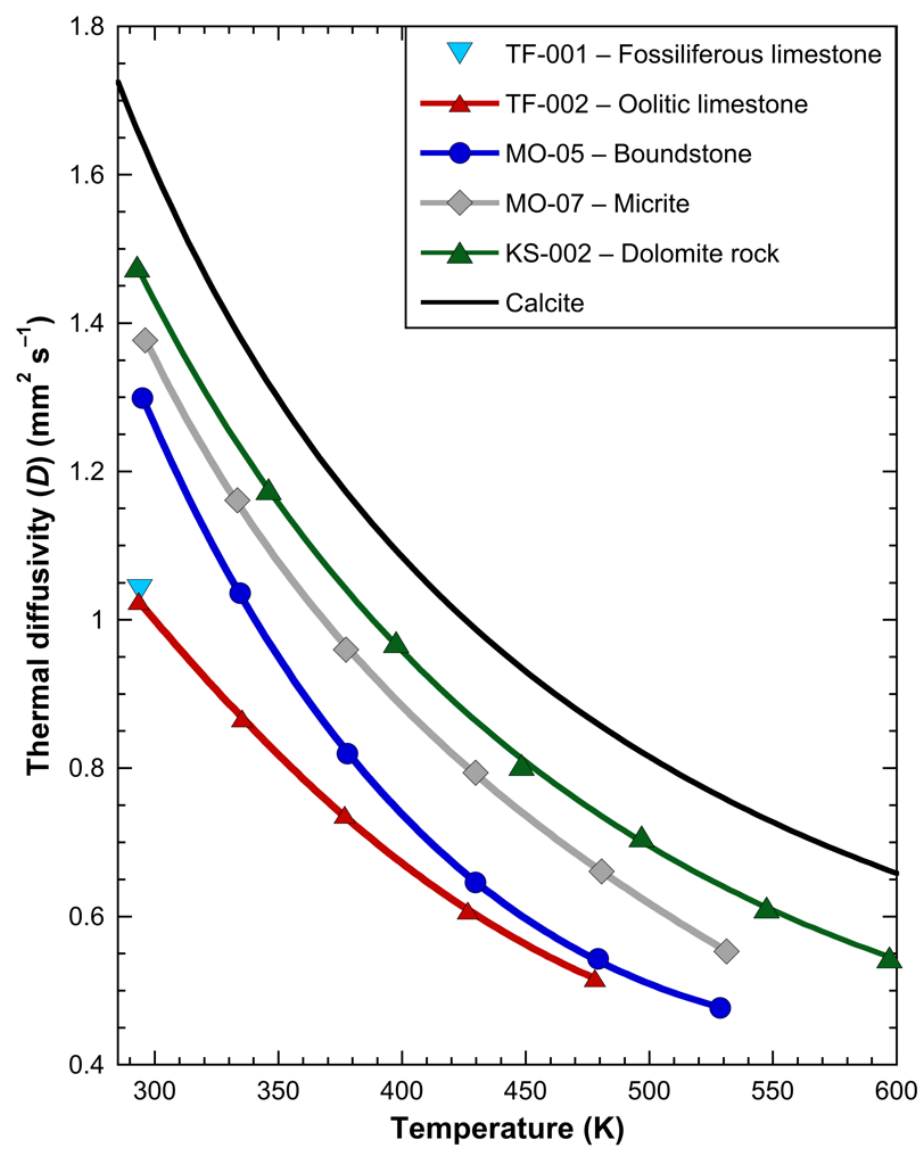

Figure 2-6) Thermal diffusivity $(D)$ of lime- stones and dolomite rock. Symbols are data collected, and lines are fits to data points. Given that most of these samples are dominated by calcite (except dolomite-dominated sample KS-002), the strongest control on bulk-rock $D$ is likely textural. $D$ generally decreases with increasing porosity (Table 1-1). Despite very high porosity $(15 \%)$, dolomite rock KS-002 has higher $D$ than all of the limestones measured. Note that "calcite" is a fit of the directionally averaged $D$ of our calcite spar sample, as exact temperatures were not reproduced for each point for both orientations. 
to the touch, but when outer layers were removed, the interior was found to be less brittle. Disk 3 was reground twice, each time reducing outer-layer brittleness and increasing $D$ at room $T$ (Fig. 2-8). Finally, disk 4 (trapezoid) was measured at elevated temperature, and its $D$ dropped rapidly to within error of results for disk 1 by $\sim 500 \mathrm{~K}$.
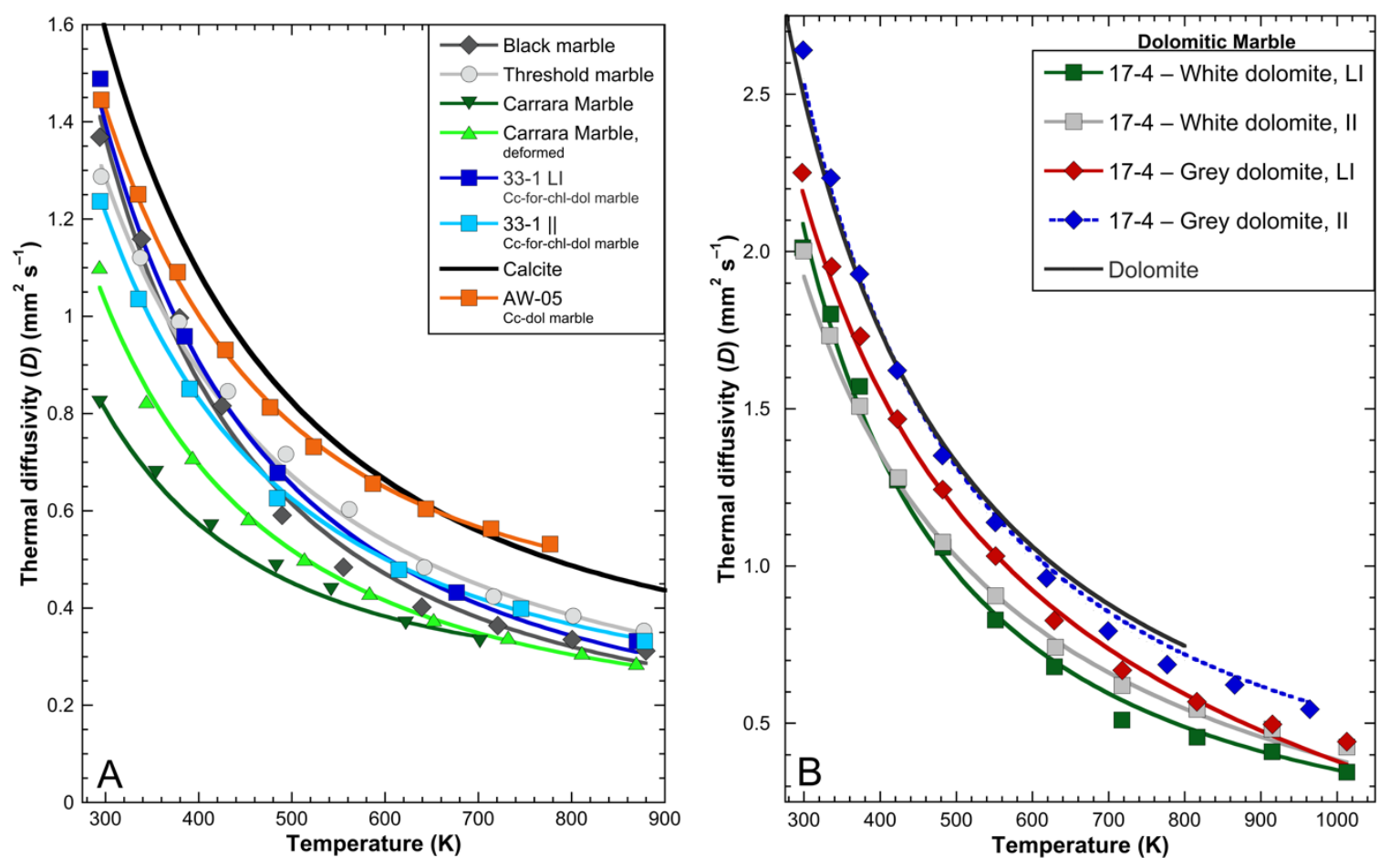

Figure 2-7) Thermal diffusivity $(D)$ of marbles. Symbols are measured $D$ data, and lines are fits to data points. The Carrara marble data shown here is run \#1 (see Thermal Diffusivity of Marbles in the text for more information). (A) Calcite-dominated marble. The low $D$ of Carrara Marble may be a consequence of poor cohesion of the outer layers of the sample (see text for discussion). Porosity was low for all samples, which resulted in a low spread of measured $D$ for samples with similar mineralogy (Table 1-1). The lower $d D / d T$ ( $T$ is temperature) for sample AW-05 may be a result of a high proportion of dolomite in the sample $(37 \mathrm{wt} \%)$. cc — calcite; for—forsterite; chl—chlorite; dol—dolomite. (B) Dolomite-dominated marble (sample 17-4). "Dolomite" is directionally averaged dolomite (both white and grey dolomite). Directionally averaged calcite (calcite spar) is included for reference. For samples 33-1 (A) and 17-4 (B), "LI" indicates heat flowing perpendicular to (across) bedding, and "II" indicates heat flowing with bedding layers. 
Experimental data for some of the Carrara runs (run 1, trapezoid, and de- formed), Threshold marble, Black marble, sample 33-1, and magnesite con- glomerate were fit to Equation 2-3. Data for sample 17-4 were fit to Equation 2-3.

\subsubsection{Thermal Conductivity}

For minerals, $k$ was calculated using published values for $\rho$ and $C_{P}$. Fitting parameters for $C_{P}, D$, and $k$ can be found in Table 4 . For rocks, $k$ was calculated from Equation 1-1, with geometric $\rho$, and measured $C_{P}$ which was fitted to Equation 2-2 to obtain values for the temperatures at which $D$ was measured. For use in numerical modeling, the derived values of $k\left(\mathrm{~W} \mathrm{~m}^{-1} \mathrm{~K}^{-1}\right)$ were fitted to:

$$
k=h+i T+j T^{-2}+n T^{-1 / 2}
$$

Equation 2-4.

where $h, i, j$, and $n$ are fitting parameters and $T$ is in Kelvin. This empirical equation is commonly used to model heat capacity (e.g., Robie and Hemingway, 1995), and its success in fitting experimental data for thermal conductivity points to the strong influence of heat capacity in determining thermal conductivity (Equation 1-1). Propagation of errors using all three measured components of thermal conductivity results in a cumulative experimental uncertainty of 5.5\% at ambient temperature, and 3\% at elevated temperatures.

\subsubsection{Mineral Thermal Conductivity}


Because $C_{P}$ and $\rho$ typically vary less than $D$ between carbonate minerals, mineral $k$ mirrors $D$, with dolomite displaying high $k$ at room $T$, and a steep negative $d k / d T$ (Fig. 9). Room-temperature $k$ was as high as $6.85 \mathrm{~W} \mathrm{~m}^{-1} \mathrm{~K}^{-1}(298 \mathrm{~K}$ ) for grey dolomite ( $a c$ orientation) and as low as $5.97 \mathrm{~W} \mathrm{~m}^{-1} \mathrm{~K}^{-1}(297 \mathrm{~K})$ for white dolomite ( $a c$ orientation). As with $D$, there is no strong dependence on orientation for either grey or white dolomite, as grey dolomite has a higher $k$ at room $T$ in the $a a$ orientation, but white dolomite in the $a a$ orientation has lower room-temperature $k$ compared to the $a c$ orientation. All $k$ values for dolomite converge to a narrow range as temperature increases, and by $\sim 500 \mathrm{~K}$ vary by $<4 \%$. The decrease in $k$ as temperature increases appears to level off and approach minimal values near $\sim 2.3 \mathrm{~W} \mathrm{~m}^{-1} \mathrm{~K}^{-1}$ for the highest temperatures at which $D$ was measured (898 K, grey dolomite $[a a])$.

Calcite shows a similar small dependence of $k$ on orientation of the crystal, with nearly identical $k$ at room $T$, departing slightly as temperature increases (Fig. 9). Calculated $k$ for calcite remains roughly $60 \%$ that of any dolomite sample over the range of temperatures measured. For example, $k$ at room $\mathrm{T}$ was $\sim 3.7 \mathrm{~W} \mathrm{~m}^{-1} \mathrm{~K}^{-1}$ in the aa orientation, compared to $\sim 6.6 \mathrm{~W} \mathrm{~m}^{-1} \mathrm{~K}^{-1}$ for grey dolomite (aa). At $620 \mathrm{~K}$, this difference was $\sim 2.1 \mathrm{~W} \mathrm{~m}^{-1} \mathrm{~K}^{-1}$ versus $\sim 3.3 \mathrm{~W} \mathrm{~m}^{-1} \mathrm{~K}^{-1}$ respectively. Both minerals showed similar decreases in $k$ over the range of temperatures in which $D$ was measured. Calcite (aa) $k$ drops by $\sim 58 \%$ between $300 \mathrm{~K}$ and $890 \mathrm{~K}$, and grey dolomite (aa) $\sim 66 \%$ over the same temperature range.

For magnesite, the product of high $D$ at all temperatures with higher $\rho(3010 \mathrm{~kg}$ $\mathrm{m}^{-3}$ ) and $C_{P}$ (Fig. 9) combined to produce $k \sim 80 \%$ higher than for dolomite. Although $D$ of magnesite was measured to only $600 \mathrm{~K}$, the $k$ of magnesite was highly $T$-dependent, 
dropping by $45 \%$ between $300 \mathrm{~K}$ and $600 \mathrm{~K}$. Similar percentage decreases in $k$ for both calcite and dolomite occurred across the same temperature range ( $45 \%-48 \%)$. The $k$ of rhodochrosite was between that of calcite and dolomite. Lower $C_{P}$ for rhodochrosite $\left(\sim 700 \mathrm{~J} \mathrm{~kg}^{-1} \mathrm{~K}^{-1}\right.$ at $\left.296 \mathrm{~K}\right)$ is somewhat offset by higher $\rho\left(3700 \mathrm{~kg} \mathrm{~m}^{-3}\right)$ resulting in a room-temperature $k$ of $5.59 \mathrm{~W} \mathrm{~m}^{-1} \mathrm{~K}^{-1}(296 \mathrm{~K})$, remaining higher than calcite and lower than dolomite to high $T\left(2.50 \mathrm{~W} \mathrm{~m}^{-1} \mathrm{~K}^{-1}\right.$ at $\left.634 \mathrm{~K}\right)$. Rhodochrosite $k$ shows a similar $\mathrm{d} k / \mathrm{d} T$ to that of calcite and dolomite.

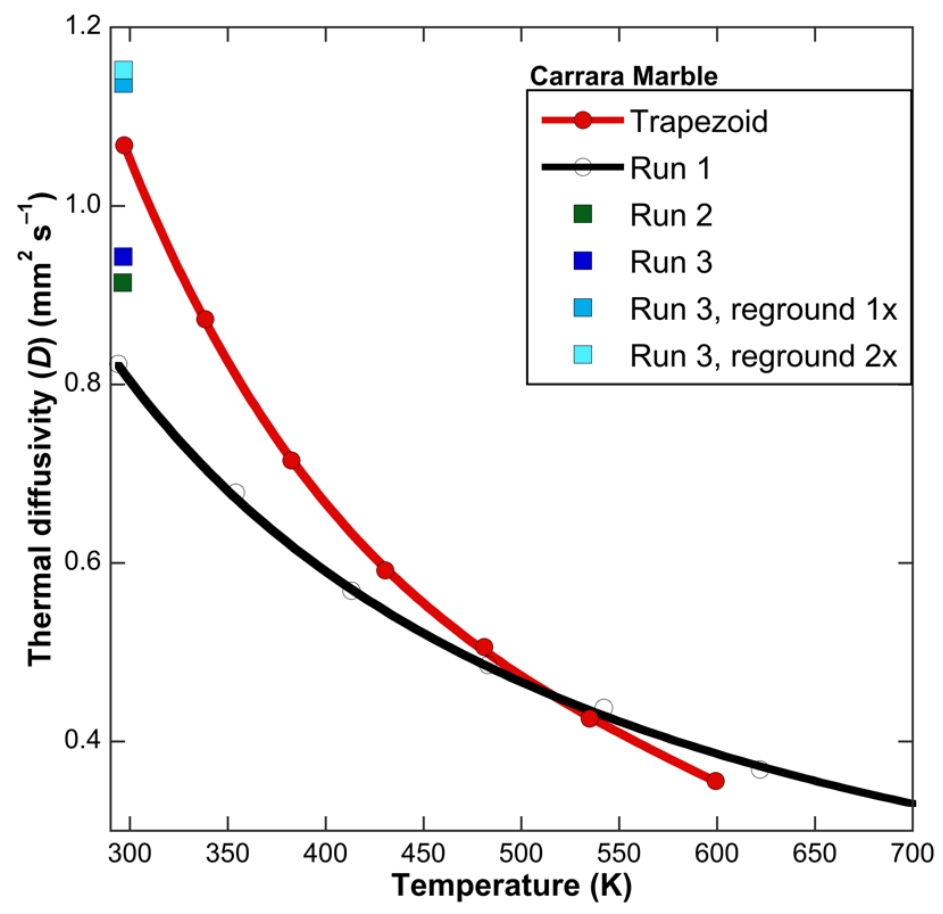

Figure 2-8) Effects on thermal diffusivity $(D)$ of sample preparation on Carrara Marble. Runs 1-3 are disks of Carrara Marble (Table 1). "Trapezoid" is a trapezoidal cut of the same sample. "Run 3, reground" indicates the effects of grinding off outer layers of the run 3 disk to remove loosely coherent grains (" $1 \times "$ is reground once, " $2 \times "$ twice). Runs 2 and 3 were measured at room temperature only.

\subsubsection{Limestone and Dolomite Rock Thermal Conductivity}

As with most of the carbonate minerals, all samples of limestone and dolomite rock show a strong decrease in $k$ with increasing $T$ (Fig. 2-10A). Samples MO-07 (micrite) and KS-002 (dolomite rock) had very similar $k$ values through- out the range of temperatures calculated, with MO-07 having a $k$ of $3.14 \mathrm{~W} \mathrm{~m}^{-1} \mathrm{~K}^{-1}$ at $296 \mathrm{~K}$, decreasing 


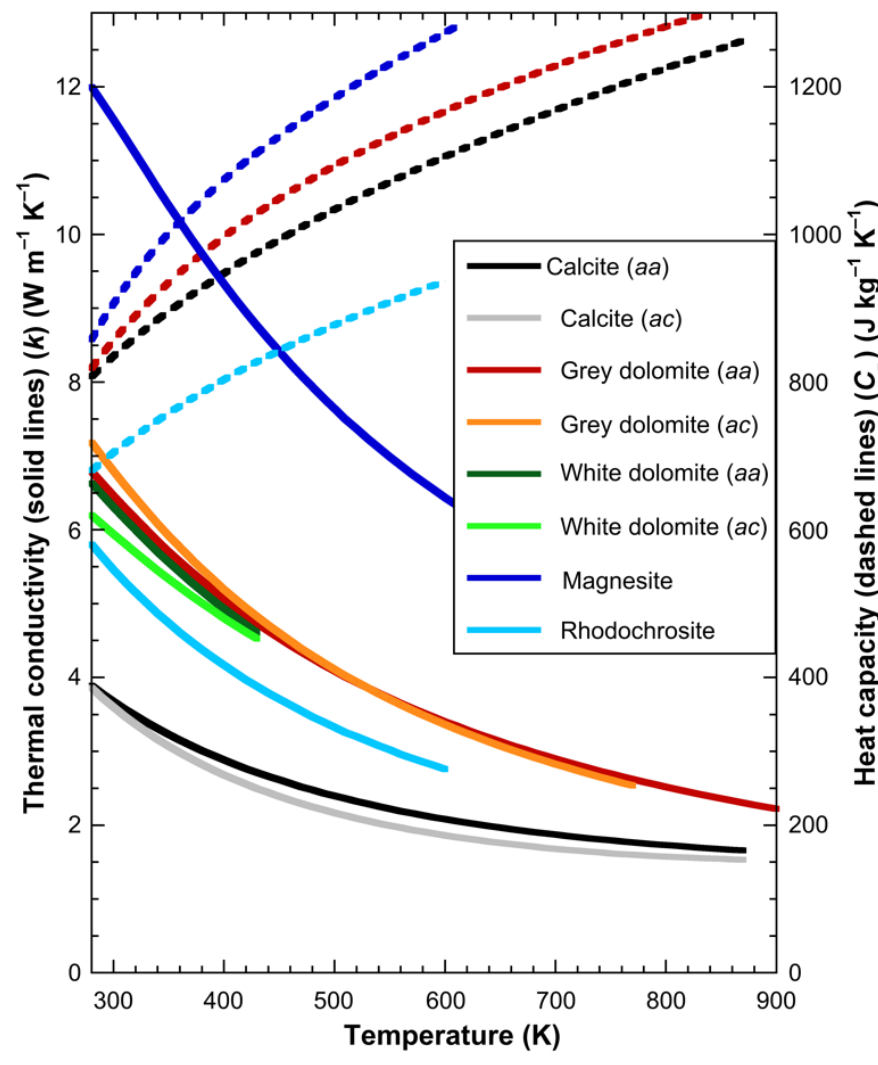

Figure 2-9) Thermal conductivity ( $k$ ) and isobaric heat capacity $\left(C_{\mathrm{P}}\right)$ of carbonate minerals calculated using measured thermal diffusivity $(D)$ and literature values for $C_{\mathrm{P}}$ and density (calcite—Jacobs et al. [1981]; dolomite — Krupka et al. [1985]; magnesiteRobie and Hemmingway [1994]; rhodochrosite-Moore [1943]). Solid lines are for $k$, dashed lines for $C_{\mathrm{P}}$. For $C_{\mathrm{P}}$, dark blue is magnesite, red is dolomite, black is calcite, and light blue is rhodochrosite. Line lengths are restricted by maximum measured $D$. For $k$ measured in multiple orientations, $a a$ indicates heat flow parallel to the $c$-axis, and ac heat flow perpendicular to the $c$-axis.

by $\sim 50 \%$ to $1.64 \mathrm{~W} \mathrm{~m}^{-1} \mathrm{~K}^{-1}$ at $531 \mathrm{~K}$ and similar values for $\mathrm{KS}-002$. Calcitic boundstone MO-05 had a higher $\mathrm{d} k / \mathrm{d} T$ than any other sample calculated as $k$ dropped by $\sim 55 \%$ from an already low $2.74 \mathrm{~W} \mathrm{~m}^{-1} \mathrm{~K}^{-1}$ at $295 \mathrm{~K}$ to a very low $1.27 \mathrm{~W} \mathrm{~m}^{-1} \mathrm{~K}^{-1}$ at $529 \mathrm{~K}$. Oolitic limestone TF-002 was similarly insulating at high $T$, but across the entire temperature range calculated $\left(\sim 2.0 \mathrm{~W} \mathrm{~m}^{-1} \mathrm{~K}^{-1}\right.$ at $294 \mathrm{~K}$, and $\sim 1.2 \mathrm{~W} \mathrm{~m}^{-1} \mathrm{~K}^{-1}$ at $\left.478 \mathrm{~K}\right)$.

\subsubsection{Marble Thermal Conductivity}

Thermal conductivity of undeformed Carrara Marble at 294 K (Fig. 2-10B) was lower than that of any of the limestones at $\sim 1.8 \mathrm{~W} \mathrm{~m}^{-1} \mathrm{~K}^{-1}$, but the de- formed sample had a higher $k$ of $\sim 2.1 \mathrm{~W} \mathrm{~m}^{-1} \mathrm{~K}^{-1}(294 \mathrm{~K})$. This contrast disappeared at elevated temperatures, with the undeformed sample having a $k$ of $1.29 \mathrm{~W} \mathrm{~m}^{-1} \mathrm{~K}^{-1}$ at $484 \mathrm{~K}$ and the deformed 
sample a similar $k$ of $1.19 \mathrm{~W} \mathrm{~m}^{-1} \mathrm{~K}^{-1}$ at $513 \mathrm{~K}$. Threshold marble and Black marble both

had $k$ in the range of measured limestones as well, but higher than that of the Carrara

Marble. Marble 33-1 was the only calcite-dominated marble with room-temperature $k$

higher than that of the limestones at $3.17 \mathrm{~W} \mathrm{~m}^{-1} \mathrm{~K}^{-1}$ (average of all orientations), but
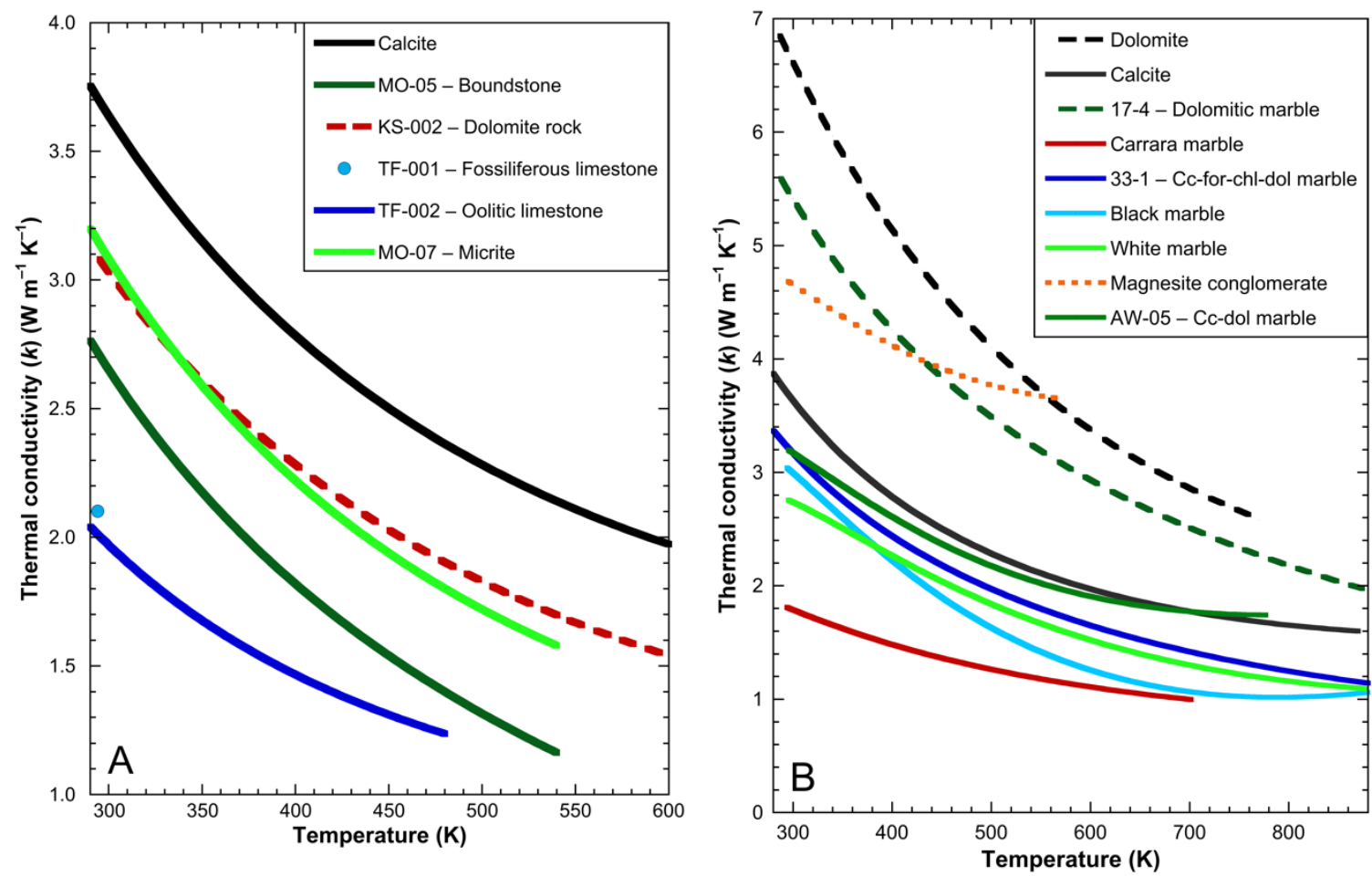

Figure 2-10) Thermal conductivity $(k)$ of carbonate limestone and marble samples, calculated using measured thermal diffusivity $(D)$ and isobaric heat capacity $\left(C_{\mathrm{P}}\right)$ and measured geometric density. (A) Limestone $k$, including dolomite rock KS-002, calculated using measured $D$ and $C_{\mathrm{P}}$ and measured geometric density. Unlike for $D$, where KS-002 values were higher across the range of temperatures measured, samples KS-002 and MO-07 have similar $k$ values at low temperature $(T)$, with MO-07 having a higher $d D / d T$. This reflects the lower density of KS-002 resulting from high porosity, whereas MO-07 has very low porosity (Table 1). Calcite values are from directionally averaged calcite spar. (B) Marble $k$ using measured $D$ and $C_{\mathrm{P}}$ with measured geometric density. Solid lines are rocks dominated by calcite; dashed lines, rocks dominated by dolomite; and the dotted line, magnesite. Values for dolomite, calcite, and samples 17-4 and 33-1 are directionally averaged. Carrara Marble data are from run 1 (Fig. 2-8). Low $d D / d T$ for the magnesite conglomerate likely results from the higher $D$ of magnesite relative to dolomite (see Fig. 5). cc_calcite; forforsterite; chl—chlorite; dol—dolomite. 
contains high- $D$ forsterite and dolomite (Table 2-1).

Unlike sample TF-002 (dolomite rock), dolomite-dominated marble 17-4 strongly

reflected the higher $k$ of the mineral dolomite with a room-temperature $k$ of $5.4 \mathrm{~W} \mathrm{~m}^{-1} \mathrm{~K}^{-1}$ ( $300 \mathrm{~K}$, average of four orientations). The decrease in $k$ for sample $17-4$ was $\sim 45 \%$ between $300 \mathrm{~K}$ and $600 \mathrm{~K}$. This decrease mirrors that of the mineral dolomite across the same temperature range.

\subsection{DISCUSSION}

\subsubsection{Controls on Mineral Thermal Diffusivity}

Previous LFA measurements have shown that minerals rich in magnesium tend to produce high $D$ when compared to isochemical analogs with heavier cations. For example, Pertermann and Hofmeister (2006) reported a room-temperature $D$ for pure forsterite in [001] of $5.14 \mathrm{~mm}^{2} \mathrm{~s}^{-1}$, but substitution of 0.005 mole fraction Co for $\mathrm{Mg}$ in the same orientation lowered $D$ to $4.17 \mathrm{~mm}^{2} \mathrm{~s}^{-1}$, and 0.08 mole fraction $\mathrm{Fe}$ for $\mathrm{Mg}$ further reduced $D$ to $2.60 \mathrm{~mm}^{2} \mathrm{~s}^{-1}$ also in [001]. This relationship appears to hold for carbonates (Fig. 2-11). Magnesite, dolomite, and calcite fall on a linear trend of increasing $D$ with decreasing cation mass for group 2 cations. We predict that huntite, a compound carbonate with the formula $\mathrm{Mg}_{3} \mathrm{Ca}\left(\mathrm{CO}_{3}\right)_{4}$, thus would have a room- $T$ thermal diffusivity of $\sim 3.3 \mathrm{~mm}^{2} \mathrm{~s}^{-1}$ if it also follows this trend.

Rhodochrosite does not follow this trend, despite having the same trigonal structure. This suggests that $D$ for the other transition-metal trigonal carbonates (siderite, otavite, smithsonite, sphaerocobaltite, and the compound trigonal carbonate ankerite) cannot be projected from these results using cation mass alone, however we were unable 
to locate sufficiently pure samples of these minerals to test this hypothesis. A similar pattern is observed when plotting $D$ versus unit cell size (Fig. 2-11B), with $D$ increasing with decreasing unit cell size from calcite to dolomite to magnesite, and rhodochrosite similarly plotting off of this trend.
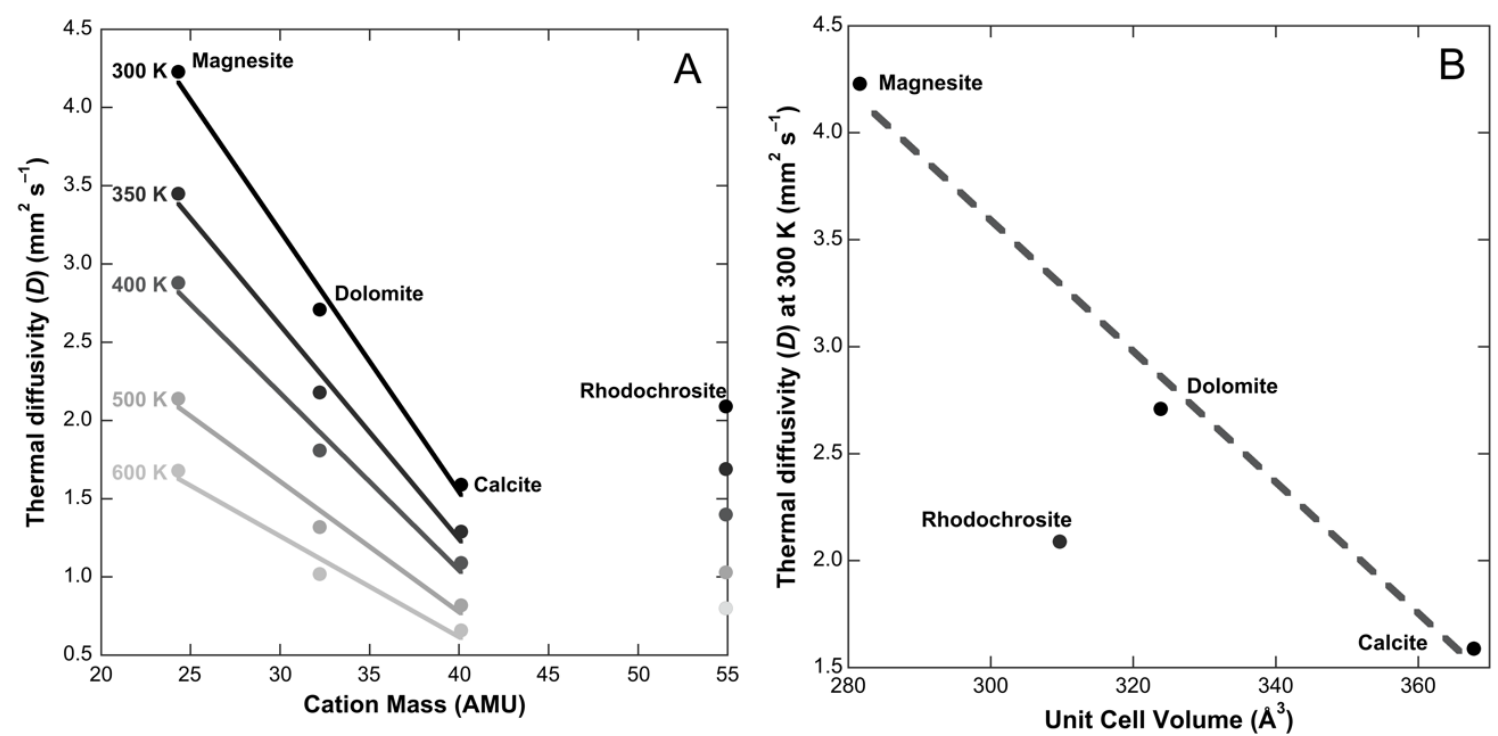

Figure 2-11) (A) Thermal diffusivity $(D)$ versus cation mass of minerals at temperatures indicated. Magnesitedolomite-calcite form a roughly linear trend at all temperatures, but rhodochrosite falls outside of this trend, with higher $D$ than the trend would suggest. AMU—atomic mass units. (B) $D$ versus unit cell volume. Like for $D$ versus cation mass, magnesite-dolomite-calcite form a roughly linear trend, but here rhodochrosite has much lower $D$ than this trend would indicate. Values are for room temperature.

\subsubsection{Rock Thermal Diffusivity}

Rock thermal diffusivity varies as a function of both mineralogy and texture.

Dolomite-dominated rocks reflect the higher $D$ of the mineral dolomite across all temperatures measured for similarly textured rocks. For example, Threshold marble, which is dominated by calcite, had a room-temperature $D$ of $1.29 \mathrm{~mm}^{2} \mathrm{~s}^{-1}$, but $D$ of dolomitic marble 17-4 was nearly twice that $\left(2.00-2.64 \mathrm{~mm}^{2} \mathrm{~s}^{-1}\right.$ depending on orientation). Both Threshold marble and marble 17-4 have moderately large grains, clean 
grain boundaries, and low porosities $(<5 \%)$. This same effect is reflected in sedimentary rocks, where the dolomite rock KS-002 had a $D$ at room $T$ of $1.48 \mathrm{~mm}^{2} \mathrm{~s}^{-1}$, compared to $1.03 \mathrm{~mm}^{2} \mathrm{~s}^{-1}$ for oolitic limestone (TF-002), despite similar porosities (15\% versus $13 \%$ respectively).

Several previous studies have explored textural controls on thermal transport properties within carbonate rocks, specifically the effects of porosity $(\varphi)$ on $k$, resulting in theoretical models based on experimental results, statistical analysis, and numerical models of heat flow on a hand-sample scale (e.g., Carson et al., 2005; Çanakci et al., 2007; Yaşar et al., 2008; Alishaev et al., 2012; Füchs et al., 2013). Carson et al. (2005) proposed two end-member models of effective $k$ in which heat flow within the material is through either "internal" porosity or "external" porosity (Fig. 2-12, where MaxwellEucken 1 represents the upper bounds of internal porosity and Maxwell-Eucken 2 the lower bounds of external porosity). In "internal porosity materials", heat flows primarily through the continuous medium surrounding the dispersed phase (in this case, pore spaces), and in "external porosity materials", heat flows through both the continuous phase and dispersed medium, but preferentially takes the pathway through the dispersed phase. The practical repercussions of this are that $k$ does not necessarily vary linearly with porosity, and consequently neither does $D$.

Besides porosity, factors affecting $D$ can include grain size, distribution of dispersed phases within the rock, and the presence and nature of fluids within pore space. 


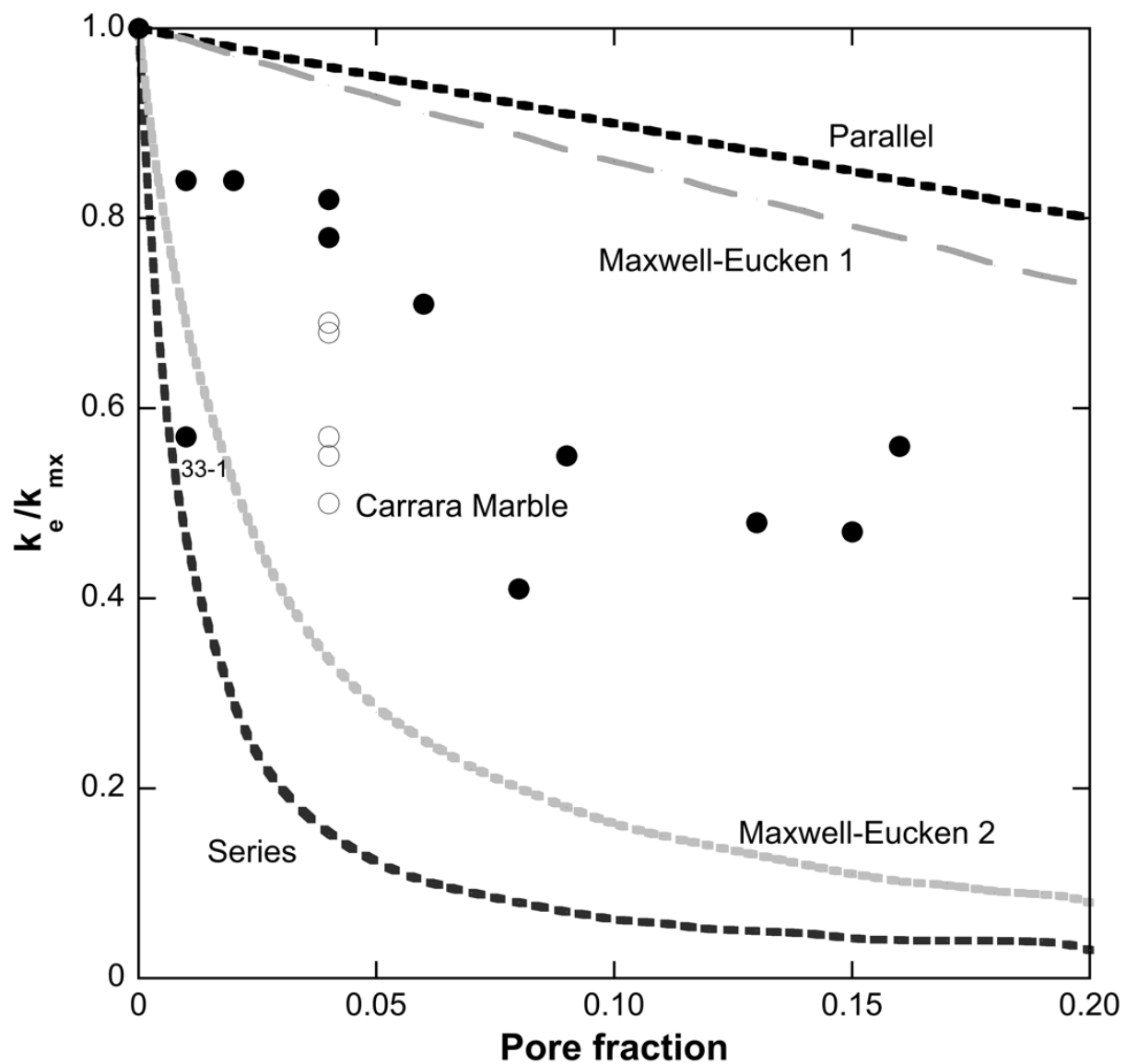

Figure 2-12) Ratio of effective thermal conductivity (thermal conductivity $[k]$ including pore space, $k_{\mathrm{e}}$ ) to matrix thermal conductivity $\left(k\right.$ calculated from mineral proportions without pore space, $k_{\mathrm{mx}}$ ) versus pore fraction for samples used in this study. Open circles are Carrara Marble values calculated using measured porosity indicated in Table 2-1 (porosity for each disk was not available). All samples fall within the boundaries of the Maxwell-Eucken model (where Maxwell-Eucken 1 is the upper limit of internal porosity, and Maxwell-Eucken 2 is the lower limit of external porosity), except for sample 33-1. Parallel and series indicate calculation of $k_{e}$ using a resistor-in-parallel and resistorin-series model respectively. All four curves are mixing models wherein pore space is distributed in parallel (heat flows indiscriminately through matrix and pore space and thus is averaged), series (wherein heat must flow through all components in series), and is either a dispersed phase with no connected pore space (Maxwell-Eucken 1), or composes the matrix (Maxwell-Eucken 2). See Carson et al. (2005) for more information.

Grain size varied little for the samples in this study. The LFA method requires rocks to be measured "dry", allowing us to focus on mineralogy and porosity. Porosities 
vary from $\sim 3 \%$ to $19 \%$ within the suite, and higher porosity correlates with lower bulkrock $D$ (and consequently, $k$; see Fig. 1-12).

Sample selection and preparation may influence measured $D($ or $k$ ). For example, Carrara Marble is dominated by calcite and has a low porosity $(\varphi=4 \%)$, but had the lowest $D$ of any sample studied here. The sample is brittle to the touch, but contains a more cohesive core when the outer layers are removed. When $D$ was measured for the internal cohesive core, the sample produced higher a higher $D$ (Fig. 2-8, Run 3 [reground $2 \times$ ], "Trapezoid"). This has two implications: First, poorly cohesive rocks may be slow conductors even if little pore space is present. Cement between grains may consist of very fine material, which acts as a thermal barrier to conduction (Branlund and Hofmeister, 2008). Second, poorly consolidated rocks could produce anomalously low $D$ or $k$ even if measured with accurate methods because sample cohesion has been compromised during or following depressurization.

\subsubsection{Comparison to Silicate Minerals}

The thermal diffusivity of carbonate minerals is broadly similar to that of many common silicate minerals. For example, directionally averaged forterite has a room- $T$ thermal diffusivity of $\sim 2.5 \mathrm{~mm}^{2} \mathrm{~s}^{-1}$ (Pertermann and Hofmeister, 2006), compared to directionally averaged dolomite of this study (white + grey) at $2.6 \mathrm{~mm}^{2} \mathrm{~s}^{-1}$. This is significantly lower than the $D$ of directionally averaged quartz $\left(4.9 \mathrm{~mm}^{2} \mathrm{~s}^{-1} ;\right.$ Branlund and Hofmeister, 2007), but $d D / d T$ of dolomite is higher than that of forsterite. Near 600 $\mathrm{K}$, dolomite $D$ falls to $\sim 1.1 \mathrm{~mm}^{2} \mathrm{~s}^{-1}$, where $D$ for directionally averaged quartz is $\sim 1.7$ $\mathrm{mm}^{2} \mathrm{~s}^{-1}$ and for forsterite is $\sim 2 \mathrm{~mm}^{2} \mathrm{~s}^{-1}$. At the maximum temperature measured for 
dolomite $(898 \mathrm{~K}), D$ approaches a limit of $\sim 0.6 \mathrm{~mm}^{2} \mathrm{~s}^{-1}$, while both forsterite and quartz approach $\sim 1 \mathrm{~mm}^{2} \mathrm{~s}^{-1}$. Magnesite displays a $D$ that is similar to that of quartz, with $D$ of magnesite of $4.2 \mathrm{~mm}^{2} \mathrm{~s}^{-1}$ at $300 \mathrm{~K}$, and falling to $1.7 \mathrm{~mm}^{2} \mathrm{~s}^{-1}$ at $600 \mathrm{~K}$.

Calcite has $D$ values that compare to those of more insulating silicate minerals such as albite (directionally averaged Amelia albite $D=1.36 \mathrm{~mm}^{2} \mathrm{~s}^{-1}$ at $293 \mathrm{~K}$; Hofmeister et al., 2009), but significantly lower than that of dolomite. Furthermore, calcite $D$ appears to reach a minimum at a much lower temperature and lower values $\left(\sim 0.5 \mathrm{~mm}^{2} \mathrm{~s}^{-1}\right.$ near $\left.600 \mathrm{~K}\right)$ than that of dolomite. This suggests that, barring textural differences, calcite-dominated rocks should be more insulating than dolomite-, quartz-, or olivine-dominated rocks, and that sedimentary basins dominated by calcite are more insulating than those dominated by dolomite or quartz.

\subsubsection{Models of Temperature Dependence in the Literature}

Several models have been published that use single-value low-temperature $k$ measurements to model the temperature dependence of $k$ for the rock. This is an attractive concept, as measuring the temperature dependence of $k$ for every rock from a drill-hole core is impractical and expensive. Figures 13A-13C show the results of using several of these models with low $T$ values for rocks from this study to predict the temperature response of $k$ for the sample compared to the calculated $k$ values using measured $D, C \mathrm{P}$, and $\rho$.

Although several models produce similar $T$ versus $k$ trends for some samples (e.g., calculated $k$ for sample 33-1 is reproduced by the Chapman et al. [1984] model with $<5 \%$ error), no model consistently predicts the $T$ dependence of $k$ for the suite of rocks 

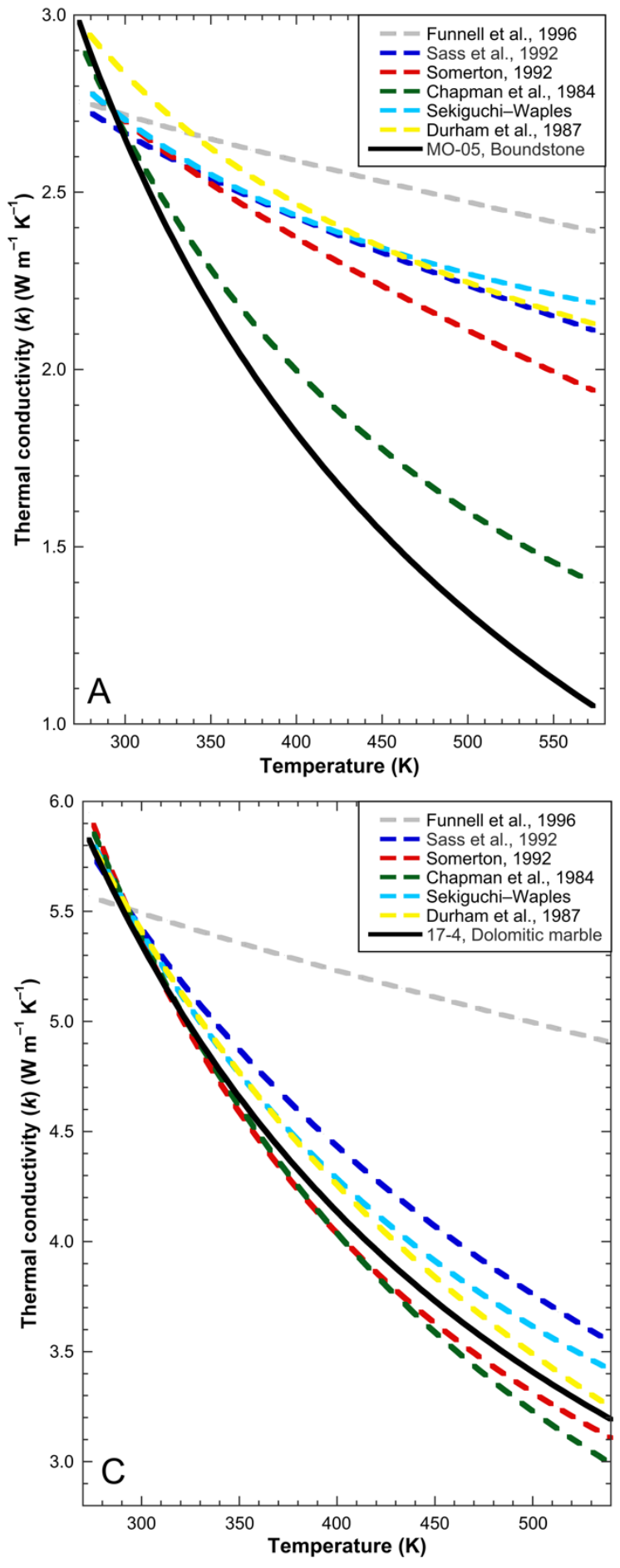

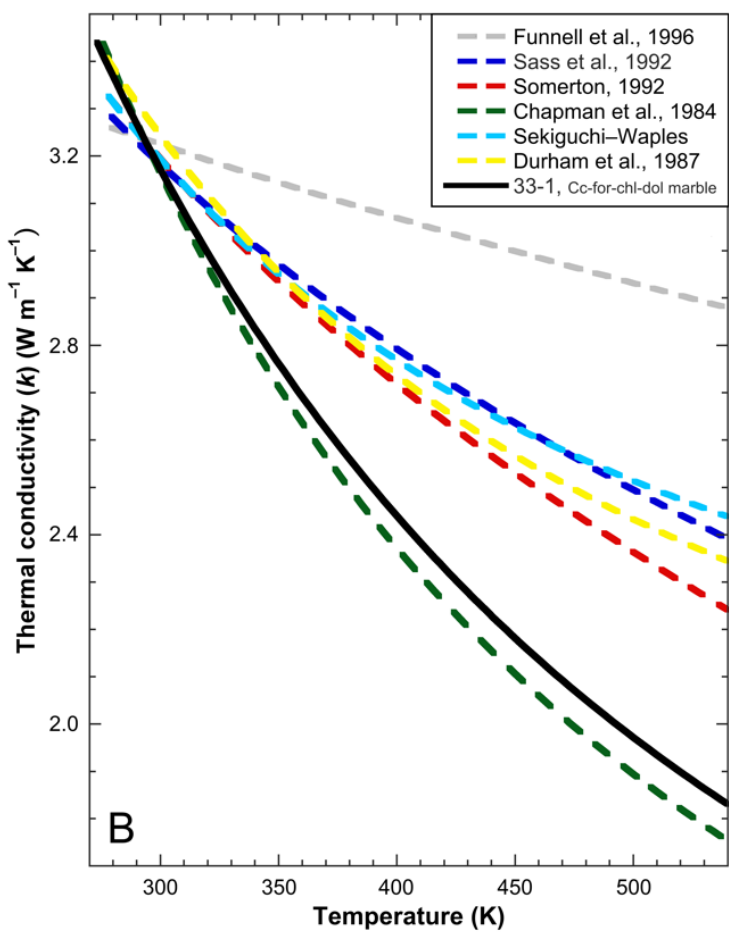

Figure 2-13) Comparison of temperature-dependent thermal conductivity $(k)$ calculated using measured values of thermal diffusivity $(D)$, isobaric heat capacity $(C \mathrm{P})$, and density for samples MO-05 (A), 33-1 (B), and 17-4 (C) with models for the temperature dependence of $k$ using single measurements at low temperature. The model of Durham et al. (1987) uses $k$ measured at $273 \mathrm{~K}$, the model of Sass et al. (1992) at 297 K, and all others at 293 K. The Sekiguchi-Waples model is found in Hantschel and Kauerauf (2009). cc_calcite; forforsterite; chl—chlorite; dol—dolomite. 
studied here. Thus, using these models to predict $k$ for a sample across temperatures found in the crust would produce moderate to significant error $(\sim 5 \%-125 \%)$. This is unsurprising, as these models are calibrated using techniques with systematic errors resulting from contacts and/or ballistic radiative transfer, and commonly do not use equations that have a basis in the physics of diffusive transport. Thus, even an accurate low- $T$ measurement used with one of these models will produce an unpredictable error in calculated elevated- $T$ properties.

\subsubsection{Implications for Thermal Modeling}

The results of this study have several implications for basin modeling, and suggest further lines of enquiry. First, closure of pore space with depth in a basin is predicted to lead to an increase in $D$ and $k$ as recrystallization occurs and low-conductivity pore space and amorphous or organic material are replaced with crystalline grains. This is apparent from the contrast in both $D$ and $k$ between porous limestones TF-002 and MO-05, low-porosity MO-07, and calcite-dominated Threshold marble and Black marble (Figs. 2-6 and 210A), which persists to elevated temperatures. This result is not a new concept (e.g., Carson et al., 2005), but previous methods used to constrain the effects on porosity have an uncontrolled parameter in the form of experimental error associated with imperfect contacts. Note that pressures attained in the crust are on the order of $\sim 1-1.5 \mathrm{GPa}$, and because $D$ increases only $\sim 4 \%$ per gigapascal, this effect can be neglected (see introduction and references therein).

Because the results presented here show a stronger temperature dependence and variability for $D$ and $k$ of carbonate rocks than predicted by current models (Fig. 2-13), 
the geothermal gradient of crusts with carbonate rocks and the conductive properties that influence it are more strongly coupled. As an example of the interplay of these effects, we present a model of two ad hoc crustal columns with $10 \mathrm{~km}$ of carbonate rocks in the upper crust as shown in Figure 14, and using input parameters as listed in Table 2-6. The two model columns differ by the dominant upper-crustal mineral: one is calcite dominated, and one is dolomite dominated. Inputs for thermal diffusivity were chosen to roughly mirror a reduced porosity with depth, with limestones composing the upper $6 \mathrm{~km}$ of the calcite-dominated model, and the calcite marble Threshold marble filling out the lower $4 \mathrm{~km}$ of the upper crust. By comparison, dolomite rock KS-002 overlies dolomitic marble 17-4 in the dolomite-dominated upper crust. Both crusts are $30 \mathrm{~km}$ thick, with a middle $10 \mathrm{~km}$ of a high-modal-quartz tonalite and a lower $10 \mathrm{~km}$ of granulite (thermal diffusivity values from Merriman et al., 2013).

The finite-difference software package Lithoheat (Nabelek et al., 2010) was used to calculate geothermal gradients and heat fluxes for both model columns. Lithoheat uses boundary conditions of surface temperature $(298 \mathrm{~K})$ and basal temperature (1573 K). Constant basal heat flux was not used because it implies temperatures increase (or decrease) in the asthenosphere in response to elevated (or reduced) temperatures at the base of the lithosphere to keep heat flux into the lithosphere constant (Nabelek and Liu, 2004). Heat production within the lithosphere is thus the major driving force behind the thermal structure of the lithosphere, and in our models was concentrated in the middle tonalite layer, with minor heat production in the granulite layer. Although basins typically contain higher heat production in the upper crust, this is usually concentrated in other rock types such as shales (e.g., Norden and Förster, 2006). Each model column was run 


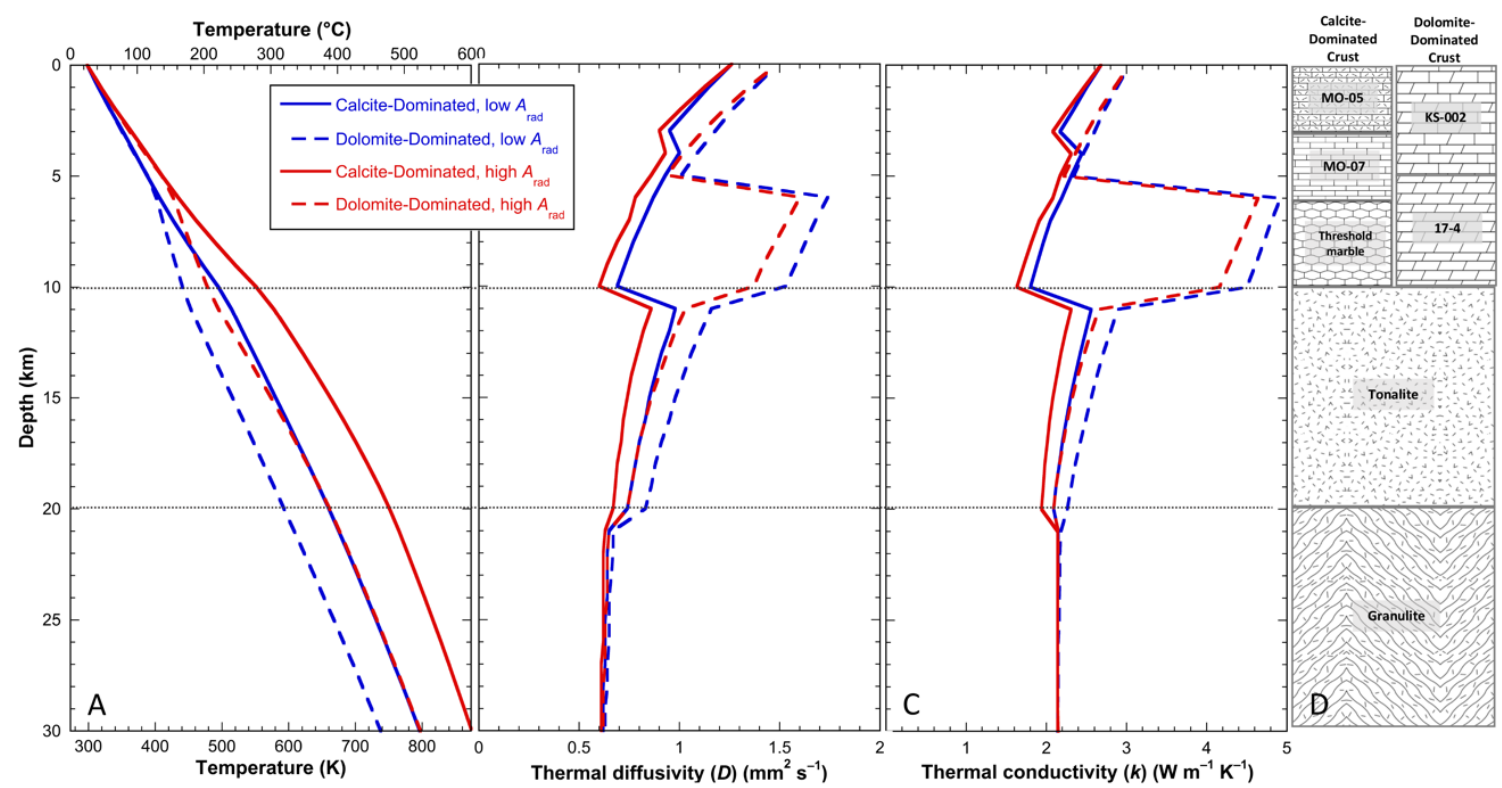

Figure 2-14) Modeled geothermal gradients (A) showing variability in the geotherm resulting from

coupling between thermal diffusivity $(D ; \mathrm{B})$ and internal heat production $\left(A_{\mathrm{rad}}\right.$; Table 6$)$. Heat production is concentrated in the lower tonalite (lower crust) and granite (middle crust). Thermal conductivity ( $k$; C) was calculated from model results for the geothermal gradient and thermal diffusivity. Rock inputs for the crustal structure (D) were chosen to roughly simulate reduced porosity with depth within the "basin" and illustrate the effects of dolomitization on the ability of a basin to conduct heat. All rock inputs are from this paper except tonalite and granodiorite (Merriman et al., 2013). MO-05-boundstone; MO-07—micrite; Threshold marble_- pure calcite marble; KS-002_-sedimentary dolomite rock; 17-4_dolomitic marble.

to steady state using two different internal heat production $\left(A_{\mathrm{rad}}\right)$ values by varying the heat production in the tonalite layer $\left(2.38 \mathrm{~mW} \mathrm{~m}^{-3}\right.$ versus $\left.1.19 \mathrm{~mW} \mathrm{~m}^{-3}\right)$, for a total of four models.

Figure 2-14 shows the resulting geothermal gradients, thermal diffusivity, and thermal conductivity profiles. Two columns are shown: one with an upper $10 \mathrm{~km}$ of calcite-rich rocks (solid lines), and one with an upper $10 \mathrm{~km}$ of dolomitized carbonates 
(dashed lines). The models predict values of $D$ resulting from computed geothermal gradients that vary strongly depending on the texture and mineralogy of the different layers. For example, $D$ varied by as much as $0.87 \mathrm{~mm}^{2} \mathrm{~s}^{-1}$ between the calcite-dominated crust $\left(0.87 \mathrm{~mm}^{2} \mathrm{~s}^{-1}\right.$ at $6 \mathrm{~km}$ depth$)$ and the dolomitized crust $\left(1.74 \mathrm{~mm}^{2} \mathrm{~s}^{-1}\right)$. Even within a single layer for identical crustal configurations, the calculated value of $D$ varied by as much as $13 \%$, and the resulting $k$ as much as $10 \%$, because of variations in temperature

between hot and cold models. In other words, the geothermal gradient depends on the ability of the rocks to conduct heat, which in turn influences the geotherm. The resulting temperatures vary by as much as $90 \mathrm{~K}$ between calcite- and dolomite-dominated models, even when heat production was the same for both crustal columns. Some of these results would be hidden by surface heat flow measurements, as predicted heat flow at the surface is nearly identical for both low- $A_{\text {rad }}$ models $\left(43.4 \mathrm{~mW} \mathrm{~m}^{-2}\right.$ for the calcitedominated crust versus $45.6 \mathrm{~mW} \mathrm{~m}^{-2}$ for the dolomite-dominated crust).

\section{Table 2-6. Model Parameters}

\begin{tabular}{|c|c|c|c|c|c|}
\hline Model & $\begin{array}{c}\text { Upper Crust Composition } \\
\text { and thickness* }\end{array}$ & $\begin{array}{l}\text { Middle Crust Heat } \\
\text { Production } \\
\left(\mathrm{mW} \mathrm{m}^{-3}\right)\end{array}$ & $\begin{array}{c}\text { Lower Crust Heat } \\
\text { Production } \\
\left(\mathrm{mW} \mathrm{m}^{-3}\right)\end{array}$ & $\begin{array}{c}\text { Surface } \\
\text { heat flux } \\
\left(\mathrm{mW} \mathrm{m}^{-3}\right)\end{array}$ & $\begin{array}{c}\text { Asthenospheric } \\
\text { heat flux } \\
\left(\mathrm{mW} \mathrm{m}^{-3}\right)\end{array}$ \\
\hline CC - Low $A_{\text {rad }}$ & $\begin{array}{c}\text { MO-05 - } 3 \mathrm{~km} \\
\text { MO-07 - } 3 \mathrm{~km} \\
\text { Threshold marble }-4 \mathrm{~km}\end{array}$ & 1.19 & 0.42 & 43.4 & 24.7 \\
\hline CC - High A rad & $\begin{array}{c}\text { MO-05 - } 3 \mathrm{~km} \\
\text { MO-07 - } 3 \mathrm{~km} \\
\text { Threshold - } 4 \mathrm{~km}\end{array}$ & 2.38 & 0.42 & 52.4 & 21.8 \\
\hline Dol - Low $A_{\text {rad }}$ & $\begin{array}{c}\text { KS-002 - } 5 \mathrm{~km} \\
17-4-5 \mathrm{~km}\end{array}$ & 1.19 & 0.42 & 45.6 & 26.9 \\
\hline Dol - High $A_{\text {rad }}$ & $\begin{array}{c}\text { KS-002 - } 5 \mathrm{~km} \\
17-4-5 \mathrm{~km} \\
\end{array}$ & 2.38 & 0.42 & 55.3 & 24.7 \\
\hline \multicolumn{6}{|c|}{$\begin{array}{l}\text { Note: Middle crust transport properties of tonalite KB12 (Merr } \\
\text { (Whittington et al, 2009). } \\
\text { Middle crust }=10 \mathrm{~km} \text {, lower crust }=10 \mathrm{~km} \text {. } \\
\text { Lithospheric mantle }=90 \mathrm{~km} \text {. } \\
\text { Lower boundary condition }=1300^{\circ} \mathrm{C} \text {, see text for discussion. } \\
\text { Upper boundary condition }=25^{\circ} \mathrm{C} \text {. }\end{array}$} \\
\hline
\end{tabular}


Furthermore, variations in thermal transport properties partially obscure variations in heat production in the crust. This is highlighted by temperatures in the low-Arad calcite-dominated crust versus those in the high- $A_{\text {rad }}$ dolomitized crust, where average crustal temperatures vary by only $<1 \mathrm{~K}$, and peak temperature contrasts are a modest 22 $\mathrm{K}$ at $5 \mathrm{~km}$ depth $\left(410 \mathrm{~K}\right.$ for high- $A_{\text {rad }}$ dolomitized crust, $388 \mathrm{~K}$ for low- $A_{\text {rad }}$ calcitedominated crust).

\subsection{CONCLUSIONS}

Multiple properties combine to control thermal diffusivity of both minerals and rocks, the effects of which are more variable at low temperatures. Rock thermal diffusivity is in part controlled by mineralogy, which in carbonate rocks is typically dominated by either generally low- $D$ calcite or higher- $D$ dolomite, with proportions of other common minerals such as quartz or feldspar adding an additional layer of complexity. Mineral $D$ itself is controlled by mineral structure and cation mass, as well as volume of the unit cell. The composite mineral dolomite has $D$ that is the weighted average of that of calcite and magnesite at all temperatures. The data for rhodochrosite suggest that transition-metal carbonates do not follow the same trend as those with alkaline-earth metals (calcite-dolomite-magnesite), and that properties of other carbonate minerals not studied here (e.g., siderite, smithsonite) cannot be predicted from this trend.

For carbonate rocks, texture is a primary control on bulk-rock $D$, as porosity generally reduces $D$ across all measured temperatures, but in a nonlinear fashion. 
Additional textural concerns may include dispersed minor phases such as graphite, sample cohesion, and grain size. The size of the suite measured for this work, however, is insufficient to fully characterize these effects. Metamorphism of sedimentary carbonates may increase bulk-rock $D$, in part by porosity reduction, which occurs in sedimentary rocks under confining pressure or in the presence of fluids, but also by increasing grain size and replacement of lower- $D$ minerals such as calcite with higher- $D$ minerals such as forsterite.

Composition also has the potential to influence the thermal structure of crust that has a large component of carbonate rocks, as a higher contrast exists between the conductive ability of the minerals calcite and dolomite than previously thought. This contrast exists across all temperatures measured (Figs. 2-5 and 2-9), and strongly suggests that basins that have undergone dolomitization will conduct heat more efficiently than those that are dominated by calcite (Fig. 2-14). All other factors being equal, this suggests that geothermal gradients would be lower in dolomitized basins, and petroleum maturation windows or sources of geothermal energy would be deeper.

Thermal conductivity results presented here suggest that published values of $k$ for both carbonate minerals and carbonate rocks contain systematic errors similar to those found in other mineral and rock groups. This typically results in published values for $k$ using contact methods being lower at low temperatures and higher at high temperatures than values calculated through the LFA method. These results show that the conductive ability of carbonate regimes is likely more sensitive to local temperature than previously thought, and models using older $k$ data or temperature-dependent models for $k$ based on older data need re-evaluation. This is particularly true for models that in- corporate a 
large temperature gradient over a small distance. For example, Nabelek et al. (2012) modeled emplacement of a granitic pluton into dolomitic marble using $T$-dependent $D$. Compared to a model with a fixed $D$ of $1 \mathrm{~mm}^{2} \mathrm{~s}^{-1}$, temperatures in the pluton remained above the solidus more than twice as long because of the feedback between elevated temperatures in the country rock and its ability to diffuse the heat away. An extended residence time provides a longer-lasting thermal engine to drive metamorphic processes such as contact metamorphism or skarn mineralization. Furthermore, models that use a single, low-temperature value of $k$ to predict its change with temperature are based on methods that include significant error, and do not correctly predict the change in $k$ with temperature.

\section{ACKNOWLEDGMENTS}

We thank Peter Nabelek for providing samples 17-4 and 33-1, Tom Freeman and Kevin Shelton for samples TF-001 and TF-002, and Brian Evans for samples of Carrara Marble. We also thank Paul Carpenter for feedback on this research and assistance with XRD and microprobe analysis. The comments of two anonymous reviewers significantly improved the manuscript. This research was funded in part by National Science Foundation awards EAR-1524796 to AGW and EAR-1524495 to AMH, American Chemical Society (ACS) Petroleum Research Fund grant 56166-ND8, and a University of Missouri Research Council grant to AGW. We also thank the donors of the ACS Petroleum Research Fund for partial support of this research. 


\section{REFERENCES CITED}

Aines, R.D., and Rossman, G.R., 1985, The high temperature behavior of trace hydrous components in silicate minerals: The American Mineralogist, v. 70, p. 1169-1179.

Alishaev, M.G., Abdulagatov, I.M., and Abdulagatova, Z.Z., 2012, Effective thermal conductivity of fluid-saturated rocks: Experiment and modeling: Engineering Geology, v. 135-136, p. 24- 39, https://doi.org/10.1016/j.enggeo.2012.03.001.

Armstrong, J.T., 1995, CITZAF, a package of correction programs for the quantitative electron microbeam X-ray analysis of thick polished materials, thin films, and particles: Microbeam Analysis, v. 4, p. 177-200.

Avard, G., and Whittington, A.G., 2012, Rheology of arc dacite lavas: Experimental determina- tion at low strain rates: Bulletin of Volcanology, v. 74, p. 1039-1056, https://doi.org/10.1007/s00445-012-0584-2.

Berner, R.A., and Caldeira, K., 1997, The need for mass balance and feedback in the geochemical carbon cycle: Geology, v. 25, p. 955-956, https://doi.org/10.1130/00917613(1997)025<0955: TNFMBA>2.3.CO;2.

Bickle, M.J., 1996, Metamorphic decarbonation, silicate weathering, and the long-term carbon cycle: Terra Nova, v. 8, p. 270-276, https://doi.org/10.1111/j.13653121.1996.tb00756.x. 
Birch, A.F., and Clark, H., 1940, The thermal conductivity of rocks and its dependence upon temperature and composition: American Journal of Science, v. 238, p. 529-558, https://doi.org /10.2475/ajs.238.8.529.

Branlund, J.M., and Hofmeister, A.M., 2007, Thermal diffusivity of quartz to $1,000^{\circ} \mathrm{C}$ : Effects of impurities and the $\alpha-\beta$ transition: Physics and Chemistry of Minerals, v. 34, p. 581-595, https://doi.org/10.1007/s00269-007-0173-7.

Branlund, J.M., and Hofmeister, A.M., 2008, Factors affecting heat transfer in natural SiO2 solids: The American Mineralogist, v. 93, p. 1620-1629, https://doi.org/10.2138/am.2008.2821.

Branlund, J.M., and Hofmeister, A.M., 2012, Heat transfer in plagioclase feldspars: The American Mineralogist, v. 97, p. 1145-1154, https://doi.org/10.2138/am.2012.3986.

Bräuer, H., Dusza, L., and Schulz, B., 1992, New laser flash equipment LFA 427: Interceram, v. 41, p. 489-492.

Çanakci, H., Demirboğa, R., Karakoç, M.B., and Şirin, O., 2007, Thermal conductivity of limestone from Gaziantep (Turkey): Building and Environment, v. 42, p. 1777-1782, https://doi.org/10 .1016/j.buildenv.2006.01.011. 
Carson, J.K., Lovatt, S.J., Tanner, D.J., and Cleland, A.C., 2005, Thermal conductivity bounds for isotropic, porous materials: International Journal of Heat and Mass Transfer, v. 48, p. 2150-2158, https://doi.org/10.1016/j.ijheatmasstransfer.2004.12.032.

Chapman, D.S., Keho, T.H., Bauer, M.S., and Picard, M.D., 1984, Heat flow in the Uinta Basin determined from bottom hole temperature (BHT) data: Geophysics, v. 49, p. 453466, https:// doi.org/10.1190/1.1441680.

Clauser, C., and Huenges, E., 1995, Thermal conductivity of rocks and minerals, in Ahrens, T.J., ed., Rock Physics and Phase Relations: A Handbook of Physical Constants, American Geo- physical Union Reference Shelf 3, p. 105-126, https://doi.org/10.1029/RF003p0105.

Cowan, D.R., 1963, Pulse method of measuring thermal diffusivity at high temperatures: Journal of Applied Physics, v. 34, p. 926-927, https://doi.org/10.1063/1.1729564.

Criss, E.M., and Hofmeister, A.M., 2017, Isolating lattice from electronic contributions in thermal transport measurements of metals and alloys and a new model: International Journal of Modern Physics B, v. 31, 175020, https://doi.org/10.1142/S0217979217502058.

Deer, W.A., Howie, R.A., and Zussman, J., 1992, An Introduction to the Rock-Forming Minerals (second edition): Harlow, Essex, Pearson Education Limited, 696 p. 
Durham, W.B., Mirkovich, V.V., and Heard, H.C., 1987, Thermal diffusivity of igneous rocks at elevated pressure and temperature: Journal of Geophysical Research, v. 92, p. 11,615-11,634, https://doi.org/10.1029/JB092iB11p11615.

Fei, Y., 1995, Thermal expansion, in Ahrens, T.J., ed., Mineral Physics and Crystallography: A Handbook of Physical Constants: Washington, DC, American Geophysical Union, p. 29-44, https://doi.org/10.1029/RF002p0029.

Füchs, S., Schütz, F., Förster, H.-J., and Förster, A., 2013, Evaluation of common mixing models for calculating bulk thermal conductivity of sedimentary rocks: Correction charts and new conversion equations: Geothermics, v. 47, p. 40-52, https://doi.org/10.1016/j.geothermics .2013.02.002.

Funnell, R., Chapman, D., Allis, R., and Armstrong, P., 1996, Thermal state of the Taranaki Basin, New Zealand: Journal of Geophysical Research, v. 101, p. 25,19725,215, https://doi.org/10 .1029/96JB01341.

Gratz, K., 2006, Über den Wärmetransport in Karbonaten, [Ph.D. thesis]: Potsdam, Freie Univer- sität Berlin, 95 p.

Hantschel, T., and Kauerauf, A.I., 2009, Fundamentals of Basin and Petroleum Systems Modeling: Dordrecht, Springer, 475 p. 
He, M., Su, C., Liu, X., Qi, X., and Lv, N., 2015, Measurement of isobaric heat capacity of pure water up to supercritical conditions: The Journal of Supercritical Fluids, v. 100, p. 1-6, https:// doi.org/10.1016/j.supflu.2015.02.007.

Henderson, J.B., Hagemann, L., and Blumm, J., 1998a, Development of SRM 8420 series electro- lytic iron a thermal diffusivity standard: Netzsch Applications Laboratory Thermophysical Properties Section Report I-9E, 11 p.

Henderson, J.B., Giblin, F., Blumm, J., and Hagemann, L., 1998b, SRM 1460 series as a thermal diffusivity standard for laser flash instruments: International Journal of Thermophysics, v. 19, p. 1647-1656, https://doi.org/10.1007/BF03344916.

Hofmeister, A.M., 2006, Thermal diffusivity of garnets at high temperature: Physics and Chemistry of Minerals, v. 33, p. 45-62, https://doi.org/10.1007/s00269-005-0056-8.

Hofmeister, A.M., 2007, Pressure dependence of thermal transport properties: Proceedings of the National Academy of Sciences of the United States of America, v. 104, p. 9192-9197, https:// doi.org/10.1073/pnas.0610734104.

Hofmeister, A.M., 2010, Scale aspects of heat transport in the diamond anvil cell, in spectroscopic modeling, and in Earth's mantle: Implications for secular cooling: Physics of the Earth and Planetary Interiors, v. 180, p. 138-147, https://doi.org/10.1016/j.pepi.2009.12.006. 
Hofmeister, A.M., and Branlund, J.M., 2015, Thermal conductivity of the Earth, in Schubert, G., Price, G.D., and Stixrude, L., eds., Treatise on Geophysics (second edition), Volume 2: Mineral Physics: Elsevier, Amsterdam, p. 583-608, https://doi.org/10.1016/B978-0-444-53802-4 .00047-6.

Hofmeister, A.M., and Pertermann, M., 2008, Thermal diffusivity of clinopyroxenes at elevated temperature: European Journal of Mineralogy, v. 20, p. 537-549.

Hofmeister, A.M., Pertermann, M., and Branlund, J.M., 2007, Thermal conductivity of the Earth, in Price, G.D., ed., Treatise on Geophysics, Volume 2: Mineral Physics: Amsterdam, The Netherlands, Elsevier, p. 543-577, https://doi.org/10.1016/B978$\underline{044452748-6.00048-1 .}$

Hofmeister, A.M., Whittington, A.G., and Pertermann, M., 2009, Transport properties of high albite crystals, near-endmember feldspar and pyroxene glasses, and their melts to high temperature: Contributions to Mineralogy and Petrology, v. 158, p. 381-400, https://doi.org /10.1007/s00410-009-0388-3.

Hofmeister, A.M., Dong, J., and Branlund, J.M., 2014, Thermal diffusivity of electrical insulators at high temperatures: Evidence for diffusion of bulk phonon-polaritons at infrared frequencies augmenting phonon heat conduction: Journal of Applied Physics, v. 115, 163517, https:// doi.org/10.1063/1.4873295. 
Horai, K.-i., 1971, The thermal conductivity of rock-forming minerals: Journal of Geophysical Research, v. 76, p. 1278-1308, https://doi.org/10.1029/JB076i005p01278.

Hust, J.G., and Lankford, A.B., 1984, Update of thermal conductivity and electrical resistivity of electrolytic iron, tungsten, and stainless steel: National Bureau of Standards Special Publication 260-90, 71 p.

Jacobs, G.K., Kerrick, D.M., and Krupka, K.M., 1981, The high-temperature heat capacity of natural calcite (CaCO3): Physics and Chemistry of Minerals, v. 7, p. 55-59.

Krupka, K.M., Hemingway, B.S., Robie, R.A., and Kerrick, D.M., 1985, Hightemperature heat capacities and derived thermodynamic properties of anthophyllite, diopside, dolomite, enstatite, bronzite, talc, tremolite, and wollastonite: The American Mineralogist, v. 70, p. 261-271.

Lee, Y., and Deming, D., 1998, Evaluation of thermal conductivity temperature corrections applied in terrestrial heat flow studies: Journal of Geophysical Research, v. 103, p. 2447-2454, https://doi.org/10.1029/97JB03104.

Lippmann, F., 1973, Sedimentary Carbonate Minerals: New York, Springer-Verlag, 228 p., https:// doi.org/10.1007/978-3-642-65474-9. 
Liu, S., Feng, C., Wang, L., and Li, C., 2011, Measurement and analysis of thermal conductivity of rocks in the Tarim Basin, northwest China: Acta Geologica Sinica, v. 85, p. 598-609, https:// doi.org/10.1111/j.1755-6724.2011.00454.x.

Maglić, K.D., and Taylor, R.E., 1992, The apparatus for thermal diffusivity measurement by the laser pulse method, in Maglić, K.D., Cezairliyan, A., and Peletsky, V.E., eds., Compendium of Thermophysical Property Measurement Methods, Volume 2:

Recommended Measurement Techniques and Practices: New York, Plenum Press, p. 281-314, https://doi.org/10.1007/978 -1-4615-3286-6_10.

Mehling, H., Hautzinger, G., Nilsson, O., Fricke, J., Hofmann, R., and Hahn, O., 1998, Thermal diffusivity of semitransparent materials determined by the laser-flash method applying a new mathematical model: International Journal of Thermophysics, v. 19, p. 941-949, https:// doi.org/10.1023/A:1022611527321.

Merriman, J.D., Whittington, A.G., Hofmeister, A.M., Nabelek, P.I., and Benn, K., 2013, Thermal transport properties of major Archean rock types to high temperature and implications for cratonic geotherms: Precambrian Research, v. 233, p. 358-372, https://doi.org/10.1016/j .precamres.2013.05.009.

Miao, S.Q., Li, H.P., and Chen, G., 2014, Temperature dependence of thermal diffusivity, specific heat capacity, and thermal conductivity for several types of rocks: Journal of 
Thermal Analysis and Calorimetry, v. 115, p. 1057-1063, https://doi.org/10.1007/s10973-013-3427-2.

Moore, G.E., 1943, Heat content of manganese dioxide and carbonate at high temperatures: Journal of the American Chemical Society, v. 65, p. 1398-1399, https://doi.org/10.1021/ja01247a034.

Nabelek, P.I., and Liu, M., 2004, Petrologic and thermal constraints on the origin of leucogranites in collisional orogens: Transactions of the Royal Society of Edinburgh: Earth Sciences, v. 95, p. 73-85, https://doi.org/10.1017/S0263593300000936.

Nabelek, P.I., and Morgan, S.S., 2012, Metamorphism and fluid flow in the contact aureole of the Eureka Valley-Joshua Flat-Beer Creek pluton, California: Geological Society of America Bulletin, v. 124, p. 228-239, https://doi.org/10.1130/B30425.1

Nabelek, P.I., Whittington, A.G., and Hofmeister, A.M., 2010, Strain heating as a mechanism for partial melting and ultrahigh temperature metamorphism in convergent orogens: Implications of temperature-dependent thermal diffusivity and rheology: Journal of Geophysical Research, v. 115, B12417, https://doi.org/10.1029/2010JB007727.

Nabelek, P.I., Hofmeister, A.M., and Whittington, A.G., 2012, The influence of temperature- dependent thermal diffusivity on the conductive cooling rates and 
temperature-time paths in contact aureoles: Earth and Planetary Science Letters, v. 317318, p. 157-164, https://doi .org/10.1016/j.epsl.2011.11.009.

Norden, B., and Förster, A., 2006, Thermal conductivity and radiogenic heat production of sedimentary and magmatic rocks in the Northeast German Basin: American Association of Petroleum Geologists Bulletin, v. 90, p. 939-962, https://doi.org/10.1306/01250605100.

Parker, J.W., Jenkins, J.R., Butler, P.C., and Abbott, G.I., 1961, Flash method of determining thermal diffusivity, heat capacity, and thermal conductivity: Journal of Applied Physics, v. 32, p. 1679-1684, https://doi.org/10.1063/1.1728417.

Pertermann, M., and Hofmeister, A.M., 2006, Thermal diffusivity of olivine-group minerals at high temperature: The American Mineralogist, v. 91, p. 1747-1760, https://doi.org/10.2138/am.2006.2105.

Pertermann, M., Whittington, A.G., Hofmeister, A.M., Spera, F.J., and Zayak, J., 2008, Transport properties of low-sanidine single-crystals, glasses and melts at high temperature: Contributions to Mineralogy and Petrology, v. 155, p. 689-702, https://doi.org/10.1007/s00410-007 -0265-x.

Ramachandran, E., Raji, P., Ramachandran, K., and Natarajan, S., 2006, Photoacoustic study of the thermal properties of calcium carbonate-The major constituent of 
pancreatic calculi: Crystal Research and Technology, v. 41, p. 64-67, https://doi.org/10.1002/crat.200410531.

Rietveld, H.M., 1968, A profile refinement method for nuclear and magnetic structures: Journal of Applied Crystallography, v. 2, p. 65-71, https://doi.org/10.1107/S0021889869006558.

Robie, R.A., and Hemingway, B.S., 1994, Heat capacities of synthetic grossular (Ca3Al2Si3O12), macrocrystals of magnesite ((Mg0.991Fe0.005Ca0.003Mn0.001)CO3), high-temperature superconductors $\mathrm{YBa} 2 \mathrm{Cu} 3 \mathrm{O} 6+\mathrm{x}$ and $\mathrm{BiCaSrCu} 2 \mathrm{O} 6+\mathrm{x}$, and type 321 stainless steel: U.S. Geological Survey Open-File Report 94-223, 12 p.

Robie, R.A., and Hemingway, B.S., 1995, Thermodynamic properties of minerals and related substances at $298.15 \mathrm{~K}$ and 1 bar (105 pascals) pressure and at higher temperature: U.S. Geological Survey Bulletin 2131, 470 p.

Ronov, A.B., and Yaroshevsky, A.A., 1976, A new model for the chemical structure of the Earth's crust: Geokhimiya, v. 12, p. 1761-1795.

Rossman, G.R., 1988a, Vibrational spectroscopy of hydrous components: Reviews in Mineralogy, v. 18, p. 193-206. 
Rossman, G.R., 1988b, Optical spectroscopy: Reviews in Mineralogy, v. 18, p. 207-254. Rudnick, R.L., and Gao, S., 2003, Composition of the continental crust, in Rudnick, R.L., ed., Treatise on Geochemistry, Volume 3: The Crust: Amsterdam, Elsevier, p. 1-64, https://doi.org/10.1016/B0-08-043751-6/03016-4.

Sass, J.H., Lachenbruch, A.H., Moses, T.H., Jr., and Morgan, P., 1992, Heat flow from a scientific research well at Cajon Pass, California: Journal of Geophysical Research, v. 97, p. 5017-5030, https://doi.org/10.1029/91JB01504.

Schütz, F., Norden, B., Förster, A., and the DESIRE Group, 2012, Thermal properties of sediments in southern Israel: A comprehensive data set for heat flow and geothermal energy studies: Basin Research, v. 24, p. 357-376, https://doi.org/10.1111/j.13652117.2011.00529.x

Smith, D.S., Fayette, S., Grandjean, S., Martin, C., Telle, R., and Tonnessen, T. 2003, Thermal resistance of grain boundaries in alumina ceramics and refractories: Journal of the American Ceramic Society, v. 86, p. 105-111, https://doi.org/10.1111/j.11512916.2003.tb03285.x.

Somerton, W.H., 1992, Thermal Properties and Temperature-Related Behavior of Rock/Fluid Systems: New York, Elsevier, 257 p.

Vozár, L., and Hohenauer, W., 2003, Flash method of measuring the thermal diffusivity: 
A review: High Temperatures-High Pressures, v. 35-36, p. 253, https://doi.org/10.1068/htjr119.

Vozár, L., and Hohenauer, W., 2005, Uncertainty of thermal diffusivity measurements using the laser flash method: International Journal of Thermophysics, v. 26, p. 1899 1915, https://doi.org/10.1007/s10765-005-8604-5.

Waples, D.W., and Waples, J.S., 2004, A review and evaluation of specific heat capacities of rocks, minerals, and subsurface fluids; Part 2: Fluids and porous rocks: Natural Resources Research, v. 13, p. 123-130, https://doi.org/10.1023/B:NARR.0000032648.15016.49.

Whittington, A.G., Hofmeister, A.M., and Nabelek, P.I., 2009, Temperature-dependent thermal diffusivity of Earth's crust: Implications for crustal anataxis: Nature, v. 458, p. 319-321, https://doi.org/10.1038/nature07818.

Xu, L., and Evans, B., 2010, Strain heterogeneity in deformed Carrara marble using a microscale strain mapping technique: Journal of Geophysical Research, v. 115, B04202, https://doi.org /10.1029/2009JB006458.

Yaşar, E., Erdoğan, Y., and Güneyli, H., 2008, Determination of thermal conductivity from physico-mechanical properties: Bulletin of Engineering Geology and the Environment, v. 67, p. 219-225, https://doi.org/10.1007/s10064-008-0126-5. 


\section{Chapter 3: A Model for Temperature-Dependent Thermal Diffusivity of Crystalline Rocks, Part I: Samples, Characteristics, Methods, and Thermal Diffusivity Results}

\subsection{INTRODUCTION}

Heat flow within the Earth was an early focus of geology. William Thomson (1863), better known as Lord Kelvin, in proposing "special geothermic surveys should be made for the purpose of estimating absolute dates in geology..." opined on the importance of conductive heat flow within the lithosphere, and in particular, the mathematical formulation of Fourier as a "beautiful working out of a particular case belonging to the general doctrine of the Dissipation of Energy". What would later become Fourier's law describes the influence of thermal conductivity $\left(k\right.$, in $\left.\mathrm{W} \mathrm{m}^{-1} \mathrm{~K}^{-1}\right)$ on the rate of thermal conduction within a body under a thermal gradient (in one dimension):

$$
q=-k \frac{d T}{d z}
$$

Equation 3-1.

Where $q$ is heat flux $\left(\mathrm{W} \mathrm{m}^{-3}\right), T$ is temperature $(\mathrm{K})$, and $z$ is length $(\mathrm{m})$ of the domain along the steepest thermal gradient, in the case of Earth reported in depth within the Earth. Equation 3-1, however, applies only to simple cases in which the thermal gradient is steady over time (steady-state). Because few processes within a dynamic Earth can be described as steady-state (a fact Thomson, and others struggled to account for, and for which he showed some concern that the "disturbing influences affecting underground temperature... are too great to allow us to expect any very precise or satisfactory results" 
(Thomson, 1863)), the equation for time-dependent thermal conduction is required to model temperature within the Earth:

$$
\frac{\partial T}{\partial t}=D(T) \nabla^{2} T
$$

Equation 3-2.

where $t$ is time (s) and $D$ is thermal diffusivity $\left(\mathrm{m}^{2} \mathrm{~s}^{-1}\right)$. Thermal diffusivity is related to thermal conductivity by the equation:

$$
D=\frac{\rho C_{P}}{k}
$$

Equation 3-3.

where $\rho$ is density $\left(\mathrm{kg} \mathrm{m}^{-3}\right)$, and $C_{\mathrm{P}}$ is heat capacity $\left(\mathrm{J} \mathrm{kg}^{-1} \mathrm{~K}^{-1}\right)$ and is effectively the rate at which a thermal disturbance will propagate through a material.

Hofmeister et al. (2014) proposed an equation which describes the ability of a material to conduct heat at a given temperature:

$$
D(T)=f T(K)^{g}+h T(K)
$$

Equation 3-4.

Where $\mathrm{f}, \mathrm{g}$, and $\mathrm{h}$ are experimentally-determined parameters which are mineral-specific. The terms of this equation describe some of the mechanisms behind variability in mineral thermal diffusivity. The first term (f) determines the magnitude of $D$, and the second (g) describes the rate at which $D$ will change due to vibrational interference. The primary method of conduction at ambient conditions is generally thought to be propagation of vibrational quasi-particles known as "phonons", and as temperature increases, the mean- 
free-path for a phonon decreases, reducing the rate with which a thermal disturbance will propagate. The final term, $\mathrm{h}$, describes the contribution of radiative heat transport to thermal conduction, and generally is negligible-to-absent at ambient conditions, but causes $D$ to approach a constant value near the mineral's melting temperature (see Fig 33).

Much research has been focused on variations in $k$ within the lithosphere (e.g. Birch and Clark, 1940; Robertson, 1988; Clauser and Huenges 1995; Vosteen and Schellschmidt, 2003; Merriman et al. 2013; Fuchs et al., 2013; Ray et al., 2015; Hofmeister and Branlund 2015; Andrés et al., 2016) because models of lithospheric processes and deformation are strongly temperature-dependent (e.g. lithospheric strength models (Afonso and Ranalli 2004; Regenauer-Lieb et al. 2006; Burov and Watts 2006), anatexis (Nabelek and Liu 2004; Whittington et al. 2009; Sawyer et al. 2011), cooling rates and residence times of magmatic bodies (Nabelek et al., 2012; Blundy and Annen, 2016) and metamorphism (Kramers et al. 2001; Nabelek et al., 2010)). A model for calculating thermal conductivity of rocks is attractive in part because measured $k$ varies strongly between different rocks, or within the same rock unit (Liu et al., 2011; Fuchs et al., 2015). Furthermore, measurement of $k$ for an entire crustal section or even a subsection of the crust is impractical. Recently, several studies have presented models for calculating $k$ based on physical properties of rocks such as mineralogy or porosity (e.g. Fuchs et al., 2013; Ray et al., 2015; Fuchs et al., 2015; Pasquale et al., 2015; Andrés et al., 2016). However, these studies often focus on subsets of common crustal rocks, overemphasizing the importance of porosity, which is rare-to-absent in rocks crystallized at depth, and most studies directly measure $k$, ignoring $D$ or evaluating it as a secondary 
component. The importance of $D$ as a control on time-dependent thermal conduction (Eq. 3-2 above), combined with the uncertainty associated with deriving $D$ from measured, or modeled $k$ (see Hofmeister et al., 2007; Hofmeister, 2019), emphasizes the need for direct measurements of $D$ on rocks and minerals, and a model for $D$ which is developed from those data, with an accounting of the many properties that may influence it.

Over the last 15 years, work with Laser Flash Analysis (LFA) has established a considerable database of temperature-dependent $D$ of minerals (Hofmeister and Branlund, 2015; Hofmeister, 2019), with particular focus on the structural and chemical components of minerals controlling $D$ within them (e.g. Yu and Hofmeister, 2011; Branlund and Hofmeister, 2012; Criss and Hofmeister, 2017). Heat capacity varies on the order of $50 \%$ between common rock-forming minerals over the range of lithospheric temperatures ( 300-1800K, e.g. Robie and Hemingway, 1995). Density of common rock forming minerals varies between different groups by $\sim 20 \%$ (Gaines et al., 1998), and typically $<5 \%$ for a given mineral over the same temperature range (Fei, 1995). By contrast, at ambient temperature $D$ of quartz along the c-axis is $\sim 10 \mathrm{x}$ that of anorthite, $\sim 7 \mathrm{x}$ the $D$ of quartz at $1300 \mathrm{~K}$, and $\sim 2 \mathrm{x}$ the $D$ of quartz along the a-axis (Branlund and Hofmeister, 2007; Branlund and Hofmeister, 2012). Similar variability has been found between other rock-forming minerals, and for single minerals measured across large temperature ranges. Measurements using the LFA method show that thermal diffusivity of common rock types can vary by as much as a factor of five (Fig. 3-1).

Although a number of models have been proposed to calculate the temperaturedependence of $k$ from single measurements at ambient (or near-ambient) temperature (e.g. Clauser and Huenges, 1995; Lee and Deming, 1998), some question of the 


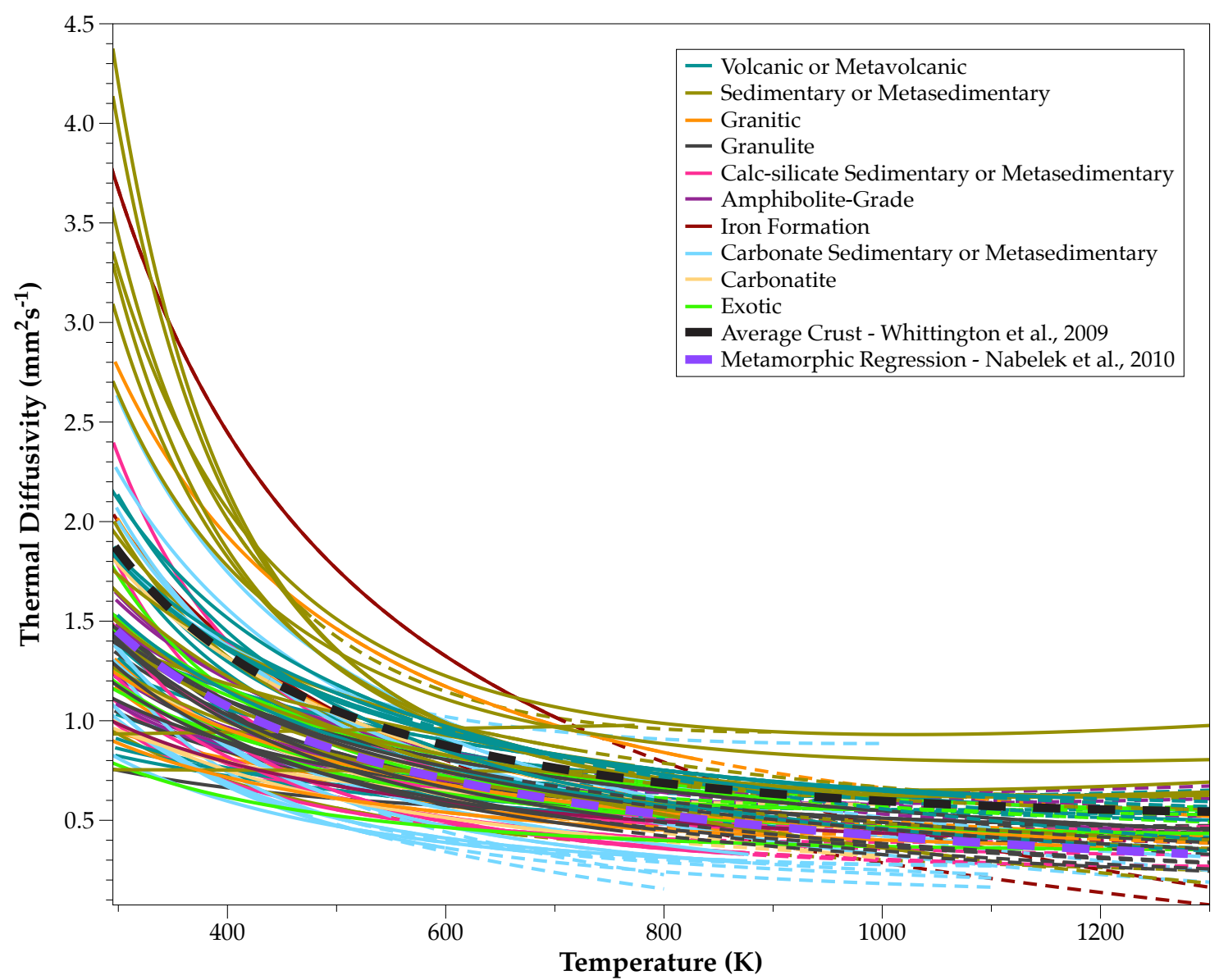

Figure 3-1) 81 sample measurements of $D$ performed across temperatures ranging from ambient to $>1300 \mathrm{~K}$. Thermal diffusivity values vary by nearly a factor of $10: \sim 0.7 \mathrm{~mm}^{2} \mathrm{~s}^{-1}$ to $\sim 4.5 \mathrm{~mm}^{2} \mathrm{~s}^{-1}$ at ambient-temperature, and $\sim 0.4 \mathrm{~mm}^{2} \mathrm{~s}^{-1}$ to $\sim 1.3 \mathrm{~mm}^{2} \mathrm{~s}^{-1}$ at $1000 \mathrm{~K}$. Solid lines are measured values, and thin, dashed lines are projections from measured $d D / d T$ using equation 3-4. Most rock $D$ decreases with increasing $T$ with the notable exception of two samples of opal (Branlund and Hofmeister, 2008), which have increasing $D$ from $\sim 295 \mathrm{~K}-800 \mathrm{~K}$, and some rocks near their melting points. High- $D$ samples at room temperature are typically quartz-rich or quartz-dominant (quartzites), but hematitedominated iron formation and dolomite-heavy samples also display high- $D$ at low $T$. Data in this figure are from Branlund and Hofmeister (2008), Whittington et al. (2009), Nabelek et al. (2010), Merriman et al. (2013), Miao et al. (2014), Merriman et al. (2018), Roy et al. (in review), methods as described in Merriman et al. (2018), and this paper.

applicability of these models to an Earth-sized variety of rocks is warranted. This arises in part because of high contrasts in $\mathrm{d} k / \mathrm{d} T$ between major rock types (Merriman et al., 2018). The common lack of detailed physical and chemical sample characterization 
produces unknown uncertainties when calculating $D$, and results in a lack of convergence between $k$ and $D$ measured by different methods.

For these reasons we chose to focus this research on thermal diffusivity rather than thermal conductivity. The present work combines measurements of $D$ using the LFA method for a suite of 122 rock samples with the considerable database of mineral $D$ published over the past 15 years (Hofmeister, 2019 and references therein), and careful characterization of the rock disks used in LFA measurement to develop a model for calculating rock $D$. Part I of this work focuses on sample characterization, new measurements of $D$ at ambient and high temperature, and evaluating the effectiveness of equations for calculating high-temperature $k$ from ambient-T $k$. Part II presents a model for interpolation of plagioclase feldspar $D$ between measured compositions, and compares measured and calculated rock $D$ at ambient temperature. Part III combines results from parts I and II to produce a mineralogy- and temperature-dependent model for thermal diffusivity of crystalline rock. This part includes a Microsoft Excel $\mathbb{C}$ spreadsheet for calculating $D$ from rock properties as well as suggestions for further research in metamorphic petrology. These three works show that $D$ can be predicted to a useful degree of uncertainty if the characteristics of the rock are well known. Application of these results will provide a framework around which future geodynamic models incorporating thermal conduction can more deeply explore the effects of the diversity of rock $D$ shown in figure 3-1. The growing database of $D, C_{P}$, and $\rho$ in the literature can be incorporated into this framework and used as a tool for developing new and better understanding of the Earth system. 


\subsection{SMALL-SCALE HEAT FLOW IN NATURAL CRYSTALLINE MATERIALS}

\subsubsection{Thermal diffusivity, heat capacity, and thermal conductivity of minerals}

\subsubsection{The LFA mineral database}

In order to evaluate the influence of the rock characteristics described in the following sections on bulk-rock $D$, careful and thorough characterization of the thermal transport properties of the major rock forming minerals is essential. Thermal diffusivity measurements using the LFA method have been completed and published for most of the major rock-forming minerals found in the crust (Hofmeister, 2019). Figure 3-2 shows the temperature-dependent $D$ for quartz (Branlund and Hofmeister, 2007), forsteritic olivine (Pertermann and Hofmeister, 2006), the clinopyroxenes diopside and augite (Hofmeister and Pertermann, 2008), hematite (Hofmeister et al., 2014), calcite (Merriman et al., 2018), near-endmember albite and anorthite (Hofmeister et al., 2009; Branlund and Hofmeister, 2012) and halite (Yu and Hofmeister, 2011). Data are also available for multiple orthopyroxenes (Hofmeister, 2012), garnets (Hofmeister, 2006), spinels and magnetite (Hofmeister, 2007), and low sanidine (Pertermann et al., 2008), as well as additional compositions in the mineral groups represented in figure $3-2$.

\subsubsection{Anisotropy in mineral thermal diffusivity}

Many minerals have highly anisotropic $D$ between different orientations. Figure 3-2B shows $D$ of two orientations of six minerals included in figure 3-2A. Anisotropy in $D$ between orientations varies strongly between different minerals and mineral groups. 
For example, the phyllosilicate mineral biotite has an anisotropy factor of $\sim 10 \mathrm{x}$, and quartz, an anisotropy of $\sim 2 \mathrm{x}$ (Hofmeister and Carpenter, 2015; Branlund and Hofmeister, 2007). But measured differences in orientations for the carbonates calcite and dolomite were $<10 \%$ (Merriman et al., 2018), and many minerals such as halite or garnet are thermally isotropic as dictated by their structures (Yu and Hofmeister, 2011; Hofmeister, 2006). Although previous work by Nabelek et al. (2010) and Merriman et al. (2013) found modest anisotropy in highly foliated and lineated amphibolites and schists, these differences were within the range found for multiple samples of isotropic rocks. The potential for thermal transport anisotropy is considerably higher, however. Figure 3-2B shows that if minerals are aligned along a crystal preferred orientation, anisotropy in metamorphic rocks could be much higher than the factor of $\sim 1.2 \mathrm{x}$ found in the above studies. Additionally, strong anisotropy of $k$ has been found in some sedimentary rocks, primarily shales and mudstones (e.g. Robertson, 1988; Fjeldskaar et al., 2009; Füchs et al., 2013; Füchs et al., 2015). Effects of anisotropy on rocks are discussed in more detail in chapters 4 and 5 .

\subsubsection{Heat Capacity and Density of Minerals}

Although mineral $D$ can vary with orientation of the crystal, heat capacity and density do not. Furthermore, both heat capacity and density can be effectively calculated for rocks if the mineral mode and compositions are known (e.g. Büttner, 2012). Like thermal diffusivity, both of these properties of minerals vary by temperature, with heat capacity increasing asymptotically by up to a factor of two (Robie and Hemingway, 1995), and density decreasing by $<\sim 5 \%$ across the temperature range $300-1700 \mathrm{~K}$ (Fei, 1995). 

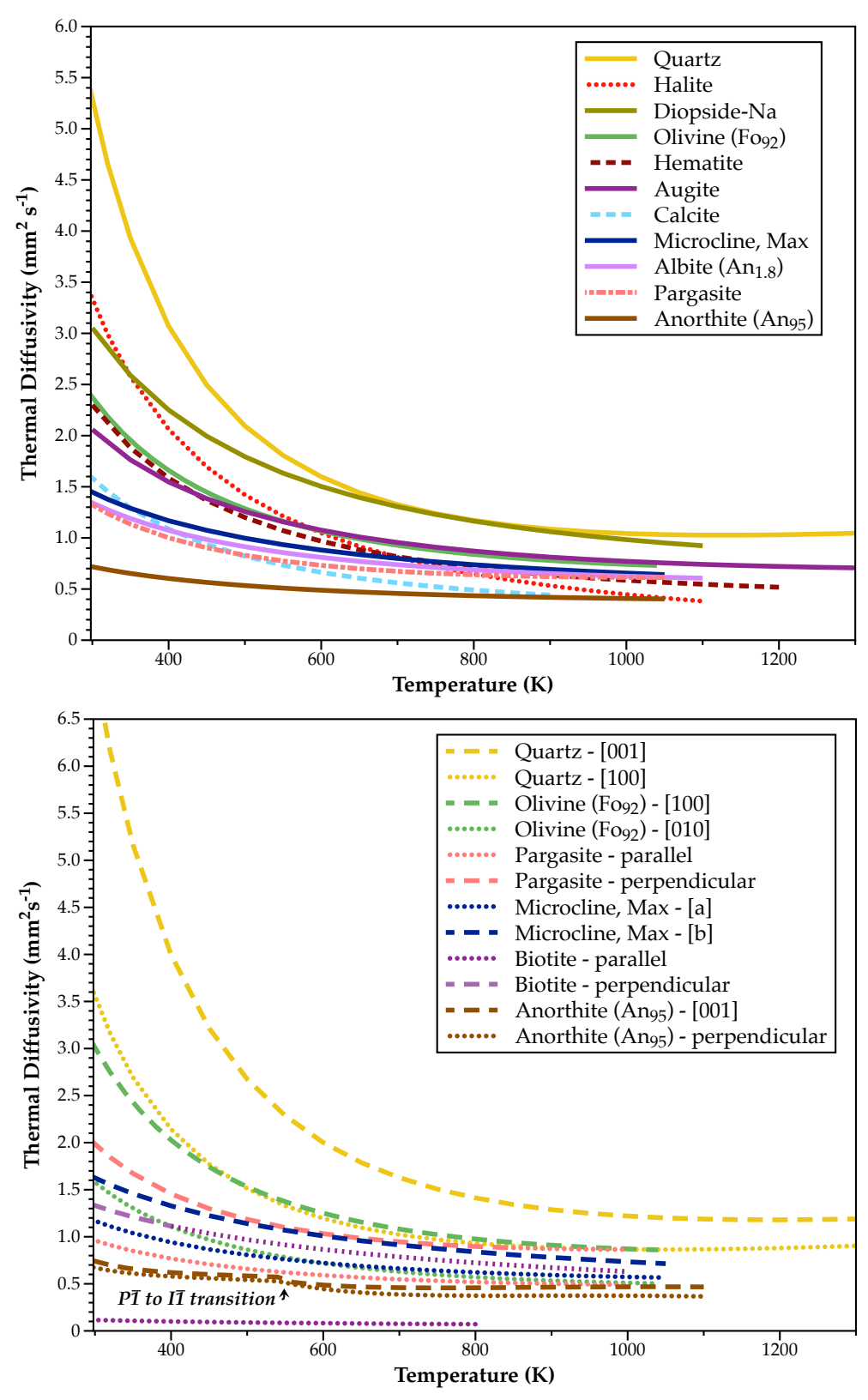

Figure 3-2) Thermal diffusivity of select minerals to high temperature. (A) Directionallyaveraged $D$. Solid lines are minerals typical of felsic rocks. Dashed lines are minerals with a-typical $d D / d T$. Data for pargasite and microcline are new, and will be discussed in more detail in forthcoming papers by Hofmeister and Branlund (amphiboles) and Roy and Hofmeister (alkali feldspars). All lines are arithmetic averages calculated from previous results for directly measured orientations. Sources: Quartz, Branlund and Hofmeister (2007); Olivine (Fo92), Petermann and Hofmeister, 2006; Sodic

diopside and Augite, Hofmeister and Pertermann, 2008; Hematite, Hofmeister et al., 2014; Calcite, Merriman et al., 2018; An95 and Amelia Albite (An1.8), Branlund and Hofmeister, 2012; Halite, Yu and Hofmeister, 2011. (B) Fast and slow orientations for select minerals, as well as biotite (Hofmeister and Carpenter, 2015). Long-dashed lines are fast orientations, whereas dotted lines are slow orientations. Data for Biotite - perpendicular was extrapolated using the measured trend below 400K and the Hofmeister equation. Note the strong contrast between orientations of Biotite compared to the minor contrast between high ([001]) and low (Perpendicular) $D$ orientations of anorthite. 


\subsubsection{Thermal Diffusivity of Rocks}

Similar to minerals, rock $D$ varies considerably between samples. Figure 3-1 shows 90 fits of temperature-dependent $D$ measurements on crystalline sedimentary, igneous and metamorphic rocks using the LFA method. Although use of a single temperature-dependent equation (e.g. Average Crust - thick black dashed line, or Metamorphic Regression - thick violet dashed line) to model the $D$ of the crust is an improvement over using a single invariant number (e.g. $1 \mathrm{~mm}^{2} \mathrm{~s}^{-1}$ ), any model using such a value could potentially over- or under-estimate the $D$ by as much as $50 \%$ (c.f. carbonate sedimentary (light blue lines) to "Average Crust"). However, simply choosing a single value for specific crustal subsections could also produce high error, as subgroups of rocks contain almost as much variability as the full range of crustal rocks measured.

High variability in rock $D$ is a result of microscopic characteristics within the rocks (e.g. Branlund and Hofmeister, 2008; Merriman et al., 2013, Merriman et al., 2018). Previous work has suggested that the major characteristics are mineralogical composition, porosity, grain-size and grain-boundary resistance (Clauser and Huenges, 1995; Smith et al., 2003; Branlund and Hofmeister, 2008; Ray et al., 2015), although Seipold (1998), and Gibert et al. (2003) suggest that grain-boundary resistance does not interfere with heat transport because the mean free path of phonon propagation (the commonly-accepted control on $D$ ) is considerably shorter than typical grain sizes in rocks. The following sections present background information on each of these potential contributions, and present previously proposed models for mixing of these parameters which will be evaluated later in this paper and in part II. 


\subsection{SAMPLE SELECTION AND CHARACTERIZATION METHODS}

Variability in rock characteristics within the same unit is an issue of concern throughout much of geology (e.g. Gill et al., 2005; Villaseñor and Jaeger, 2013; Glazner et al., 2019), in part because applications such as geothermobarometry or other thermodynamic work are sensitive to modest changes in bulk composition (Palin et al., 2016; Boyd et al., 2018). This study was not designed to evaluate the entire range of possible crustal rocks, but rather to provide a broad enough sampling to elucidate the major properties that may influence rock thermal conduction, and thus build a foundation for application to the broader range of rocks found in the Earth.

Of primary concern for this study is heterogeneity from the scales of the crust, to a single hand sample or thin section. Potential first-order problems when evaluating controls on rock $D$ include (but are not limited to): Contrast between the slice of sample used to estimate mineral abundances, and the sample measured in the analytical apparatus (sample heterogeneity); stereoscopic issues associated with calculating a volume from a 2-dimensional observed area (e.g. Heilbronner and Barrett, 2014); and incompletely characterized microscopic components of a rock such as crystal orientation (e.g. Nabelek et al., 2010; Merriman et al., 2013; Ray et al., 2015; Merriman et al., 2018). To reduce the errors associated with these issues, a series of methods were developed that isolate individual LFA disk properties thought to influence $D$ results. These properties include mineralogical composition and abundance, bulk-rock chemistry, porosity, grain-size, within-sample heterogeneity, and crystal preferred orientation. Each LFA disk was analyzed using some combination of the procedures below, however because some methods are destructive (e.g. powdering for XRD), and disk size becomes an issue for 
several of the methods (especially density measurements), the use of each method was a trade-off between the relative contribution of data collected from each, and the destruction of the sample.

\subsubsection{Sample Selection}

The sample suite presented in this study also includes samples from previous publications that were measured with the LFA method (Merriman et al., 2013; Merriman et al., 2018; Roy et al., in review). Additional characterization such as XRD analysis was performed on most of these samples. Data on quartzite from Branlund and Hofmeister (2008) are also included in analysis, although no additional characterization was

performed. The bulk of the suite is composed of samples collected in May 2014 and 2016 from the central Wawa-Abitibi Subprovince of the Superior Craton, Ontario, Canada (see Percival and Card, 1983; Percival and Easton 2007 for a reviews of local geology). Here, a cross-section of approximately $25-30 \mathrm{~km}$ of late-Archean crust, collectively known as the Kapuskasing uplift, exposes rocks from paleodepths of up to $40 \mathrm{~km}$, roughly increasing in metamorphic grade from West to East. This location was selected to facilitate sampling of a broad range of rocks from throughout a single crustal section. Rocks from here include samples from the Michipicoten (Sage, 1994; Sage et al., 1996 ) and Swayze greenstone belts (van Breemen et al., 2006), the largely amphibolite-facies Wawa gneiss belt (Moser, 1994; Polat and Kerrich, 2000), and the lower-crustal amphibolite-to-granulite facies Chapleau Block (Percival and Card, 1983; Percival and West, 1994; Benn and Kamber, 2009). Samples include a range of rock types and compositions from upper-crustal greenschist-facies metasedimentary and metavolcanics, to mid-crustal felsic plutonic and metapelitic rocks, lower-crustal granulite-facies mafic 
and felsic metaplutonic, and metapelitic rocks, and leucosome and melanosome produced during high-temperature amphibolite dehydration (Hartel and Pattison, 1996; Pattison et al. 2003).

Additional samples were collected from the Penokean Orogeny, Upper Peninsula, Michigan, (Marshak et al., 1997; Tohver et al., 2007) a Paleoproterozoic collisional orogenic belt along the margin of the Superior Province in Michigan, USA. Samples from the Penokean Orogeny were included to expand the suite of upper-crustal rocks, as the top $\sim 5-10 \mathrm{~km}$ of the crust in Ontario has been eroded. These rocks include foliated and lineated micaceous metasedimentary rocks, quartzite, and dolomite-bearing quartzite. Samples from previous studies include carbonatite volcanic rocks (Roy et al., in review), carbonate sedimentary and metasedimentary rocks (Merriman et al., 2018), and highgrade metamorphic and volcanic or hypabyssal rocks (Merriman et al., 2013), with several from the Chapleau Block. Table 3-1 includes sample names, locations (including GPS coordinates where available), applied characterization methods, sample sources, and sample types. 
TABLE 3-1. SAMPLE CHARACTERISTICS AND SOURCES

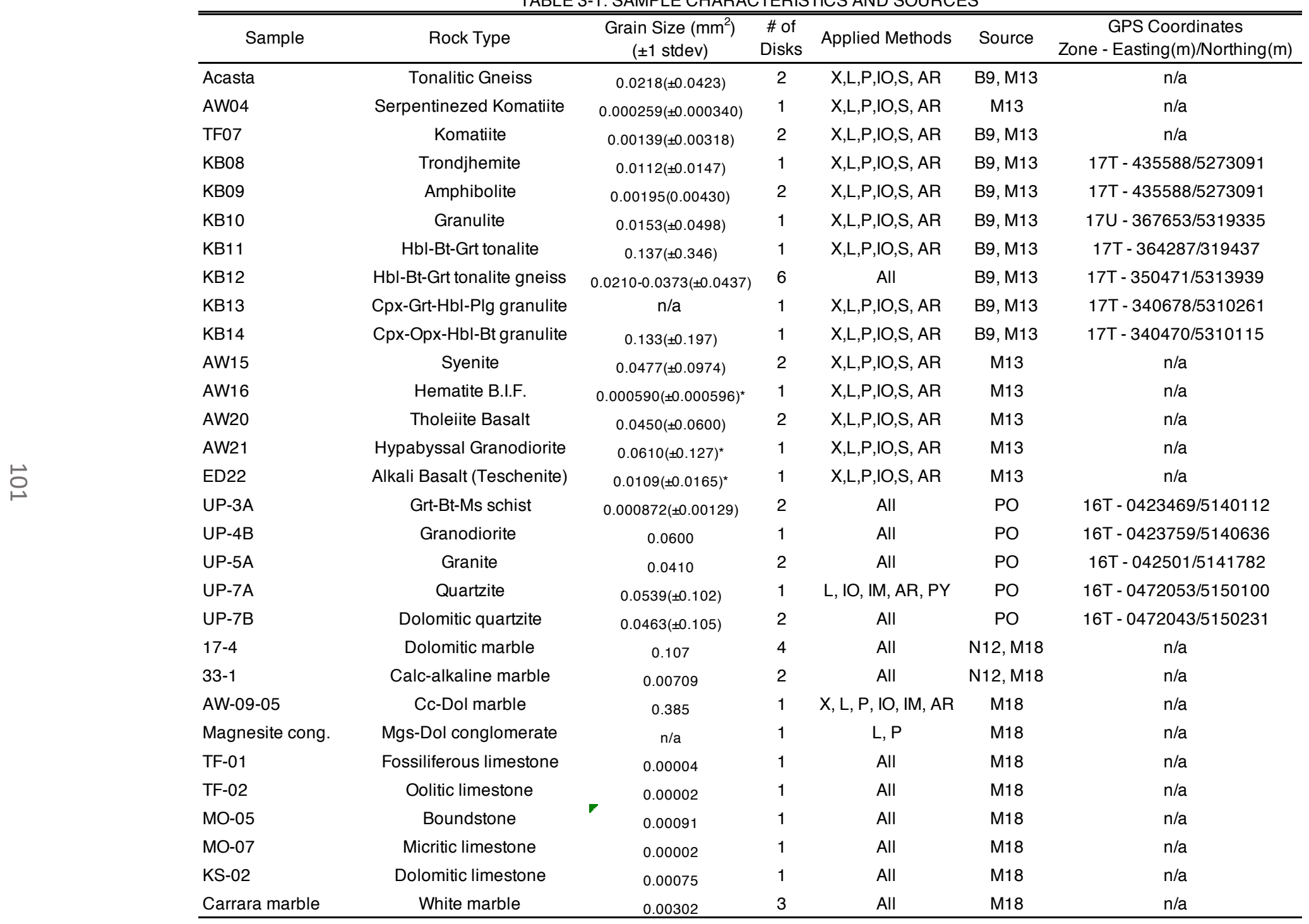


TABLE 3-1 CONTINUED. SAMPLE CHARACTERISTICS AND SOURCES

\begin{tabular}{|c|c|c|c|c|c|c|}
\hline Sample & Rock Type & $\begin{array}{c}\text { Grain Size }\left(\mathrm{mm}^{2}\right) \\
( \pm 1 \mathrm{stdev})\end{array}$ & $\begin{array}{c}\text { \# of } \\
\text { Disks }\end{array}$ & Applied Methods & Source & $\begin{array}{c}\text { GPS Coordinates } \\
\text { Zone - Easting }(\mathrm{m}) / \text { Northing }(\mathrm{m})\end{array}$ \\
\hline Carrara def. & Experimentally def. marble & 0.00003 & 1 & All & $\mathrm{X} 10, \mathrm{M} 18$ & $\mathrm{n} / \mathrm{a}$ \\
\hline Black marble & Graphitic marble & 0.00515 & 1 & All & M18 & $\mathrm{n} / \mathrm{a}$ \\
\hline Threshold marble & White marble & 0.00152 & 1 & All & M18 & $\mathrm{n} / \mathrm{a}$ \\
\hline $14-4 \mathrm{D}$ & Tonalitic Amphibolite & $0.0490-0.0800$ & 6 & All & KSZ & $17 \mathrm{~T}-0340842 / 5310344$ \\
\hline $14-5 B$ & Garnet amphibolite & $0.0882( \pm 0.132)$ & 6 & All & KSZ & $17 \mathrm{~T}-0350396 / 5313910$ \\
\hline $14-10$ & inorthosite w/ mafic phenocryst & $0.268-0.595$ & 4 & All & SA & 17Т 0381806/5341957 \\
\hline $14-12$ & Foliated Grt-Hbl anorthosite & $0.680( \pm 0.670)$ & 1 & $\begin{array}{c}X, L, P, I O, I M, G \\
P Y\end{array}$ & SA & $17 \mathrm{U} 380788 / 5345777$ \\
\hline $14-14$ & Anorthosite & $1.893( \pm 4.181)$ & 1 & $X, L, P, I O, I M, G$ & SA, R & $17 \mathrm{U} 366701 / 5332595^{1}$ \\
\hline 14-15B & Amphibolite Xenolith & $0.424( \pm 0.507)$ & 1 & All & SA & 17U 366856/5332399 \\
\hline $16-03$ & etagreywacke w/ slatey cleava! & $0.000298( \pm 0.000633)$ & 1 & All & MGB & $16 U-0666423 / 5319087$ \\
\hline $16-04$ & ilicified greenshist metavolcani & $0.0000892( \pm 0.000214)$ & 2 & All & MGB & $16 U-0666322 / 5318917$ \\
\hline JM16-ON-007 & Chloratized carbonatite & $\mathrm{n} / \mathrm{a}$ & 1 & $X, L, P, I O, I M, G$ & MGB, R & $16 \mathrm{~T}-0673567 / 5318240$ \\
\hline JM16-ON-011 & Fe-rich carbonatite & $\mathrm{n} / \mathrm{a}$ & 1 & $X, L, P, I O, I M, G$ & MGB, R & $16 \mathrm{~T}-0673524 / 5318258$ \\
\hline JM16-ON-012 & Dolomitic carbonatite & $\mathrm{n} / \mathrm{a}$ & 1 & $X, L, P, I O, I M, G$ & MGB, R & $16 \mathrm{~T}-0673569 / 5318391$ \\
\hline JM16-ON-013 & Pegmatite carbonatite & $\mathrm{n} / \mathrm{a}$ & 1 & $X, L, P, I O, I M, G$ & MGB, R & $16 U-0673976 / 5318424$ \\
\hline $16-14$ & Mafic metavolcanic & $0.000126( \pm 0.000163)$ & 1 & All & MGB & $16 U-0673007 / 5323785$ \\
\hline $16-15$ & Cc-Sid B.I.F. & $0.000989( \pm 0.000719)^{*}$ & 3 & All & MGB & $16 U-0673007 / 5323785$ \\
\hline $16-16$ & Mafic slate & $0.000199( \pm 0.000900)$ & 1 & All & MGB & $16 U-0672371 / 5324081$ \\
\hline $16-17$ & Conglomerate matrix & $0.0073( \pm 0.0143)$ & 1 & All & MGB & $16 U-0661309 / 5322599$ \\
\hline $16-18$ & Metagreywacke pebble & $0.116( \pm 0.187)$ & 1 & All & MGB & $16 U-0661310 / 5322601$ \\
\hline $16-28$ & Granodiorite & 0.107 & 6 & All & WGB & $17 \mathrm{~T}-0297635 / 5300790$ \\
\hline $16-36$ & Tonalite & $0.479( \pm 0.593)$ & 6 & All & SGB, KSZ & $17 U-0378851 / 5331351$ \\
\hline $16-39$ & Phyllitic schist & $0.000410( \pm 0.00100)$ & 3 & All & SGB & $17 \mathrm{U}-0406817 / 5338299$ \\
\hline $16-44$ & Magnetite B.I.F. & $\mathrm{n} / \mathrm{a}$ & 2 & All & SGB & $17 U-0480462 / 5339365$ \\
\hline
\end{tabular}

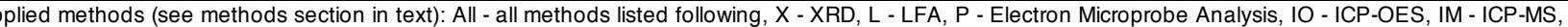

$S$ - SEM EDS and Backscatter imaging, $G$ - geometric density, AR - Archimedean density, PY - pynometric density

stdev - standard deviation, not available for all samples

cong. Indicates conglomerate, def. indicates deformed

* - indicates grain size measurements taken on low-resolution binocular microscope images

n/a indicates not available

1 - GPS coordinates approximate

Source codes - B9 - Benn and Kamber, 2009; M13 - Merriman et al., 2013; PO - Penokean Orogeny, Upper Peninsula, Michigan; N12 - Nabelek and Morgan, 2012 ; M18 - Merriman et al., 2018; X10 - Xu and Evans, 2010, KSZ - Kapuskasing Structural Zone, Superior Craton, Abitibi-Wawa Subprovinces, Ontario, Canada; SA Shawmere Anorthosite, KSZ; R - Roy et al., under review; MGB - Michipicoten Greenstone Belt, Wawa Subprovince, Ontario, Canada; WGB - Wawa Gneiss Belt, Wawa Subprovince, Ontario, Canada; SGB - Swayze Greenstone Belt, Abitibit Subprovince, Ontario, Canada; 


\subsubsection{Sample Characterization}

\subsubsection{Density}

Density was measured using three methods: geometric measurements, the Archimedean method, and He-based multipycnometry. The geometric density includes all pore space and was performed by measuring the lengths and diameters of $\sim 1-5 \mathrm{~cm}$ cores of samples with a micrometer. Mass was measured by analytical balance following drying at $\sim 100^{\circ} \mathrm{C}$ for $>24$ hours. Total error for this method is estimated as $<2 \%$ by samecore remeasurement and comparison to standards such as quartz. Following geometric measurements, the Archimedean method was performed after samples were soaked in ethanol for $>24$ hours to fill open pore space. Density is determined by comparing the weight of the sample in air after drying, and in an ethanol bath following soaking. The density measured with this method includes isolated pore space. Measurements performed with the ethanol bath method have a high reproducibility $(\sim 0.1 \%$ between measurements taken on the same slice or core on separate days). Skeletal density was measured using a He-based Quantachrome multipycnometer. Most samples were measured following powdering to $<150 \mu \mathrm{m}$ diameter to eliminate pore space. Error for this method is dependent upon sample size. For large sample sizes (mass $>\sim 10 \mathrm{~g}$ ), expected error is $<0.5 \%$ by remeasurements on the same sample and comparison to standards such as quartz and halite. However, for sample sizes on the order of an LFA disk (mass of $\sim 0.25-1.00 \mathrm{~g}$ ), error is typically on the order of $5 \%$, and as high as $15 \%$, which limits the usability of measurements on LFA disks. 


\subsubsection{Porosity}

Porosity was determined indirectly by combining the multiple methods for density measurement described above. Following Avard and Whittington (2012), total porosity is calculated by comparing the geometric density to the skeletal density.

$$
\phi=\frac{V_{\text {Skel }}-V_{G e o}}{V_{\text {Skel }}}
$$

Equation 3-5.

Where $\phi$ is pore fraction, $V_{S k e l}$ is skeletal volume, and $V_{G e o}$ is the geometric volume.

All of the above methods for determining volume of LFA disks have errors that are not complementary and therefore produce low confidence results for samples with pore fractions below $\sim 0.01$. Thus pore fraction measurements were performed on bulk sample, rather than LFA disks because of limitations in reproducibility for small sample sizes in the multipycnometer, and high error in geometric volume measurements when the primary surface area of a disk is two parallel surfaces, rather than a diameter set by drill core.

\subsubsection{X-Ray Diffraction}

Following collection of LFA data and imaging, disks were crushed and sieved to a powder size of $<15 \mu \mathrm{m}$. These were then analyzed in a Bruker D8 ADVANCE X-Ray Diffractometer (XRD) located at Washington University, St. Louis, Missouri. Rietveld analysis (Rietveld, 1968) was performed using the Bruker software package and Topas version 5, which produces phase abundances in weight percent. The Weighted Profile Rfactor (Rwp), a measurement of residual area under the XRD curve following fitting, was 
typically $<20$, and as low as 12 . In most cases, the mass of the disk was close to the minimum mass needed for XRD analysis $(\sim 0.25 \mathrm{~g})$, but when thicker disks were available, the center $\sim 0.5 \mathrm{~cm}$ of the disk was cut-out and powdered, as this is the primary area of interaction for the LFA laser and detector.

\subsubsection{Optical Analysis}

Heterogeneity within different slices of the same sample likely results in poor accuracy when using thin sections to determine rock mineral proportions. However, thin sections analyzed using Polarizing Light Microscopy (PLM) are still useful for textural analysis, including grain-size, and determination of suitability for LFA measurements. Most samples were imaged using both Plane Polarized Light (PPL) and Cross-Polarized Light (XPL). Some samples had textural features suggesting crystallographic preferred orientation, which may influence thermal diffusivity results, and these samples were also imaged with the accessory plate inserted $(+530 \mathrm{~nm})$. This, when combined with XPL produces interference colors consistent with the optical orientation of the crystal, and minerals within samples with a true crystallographic preferred orientation have the same interference color.

Each disk was also imaged using a binocular microscope prior to crushing, but following LFA measurement (see below). Most disks were thin enough for light from below the microscope to illuminate textural features such as grain boundaries and cleavage, and images could then be combined with SEM images (described below) to provide additional information about both sides of the disk as well any as areas of the disk not imaged in the SEM. 


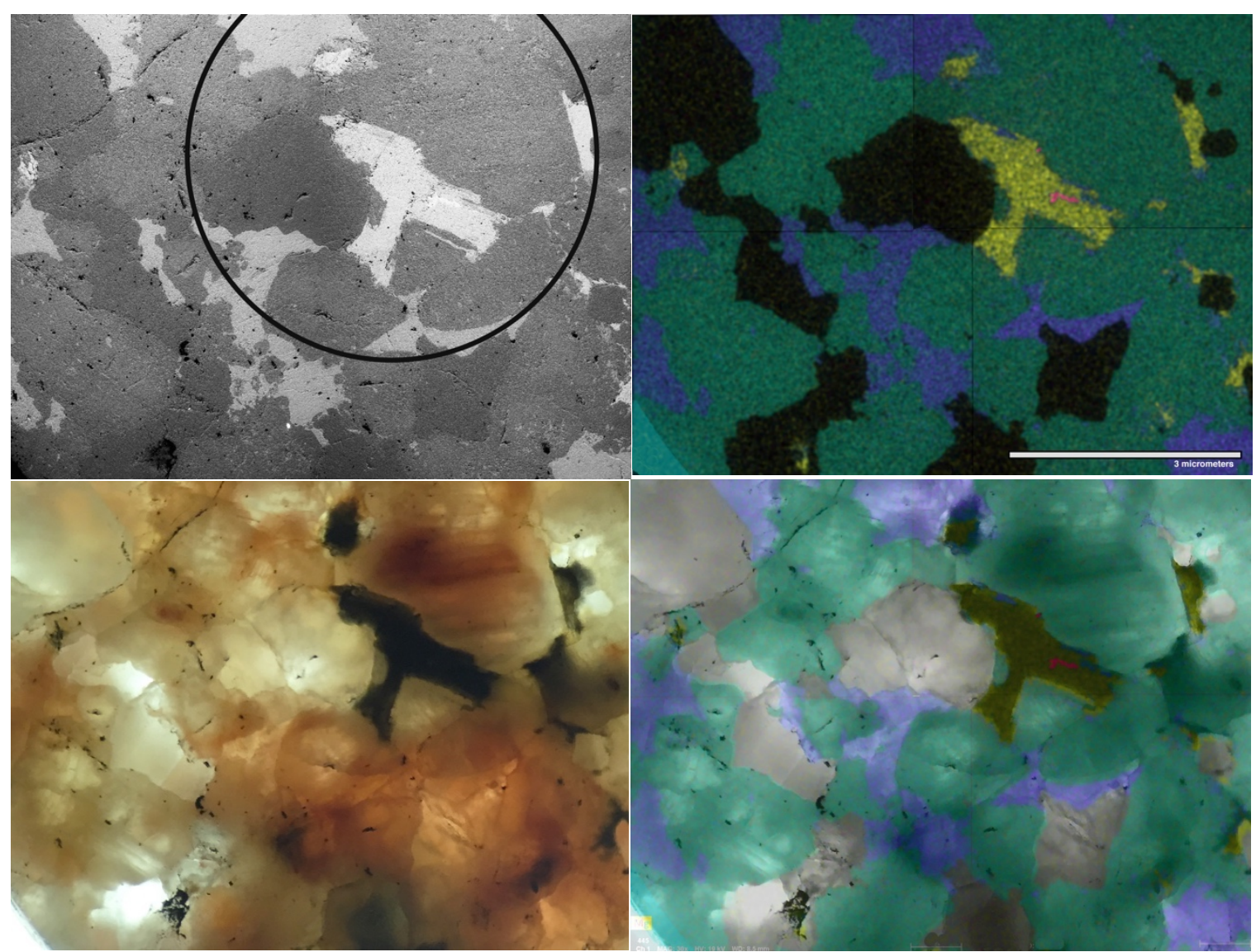

Figure 3-3) Images of sample 16-28 disk c8d1. In

all 4 images, the disk rim is just visible to the bottom left. (A) SEM backscatter composite of four images of the disk. (B) The same view under EDS with brightness and color relative to elemental abundance. Element channels chosen to highlight different phases. (C) disk illuminated from below in a binoscopic microscope. Textural, color, and brightness shows some phases, but considerable ambiguity exists. (D) composite of EDS and binoscopic images. Highlights both textural and compositional differences between grains, as well as grain-size. Black circle in panel a is approximate location of the center of the disk analyzed in the LFA. The scale bar in (B) is $3 \mathrm{~mm}$.

\subsubsection{Scanning Electron Microscopy}

To analyze specific disk textures and mineral placement, as well as record individual disk features prior to crushing for XRD, LFA disks were imaged using a Sigma 500 VP Scanning Electron Microscope (SEM) located at the University of Missouri's X-ray Microanalysis Core $(\operatorname{Mizzo} \mu \mathrm{X})$. Four sections of each disk were 
imaged with backscatter electrons and Energy-dispersive X-ray spectroscopy (EDS). These images were stitched together into a Backscatter and EDS map using Adobe Photoshop $\odot$ (e.g. Figure 3-3) which includes most of the interaction surface of the LFA laser for one side of the disk, and some of the surrounding disk material. These images also provide a (rough) check on the reported abundance of minerals using XRD (see below), albeit, on a 2D surface, and insight into mineral distribution within the disk.

\subsubsection{Bulk-Rock Composition}

Bulk rock major- and trace-element compositions were analyzed using Inductively-Coupled Plasma Optical Emission Spectroscopy (ICP-OES) on lithium metaborate fusions, and mass spectroscopy (ICP-MS), respectively by Activation Laboratories Incorporated (Ontario, Canada). In preparation for analysis, the outer $\sim 1 \mathrm{~cm}$ of each sample was removed and discarded to ensure samples were not contaminated by surface weathering effects (e.g. Ashwal et al., 1987). Samples were then powdered and physically mixed to ensure homogeneity. With the exception of the carbonatite and carbonate samples (Merriman et al., 2018; Roy et al., in review), bulk chemical analysis did not include Sulfur or Carbon, thus samples with sulfate, sulfide or carbonate minerals have unknown Sulfur and Carbon contents.

\section{3..2.7. Laser Flash Analysis}

Thermal diffusivity measurements were performed using a Netzsch LFA 427 (Bräuer et al., 1992) located at Washington University in St. Louis, Missouri. One cmdiameter cores were cut of each sample, and following core density measurements, sliced to disk thicknesses (L) of 1-2 mm (Table 3-1). Disks were hand ground to ensure even thicknesses ( $\Delta \mathrm{L}$ of less than $\sim 0.05 \mathrm{~mm}$ across the disk surface). Each disk was coated 
with a thin, double layer of graphite on both sides, and placed in an atmospherecontrolled chamber. For samples not analyzed above $\sim 100^{\circ} \mathrm{C}$, the sample chamber was not evacuated, but a constant flow of Argon was maintained. For high-temperature measurements, the sample chamber was evacuated and filled with Argon twice, and then pressurized to $\sim 1.25$ bar. A Nd-GGG laser was used to heat the bottom of the sample, and the resulting $d T / d t$ was measured on the opposite side of the disk (see eq. 1 in Pertermann and Hofmeister 2006). Typically, a spot size (interaction area) of $0.5 \mathrm{~cm}$, and a laser pulse-width of $\sim 0.5 \mathrm{~ms}$ was used. For a detailed description on the LFA method, see Maglic and Taylor (1992), Vozár and Hohenauer (2003, 2005), and Criss and Hofmeister (2017).

The aperture of a graphite cap determines the area analyzed by an IR detector on the opposite side of the disk from the laser pulse, and thus the section of the disk being measured. This limits the samples that can be analyzed in the LFA to those with a grainsize smaller than the combination of the aperture opening and the thickness of the disk.

Detector error is $\sim 5 \%$ at ambient conditions, and thus between 6 and 12 laser pulses were used to increase confidence in ambient- $T$ measurements. Error is much lower at elevated temperatures such that $3-5$ measurements are needed to confidently reproduce results above $\sim 100^{\circ} \mathrm{C}(\sim 2 \%$ error). Steel, iron, graphite, and Pyroceram standards from the National Institute of Standards and Technology are used to assess reproducibility (Henderson et al., 1998a, 1998b), and the Curie point of iron and cobalt is used to calibrate the temperature. Thermal diffusivity was calculated from the temperature-time curve using the algorithm of Mehling et al. (1998) unless otherwise noted. 


\subsubsection{Electron Microprobe Analysis}

Mineral $D$ can vary strongly between endmembers of the same solid solution (e.g. Hofmeister, 2006; Branlund and Hofmeister, 2012). For this reason, mineral phases were analyzed using a JEOL JXA-8200 Electron Microprobe (EMPA) also located at Washington University. Calibration was performed on the following oxides and silicates: Amelia albite for $\mathrm{Na}$ and $\mathrm{Si}$; microcline for $\mathrm{K}$; Gates wollastonite for $\mathrm{Ca}$; Alaska anorthite for $\mathrm{Al}$; synthetic fayalite for $\mathrm{Fe}$; synthetic forsterite for $\mathrm{Mg}$; synthetitc $\mathrm{TiO}_{2}$ for Ti; synthetic Mn-olivine for Mn; and synthetic $\mathrm{Cr}_{2} \mathrm{O}_{3}$ for $\mathrm{Cr}$. Probe for Windows software was used for data reduction (Probe Software, Inc., Eugene, Oregon, USA; http://probesoftware.com/), and corrections were performed with the software package CITZAF after Armstrong (1995). Additional slices of each rock sample were used rather than LFA disks, because sample preparation for the probe would prohibit further analysis of LFA disks using XRD. Whenever possible, multiple grains of the same mineral were analyzed, as well as grains from disparate parts of the sample to identify potential inhomogeneity in mineral compositions.

\subsubsection{Image Analysis}

Image analysis was performed with several goals in mind: First, as a first-order check on the modal mineral abundances reported by the XRD software, and second, to quantify grain size modes and distributions. Thus, we used several image types in analysis: EDS-backscatter composite maps discussed in section 3.3.2.5 provided qualitative compositional and mineral abundance information. However, poor contrast 
along grain boundaries in these images prevented quantitative grain-size analysis. The binocular microscope images also show individual disks, but grain boundary traces of phases at-depth in the disk are often projected onto the surface, and image resolution is poor for fine-grained rocks due to limited magnification. As a result, most grain-size analysis was performed on images captured with the PLM, and thus are representative of the bulk rock rather than capturing heterogeneity in grain-size between disks.

Detailed grain-size analysis, and imaged-based modal mineralogy was performed on PLM images of samples 14-4D, 14-5B, 14-10, 16-28, 16-36, KB12, UP-03, UP-4B, and UP-5A. Images were enhanced to increase grain boundary contrast, and then manually outlined using a tablet (2017 iPad Pro) and stylus with the freely available drawing application Autodesk ${ }^{\circledR}$ Sketchbook ${ }^{\circledR}$. Grains were then color-coded to specific grey values (e.g. quartz $=16$, plagioclase $=208)$ using the "fill" command and stylus with a tolerance of $\sim 120$. This automatically fills each outline to the boundaries drawn if the shape is fully closed. Following grain outlining, images were converted into TIFF files in Adobe Photoshop, and final image processing and analysis was carried out using the software package Image SXM following the procedure outlined in Heilbronner and Barrett (2014).

For the remaining samples, grain-size analysis was performed using the "measure" tool in Adobe Photoshop CC after calibration for image magnification performed with a caliper fixed to the PLM. Random straight-line lengths from boundary to boundary were taken on several hundred grains for each PLM image, converted to area assuming a perfect circle, and then averaged for all phases. This method should produce a roughly correct grain-boundary density. 


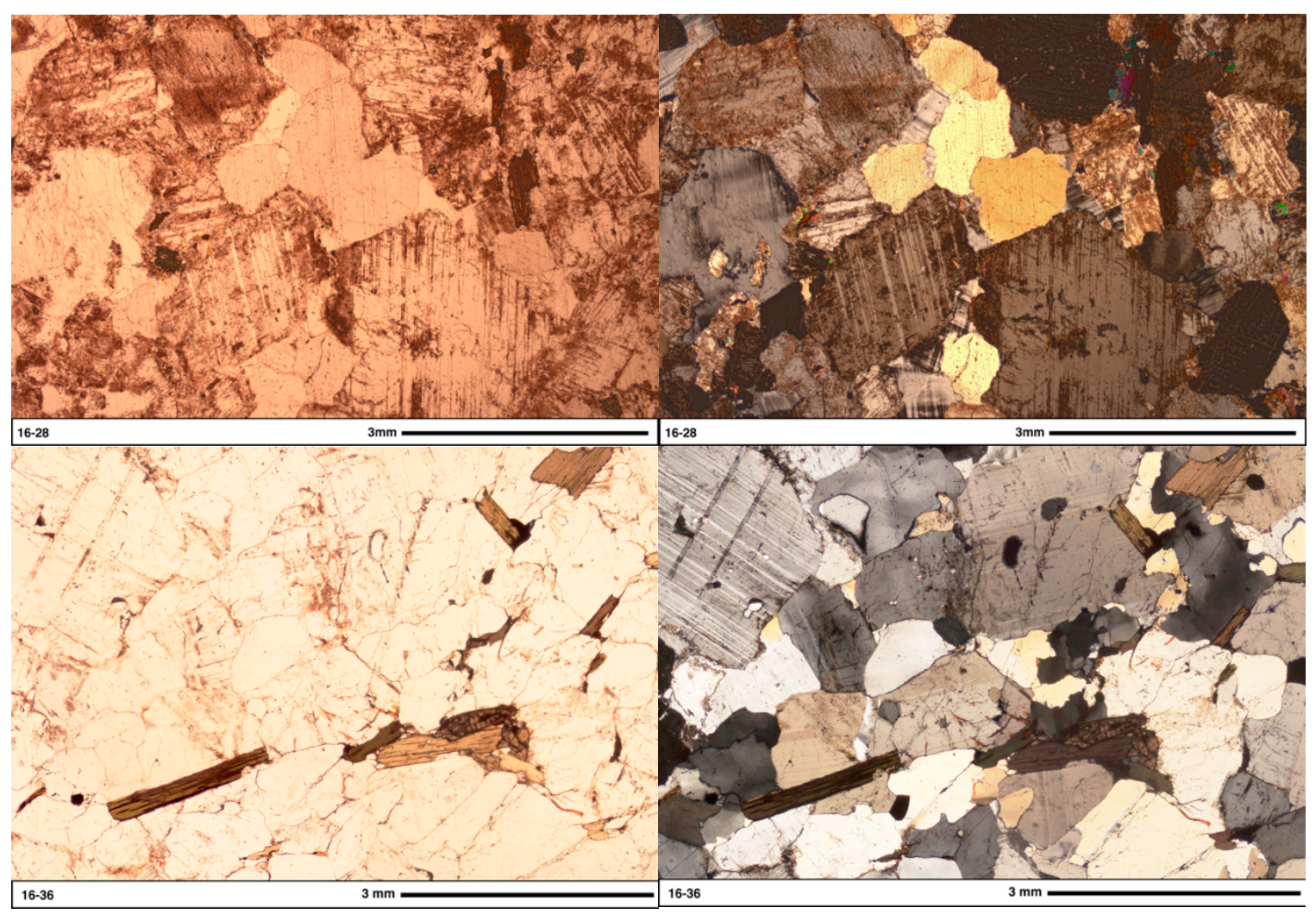

Figure 3-4) Polarizing light images of samples 16-28 (top) and 16-36 (bottom) under plane polarized light (left) and cross-polarized light (right). Alteration in 16-28 is strong, but concentrated mostly in plagioclase feldspar, whereas fine-grained alteration is rare to absent in 16-36. Also pictured - biotite (both), titanite (16-36), apatite (both), and ilmenite (16-36). Microcline is minor in 16-36, but more common in 16-28.

\subsection{RESULTS AT AMBIENT TEMPERATURE}

\subsubsection{Sample Optical Descriptions}

Optical and SEM images reveal most high-grade metamorphic samples from Ontario and the Upper Peninsula to be largely unaltered from peak metamorphic conditions. Optical analysis shows only minor retrogression, except for sample 16-28, which displays some micaceous alteration largely extending into plagioclase grains (3-4). 
Alteration appears to occur preferentially in one or two phases, with 16-28 possessing moderately-to-heavily altered plagioclase, but clean microcline and quartz grains. By comparison, tonalite 16-36 (Fig 3-4) contains virtually no alteration, with very minor fine-grained micas concentrated at intersections of three or more grains, or along biotite laths. This latter form of retrogression is more typical of most samples.

Higher-grade rocks from the KSZ often show evidence of progressive dehydration of amphiboles likely associated with increasing metamorphic grade (Hartel and Pattison, 1996). Figure 3-5 shows granulite 14-4D from near the transition from amphibolite to granulite facies in the KSZ. This section of the sample is dominated by plagioclase, clinopyroxene, and quartz with trace titanite and apatite, but remnants of earlier amphibole remain, with some cpx containing inclusions of hornblende, or diffuse boundaries between rare remnant grains of hornblende. A few mm away, however, hornblende dominates over cpx, quartz becomes less abundant, and titanite rare. This side of the slide more closely resembles the lower-grade sample 14-5B, which contains anhedral, but coarse grains of hornblende, plagioclase and quartz, laths of unaltered biotite, and rare, subhedral garnets that are rich with inclusions of plagioclase and quartz.

Most high-grade rocks are almost completely free of clear retrogression textures or minerals. Sample 14-10 is a coarse-grained garnet amphibolite with mostly euhedral hornblende, and euhedral to subhedral garnet, again rich in inclusions. However, rounded, smaller grains of plagioclase are present in sub-continuous patches. Similarly, sample 14-12 is an anorthosite with large, angular plagioclase of fairly uniform grain size. However, triple- and quadruple-junctions of euhedral plagioclase are often interrupted by much smaller, rounded, subrounded, or lenticular grains of amphibole. 


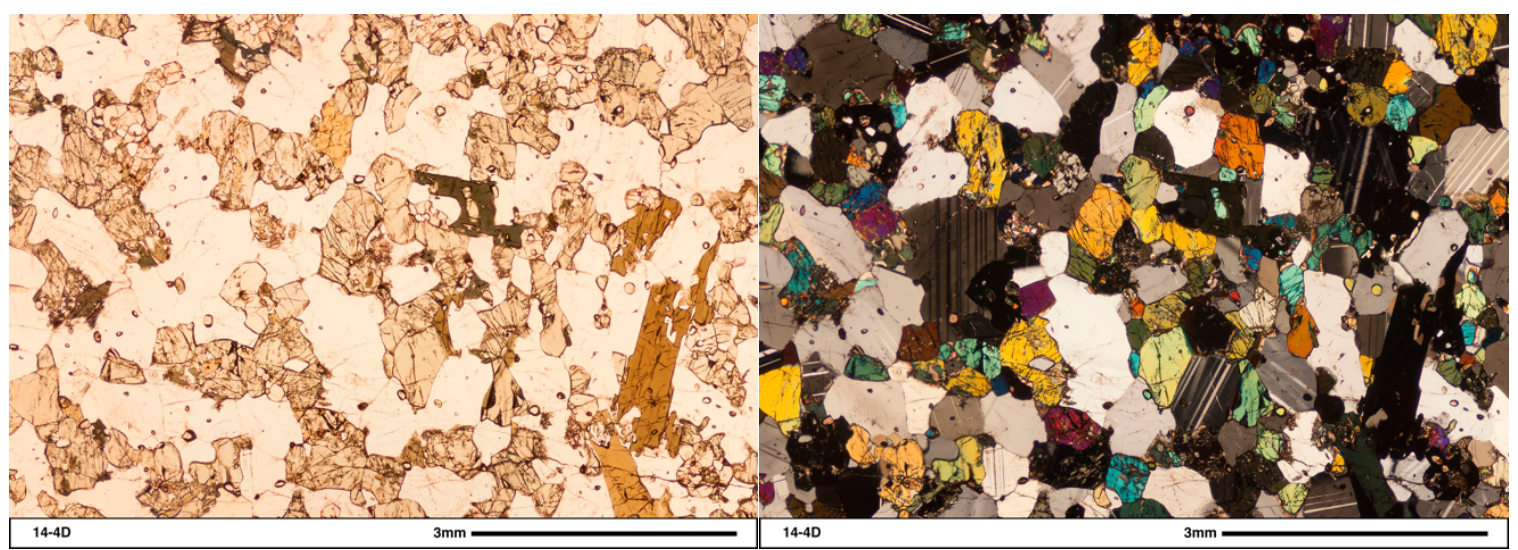

Figure 3-5) Photomicrographs of sample 14-4D under plane polarized light (A) and cross-polarized light

(B). The sample is largely free of retrogression textures, but minor alteration occurs near relict amphiboles.

This sample displays the progressive dehydration of amphibole that occurs at deeper depths within the KSZ. Most amphiboles have transformed to pyroxene, but relicts of amphibole remain on the right side of the image, and in trace quantities surrounding some cpx grains. Additional phases are plagioclase, quartz, titanite, and apatite.

Sample 14-15B is the intersection of the Shawmere Anorthosite and an amphibolite xenolith. For a 1" round prepared for microprobe analysis, the anorthosite side of the slide is similar to sample 14-12, but contains additional rounded, occasionally wormy-textured quartz, whereas the xenolith is composed of largely angular calcic amphibole, in addition to wormy quartz and as well as small, rounded plagioclase residing along junctions of larger amphibole grains.

Lower grade metamorphic rocks display more diverse textures and mineralogy. Samples from the Michipicoten and Swayze greenstone belts are mostly very finegrained or highly brecciated. Along with plagioclase and quartz, calcite, chlorite, and muscovite are present in variable amounts in samples 16-03, 16-04, and 16-16, along with epidote and amphibole in 16-14, siderite, pyrrhotite, and dolomite in the banded iron 
formation (BIF) 16-15, clinopyroxene in sample 16-17, and patchy, brecciated microcline in sample 16-18. The latter sample is highly brecciated overall, with large, angular fragments of untwined plagioclase as well as quartz with strong undulose extinction. The latter are typically surrounded by lightly deformed, smaller grains of plagioclase, quartz and microcline, and random fine-grained muscovite, calcite, and chlorite. Similarly, sample 16-39 has a strong contrast in grain size between rounded plagioclase and quartz grains, and fine-grained muscovite, biotite and chlorite. All of these rocks have fairly continuous fabrics of quartz and/or plagioclase with variable amounts of phyllosilicates and occasional patchy clumps of large grains, often composed of carbonate minerals or quartz.

Most samples have no apparent strong preferred orientation, apart from samples UP-3A, and 16-39 (Fig. 3-6), which were deliberately cut in orientations intended to maximize the effects of preferred orientation on disk $D$. Anisotropy effects are discussed in more detail in Chapters 4 and 5.

\subsubsection{Density and Porosity}

Full results for density and porosity are shown in table 3-2. In general, density results are typical for crustal rocks, and fall in the range $\left(\sim 2.6-4.1 \mathrm{gcm}^{-3}\right)$ for all three methods described in section 3. Variations between different cores or disks of the same sample were typically $<2 \%$, with a few samples showing much higher variability (e.g. sample 14-10 varied by 5\% between core 3 and core 1). Densities measured with all three 


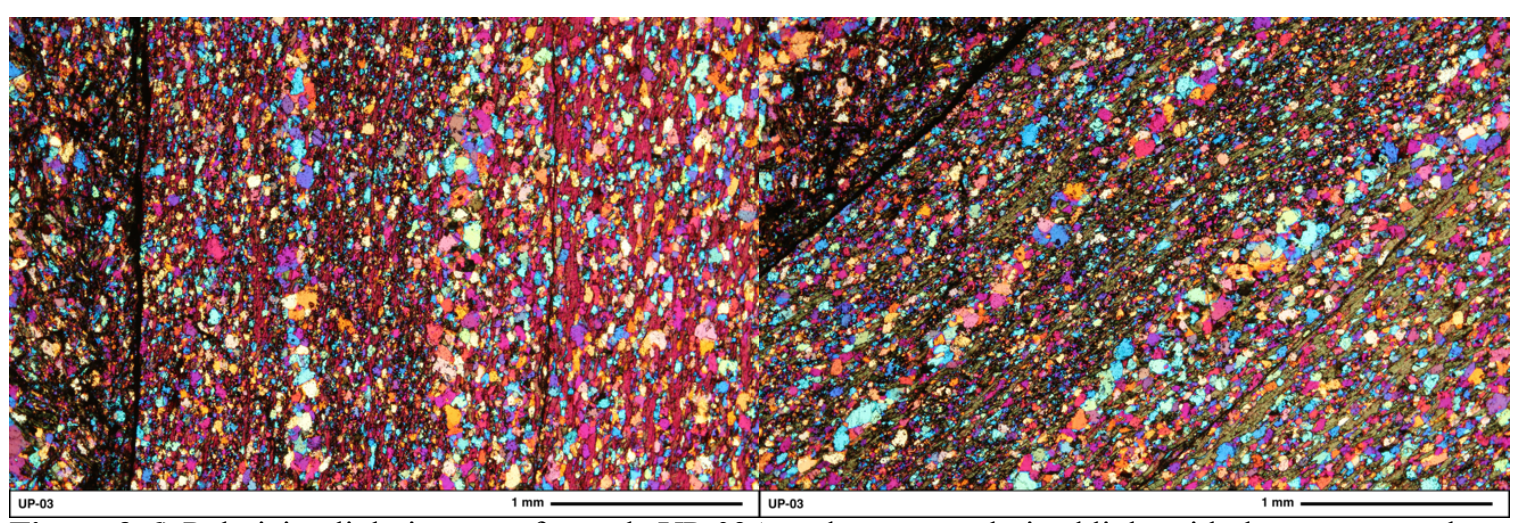

Figure 3-6) Polarizing light images of sample UP-03A under cross-polarized light with the accessory plate

$(+530 \mathrm{~nm}$ wavelength) inserted. Although coarser-grained plagioclase and quartz (typically light blue, violet, orange or yellow) appears to have a random crystallographic orientation, biotite is distributed throughout that has a strong crystallographic preferred orientation. When the sample is oriented with the long-axis of biotite perpendicular to the orientation of the upper polarizer (A), biotite appears deep magenta throughout the section, but when the stage is rotated $45^{\circ}(\mathrm{B})$, biotite has olive-green interference colors.

methods largely agreed to within $2 \%$. As expected, powder skeletal densities measured by pycnometry were the highest densities measured for most samples. The Archimedean method produced robust, and reproducible results with a high degree of confidence for individual disks, while the geometric and powder methods did not due, to small sample size.

Porosity of most crystalline samples was calculated as less than $1 \%$, which is close to the combined uncertainties in our density measurement methods. We could not estimate porosity in BIF sample 16-15 due to strong sample layering and the high density contrast between low density calcite $\left(\rho=2.71 \mathrm{~g} \mathrm{~cm}^{-3}\right)$ and quartz $\left(\rho=2.65 \mathrm{~g} \mathrm{~cm}^{-3}\right)$, and high density pyrrhotite $\left(\rho=4.65 \mathrm{~g} \mathrm{~cm}^{-3}\right)$, which resulted in core geometric measurements $\left(\rho=2.61 \mathrm{~g} \mathrm{~cm}^{-3}\right)$ that were quite different from bulk powder pycnometer measurements 
$\left(\rho=3.72 \mathrm{~g} \mathrm{~cm}^{-3}\right)$. Higher porosity was previously reported for the sedimentary

carbonates $(\sim 0.01-0.14$, Merriman et al. 2018$)$, and the quartzites $(\sim 0.05-0.19$, Branlund and Hofmeister, 2008), consistent with previous observations on porosity in sedimentary rocks, where porosity tends to be high and vary strongly (e.g. Clauser and Huenges, 1995; Carson et al., 2005; Fuchs et al., 2013; Fuchs et al. 2015).

\subsubsection{Grain-size}

Detailed image analysis was carried out on several samples using multiple image analysis methods to compare and contrast grain-size results. Images of sample 14-4D, which in hand sample appeared to have a high contrast in grain size, included an SEM image of a disk (s1c1d1), and PLM images captured from the 1" round used for microprobe analysis. These analyses involved full evaluation of the entire image with the exclusion of grains touching the border of the images. Mean grain size (by area) was $0.046 \mathrm{~mm}^{2}$ and $0.049 \mathrm{~mm}^{2}$ for the SEM image and the 1 " round respectively. Mean grain size of individual major phases was analyzed separately with similar results. The SEM image produced mean areas of $0.046( \pm 0.048) \mathrm{mm}^{2}$ for quartz, $0.064( \pm 0.095) \mathrm{mm}^{2}$ for plagioclase, and $0.014( \pm 0.018) \mathrm{mm}^{2}$ for biotite. The PLM image had mean grain sizes that were smaller than one standard deviation for each phase: $0.035( \pm 0.059) \mathrm{mm}^{2}$ for quartz, $0.159( \pm 0.198)$ for plagioclase, $0.025( \pm 0.041)$ for hornblende, and $0.043( \pm 0.081)$ for garnet, indicating a large number of small grains, and a few much larger crystals.

Similarly, grain size was analyzed for sample 16-36 using SEM disk images (c1d1) and polarizing light images, but additional measurements were taken on a binocular microscope image lit from underneath. Using ImageSXM, mean grain size 
TABLE 3-2. DISK CHARACTERISTICS

\begin{tabular}{|c|c|c|c|c|c|c|c|c|c|c|c|}
\hline Sample & Disk & $\begin{array}{c}\text { Mean D } \\
\text { (ambient } \\
\text { temperature) } \\
\left(\mathrm{mm}^{2} \mathrm{~s}^{-1}\right) \\
\end{array}$ & $\begin{array}{c}\text { Maximum } \\
\text { LFA } \\
\text { Temperature } \\
\text { (K) } \\
\end{array}$ & $\begin{array}{c}\text { Thickness } \\
\text { (mm) }\end{array}$ & $\begin{array}{c}\text { Core } \\
\text { Geometric } \\
\text { Density } \\
\left(\mathrm{g} \mathrm{cm}^{-3}\right) \\
\end{array}$ & $\begin{array}{c}\text { Core } \\
\text { Archimedean } \\
\text { Density } \\
\left(\mathrm{g} \mathrm{cm}^{-3}\right) \\
\end{array}$ & $\begin{array}{c}\text { Disk } \\
\text { Archemedian } \\
\text { Density } \\
\left(\mathrm{g} \mathrm{cm}^{-3}\right) \\
\end{array}$ & $\begin{array}{c}\text { Core } \\
\text { Pycnometric } \\
\text { Density } \\
\left(\mathrm{g} \mathrm{cm}^{-3}\right) \\
\end{array}$ & $\begin{array}{c}\text { Powder } \\
\text { Pycnometric } \\
\text { Density } \\
\left(\mathrm{g} \mathrm{cm}^{-3}\right) \\
\end{array}$ & $\begin{array}{c}\text { Calculated } \\
\text { Skeletal } \\
\text { Density } \\
\left(\mathrm{g} \mathrm{cm}^{-3}\right) \\
\end{array}$ & Pore fraction \\
\hline \multicolumn{12}{|l|}{ Acasta } \\
\hline & Run \#1 & 1.613 & 777.4 & 1.12 & - & 2.859 & 2.852 & $3.17^{\circ}$ & - & 2.7251 & $<0.01-0.1$ \\
\hline & Run \#3 & 1.664 & 706.4 & 0.965 & - & 2.59 & 2.8699 & - & - & 2.7607 & 0.04 \\
\hline \multicolumn{12}{|l|}{ AW04c } \\
\hline & Run \#1 & 1.361 & 802.9 & - & - & 2.899 & 2.6746 & - & - & 2.911 & $<0.01$ \\
\hline \multicolumn{12}{|l|}{ IF07x } \\
\hline & Run \#1 & 1.251 & 1273.8 & 1.36 & - & 2.884 & 3.1307 & $2.96^{\circ}$ & - & 3.285 & $0.03-0.12$ \\
\hline & Run \#2 & 1.329 & 298.9 & 0.983 & - & 2.884 & 2.901 & - & - & 2.932 & 0.01 \\
\hline \multicolumn{12}{|l|}{ KBO8C } \\
\hline & Run \#1 & 1.998 & 736.4 & 1.221 & - & 2.700 & 2.7056 & $2.83^{\circ}$ & - & 2.737 & 0.01 \\
\hline \multicolumn{12}{|l|}{$\underline{\text { KB09 }}$} \\
\hline & a1 - Run \#1 & 1.49 & 704.7 & 0.905 & - & 3.039 & 3.0072 & - & - & 2.953 & $<0.01$ \\
\hline & c1 - Run \#1 & 1.241 & 1249.2 & 1.21 & - & 3.047 & - & $3.10^{\circ}$ & - & 2.972 & $<0.01-0.01$ \\
\hline \multicolumn{12}{|l|}{ KB10ab } \\
\hline & Run \#1 & 1.068 & 1273.4 & 1.137 & - & 3.228 & - & $3.16^{\circ}$ & - & 2.907 & $<0.01$ \\
\hline & Run \#2 & 1.239 & 300.0 & 1.051 & - & 3.228 & 3.2461 & $3.16^{\circ}$ & - & 2.85 & $<0.01$ \\
\hline \multicolumn{12}{|l|}{$\underline{\text { KB11ab }}$} \\
\hline & Run \#2 & 1.206 & 874.2 & 1.121 & - & 2.919 & - & $2.85^{\circ}$ & - & 2.912 & $<0.01$ \\
\hline \multicolumn{12}{|l|}{ KB12ab } \\
\hline & Run \#1 & 2.847 & 854.3 & 0.787 & - & 2.711 & - & - & - & 2.7172 & $<0.01$ \\
\hline & $\mathrm{d} 4$ & 1.967 & 297.5 & 1.984 & - & 2.728 & 2.709 & - & 2.741 & 2.679 & $<0.01$ \\
\hline & $\mathrm{c} 2 \mathrm{~d} 1$ & 1.166 & 296.7 & 1.633 & - & 2.728 & 2.767 & - & 2.741 & 2.751 & $<0.01$ \\
\hline & c1d1 & 0.917 & 301.4 & 1.579 & - & 2.728 & 2.784 & - & 2.741 & 2.749 & $<0.01$ \\
\hline & OM1a & 2.212 & 296.1 & 2.687 & 2.703 & 2.728 & 2.720 & - & 2.741 & 2.702 & $<0.01$ \\
\hline & OM3a & 1.348 & 296.4 & 2.086 & 2.787 & 2.728 & 2.757 & - & 2.741 & 2.730 & $<0.01$ \\
\hline \multicolumn{12}{|l|}{$\underline{\text { KB14x }}$} \\
\hline & Run\#1 & 1.107 & 704.1 & 1.159 & - & 3.093 & - & $3.10^{\circ}$ & - & 2.79 & $<0.01$ \\
\hline \multicolumn{12}{|l|}{ AW15x } \\
\hline & Run \#1 & 0.822 & 1098.9 & 1.195 & - & 2.723 & - & $2.72^{\circ}$ & - & 2.704 & $<0.01$ \\
\hline & Run \#2 & 0.904 & 704.7 & 1.215 & - & 2.723 & 2.736 & $2.72^{\circ}$ & - & 2.75 & $<0.01$ \\
\hline \multicolumn{12}{|l|}{ AW16ab } \\
\hline & Run \#1 & 3.629 & 706.4 & 1.03 & - & 4.067 & 4.0541 & - & - & 3.349 & $<0.01$ \\
\hline \multicolumn{12}{|l|}{ AW20 } \\
\hline & Run 1 & 1.417 & 1471.9 & 1.0905 & - & 3.021 & - & $3.00^{\circ}$ & - & 2.830 & $<0.01$ \\
\hline & Run \#3 & 1.039 & 824.2 & 0.67 & - & 3.021 & 3.0333 & - & - & 2.843 & $<0.01$ \\
\hline \multicolumn{12}{|l|}{ AW21 } \\
\hline & Run \#1 & 0.957 & 705.4 & 1.052 & - & 2.743 & 2.6006 & - & - & 2.737 & $<0.01$ \\
\hline ED22 & & & & & & & & & & & \\
\hline
\end{tabular}


TABLE 3-2. DISK CHARACTERISTICS

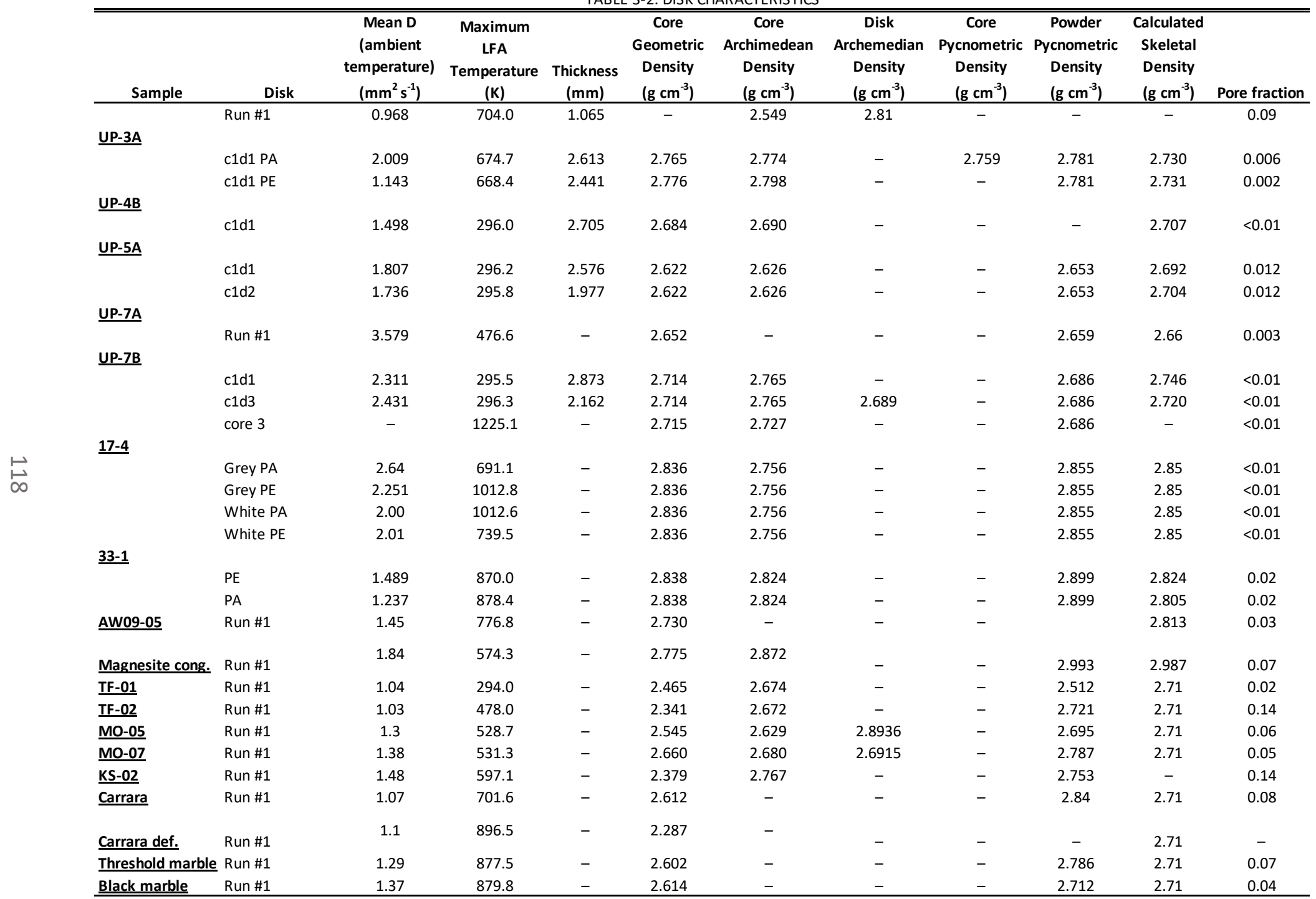


TABLE 3-2. DISK CHARACTERISTICS

\begin{tabular}{|c|c|c|c|c|c|c|c|c|c|c|c|}
\hline Sample & Disk & $\begin{array}{c}\text { Mean D } \\
\text { (ambient } \\
\text { temperature) } \\
\left(\mathrm{mm}^{2} \mathrm{~s}^{-1}\right)\end{array}$ & $\begin{array}{c}\text { Maximum } \\
\text { LFA } \\
\text { Temperature } \\
\text { (K) } \\
\end{array}$ & $\begin{array}{l}\text { Thickness } \\
(\mathrm{mm})\end{array}$ & $\begin{array}{c}\text { Core } \\
\text { Geometric } \\
\text { Density } \\
\left(\mathrm{g} \mathrm{cm}^{-3}\right)\end{array}$ & $\begin{array}{c}\text { Core } \\
\text { Archimedean } \\
\text { Density } \\
\left(\mathrm{g} \mathrm{cm}^{-3}\right)\end{array}$ & $\begin{array}{c}\text { Disk } \\
\text { Archemedian } \\
\text { Density } \\
\left(\mathrm{g} \mathrm{cm}^{-3}\right)\end{array}$ & $\begin{array}{c}\text { Core } \\
\text { Pycnometric } \\
\text { Density } \\
\left(\mathrm{g} \mathrm{cm}^{-3}\right)\end{array}$ & $\begin{array}{c}\text { Powder } \\
\text { Pycnometric } \\
\text { Density } \\
\left(\mathrm{g} \mathrm{cm}^{-3}\right)\end{array}$ & $\begin{array}{c}\text { Calculated } \\
\text { Skeletal } \\
\text { Density } \\
\left(\mathrm{g} \mathrm{cm}^{-3}\right) \\
\end{array}$ & Pore fraction \\
\hline \multirow[t]{7}{*}{ 14-4D } & Mean of 9 cores & & & & 2.711 & 2.739 & & & & & \\
\hline & s1c2d1 & 1.165 & 297.6 & 1.229 & 2.6510 & 2.6747 & 2.6818 & - & 2.8292 & 2.7143 & $0.02-0.06$ \\
\hline & s1c3d1 & 1.524 & 715.9 & 2.059 & 2.6410 & 2.6676 & 2.6951 & - & 2.8239 & 2.7139 & $0.02-0.06$ \\
\hline & $\mathrm{s} 2 \mathrm{c} 1 \mathrm{~d} 1$ & 1.184 & 300.6 & 1.284 & 2.6520 & 2.6836 & 2.7884 & 2.686 & 2.8161 & 2.7404 & $0.03-0.06$ \\
\hline & $\mathrm{s} 2 \mathrm{c} 3 \mathrm{~d} 1$ & 1.319 & 297.4 & 1.131 & 2.8460 & 2.8676 & - & - & 2.8292 & & $<0.01$ \\
\hline & s1c1d1 & 1.028 & 296.5 & 1.207 & 2.6430 & 2.6766 & 2.6944 & - & 2.8292 & 2.7129 & $0.03-0.06$ \\
\hline & $\mathrm{s} 2 \mathrm{c} 2 \mathrm{~d} 1$ & 0.861 & 296.9 & 1.243 & 2.7090 & 2.7405 & 2.9981 & - & 2.8292 & 2.8335 & 0.04 \\
\hline \multirow[t]{7}{*}{$\underline{14-5 B}$} & mean of 6 cores & & & & 2.843 & 2.839 & 2.859 & 2.837 & 2.842 & 2.752 & $<0.01$ \\
\hline & c2Ad1 & 1.189 & 296.1 & 1.255 & 2.788 & 2.7836 & 2.812 & 2.804 & 2.8425 & 2.7649 & 0.020 \\
\hline & c2Bd1 & 1.277 & 296.2 & 1.201 & 2.821 & 2.8148 & - & - & 2.8425 & 2.7446 & $<0.01$ \\
\hline & $\mathrm{c} 2 \mathrm{Bd} 2$ & 1.312 & 296.5 & 1.316 & 2.821 & 2.8148 & 2.814 & - & 2.8425 & 2.7466 & $<0.01$ \\
\hline & c5d2 & 1.105 & 296.5 & 1.172 & 2.897 & 2.8968 & 2.906 & - & 2.8425 & 2.7731 & $<0.01$ \\
\hline & $\mathrm{c} 5 \mathrm{~d} 1$ & 1.162 & 296.5 & 1.217 & 2.897 & 2.8968 & 2.906 & - & 2.8425 & 2.7325 & $<0.01$ \\
\hline & c1d1 & 1.206 & 716.9 & 2.281 & 2.835 & 2.8297 & - & 2.871 & 2.8425 & - & $<0.01$ \\
\hline \multirow[t]{5}{*}{$\underline{14-10}$} & Mean of 5 cores & & & & 3.189 & 3.2010 & & 3.246 & 3.2520 & & 0.02 \\
\hline & s1c1d1 & 1.188 & 296.4 & 1.018 & 3.259 & 3.30 & 3.29 & - & 3.2369 & 3.105 & $<0.01$ \\
\hline & $\mathrm{s} 1 \mathrm{c} 3 \mathrm{~d} 2$ & 1.110 & 295.9 & 1.311 & 3.125 & 3.13 & 2.61 & - & 3.2369 & 3.003 & 0.03 \\
\hline & s1c4d1 & 1.190 & 296.0 & 1.252 & 3.183 & 3.18 & 3.42 & - & 3.2369 & 3.119 & 0.02 \\
\hline & s1c1d2 & 1.153 & 296.3 & 1.225 & 3.259 & 3.30 & 3.31 & - & 3.2369 & 3.093 & $<0.01$ \\
\hline \multicolumn{12}{|l|}{$\underline{14-12}$} \\
\hline & $\mathrm{c} 4 \mathrm{~d} 1$ & 0.947 & 297.0 & 2.424 & 2.7878 & 2.78 & - & - & 2.811 & 2.82 & $<0.01$ \\
\hline \multicolumn{12}{|l|}{ 14-14 } \\
\hline & Run \#1 & 0.715 & 368.2 & - & 2.796 & 2.811 & - & - & - & 2.743 & $<0.01$ \\
\hline \multicolumn{12}{|l|}{ 14-15B } \\
\hline & Run \#1 & - & & - & - & - & - & - & 3.112 & - & - \\
\hline \multicolumn{12}{|l|}{$\underline{16-03}$} \\
\hline & d1 & 1.852 & 679.6 & 1.311 & 2.748 & 2.752 & 2.766 & 2.769 & 2.770 & 2.709 & 0.01 \\
\hline \multirow[t]{3}{*}{$\underline{16-04}$} & (Core 2) & & & & & & & 2.711 & & & \\
\hline & c1d1 & 2.112 & 295.0 & 0.990 & 2.680 & 2.697 & 2.719 & - & 2.717 & 2.70 & 0.01 \\
\hline & $\mathrm{c} 1 \mathrm{~d} 2$ & 2.037 & 297.5 & 1.024 & 2.680 & 2.697 & 2.728 & - & 2.717 & 2.72 & 0.01 \\
\hline JM16-ON-007 & Run \#1 & 0.968 & & - & - & - & - & - & - & - & - \\
\hline$\underline{\mathrm{JM16}-\mathrm{ON}-010}$ & Run \#1 & 1.001 & & - & - & - & - & - & - & - & - \\
\hline JM16-ON-012 & Run \#1 & 1.277 & & - & - & - & - & - & - & - & - \\
\hline$\underline{\mathrm{JM} 16-\mathrm{ON}-013}$ & Run \#1 & 1.810 & & - & - & - & - & - & - & - & - \\
\hline$\underline{16-14}$ & $\mathrm{~d} 1$ & 1.413 & 663.3 & 1.202 & 2.793 & 2.817 & 2.828 & 2.837 & 2.855 & 2.766 & 0.02 \\
\hline \multirow[t]{4}{*}{$\underline{16-15}$} & (core 4) & & & & & & & 3.719 & & & \\
\hline & c1d1 & 1.153 & 295.3 & 1.341 & 2.61 & 2.63 & 4.135 & - & 3.718 & 4.26 & 0.30 \\
\hline & c1d2 & 0.893 & 295.5 & 1.172 & 2.61 & 2.63 & 4.061 & - & 3.718 & 3.72 & 0.30 \\
\hline & c1d3 & 1.110 & 297.2 & 1.139 & 2.61 & 2.63 & 4.118 & - & 3.718 & 3.66 & 0.30 \\
\hline
\end{tabular}


TABLE 3-2. DISK CHARACTERISTICS

\begin{tabular}{|c|c|c|c|c|c|c|c|c|c|c|c|}
\hline Sample & Disk & $\begin{array}{c}\text { Mean D } \\
\text { (ambient } \\
\text { temperature) } \\
\left(\mathrm{mm}^{2} \mathrm{~s}^{-1}\right)\end{array}$ & $\begin{array}{l}\text { Maximum } \\
\text { LFA } \\
\text { Temperature } \\
\text { (K) } \\
\end{array}$ & $\begin{array}{c}\text { Thickness } \\
\text { (mm) }\end{array}$ & $\begin{array}{c}\text { Core } \\
\text { Geometric } \\
\text { Density } \\
\left(\mathrm{g} \mathrm{cm}^{-3}\right)\end{array}$ & $\begin{array}{c}\text { Core } \\
\text { Archimedean } \\
\text { Density } \\
\left(\mathrm{g} \mathrm{cm}^{-3}\right) \\
\end{array}$ & $\begin{array}{c}\text { Disk } \\
\text { Archemedian } \\
\text { Density } \\
\left(\mathrm{g} \mathrm{cm}^{-3}\right)\end{array}$ & $\begin{array}{c}\text { Core } \\
\text { Pycnometric } \\
\text { Density } \\
\left(\mathrm{g} \mathrm{cm}^{-3}\right) \\
\end{array}$ & $\begin{array}{c}\text { Powder } \\
\text { Pycnometric } \\
\text { Density } \\
\left(\mathrm{g} \mathrm{cm}^{-3}\right)\end{array}$ & $\begin{array}{c}\text { Calculated } \\
\text { Skeletal } \\
\text { Density } \\
\left(\mathrm{g} \mathrm{cm}^{-3}\right)\end{array}$ & Pore fraction \\
\hline \multicolumn{12}{|c|}{ ( } \\
\hline & d1 & 1.875 & 663.4 & 1.218 & 2.756 & 2.755 & 2.743 & 2.766 & 2.783 & 2.711 & 0.01 \\
\hline \multicolumn{12}{|l|}{$\underline{16-17}$} \\
\hline & $\mathrm{d} 1$ & 2.000 & 663.1 & 1.465 & 2.693 & 2.721 & 2.724 & 2.723 & 2.721 & 2.734 & 0.01 \\
\hline \multicolumn{12}{|l|}{$\underline{16-18}$} \\
\hline \multirow{8}{*}{$\underline{16-28}$} & c1d1 & 1.699 & 296.2 & 1.446 & 2.6260 & 2.6418 & 2.6407 & - & 2.65 & 2.72 & 0.01 \\
\hline & mean of 7 cores & & & & 2.595 & 2.618 & & 2.636 & 2.62625 & & 0.01 \\
\hline & $\mathrm{c} 1 \mathrm{~d} 0$ & 1.367 & 300.0 & 1.183 & 2.5923 & 2.6033 & 2.633 & - & 2.62625 & 2.716 & 0.01 \\
\hline & $\mathrm{c} 1 \mathrm{~d} 1$ & 1.587 & 297.7 & 1.327 & 2.5923 & 2.6033 & 2.6223 & - & 2.62625 & 2.737 & 0.01 \\
\hline & $\mathrm{c} 2 \mathrm{~d} 1$ & 1.310 & 774.9 & 1.679 & 2.6111 & 2.6108 & - & - & 2.62625 & 2.7340 & $<0.01$ \\
\hline & $\mathrm{c} 4 \mathrm{~d} 2$ & 1.653 & 295.9 & 1.279 & 2.5855 & 2.5991 & 2.6173 & - & 2.62625 & 2.727 & 0.02 \\
\hline & $c 8 d 1$ & 1.184 & 296.7 & 1.223 & 2.6064 & 2.6447 & 2.6432 & - & 2.62625 & 2.714 & $<0.01$ \\
\hline & $\mathrm{c} 13 \mathrm{~d} 1$ & 1.492 & 296.3 & 1.361 & 2.5693 & 2.6195 & 2.6215 & - & 2.62625 & 2.724 & 0.02 \\
\hline \multirow[t]{7}{*}{$\underline{16-36}$} & (core 4) & & & & 2.6190 & 2.6560 & & 2.684 & & & \\
\hline & $\mathrm{c} 1 \mathrm{~d} 1$ & 1.284 & 295.6 & 1.608 & 2.627 & 2.6479 & - & 2.663 & 2.661 & 2.7189 & 0.01 \\
\hline & $\mathrm{c} 1 \mathrm{~d} 2$ & 1.207 & 295.2 & 1.44 & 2.627 & 2.6479 & - & 2.663 & 2.661 & 2.7194 & 0.01 \\
\hline & $\mathrm{c} 1 \mathrm{~d} 3$ & 1.385 & 296.1 & 1.393 & 2.627 & 2.6479 & - & 2.663 & 2.661 & 2.7300 & 0.01 \\
\hline & $\mathrm{c} 2 \mathrm{~d} 1$ & 1.09 & 295.8 & 1.281 & 2.631 & 2.6491 & - & - & 2.661 & 2.737 & 0.01 \\
\hline & $\mathrm{c} 2 \mathrm{~d} 2$ & 1.085 & 365.9 & 1.252 & 2.631 & 2.6491 & - & - & 2.661 & 2.7328 & 0.01 \\
\hline & $\mathrm{c} 3 \mathrm{~d} 1$ & 1.179 & 713.2 & 1.769 & - & - & - & - & & 2.716 & - \\
\hline \multicolumn{12}{|l|}{$\underline{16-39}$} \\
\hline & $\mathrm{c} 1 \mathrm{~d} 1$ & 2.251 & 365.8 & 1.437 & 2.710 & 2.752 & 2.754 & 2.764 & 2.762 & 2.702 & 0.02 \\
\hline & $\mathrm{c} 2 \mathrm{~d} 1$ & 1.292 & 295.6 & 1.320 & 2.740 & 2.761 & 2.770 & 2.783 & 2.762 & 2.708 & $<0.01$ \\
\hline & $\mathrm{c} 2 \mathrm{~d} 2$ & 1.266 & 365.7 & 1.368 & 2.740 & 2.761 & 2.756 & 2.783 & 2.762 & 2.705 & $<0.01$ \\
\hline \multicolumn{12}{|l|}{$\underline{16-44}$} \\
\hline & c1d1 PA & 2.172 & 681.7 & 2.471 & 3.8380 & 3.9040 & 3.93 & 3.921 & 3.788 & 3.030 & $<0.01$ \\
\hline & C1d1 PE & 2.031 & 365.9 & 2.410 & 3.7420 & 3.7895 & - & 3.812 & 3.788 & 2.996 & 0.01 \\
\hline
\end{tabular}

Notes: disk abbreviations indicate relative proximity, $s=$ slice, $c=$ core, $d=$ disk, thus $c 1 d 1$ and $c 1 d 2$ indicate adjacent slices from the same core.

$\mathrm{PA}$ - parallel to layering, PE - perpendicular to layering

cong. - conglomerate,

- indicates core measurement was taken on a shorter than usual core, and thus has lower confidence results

Pore fraction numbers are based on highest-confidence skeletal density measurements

Calculated skeletal density is based on XRD results, which were not optimized for trace- and accessory-phase measurements, which can strongly-effect density. 
(disk c1d1, PLM image) was $0.171( \pm 1.285) \mathrm{mm}^{2}$, and using ImageSXM 0.488( \pm 1.16$)$

$\mathrm{mm}^{2}$. Additionally, grain size was analyzed using a rapid Photoshop method (see methods), resulting in a mean of $0.479( \pm 0.593) \mathrm{mm}^{2}$ for the PLM image.

Because similar analysis for images of samples KB12, 14-10, and UP-5A did not produce strong contrasts between methods, grain-sizes shown in table 3-1 were, in most cases, analyzed using the rapid Photoshop method. As a whole, the suite produced grain sizes ranging from $\sim 0.09( \pm 0.21) \mu \mathrm{m}^{2}$ (greenstone $\left.16-04\right)$ to $1.89( \pm 4.19) \mathrm{mm}^{2}$ (anorthosite
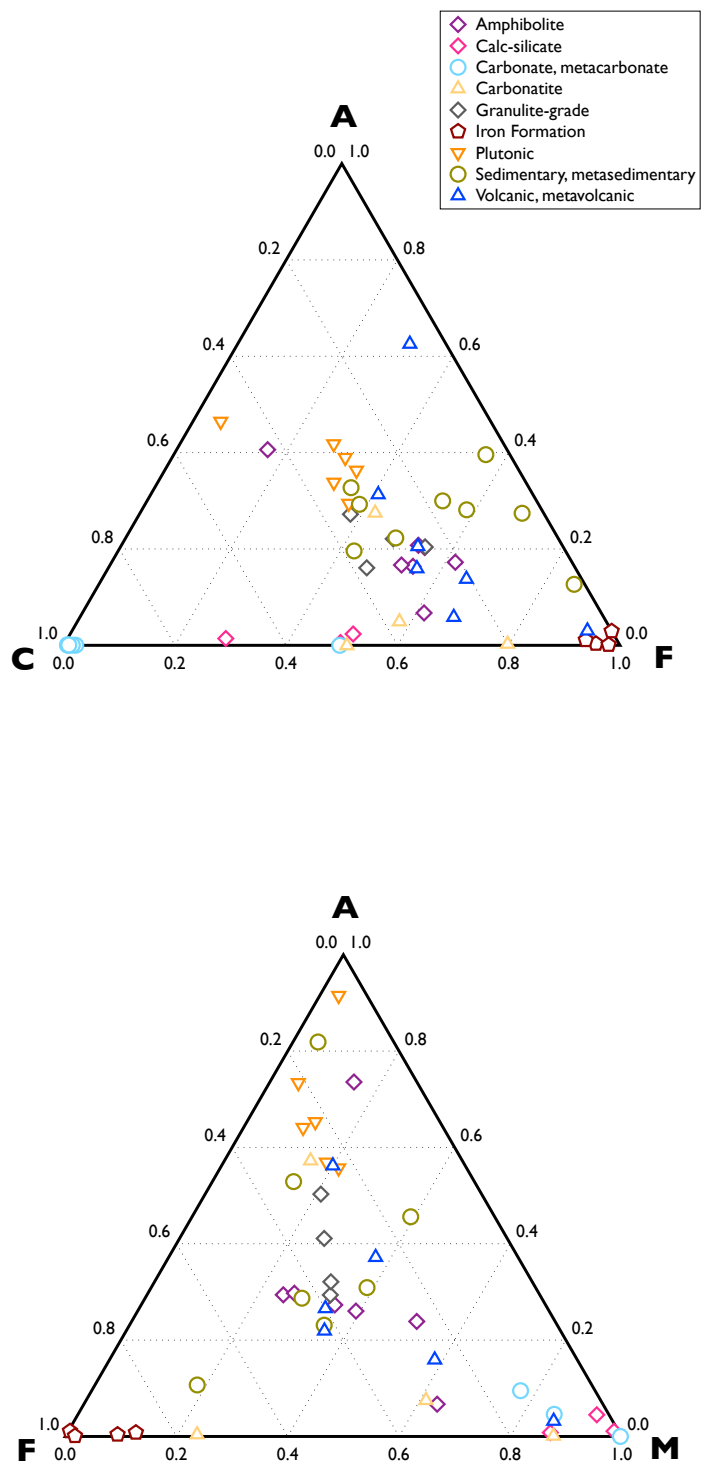

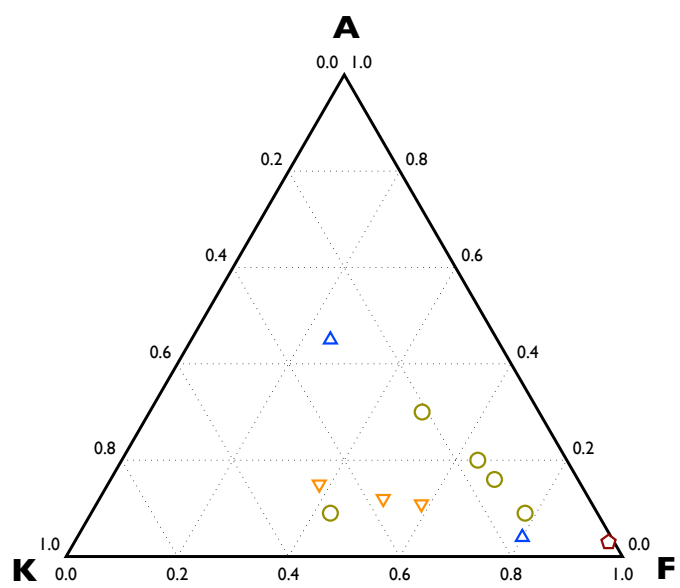

Figure 3-7) Ternary ACF (A), AKM (B), and AFM (C) diagrams generated from bulk chemical analysis of samples (see methods). For ACF and AKF diagrams, all Fe was assumed to be FeO. Samples roughly divided by suites, with symbols and designations the same for all three panels. (A) A $=\mathrm{Al}_{2} \mathrm{O}_{3}-\left[\mathrm{Na}_{2} \mathrm{O}+\mathrm{K}_{2} \mathrm{O}\right], \mathrm{C}=\mathrm{CaO}, \mathrm{F}=\mathrm{FeO}+\mathrm{MgO}+\mathrm{MnO}$; (B) $\mathrm{A}=\mathrm{Al}_{2} \mathrm{O}_{3}-\left[\mathrm{CaO}+\mathrm{Na}_{2} \mathrm{O}+\mathrm{K}_{2} \mathrm{O}\right], \mathrm{K}=\mathrm{K}_{2} \mathrm{O}, \mathrm{F}=\mathrm{FeO}+$ $\mathrm{MgO}+\mathrm{MnO}$. Few samples are shown on this figure because $\mathrm{Al}_{2} \mathrm{O}_{3}$ contents were insufficient to form aluminosilicate minerals in most of the Kapuskasing Structural Zone and Wawa Gneiss Belt. (C) $\mathrm{A}=\mathrm{Al}_{2} \mathrm{O}_{3}-3 * \mathrm{~K}_{2} \mathrm{O}, \mathrm{F}=\mathrm{FeO}, \mathrm{M}=$ $\mathrm{MgO}$. 
14-14). However, most samples had standard deviations higher than the mean, and in general, deeply-sourced rocks, dominated by nominally anhydrous minerals, are coarsergrained than shallow-sourced rocks with abundant hydrous phyllosilicate minerals. Most samples had higher standard deviations than the mean, resulting from bimodal distributions containing a few large crystals.

\subsubsection{Bulk-Rock Composition}

Bulk-rock compositions of major oxides can be found in table 3-3 and trace element compositions in appendix 1. Figure 3-7 shows ACF, AKF, and AFM plots of the suite. Samples span the breadth of typical $\mathrm{SiO}_{2}$ contents found in common continental crust, but $\mathrm{K}_{2} \mathrm{O}$ values are generally low, a result typical of Archean continental crust (see table 4.2, Rollinson, 2007). Because felsic rocks are the dominant rock group in continental crust, these samples are well-represented, but pelitic and calc-silicate rocks are also common in the suite.

\subsubsection{Electron Microprobe Results}

Representative microprobe analytical results can be found in appendix 1. Crucially, plagioclase compositions span nearly the full series from $\mathrm{An}_{0.5}$ (samples AW04 and 16-16), to highly calcic (An95 sample 14-10), with a wide distribution of samples in between. Alkali feldspars typically contained $\sim 1-5 \% \mathrm{Na}$, with $\mathrm{Ca}$ rare, or undetectable. Amphiboles, however, were typically highly calcic, as were clinopyroxenes, and garnets.

\subsubsection{SEM and EDS images}

Examples of SEM results are shown in figure 3-3. For each disk, selection of EDS results for individual elements highlights minerals within the disk. For example, in figure 3-3B, brighter yellow $(\mathrm{Mg})$ typically coincides with biotite, brighter green $(\mathrm{Al})$ with 
TABLE 3-3. MAJOR-ELEMENT CHEMICAL ANALYSIS OF ROCK SAMPLES

\begin{tabular}{|c|c|c|c|c|c|c|c|c|c|c|c|c|c|c|}
\hline Sample & $\begin{array}{l}\text { Analysis Date } \\
\text { (Month/Day/Year) }\end{array}$ & $\mathrm{SiO}_{2}$ & $\mathrm{Al}_{2} \mathrm{O}_{3}$ & $\begin{array}{c}\mathrm{Fe}_{2} \mathrm{O}_{3} \\
(\text { Total Fe) }\end{array}$ & $\mathrm{MnO}$ & $\mathrm{MgO}$ & $\mathrm{CaO}$ & $\mathrm{Na}_{2} \mathrm{O}$ & $\mathrm{K}_{2} \mathrm{O}$ & $\mathrm{TiO}_{2}$ & $\mathrm{P}_{2} \mathrm{O}_{5}$ & LOI & Total & Notes \\
\hline $\begin{array}{l}\text { Detection Limit } \\
\text { (wt \%) }\end{array}$ & & 0.01 & 0.01 & 0.01 & 0.001 & 0.01 & 0.01 & 0.01 & 0.01 & 0.01 & 0.01 & 0.01 & & \\
\hline Acasta & $10 / 20 / 10$ & 60.86 & 13.82 & 9.70 & 0.149 & 2.60 & 5.06 & 2.88 & 1.82 & 1.01 & 0.19 & 1.36 & 99.49 & \\
\hline AW04 & $10 / 20 / 10$ & 51.48 & 8.69 & 10.13 & 0.152 & 11.65 & 9.46 & 2.90 & 0.20 & 0.56 & 0.04 & 3.70 & 98.94 & \\
\hline TF07 & $10 / 20 / 10$ & 40.20 & 3.50 & 8.79 & 0.119 & 36.21 & 2.68 & 0.07 & 0.03 & 0.16 & 0.02 & 8.39 & 100.2 & \\
\hline KB08 & $10 / 20 / 10$ & 75.18 & 12.31 & 3.07 & 0.041 & 0.85 & 3.73 & 3.32 & 0.28 & 0.24 & 0.04 & $\mathrm{n} / \mathrm{a}$ & 99.06 & \\
\hline KB09 & $10 / 20 / 10$ & 49.58 & 14.93 & 12.72 & 0.189 & 7.25 & 10.32 & 2.15 & 0.85 & 1.10 & 0.10 & $\mathrm{n} / \mathrm{a}$ & 99.19 & \\
\hline KB10 & $10 / 20 / 10$ & 46.62 & 14.48 & 13.69 & 0.297 & 6.05 & 14.82 & 1.64 & 0.26 & 0.67 & 0.06 & 1.29 & 99.87 & \\
\hline KB11 & $10 / 20 / 10$ & 57.82 & 15.26 & 9.88 & 0.128 & 4.37 & 6.26 & 3.04 & 1.26 & 0.86 & 0.24 & 0.62 & 99.75 & \\
\hline KB12 & $10 / 20 / 10$ & 68.70 & 14.32 & 4.22 & 0.057 & 1.60 & 5.01 & 3.66 & 0.58 & 0.44 & 0.10 & 0.72 & 99.42 & \\
\hline KB13 & $10 / 20 / 10$ & 47.39 & 17.94 & 14.18 & 0.546 & 4.29 & 8.28 & 2.72 & 1.75 & 1.02 & 0.27 & 0.73 & 99.10 & \\
\hline KB14 & $10 / 20 / 10$ & 46.26 & 9.91 & 10.91 & 0.203 & 11.73 & 13.56 & 1.73 & 2.09 & 0.88 & 0.79 & 1.95 & 100.00 & \\
\hline AW15 & $1 / 12 / 15$ & 56.57 & 21.50 & 4.89 & 0.071 & 2.08 & 4.54 & 6.30 & 2.08 & 0.61 & 0.15 & 0.78 & 99.57 & \\
\hline AW16 & $10 / 20 / 10$ & 25.55 & 3.46 & 62.85 & 0.034 & 0.09 & 0.12 & 0.10 & 0.80 & 0.20 & 0.08 & 1.88 & 95.16 & $\mathrm{Ba}-31840 \mathrm{ppm}$ \\
\hline AW20 & $\mathrm{n} / \mathrm{a}$ & 49.20 & 14.53 & 14.06 & 0.200 & 5.95 & 9.58 & 2.50 & 0.80 & 1.99 & 0.13 & 0.45 & 100.50 & \\
\hline AW21 & $10 / 20 / 10$ & 70.19 & 15.28 & 1.82 & 0.020 & 0.85 & 2.51 & 3.91 & 2.97 & 0.31 & 0.10 & 1.52 & 99.48 & \\
\hline ED22 & $10 / 20 / 10$ & 45.26 & 15.21 & 12.62 & 0.210 & 5.35 & 6.41 & 4.03 & 2.12 & 3.50 & 0.91 & 4.22 & 99.84 & \\
\hline JM14-UP-03A & $1 / 12 / 15$ & 64.22 & 12.20 & 12.48 & 0.018 & 1.63 & 0.30 & 3.62 & 3.02 & 0.69 & 0.04 & 1.37 & 99.61 & \\
\hline JM14-UP-04B & $1 / 12 / 15$ & 47.46 & 23.67 & 6.08 & 0.082 & 7.98 & 12.90 & 1.38 & 0.07 & 0.08 & - & 0.86 & 100.60 & \\
\hline JM14-UP-05A & $1 / 12 / 15$ & 71.77 & 13.16 & 2.99 & 0.019 & 0.59 & 0.81 & 2.85 & 5.45 & 0.27 & 0.10 & 0.72 & 98.74 & \\
\hline JM14-UP-07A & $1 / 12 / 15$ & 97.51 & 1.27 & 1.17 & 0.021 & 0.08 & 0.08 & 0.09 & 0.40 & 0.03 & 0.02 & 0.05 & 100.70 & \\
\hline JM14-UP-07B & $1 / 12 / 15$ & 82.27 & 0.69 & 0.94 & 0.142 & 3.31 & 4.96 & 0.02 & 0.19 & 0.02 & 0.01 & 7.53 & 100.10 & $2.1 \mathrm{wt} \% \mathrm{C}$ \\
\hline $17-4$ & $1 / 12 / 15$ & 0.67 & 0.02 & 0.07 & 0.014 & 21.50 & 30.45 & 0.01 & - & - & 0.02 & 46.21 & 98.97 & $12.4 \mathrm{wt} \% \mathrm{C}$ \\
\hline $33-1$ & $1 / 12 / 15$ & 15.14 & 0.67 & 0.39 & 0.027 & 22.87 & 32.47 & - & - & 0.04 & 0.03 & 28.56 & 100.20 & $7.71 \mathrm{wt} \% \mathrm{C}$ \\
\hline AW-09-05 & $10 / 27 / 16$ & 4.63 & 1.58 & 0.54 & 0.017 & 11.41 & 40.17 & 0.03 & 0.06 & 0.06 & 0.03 & 39.99 & 98.51 & $11.0 \mathrm{wt} \% \mathrm{C}$ \\
\hline TF-01 & $8 / 9 / 15$ & 2.72 & 0.09 & 0.74 & 0.055 & 0.44 & 53.38 & 0.02 & 0.03 & - & 0.08 & 41.66 & 99.22 & \\
\hline TF-02 & $8 / 9 / 15$ & 3.01 & 0.22 & 0.37 & 0.045 & 0.38 & 52.73 & 0.05 & 0.10 & 0.01 & 0.13 & 41.17 & 98.20 & \\
\hline MO-05 & $1 / 12 / 15$ & 0.41 & 0.08 & 0.19 & 0.039 & 0.17 & 55.75 & 0.01 & 0.03 & - & 0.02 & 42.41 & 99.10 & $11.7 \mathrm{wt} \% \mathrm{C}$ \\
\hline MO-07 & $8 / 9 / 15$ & 0.49 & 0.16 & 0.05 & 0.009 & 0.22 & 55.28 & 0.01 & 0.04 & 0.01 & - & 43.42 & 99.70 & $\mathrm{C}$ not measured \\
\hline KS-02 & $8 / 9 / 15$ & 14.19 & 1.50 & 0.54 & 0.024 & 17.85 & 25.52 & 0.03 & 1.02 & 0.05 & 0.03 & 39.28 & 100.00 & C not measured \\
\hline Black Marble & $1 / 12 / 15$ & 1.30 & 0.09 & 0.10 & 0.017 & 0.29 & 54.56 & 0.02 & - & 0.01 & 0.04 & 43.22 & 99.64 & $11.7 \mathrm{wt} \% \mathrm{C}$ \\
\hline JM14-ON-004D & $1 / 12 / 15$ & 63.95 & 15.16 & 5.86 & 0.095 & 2.13 & 6.65 & 3.11 & 0.66 & 0.52 & 0.06 & 0.50 & 98.68 & \\
\hline JM14-ON-005B & $1 / 12 / 15$ & 59.22 & 16.25 & 8.41 & 0.106 & 3.35 & 6.75 & 3.90 & 0.88 & 0.82 & 0.14 & 0.71 & 100.50 & \\
\hline JM14-ON-010 & $1 / 12 / 15$ & 43.57 & 17.29 & 13.22 & 0.328 & 13.77 & 9.75 & 1.44 & 0.33 & 0.05 & - & 0.88 & 100.60 & \\
\hline JM14-ON-012 & $1 / 12 / 15$ & 46.56 & 28.93 & 3.43 & 0.040 & 2.31 & 14.91 & 1.97 & 0.16 & 0.17 & 0.03 & 0.45 & 98.96 & \\
\hline JM14-ON-014 & $1 / 12 / 15$ & 47.72 & 31.23 & 0.87 & 0.008 & 0.28 & 16.15 & 2.39 & 0.04 & 0.04 & - & 0.69 & 99.39 & \\
\hline JM14-ON-015B & $1 / 12 / 15$ & 47.52 & 14.74 & 15.04 & 0.171 & 6.97 & 12.15 & 1.61 & 0.27 & 1.05 & 0.08 & 0.78 & 100.40 & \\
\hline JM16-ON-003 & $10 / 27 / 15$ & 51.08 & 15.14 & 7.71 & 0.120 & 4.98 & 7.64 & 1.86 & 1.57 & 0.74 & 0.13 & 8.33 & 99.29 & \\
\hline JM16-ON-004 & $10 / 27 / 15$ & 76.69 & 12.60 & 1.93 & 0.032 & 0.41 & 0.41 & 0.65 & 4.03 & 0.18 & - & 2.12 & 99.06 & \\
\hline JM16-ON-007 & $10 / 27 / 15$ & 8.69 & 4.79 & 14.11 & 0.434 & 13.87 & 20.90 & 0.04 & 0.15 & 2.95 & 1.46 & 29.28 & 96.69 & \\
\hline JM16-ON-011 & $10 / 27 / 15$ & 1.02 & 0.28 & 45.42 & 0.815 & 7.08 & 12.27 & 0.01 & - & 0.01 & 1.21 & 18.58 & 86.70 & $4.92 \mathrm{wt} \% \mathrm{C}$ \\
\hline JM16-ON-012 & $10 / 27 / 15$ & 0.06 & 0.04 & 5.20 & 0.657 & 18.94 & 29.75 & 0.05 & - & 0.02 & 0.24 & 43.45 & 98.41 & $12.4 \mathrm{wt} \% \mathrm{C}$ \\
\hline JM16-ON-013 & $10 / 27 / 15$ & 69.11 & 13.91 & 4.75 & 0.070 & 1.36 & 4.36 & 4.42 & 0.36 & 0.11 & 0.44 & 1.56 & 100.40 & $0.08 w t \%$ C \\
\hline JM16-ON-014 & $10 / 27 / 15$ & 51.80 & 16.48 & 8.53 & 0.186 & 6.27 & 7.33 & 3.58 & 0.19 & 0.82 & 0.06 & 4.17 & 99.40 & \\
\hline JM16-ON-015 & $10 / 27 / 15$ & 14.36 & 0.42 & 56.53 & 1.517 & 2.90 & 1.97 & 0.05 & 0.04 & 0.02 & 0.01 & 21.89 & 99.71 & \\
\hline JM16-ON-015x & $10 / 27 / 15$ & 33.29 & 0.96 & 39.14 & 1.429 & 2.79 & 1.96 & 0.06 & 0.15 & 0.05 & 0.01 & 20.45 & 100.30 & \\
\hline JM16-ON-016 & $10 / 27 / 15$ & 55.98 & 17.42 & 7.82 & 0.116 & 3.30 & 3.39 & 1.83 & 3.67 & 0.89 & 0.12 & 5.80 & 100.30 & \\
\hline JM16-ON-017 & $7 / 12 / 16$ & 73.96 & 13.13 & 3.64 & 0.037 & 1.20 & 0.38 & 2.63 & 3.09 & 0.35 & 0.04 & 1.41 & 99.87 & \\
\hline JM16-ON-018 & $7 / 12 / 16$ & 78.16 & 11.14 & 1.31 & 0.030 & 0.22 & 1.12 & 5.91 & 0.34 & 0.04 & - & 0.84 & 99.10 & \\
\hline JM16-ON-028 & $7 / 12 / 16$ & 73.43 & 14.47 & 1.40 & 0.013 & 0.17 & 1.36 & 5.05 & 2.57 & 0.04 & - & 0.68 & 99.16 & \\
\hline JM16-ON-036 & $7 / 12 / 16$ & 72.05 & 15.38 & 2.52 & 0.026 & 0.54 & 2.22 & 4.93 & 2.22 & 0.23 & 0.05 & 0.22 & 100.40 & \\
\hline JM16-ON-039 & $7 / 12 / 16$ & 65.85 & 13.95 & 4.84 & 0.123 & 1.10 & 4.70 & 2.54 & 1.20 & 0.58 & 0.11 & 5.50 & 100.50 & \\
\hline JM16-ON-044 & $7 / 12 / 16$ & 34.44 & 0.24 & 64.96 & 0.036 & 0.56 & 1.14 & 0.06 & 0.04 & - & 0.15 & -0.99 & 100.70 & \\
\hline \multicolumn{15}{|c|}{ Notes: LOI indicates loss on ignition } \\
\hline \multicolumn{15}{|c|}{ - indicates oxide below detection limit for method } \\
\hline \multicolumn{15}{|c|}{ See supplimentary tables TS-CHEMREPROD for standards and same-session } \\
\hline \multicolumn{15}{|c|}{ Detection limit for $\mathrm{C}$ is $0.01 \mathrm{wt} \%$ (method is CS???) } \\
\hline \multicolumn{15}{|c|}{$\mathrm{n} / \mathrm{a}$ indicates not available } \\
\hline \multicolumn{15}{|c|}{ - indicates below detection limit } \\
\hline 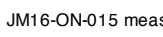 & 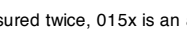 & & & & & & & & & & & & & \\
\hline
\end{tabular}


plagioclase, and brighter blue $(\mathrm{K})$ with microcline. With the Si channel turned off, black coincides with quartz. In the backscatter image (Fig 3-3A), a black circle with a diameter of $0.5 \mathrm{~cm}$ roughly coincides with the center of the disk. Because the LFA detector only measures the selected spot size (typically the center $0.5 \mathrm{~cm}$ diameter), SEM and EDS provided a record of the distribution of the specific phases within LFA disks, which could later be used to correct or evaluate XRD measurements compared to area of the disk analyzed by the LFA.

However, SEM images were only collected on one side of each disk. Binocular microscope images (Fig. 3-3C), provided a record of both sides of each disk, which when combined with EDS (Fig. 3-3D) could be used to further interpret mineral placement within disks. For example, XRD results indicated a total of $2.6 \mathrm{wt} \%$ biotite within disk c8d1, but EDS and binoscope images indicate a large grain of biotite inhabited the center. Binoscope images of five disks of sample 16-28 are shown in figure 3-8. These images serve to highlight the heterogeneity within this sample, as biotite is present in fairly large grains in disks $\mathrm{c} 13 \mathrm{~d} 1$ and $\mathrm{c} 8 \mathrm{~d} 1$, but largely absent from disks $\mathrm{c} 1 \mathrm{~d} 0, \mathrm{c} 1 \mathrm{~d} 1$, and $\mathrm{c} 4 \mathrm{~d} 2$.

\subsubsection{XRD Results}

Table 3-4 shows Rietveld fits of XRD results for all disks measured with XRD. Values for weight percent were converted to volume percent using published values of density for individual minerals (Gaines et al., 1998) combined with microprobe results. Mineral proportions of major phases typically varied by up to $20 \%$ between different disks of the same samples. For example, six disks of sample 16-36 were measured. Disk quartz content varied from 14.7 to $24.2 \%$ (by volume), and disk plagioclase content varied by 59.6 to $75.5 \%$ by volume for the same disks. 


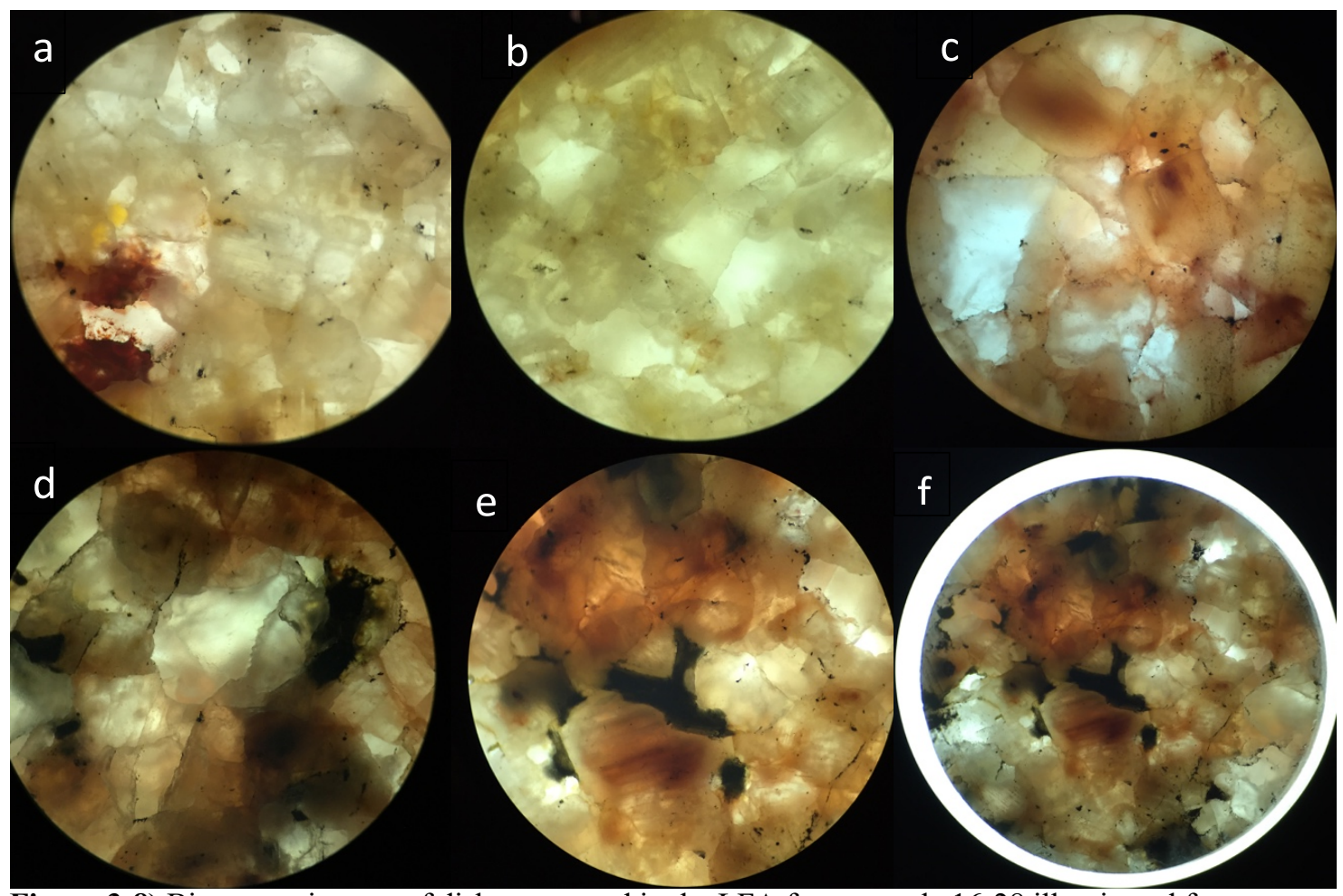

Figure 3-8) Binoscope images of disks measured in the LFA from sample 16-28 illuminated from underneath the disks. Disks are as follows a) c1d0, b) c1d1, c) c4d2, d) c13d1, e) c8d1 f) full view of c8d1. Approximate scale is $\sim 0.5 \mathrm{~cm}$ for a-e and $\sim 1.1 \mathrm{~cm}$ for $\mathrm{f}$. Although $3 \mathrm{D}$ effects can alter textural interpretation of these images, in general, clearer, brighter grains are quartz, tabular grains with cleavage are plagioclase, pink-red tinged grains are microcline, and black grains are biotite. Note that small black flecks are typically a remnant graphite coating from LFA measurement, and not a natural phase.

For the full suite, quartz, plagioclase, and biotite were the most common minerals, with plagioclase making up the largest proportion of disk volume in more than $50 \%$ of the disks measured. Quartz contents varied from 0-100\%, but the majority of samples had quartz contents less than $\sim 40 \%$ by volume, and a large gap exists in the range $\sim 60-90 \%$ quartz. Other major phases within the suite include calcic amphibole (up to 55\%), calcite and dolomite (up to 100\%), hematite (maximum of 49\%), siderite (also up to $49 \%$ ), pyrrhotite $(40 \%)$, magnetite $(39 \%)$, chlorite $(75 \%)$, serpentine $(23 \%)$, olivine $(25 \%)$, 
TABLE 3-4: X-RAY DIFFRACTION RESULTS

\begin{tabular}{|c|c|c|c|c|c|c|c|c|c|c|c|c|c|}
\hline Sample & Cut & Phase 1 & Wt Fraction & Phase 2 & Wt Fraction & Phase 3 & Wt Fraction & Phase 4 & Wt Fraction & Phase 5 & Wt Fraction & Phase 6 & Wt Fraction \\
\hline 14-10 & s1c1d1 & Plagioclase & 0.417 & Calcic Amphibole & 0.391 & Garnet & 0.180 & Chlorite & 0.012 & & & & \\
\hline $14-10$ & s1c1d2 & Plagioclase & 0.435 & Calcic Amphibole & 0.379 & Garnet & 0.175 & Chlorite & 0.011 & & & & \\
\hline $14-10$ & $\mathrm{~s} 1 \mathrm{c} 3 \mathrm{~d} 2$ & Calcic Amphibole & 0.527 & Plagioclase & 0.443 & Chlorite & 0.030 & & & & & & \\
\hline $14-10$ & s1c4d1 & Plagioclase & 0.410 & Calcic Amphibole & 0.291 & Garnet & 0.258 & Chlorite & 0.040 & & & & \\
\hline $14-12$ & c4d1 & Plagioclase & 0.741 & Calcic Amphibole & 0.196 & KSpar & 0.042 & $\mathrm{Cpx}$ & 0.021 & & & & \\
\hline $14-14$ & R\#1 & Plagioclase & 0.921 & Clinozoisite & 0.042 & Amphibole & 0.037 & & & & & & \\
\hline Shawmere & full run & Plagioclase & 0.921 & Calcic Amphibole & 0.037 & Microcline & 0.042 & & & & & & \\
\hline $14-4 \mathrm{D}$ & s1c1 & Plagioclase & 0.634 & Quartz & 0.208 & Biotite & 0.090 & & 0.032 & Microcline & 0.020 & Amphibole & 0.016 \\
\hline $14-4 \mathrm{D}$ & s1c2 & Plagioclase & 0.714 & Quartz & 0.178 & Chlorite & 0.039 & & 0.021 & muscovite & 0.026 & Kspar & 0.022 \\
\hline $14-4 D$ & s1c3 & Plagioclase & 0.602 & Quartz & 0.346 & Biotite & 0.039 & chlorite & 0.011 & apatite & 0.002 & & \\
\hline $14-4 \mathrm{D}$ & $\mathrm{s} 2 \mathrm{c} 1$ & Plagioclase & 0.514 & Quartz & 0.234 & Biotite & 0.097 & & 0.094 & Microcline & 0.038 & CPX & 0.023 \\
\hline $14-4 \mathrm{D}$ & $\mathrm{s} 2 \mathrm{c} 2$ & Plagioclase & 0.505 & Calcic Amphibole & 0.220 & Biotite & 0.095 & Micocline & 0.086 & CPX & 0.054 & Quartz & 0.040 \\
\hline $14-5 B$ & c2Ad1 & Plagioclase & 0.540 & Quartz & 0.214 & Quartz & 0.179 & Biotite & 0.052 & Microcline & 0.010 & Chlorite & 0.006 \\
\hline $14-5 B$ & c2Bd1 & Plagioclase & 0.574 & Quartz & 0.158 & Chlorite & 0.133 & Amphibole & 0.090 & Biotite & 0.035 & Garnet & 0.009 \\
\hline $14-5 B$ & $\mathrm{c} 2 \mathrm{Bd} 2$ & Plagioclase & 0.538 & Quartz & 0.300 & Biotite & 0.107 & Garnet & 0.032 & garnet & 0.018 & Chlorite & 0.006 \\
\hline $14-5 B$ & c5d1 & Plagioclase & 0.636 & Calcic Amphibole & 0.161 & Quartz & 0.131 & Chlorite & 0.069 & Biotite & 0.003 & & \\
\hline $14-5 B$ & $c 5 \mathrm{~d} 2$ & Plagioclase & 0.640 & Calcic Amphibole & 0.159 & Quartz & 0.083 & Chlorite & 0.066 & Biotite & 0.051 & & \\
\hline $16-03$ & c1d1 & Plagioclase & 0.301 & Quartz & 0.262 & Chlorite & 0.239 & Calcite & 0.130 & Muscovite & 0.067 & & \\
\hline $16-04$ & $\mathrm{c} 1 \mathrm{~d} 1$ & Quartz & 0.624 & Plagioclase & 0.196 & Muscovite & 0.180 & & & & & & \\
\hline $16-04$ & $\mathrm{c} 1 \mathrm{~d} 2$ & Quartz & 0.559 & Plagioclase & 0.236 & Muscovite & 0.179 & Pyroxene & 0.025 & & & & \\
\hline $16-13$ & R\#1 & Plagioclase & 0.639 & Quartz & 0.242 & Chlorite & 0.050 & Biotite & 0.048 & Epidote & 0.021 & & \\
\hline $16-14$ & c1d1 & Plagioclase & 0.444 & Chlorite & 0.310 & Quartz & 0.116 & Epidote & 0.068 & Amphibole & 0.062 & & \\
\hline $16-15$ & $\mathrm{c} 1 \mathrm{~d} 2$ & Siderite & 0.432 & Pyrrhotite & 0.392 & quartz & 0.114 & dolomite & 0.034 & ankerite & 0.028 & & \\
\hline $16-15$ & $\mathrm{c} 1 \mathrm{~d} 3$ & Pyrrhotite & 0.414 & Siderite & 0.352 & dolomite & 0.156 & quartz & 0.056 & ankerite & 0.022 & & \\
\hline $16-15$ & c1d1 & Pyrrhotite & 0.494 & Siderite & 0.383 & Quartz & 0.086 & Ankerite & 0.037 & & & & \\
\hline $16-15$ & $\mathrm{c} 1 \mathrm{~d} 2$ & Siderite & 0.450 & Pyrrhotite & 0.378 & Quartz & 0.118 & Dolomite & 0.055 & & & & \\
\hline $16-15$ & $\mathrm{c} 1 \mathrm{~d} 2$ & Siderite & 0.444 & Pyrrhotite & 0.403 & quartz & 0.117 & dolomite & 0.035 & & & & \\
\hline $16-16$ & c1d1 & Plagioclase & 0.325 & Quartz & 0.256 & Chlorite & 0.218 & Calcite & 0.139 & Muscovite & 0.062 & & \\
\hline $16-17$ & $\mathrm{c} 1 \mathrm{~d} 1$ & Quartz & 0.434 & Plagioclase & 0.419 & Muscovite & 0.108 & Pyroxene & 0.039 & & & & \\
\hline $16-18$ & c1d1 & Plagioclase & 0.574 & Quartz & 0.329 & KSpar & 0.050 & Chlorite & 0.025 & Calcite & 0.016 & Muscovite & 0.007 \\
\hline $16-28$ & $\mathrm{c} 1 \mathrm{~d} 1$ & Plagioclase & 0.720 & Quartz & 0.164 & Microcline & 0.055 & Biotite & 0.036 & Muscovite & 0.021 & Titanite & 0.004 \\
\hline $16-28$ & c8d1 & Plagioclase & 0.645 & Quartz & 0.210 & Microcline & 0.069 & Chlorite & 0.042 & Biotite & 0.026 & Muscovite & 0.009 \\
\hline $16-28$ & $\mathrm{c} 13 \mathrm{~d} 1$ & Plagioclase & 0.611 & Quartz & 0.228 & Microcline & 0.095 & Chlorite & 0.059 & Muscovite & 0.007 & & \\
\hline $16-28$ & $\mathrm{c} 2 \mathrm{~d} 1$ & Plagioclase & 0.747 & Quartz & 0.175 & Microcline & 0.055 & Wollastonite & 0.018 & Muscovite & 0.005 & & \\
\hline $16-28$ & $\mathrm{c} 4 \mathrm{~d} 2$ & Plagioclase & 0.659 & Quartz & 0.247 & Microcline & 0.050 & Biotite & 0.027 & Muscovite & 0.016 & & \\
\hline $16-28$ & c1d0 & Plagioclase & 0.603 & Quartz & 0.239 & Microcline & 0.114 & Biotite & 0.044 & & & & \\
\hline $16-36$ & $\mathrm{c} 1 \mathrm{~d} 3$ & Plagioclase & 0.658 & Quartz & 0.237 & Biotite & 0.053 & Microcline & 0.049 & Titanite & 0.003 & & \\
\hline $16-36$ & $\mathrm{c} 2 \mathrm{~d} 1$ & Plagioclase & 0.757 & Quartz & 0.162 & Microcline & 0.050 & Biotite & 0.028 & Titanite & 0.004 & & \\
\hline $16-36$ & c1d1 & Plagioclase & 0.549 & Quartz & 0.256 & Microcline & 0.113 & Biotite & 0.082 & & & & \\
\hline $16-36$ & $\mathrm{c} 1 \mathrm{~d} 1$ & Plagioclase & 0.622 & Quartz & 0.223 & Microcline & 0.110 & Biotite & 0.046 & & & & \\
\hline $16-36$ & $\mathrm{c} 1 \mathrm{~d} 2$ & Plagioclase & 0.619 & Quartz & 0.217 & Microcline & 0.113 & Biotite & 0.052 & & & & \\
\hline $16-36$ & $\mathrm{c} 1 \mathrm{~d} 2$ & Plagioclase & 0.625 & Quartz & 0.218 & Microcline & 0.107 & Biotite & 0.050 & & & & \\
\hline $16-36$ & $\mathrm{c} 2 \mathrm{~d} 2$ & Plagioclase & 0.716 & Quartz & 0.145 & Microcline & 0.080 & Biotite & 0.059 & & & & \\
\hline $16-36$ & c3d1 & Plagioclase & 0.668 & Quartz & 0.172 & Microcline & 0.148 & Biotite & 0.013 & & & & \\
\hline $16-39$ & $\mathrm{c} 1 \mathrm{~d} 1$ & Quartz & 0.370 & Plagioclase & 0.269 & Chlorite & 0.167 & Calcite & 0.106 & Biotite & 0.059 & Muscovite & 0.029 \\
\hline $16-39$ & $\mathrm{c} 2 \mathrm{~d} 1$ & Quartz & 0.351 & Plagioclase & 0.282 & Chlorite & 0.213 & Calcite & 0.060 & Biotite & 0.059 & Muscovite & 0.035 \\
\hline $16-39$ & $\mathrm{c} 2 \mathrm{~d} 2$ & Quartz & 0.401 & Plagioclase & 0.266 & Chlorite & 0.171 & Calcite & 0.072 & Biotite & 0.058 & Muscovite & 0.033 \\
\hline
\end{tabular}




\begin{tabular}{|c|c|c|c|c|c|c|c|c|c|c|c|c|c|}
\hline Sample & Cut & $\begin{array}{l}\text { Phase } 1 \\
\end{array}$ & Wt Fraction & Phase 2 & Wt Fraction & Phase 3 & Wt Fraction & Phase 4 & Wt Fraction & Phase 5 & Wt Fraction & Phase 6 & Wt Fraction \\
\hline $16-44$ & c1d1 PE & Quartz & $\begin{array}{ll}0.571 \\
\end{array}$ & Magnetite & 0.334 & grunerite & $\begin{array}{ll}0.071 \\
\end{array}$ & calcite & $\begin{array}{ll}0.015 \\
\end{array}$ & greenalite & $\begin{array}{ll}0.004 \\
\end{array}$ & nontronite & 0.005 \\
\hline $16-44$ & c1d1 PA & Quartz & 0.606 & Magnetite & 0.394 & & & & & & & & \\
\hline Acasta B & R\#1 & Plagioclase & 0.417 & Quartz & 0.253 & KSpar & 0.148 & Amphibole & 0.096 & Chlorite & 0.074 & Biotite & 0.012 \\
\hline Acasta B & $\mathrm{R} \# 2$ & Plagioclase & 0.515 & Quartz & 0.148 & Biotite & 0.122 & Amphibole & 0.094 & Chlorite & 0.081 & KSpar & 0.040 \\
\hline AW04c2 & R\#1 & Plagioclase & 0.584 & Calcic Amphibole & 0.270 & Chlorite & 0.134 & Calcite & 0.012 & & & & \\
\hline TF07×2 & R\#1 & Olivine & 0.311 & Chlorite & 0.310 & Amphibole & 0.147 & $\mathrm{CPX}$ & 0.232 & & & & \\
\hline TF07×2 & $\mathrm{R} \# 3$ & Amphibole & 0.272 & Olivine & 0.250 & Serpentine & 0.228 & Kaolinite & 0.117 & CPX & 0.105 & Magnetite & 0.029 \\
\hline Aw15x & $\mathrm{R} \# 2$ & Plagioclase & 0.717 & Biotite & 0.131 & Microcline & 0.108 & Zirconalite & 0.028 & Chlorite & 0.017 & & \\
\hline AW15x & R\#1 & Plagioclase & 0.819 & Biotite & 0.157 & Zirconalite & 0.024 & & & & & & \\
\hline AW15x & $\mathrm{R} \# 1$ & Plagioclase & 0.728 & Biotite & 0.153 & Microcline & 0.119 & & & & & & \\
\hline AW20 & $\mathrm{R} \# 1$ & Plagioclase & 0.754 & OPX & 0.118 & CPX & 0.083 & Orthoclase & 0.045 & & & & \\
\hline AW20 & $\mathrm{R} \# 3$ & Plagioclase & 0.639 & CPX & 0.138 & Amphibole & 0.118 & Chlorite & 0.058 & Quartz & 0.027 & Biotite & 0.020 \\
\hline AW21 & R\#1 & Plagioclase & 0.661 & Quartz & 0.126 & Biotite & 0.108 & KSpar & 0.083 & Muscovite & 0.021 & & \\
\hline КВ08c1 & R\#1 & Plagioclase & 0.414 & Quartz & 0.376 & Amphibole & 0.071 & KSpar & 0.010 & & 0.129 & & \\
\hline КВ09а1 & R\#1 & Amphibole & 0.553 & Plagioclase & 0.344 & Quartz & 0.058 & Epidote & 0.044 & & & & \\
\hline КВ09с1 & R\#1 & Plagioclase & 0.625 & Calcic Amphibole & 0.266 & CPX & 0.042 & Epidote & 0.040 & Quartz & 0.027 & & \\
\hline KB10ab & $\mathrm{R} \# 2$ & Plagioclase & 0.729 & Calcic Amphibole & 0.135 & Garnet & 0.091 & Pyroxene & 0.025 & Quartz & 0.020 & & \\
\hline KB11ab & R\#2 & Plagioclase & 0.621 & Calcic Amphibole & 0.207 & Biotite & 0.064 & Quartz & 0.059 & Garnet & 0.049 & & \\
\hline KB12ab & $\mathrm{c} 2 \mathrm{~d} 1$ & Plagioclase & 0.586 & Quartz & 0.176 & CPX & 0.088 & Chlorite & 0.054 & Amphibole & 0.049 & Biotite & 0.047 \\
\hline KB12ab & d4 & Plagioclase & 0.510 & Quartz & 0.376 & Chlorite & 0.053 & Amphibole & 0.048 & CPX & 0.007 & Biotite & 0.006 \\
\hline KB12ab & OM1a & Plagioclase & 0.460 & Quartz & 0.421 & Biotite & 0.039 & Chlorite & 0.032 & Amphibole & 0.025 & $\mathrm{CPX}$ & 0.024 \\
\hline KB12ab & омза & Plagioclase & 0.668 & Quartz & 0.147 & Biotite & 0.071 & Chlorite & 0.050 & Amphibole & 0.041 & Microcline & 0.024 \\
\hline KB12ab & R\#1 & Plagioclase & 0.519 & Quartz & 0.301 & Chlorite & 0.079 & Biotite & 0.045 & Amphibole & 0.030 & CPX & 0.027 \\
\hline KB12ab & c1d1 & Plagioclase & 0.731 & Quartz & 0.108 & Biotite & 0.055 & Chlorite & 0.042 & CPX & 0.034 & Amphibole & 0.031 \\
\hline KB13ab & R\#1 & Plagioclase & 0.539 & Calcic Amphibole & 0.302 & Biotite & 0.070 & Garnet & 0.056 & KSpar & 0.019 & Quartz & 0.014 \\
\hline KB14x & R\#1 & Plagioclase & 0.734 & Biotite & 0.148 & Amphibole & 0.118 & & & & & & \\
\hline AW16ab & R\#1 & Hematite & 0.494 & Quartz & 0.347 & Barite & 0.085 & Muscovite & 0.075 & & & & \\
\hline ED22 & $\mathrm{R \# 1}$ & Plagioclase & 0.645 & Zeolite & 0.105 & Chlorite & 0.088 & KSpar & 0.083 & CPX & 0.043 & serpentine & 0.036 \\
\hline UP-3A & c1d1 PA & Plagioclase & 0.587 & Quartz & 0.246 & Biotite & 0.115 & KSpar & 0.052 & & & & \\
\hline UP-3A & c1d1 PE & Plagioclase & 0.601 & Quartz & 0.231 & Biotite & 0.112 & KSpar & 0.056 & & & & \\
\hline UP-4B & c1d1 & Plagioclase & 0.465 & Quartz & 0.235 & Chlorite & 0.140 & KSpar & 0.104 & Biotite & 0.056 & & \\
\hline UP-5A & c1d1 & Plagioclase & 0.473 & Microcline & 0.220 & Quartz & 0.215 & Chlorite & 0.079 & Biotite & 0.014 & & \\
\hline UP-5A & $\mathrm{c} 1 \mathrm{~d} 2$ & Plagioclase & 0.565 & Quartz & 0.207 & KSpar & 0.164 & Chlorite & 0.058 & Biotite & 0.007 & & \\
\hline UP-7A & R\#1 & Quartz & 0.985 & Muscovite & 0.015 & Barite & & & & & & & \\
\hline 17-4 Grey & parallel & Dolomite & 0.982 & Topaz & 0.014 & Calcite & 0.004 & & & & & & \\
\hline 17-4 White & perpendicula & Dolomite & 0.849 & Calcite & 0.099 & Periclase & 0.027 & Portlandite & 0.005 & & & & \\
\hline 17-4 White & Parallel & Dolomite & 0.803 & Calcite & 0.136 & Periclase & 0.042 & & & & & & \\
\hline 17-4 White & Parallel & Dolomite & 0.800 & Calcite & 0.142 & Periclase & 0.039 & & & & & & \\
\hline $33-1$ & DA - perp & Calcite & 0.546 & Olivine & 0.279 & Chlorite & 0.111 & Dolomite & 0.052 & & & & \\
\hline 33-1 & DA - perp & Calcite & 0.558 & Olivine & 0.235 & Chlorite & 0.144 & Dolomite & 0.051 & & & & \\
\hline 33-1 & DB - par & Calcite & 0.668 & Olivine & 0.150 & Dolomite & 0.123 & Chlorite & 0.030 & & & & \\
\hline 33-1 & DB - par & Calcite & 0.667 & Olivine & 0.176 & Dolomite & 0.105 & Chlorite & 0.023 & & & & \\
\hline $16-07$ & R\#1 & Chlorite & 0.752 & Dolomite & 0.173 & Rutile & 0.018 & Siderite & 0.010 & & & & \\
\hline $16-11$ & R\#1 & Dolomite & 0.626 & Hematite & 0.181 & Chlorite & 0.046 & Barite & 0.038 & Apatite & 0.035 & & \\
\hline $16-12$ & R\#1 & Dolomite & 0.871 & Ankerite & 0.053 & Omphacite & 0.006 & Huntite & 0.005 & & & & \\
\hline UP-7B & $\mathrm{c} 1 \mathrm{~d} 1$ & Quartz & 0.495 & Dolomite & 0.471 & & & & & & & & \\
\hline UP-7B & c1d3 - initial & Quartz & 0.633 & Dolomite & 0.338 & & & & & & & & \\
\hline UP-7B & c1d3-initial & Quartz & 0.723 & Dolomite & 0.248 & & & & & & & & \\
\hline AW-09-05 & R\#1 & Calcite & 0.493 & Dolomite & 0.288 & Chlorite & 0.150 & Amphibole & 0.070 & & & & \\
\hline
\end{tabular}


biotite (15\%), muscovite (18\%), and a sample containing a zeolite (11\%). Multiple compositions of clinopyroxene and garnet (maximum of $23 \%$ and $26 \%$ respectively), minor epidote or clinozoisite (up to $5 \%$ ), barite (8\%), and grunerite (7\%) were also detected. Several anorthosite samples are included that were composed of up to $98 \%$ plagioclase, but the highest amount of potassium feldspar was much lower (22\%).

Additional measurements on powdered samples of the bulk rock were performed for samples 14-5B and KB12, each of which had multiple disks measured in the LFA and using XRD. Bulk-rock quartz for sample 14-5B was $15.0 \mathrm{wt} \%$, compared to individual disk quartz contents ranging from $8.3 \%$ to $30.0 \%$. Plagioclase, by comparison, varied less between bulk rock (51.4\%) and disk extremes (53.8\% to 64.0\%). Similar contrasts were found for accessory phases. High contrasts in quartz content were even more extreme for sample KB12, where bulk-rock quartz was measured as $39.9 \mathrm{wt} \%$, compared to a minimum of $10.8 \%$ and maximum of $42.1 \mathrm{wt} \%$ for individual disks. Plagioclase also varied more strongly, with bulk-rock plagioclase much lower $(37.0 \mathrm{wt} \%)$ than the minimum measured amount in a disk $(46.0 \mathrm{wt} \%)$, and half the maximum amount found $(73.1 \mathrm{wt} \%)$.

\subsubsection{Thermal Diffusivity at Ambient Conditions}

Room-temperature ( 295-300K) D measurements of all samples are listed in table 3-1. At ambient- $T, D$ varied between disks of the same sample by up to a factor of three, with variations between different samples that were even higher. For example, the lowest measured $D\left(0.75 \mathrm{~mm}^{2} \mathrm{~s}^{-1}\right)$ was for the Stillwater anorthosite, whereas the highest measured $D\left(3.63 \mathrm{~mm}^{2} \mathrm{~s}^{-1}\right)$ was of a quartz-rich (49\% by volume) slice of hematitequartz-barite banded iron formation AW16ab (Merriman et al., 2013). Variability 
between disks of $14-4 \mathrm{D}$ was a modest $35 \%\left(0.86-1.32 \mathrm{~mm}^{2} \mathrm{~s}^{-1}\right)$, compared to much higher variability between disks of KB12 of up to $65 \%\left(0.92-2.71 \mathrm{~mm}^{2} \mathrm{~s}^{-1}\right.$, disk c1d1 and Run \#1 from Merriman et al., 2013). The average $D$ of samples with multiple disks ranged from $1.05 \mathrm{~mm}^{2} \mathrm{~s}^{-1}$ (carbonate BIF 14-15) to $2.37 \mathrm{~mm}^{2} \mathrm{~s}^{-1}$ (dolomitic quartzite UP-7B). Typically, results for different disks of the same sample deviated $\sim 5-15 \%$ from the average $D$ of all disks for that sample.

Samples with strong compositional layering (KB12) or strong foliation or lineation of phyllosilicate minerals (UP-3A, 16-39) tended to have higher variability between different disks. Room-temperature results of $D$ for sample UP-3A, for example, were $2.01 \mathrm{~mm}^{2} \mathrm{~s}^{-1}$ for a disk with heat flowing parallel to layering (c1d1 PA) and 1.14 $\mathrm{mm}^{2} \mathrm{~s}^{-1}$ for heat flowing across layering (c1d1 PE). Similarly, sample 16-39 was measured parallel-to (c1d1) and perpendicular-to (c2d1 and $\mathrm{c} 2 \mathrm{~d} 2)$ layering with similar contrasts in ambient $D\left(2.25 \mathrm{~mm}^{2} \mathrm{~s}^{-1}\right.$ parallel, 1.29 and $1.27 \mathrm{~mm}^{2} \mathrm{~s}^{-1}$ perpendicular $)$. However, other samples with foliation and lineation did not produce as high of contrasts between orientations. For example, KB09 is a foliated and lineated amphibolite. Disks were cut both parallel (KB09a1) and perpendicular (KB09c1) to lineation and foliation but had measured ambient $D$ 's of 1.49 and $1.24 \mathrm{~mm}^{2} \mathrm{~s}^{-1}$ (Merriman et al., 2013).

Finally, suites of samples with similar chemical compositions showed marked differences in ambient $\mathrm{D}$, apparently depending on their modal mineralogy. For example, upper-crustal rocks had ambient $D \mathrm{~s}$ ranging from $<1 \mathrm{~mm}^{2} \mathrm{~s}^{-1}$ (carbonates, carbonatites, carbonate BIFs), to $2.5 \mathrm{~mm}^{2} \mathrm{~s}^{-1}$ (or higher) for many micaceous or quartz-rich samples. Mid- to deep-crustal rocks had somewhat lower $D$ overall, and less variability between samples, with the notable exception of sample KB12. For example, most intermediate 
and felsic rocks from the mid crust (16-28, 16-36) and lower crust (14-5B, 14-10, 14-4D) had D's in the range of $1-1.5 \mathrm{~mm}^{2} \mathrm{~s}^{-1}$.

\subsubsection{Thermal Diffusivity at Elevated Temperature}

Fifteen disks were analyzed in the LFA at temperatures higher than $100^{\circ} \mathrm{C}$, with maximum temperatures ranging from $463 \mathrm{~K}$ to $1175 \mathrm{~K}$. These disks include samples of clastic sedimentary and metasedimentary rocks (16-03, 16-17, UP-7A, UP-7B c1d1 and c1d3, UP-3A PA and UP-3A PE), metavolcanic rocks (16-14, 16-16), a banded iron formation (16-44), mid-crustal felsic plutonic rocks (16-28 c2d1, 16-36 c3d1), lowercrustal metamorphic rocks (14-4D s1c3, 14-5B c1d1), and two examples of anorthosite (Shawmere, Stillwater).

Figure 3-9A shows measurements and fits for all 15 samples. Results range from $3.58 \mathrm{~mm}^{2} \mathrm{~s}^{-1}$ to $0.75 \mathrm{~mm}^{2} \mathrm{~s}^{-1}$ at ambient temperature for the quartzite UP-7A and Stillwater anorthosite respectively. As is typical of previous measurements for $D$ using the LFA method (e.g. Whittington et al., 2009; Merriman et al., 2013), D falls rapidly as temperature increases from ambient to $\sim 600 \mathrm{~K}$, with samples with higher ambient $D$ typically having higher $\mathrm{d} D / \mathrm{d} T$ than those with low $D$ at ambient $T$. At $500 \mathrm{~K}$, quartzite UP-7A had a $D$ of $\sim 1.5 \mathrm{~mm}^{2} \mathrm{~s}^{-1}$, a decrease of $58 \%$, whereas the $D$ of Stillwater anorthosite was $\sim 0.58 \mathrm{~mm}^{2} \mathrm{~s}^{-1}$, a decrease of $\sim 25 \%$. For all samples, measured thermal diffusivity was below $1 \mathrm{~mm}^{2} \mathrm{~s}^{-1}$ by $600 \mathrm{~K}$, and at maximum measured temperatures, between the extremes of $0.5 \mathrm{~mm}^{2} \mathrm{~s}^{-1}$ (UP-3A PE, $640 \mathrm{~K}$ ) to $0.75 \mathrm{~mm}^{2} \mathrm{~s}^{-1}$ (UP-3A PA, 640 K). Most samples were not measured above $\sim 800 \mathrm{~K}$ as previous work with the LFA (Merriman et al., 2013) found that samples with quartz and hydrous phases are not stable 

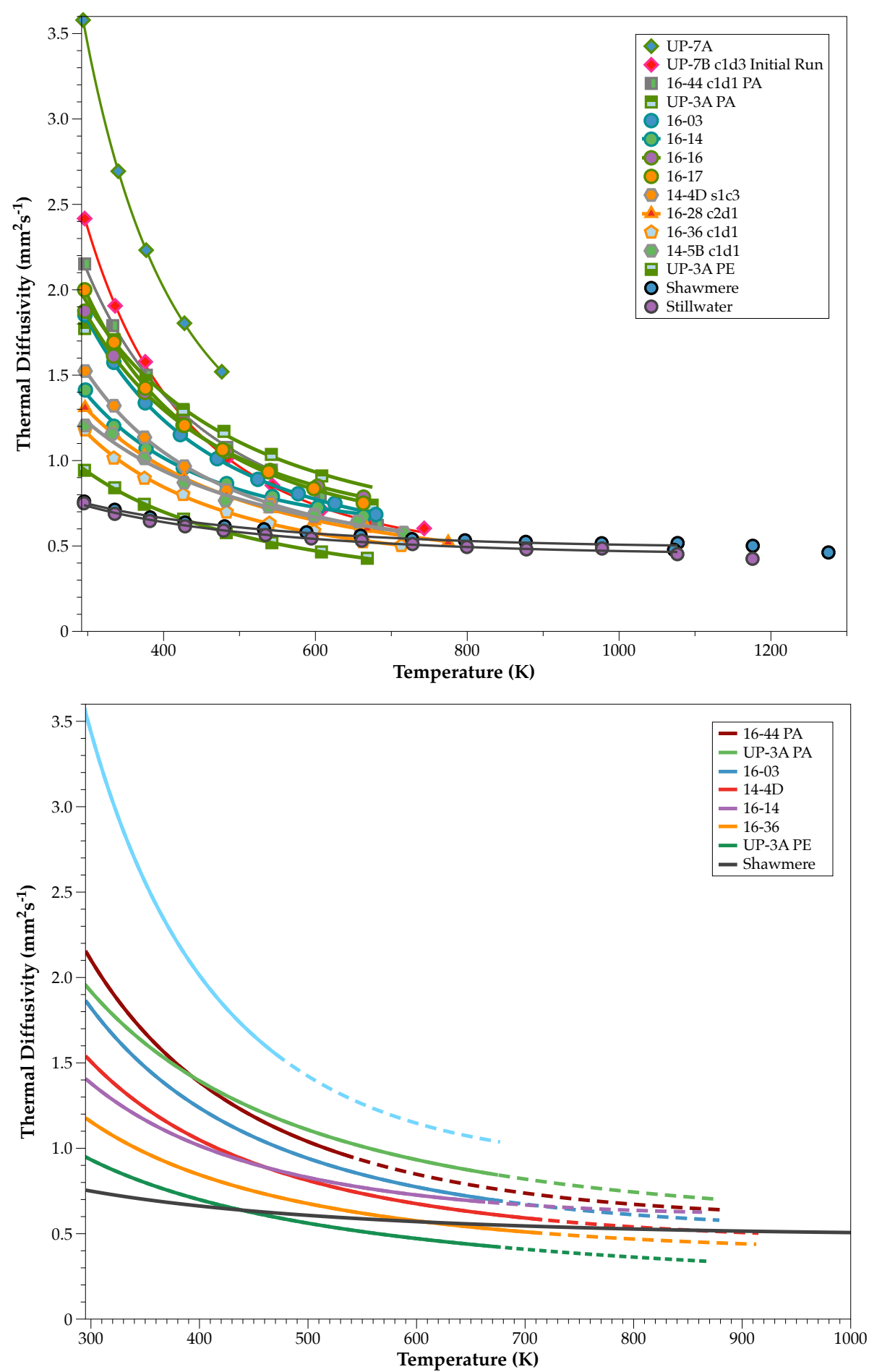

Figure 3-9) (A) High temperature thermal diffusivity results for the 15 samples discussed in section 3.4.9. Line color indicates suites from figure 3-1. Points not connected to fit lines indicate this data was not included in fits. (B) Projected (dashed lines) high-temperature $D$ from fitted measured $D$ (solid lines) for 8 of the 15 samples from A.

Projections use equation 3-4, but are limited to an additional $\sim 200 \mathrm{~K}$ above these temperatures at atmospheric pressure. The notable exceptions are the two anorthosites, which were measured to $1173 \mathrm{~K}$ (Shawmere) and $1275 \mathrm{~K}$ (Stillwater). 
above these temperatures at atmospheric pressure. The notable exceptions are the two anorthosites, which were measured to $1173 \mathrm{~K}$ (Shawmere) and $1275 \mathrm{~K}$ (Stillwater).

All samples showed a decreasing $D$ with increasing temperature. However, although $D$ for Stillwater and Shawmere is much lower than the other samples at ambient- $T$, near maximum measured temperatures for the bulk of high- $T$ samples ( $\sim 700$ $800 \mathrm{~K}), D$ for the two anorthosites was similar to the (generally) quartz-rich upper- and mid-crustal samples, and if trends continue to higher temperatures, $D$ would be higher for anorthosite than for approximately half of the remaining samples (figure 3-9B). Although $\mathrm{d} D / \mathrm{d} T$ is broadly-similar for most samples, several samples displayed atypical trends. These include the BIF (16-44), the metasedimentary quartz-dolomite rock UP-7B, and the previously-mentioned anorthosites. All four of these samples contain either unusual rock-forming phases (e.g. abundant magnetite in 16-44), or lack one of the major phases quartz or plagioclase (anorthosite Shawmere lacks quartz, UP-7B lacks plagioclase).

Equation 3-4 can be used to project $D$ to elevated temperatures, and figure 3-9B shows projections for eight high-temperature samples using observed trends. Projecting sample $D$ to $1000 \mathrm{~K}$ produced a range of $D$ s from $\sim 0.3$ to $1.2 \mathrm{~mm}^{2} \mathrm{~s}^{-1}$ (UP-3A PE and UP7A respectively).

When fitting data to equations, some high-temperature data points were excluded from fits. Two criteria were used to exclude data: either an abrupt increase in $\mathrm{d} D / \mathrm{d} T$ not associated with any known phase change (e.g. UP-3A PA between 600 and $700 \mathrm{~K}$ ), or atypical time-temperature curves produced during LFA measurements. The latter was found for measurements on both anorthosites above $\sim 1100 \mathrm{~K}$, and is reflected in the 
fitting equations. Abnormal LFA signals are thought to be associated with a change in absorption of light generated by the laser in the LFA, and could reflect unknown phase changes, or instability in accessory or trace phases in the case of the anorthosites. The Shawmere anorthosite, for example, has lenses of amphibole along some grain boundaries which are thought to be relicts of the protolith amphibolite (Hartel and Pattison, 1996), as well as minor epidote. No data above identified abnormalities were included in fits.

\subsection{ANALYSIS AND DISCUSSION}

\subsubsection{Comparing high-T results to equations for the $k$ of rock at elevated $T$}

A number of equations have been proposed to calculate the thermal conductivity of a rock at elevated temperature from ambient- $T$ measurements. Although these equations are designed to project $k$ rather than $D$, given the simple model for calculating rock $C_{P}$ and $\rho$, application to calculating $D$ is trivial if the appropriate database is available. To explore the effectiveness of these equations in predicting measured rock $D$, and consequently, $k$, we compared the $k$ resulting from measured $D$ combined with the calculated product of $C_{P}$ and $\rho$ (hereafter referred to as storativity) for six such models from Funnel et al. (1996), hereafter Fun96, Sass et al. (1992), Sa92, Somerton (1992), Som92, Chapman et al. (1984), Ch84, Sekaguchi-Waples (Hantschel and Kauerauf, 2009), SeWa, and Durham et al. (1987), Du87. Previous work by Merriman et al. (2018) suggested none of these models were consistently successful in predicting $k$ for carbonate rocks at elevated temperature from ambient measurements. This analysis includes the 
wider range of rock types presented in the high-temperature results above, as well as previous results from Branlund and Hofmeister (2008), Merriman et al. (2013), Merriman et al. (2018), and Roy et al. (in review). Sample storativity was calculated using modal mineralogy derived from XRD analyses, but quartzite storativity (Branlund and Hofmeister, 2008) was assumed to reflect that of pure quartz.

Results for none of the samples examined are reproduced by all six models, but several samples were reproduced within 5-10\% error using more than three models. For example, sample 16-16 was reproduced within 10\% error using the models of Sa92, Som92, SeWa, and Du87 with errors within the analytical error of the LFA for the models of Sa92 and SeWa. However, the models of Fun96 and Ch84 produced errors in excess of $25 \%$ at $600 \mathrm{~K}$, and $40 \%$ for the Fun92 model at $663 \mathrm{~K}$. At the extreme end, calculations for the Shawmere anorthosite produced errors higher than $10 \%$ for all models except that of Du87 by $700 \mathrm{~K}$, and in some cases, predict negative $k$ above 1000 $\mathrm{K}$ (Sa92). Furthermore, samples with similar mineralogy and similar $\mathrm{d} D / \mathrm{d} T$, but modestly different $D$ at room temperature, often results in good predictions for one sample, and poor reproduction for the other. For example, samples $16-36$ and 16-28 are both primarily plagioclase-quartz mixtures with minor biotite and microcline (Fig. 3-9). Sample 16-36 c3d1 has a room- $k$ of $2.36 \mathrm{Wm}^{-1} \mathrm{~K}^{-1}$, and $k$ of $1.44 \mathrm{Wm}^{-1} \mathrm{~K}^{-1}$ at $713 \mathrm{~K}$, compared to 2.65 $\mathrm{Wm}^{-1} \mathrm{~K}^{-1}$ and $1.64 \mathrm{Wm}^{-1} \mathrm{~K}^{-1}$ (719 K) for sample $16-38 \mathrm{c} 2 \mathrm{~d} 1$. The model of Sa92., however, produced modest error of up to $17 \%$ for $16-28$, but greater than $30 \%$ for sample 16-36. Conversely, the model of Som92 produced excellent results for sample 16-28 (maximum error of $3 \%$ ), but modest error of up to $11 \%$ for sample $16-36$. 
For the 55 samples analyzed, no model produced results within $10 \%$ for a majority of samples, and all models had multiple samples with greater than $50 \%$ error. Furthermore, several models consistently over-estimate $k$ at elevated temperature (Fun92 Sa92., SeWa), and the model of Ch84. consistently under-estimates $k$ at high-T. Of the six models tested, the model of Du97. produces the best results, with 23 samples reproduced with less than $10 \%$ maximum error. However, this model still had 32 samples with greater than $20 \%$ maximum error, and 2 samples with errors in excess of $50 \%$ above 400K.

The ineffectiveness of these models is likely tied to assumption that ambient- $T$ thermal conductivity reflects $\mathrm{d} k / \mathrm{d} T$. However, examination of the $k$ of common rockforming minerals shows that $\mathrm{d} k / \mathrm{d} T$, while somewhat correlated with ambient- $T$ thermal conductivity, is not a systematic reflection of it. Even for samples with similar modal mineralogy, modest variations in $\mathrm{d} k / \mathrm{d} T$ can be produced by varying the proportions of minerals with very different $\mathrm{d} k / \mathrm{d} T$, or even by varying the composition of the same minerals between endmembers with different thermal properties. This cause-effect relationship is explored further below, and in Chapters 4 and 5.

\subsubsection{Heterogeneity within a single sample}

High variability in $D$ between samples, and between different disks of the same sample, correlates primarily with quartz content. Other factors such as feldspar content, and plagioclase composition generate less-striking contrasts between disks because quartz has a higher $D$ than other common phases. As an example, figure 3-10 shows the 
range of ambient $D$ for several disks from the dominantly quartz-plagioclase-microcline sample 16-36, compared to modal quartz content. For this sample, quartz fractions vary from 0.16 to 0.25 , as measured $D$ increases from $1.09 \mathrm{~mm}^{2} \mathrm{~s}^{-1}$ to $1.39 \mathrm{~mm}^{2} \mathrm{~s}^{-1}$. The scatter about this general trend may result from variations in the modal abundances of microcline, plagioclase, and biotite reported by XRD, or a difference in orientations and/or distributions of these minerals between disks, and between the full disk and the center measured by the detector.

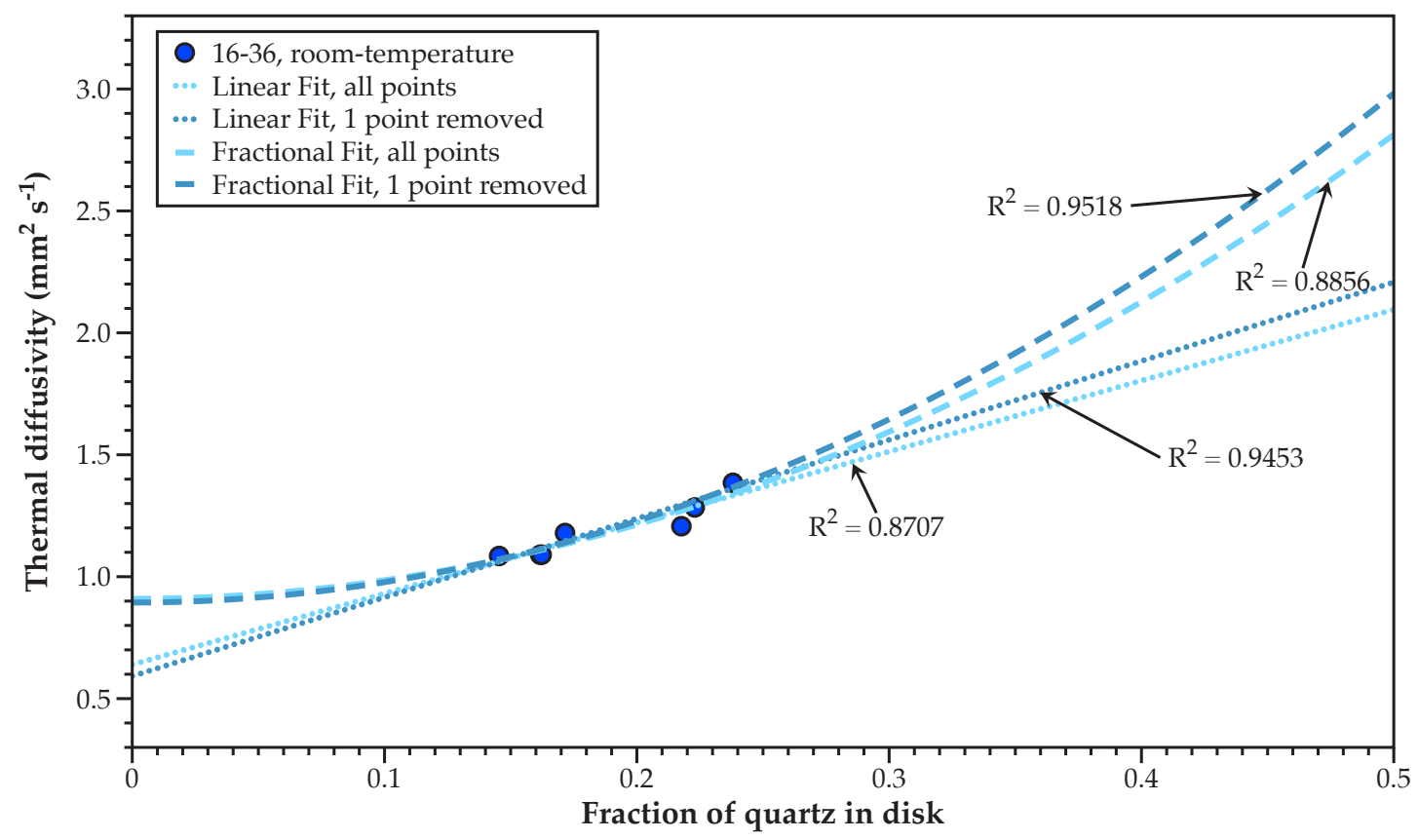

Figure 3-9) Thermal diffusivity results at ambient temperature for 6 disks of sample 16-36 with quartz fraction within the disks as measured by XRD. Thermal diffusivity increases with increasing quartz fraction, resulting in fits to equation 3-6 (Linear Fit) and equation 3-8 (Fractional Fit) which are of high confidence. The point removed for refits was the disk with $\mathrm{X}_{\mathrm{qtz}} \sim=0.21$. Residuals are as follows: Linear fit, all points RMSE $=0.045$; Linear fit, 1 point removed RMSE $=0.033$; Fractional fit, all points RMSE $=$ 0.042; Fractional fit, 1 point removed RMSE $=0.031$. 
In order to quantify the apparent relationship between observed disk quartz content and ambient $D$, fits to several equations are included in the above figure and the following figures in this section. These are:

Linear fit - An equation modeled after the resistors in parallel model (see Chapter 4).

$$
\mathrm{D}_{\text {meas }}=\mathrm{a}+\mathrm{b}^{*} \mathrm{X}_{\mathrm{qtz}}
$$

Equation 3-6.

Exponential fit - An arbitrary equation modeled after the observation that $D_{\text {meas }}$ appears to increase exponentially with quartz:

$$
\mathrm{D}_{\text {meas }}=\mathrm{a}^{*} \exp \left(\mathrm{b}^{*} \mathrm{X}_{\mathrm{qtz}}\right)
$$

Equation 3-7.

Fractional fit - An equation modeled after the resisters in series model (Chapter 4)

$$
\mathrm{D}_{\text {meas }}=\mathrm{a}+\left(\mathrm{X}_{\mathrm{qtz}} / \mathrm{b}\right)^{2}
$$

Equation 3-8.

Geometric fit - An equation modeled after the geometric model (Chapter 4)

$$
D_{\text {meas }}=a+b^{\wedge} X_{q t z}
$$

Equation 3-9. 
Each of the above equations produced fits with low residuals for the six disks of sample 16-36, with the Fractional fit having a marginally-better correlation $\left(\mathrm{R}^{2}=0.952\right)$ than the Geometric fit $\left(\mathrm{R}^{2}=0.949\right)$ and the Linear fit $\left(\mathrm{R}^{2}=0.945\right)$.

Sample 16-28 is also a quartz-plagioclase-microcline mixture but contains higher proportions of potassium feldspar in combination with plagioclase and quartz (3-4). In this case, however, there is no clear correlation between quartz and $D$ across the range $\mathrm{X}_{\mathrm{qtz}}=0.15$ to 0.25 (Fig. 3-10). The lack of correlation for this sample is a result of diskspecific issues that serve to illustrate easily-overlooked controls on $D$ on the scale of an LFA disk: Figure 3-3 shows SEM backscatter and EDS as well as under-illuminated binocular microscope images of one side of disk c8d1 of sample 16-28. XRD analysis produced volumetric abundances of $64 \%$ plagioclase, $21 \%$ quartz, $7 \%$ microcline, $4 \%$ chlorite, and 3\% total biotite and muscovite. However, an overlay of the binocular microscope image on the composite EDS image shows phases in the context of the disk architecture (D). This suggests that in this disk, quartz is concentrated more toward the rim of the disk, rather than the center analyzed by the detector in the LFA. Furthermore, a large biotite grain inhabits the center of the disk (Fig 3-3). Because the spot size we circle in (A), and the detector measures emissions only on the exposed area of the disk on the opposite side, minerals in the center of the disk dominate the reported $D$ for the disk, at the expense of those in the surrounding rim. Thus, the quartz fraction reported by XRD is likely too high for the specific area traversed by the laser pulse. The presence of the large biotite grain in the center (Fig. 3-3) could also strongly lower the disk $D$ because heat flow across cleavage planes in biotite is an order of magnitude lower than heat flow within planes (Hofmeister and Carpenter, 2015). 


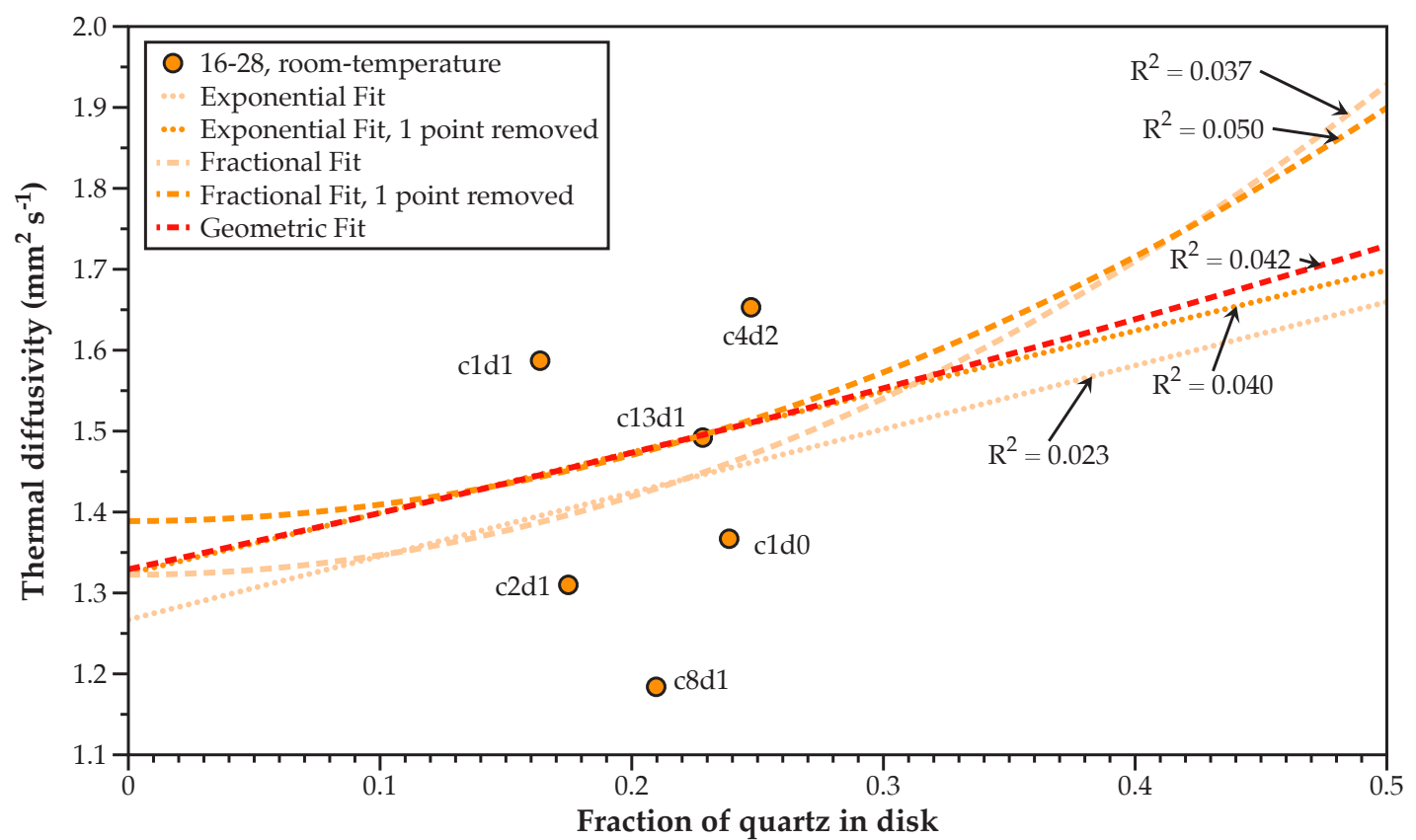

Figure 3-10) Ambient ( 298K) thermal diffusivity results from 5 disks of sample 16-28 against quartz fraction in disks measured by XRD. Fitting models are the same as in figure 3-9, but all fits are poor. For refits with 1 point removed, the lowest $\mathrm{D}$ point $\left(\mathrm{X}_{\mathrm{qtz}} \sim=0.21\right)$ was removed. selected for this project had a diameter of $0.5 \mathrm{~cm}$ (roughly illustrated by the black

\subsubsection{Variations in thermal diffusivity between samples at ambient temperature}

For larger numbers of samples, however, results like those of sample 16-28 (disk c8d1) above should be roughly balanced by disks in which quartz content is underestimated by measuring the full-disk with XRD. Figure 3-11 shows results of roomtemperature $D$ against quartz fraction for 28 disks from five samples with multiple disk measurements. Each of the three fitting equations (Linear, Fractional, and Geometric) 
produce results with a high degree of confidence $\left(\mathrm{R}^{2}=0.54,0.71\right.$, and 0.70 respectively), strongly suggesting that rock thermal diffusivity scales with quartz content. Extending the fitting parameters provided by the above equations to higher quartz fractions produces a broad range of estimated $D$ (Fig. 3-11), with values for $D$ from near those of previouslymeasured quartzites (Branlund and Hofmeister, 2008) for the Linear model, to near the $D$ of the fastest orientation of quartz for the Fractional model (Branlund and Hofmeister, 2007).

\subsubsection{Broader Compositions}

\subsubsection{Simple feldspar-quartz thermal diffusivity relationships}

Because quartz is not the most abundant phase in most samples (Table 3-4), the composition of the most abundant phase of these samples may have as strong, or stronger influence on disk $D$. In most disks, the most abundant material is plagioclase feldspar. If

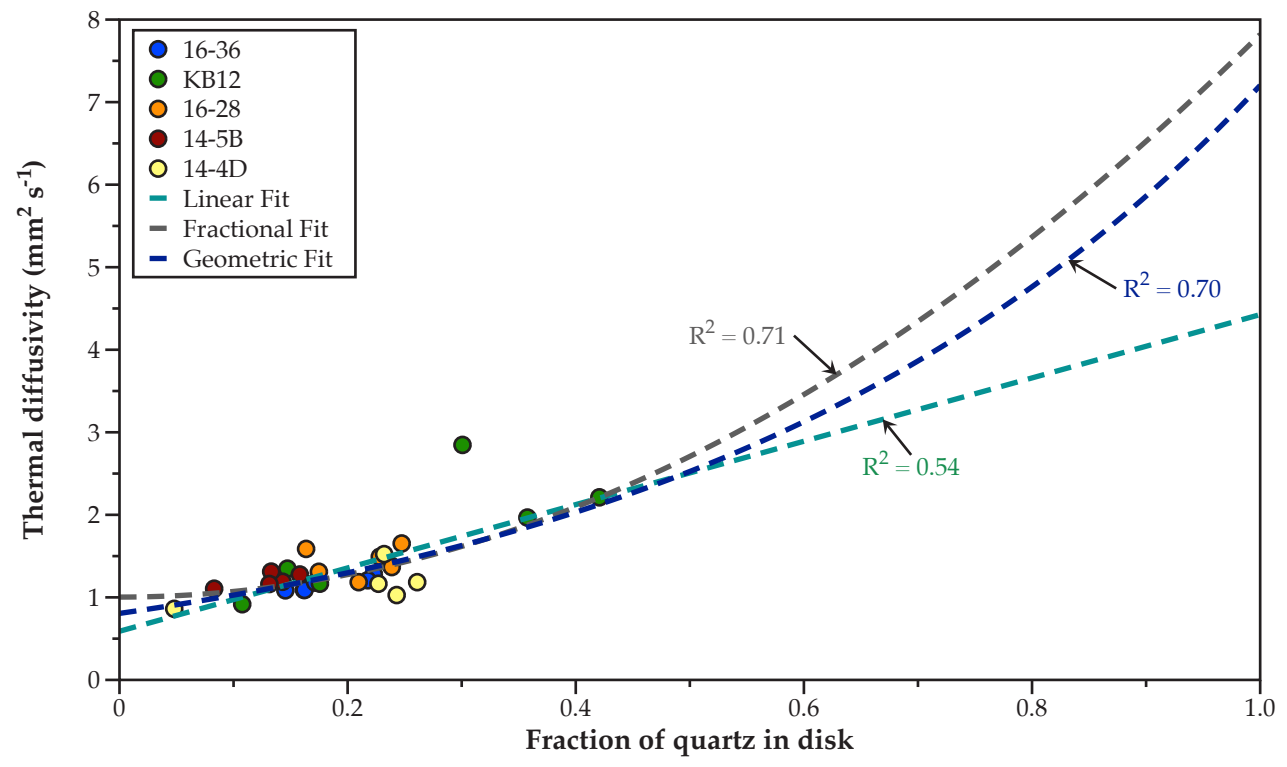

Figure 3-11) A suite of 28 quartzo-feldspathic rocks plotted against quartz fraction in disks, and projected to $100 \%$ quartz content. Results are within the measured $D$ of quartz $\left(\sim 3.7-7.0 \mathrm{~mm}^{2} \mathrm{~s}^{-1}\right)$, but the linear fit $\left(\mathrm{D} \sim=4.44 \mathrm{~mm}^{2} \mathrm{~s}^{-1}\right)$ predicts a lower $D$ at $100 \%$ quartz than either Fractional fit $\left(7.9-8.5 \mathrm{~mm}^{2} \mathrm{~s}^{-1}\right)$. 
the quartz fraction has a strong effect of raising disk $D$, then a baseline matrix $D$ is likely controlled in most samples by plagioclase. Figure 3-12 shows measured $D$ with plagioclase subtracted against quartz fraction for dominantly quartzo-feldspathic disks. For example, for a measured disk $D$ of $1.5 \mathrm{~mm}^{2} \mathrm{~s}^{-1}$ for a sample with a matrix composed of a plagioclase with a known $D$ of $1.1 \mathrm{~mm}^{2} \mathrm{~s}^{-1}$ and a quartz fraction of 0.25 , the disk plots at $0.4 \mathrm{~mm}^{2} \mathrm{~s}^{-1}$ on the ordinate axis and 0.25 on the abscissa. In both cases, matrix plagioclase $D$ was estimated using microprobe results and the plagioclase interpolation models described in Chapter 4, but samples in figure 3-12 are limited to samples with greater than $40 \%$ plagioclase in the matrix (with the exception of quartzites,

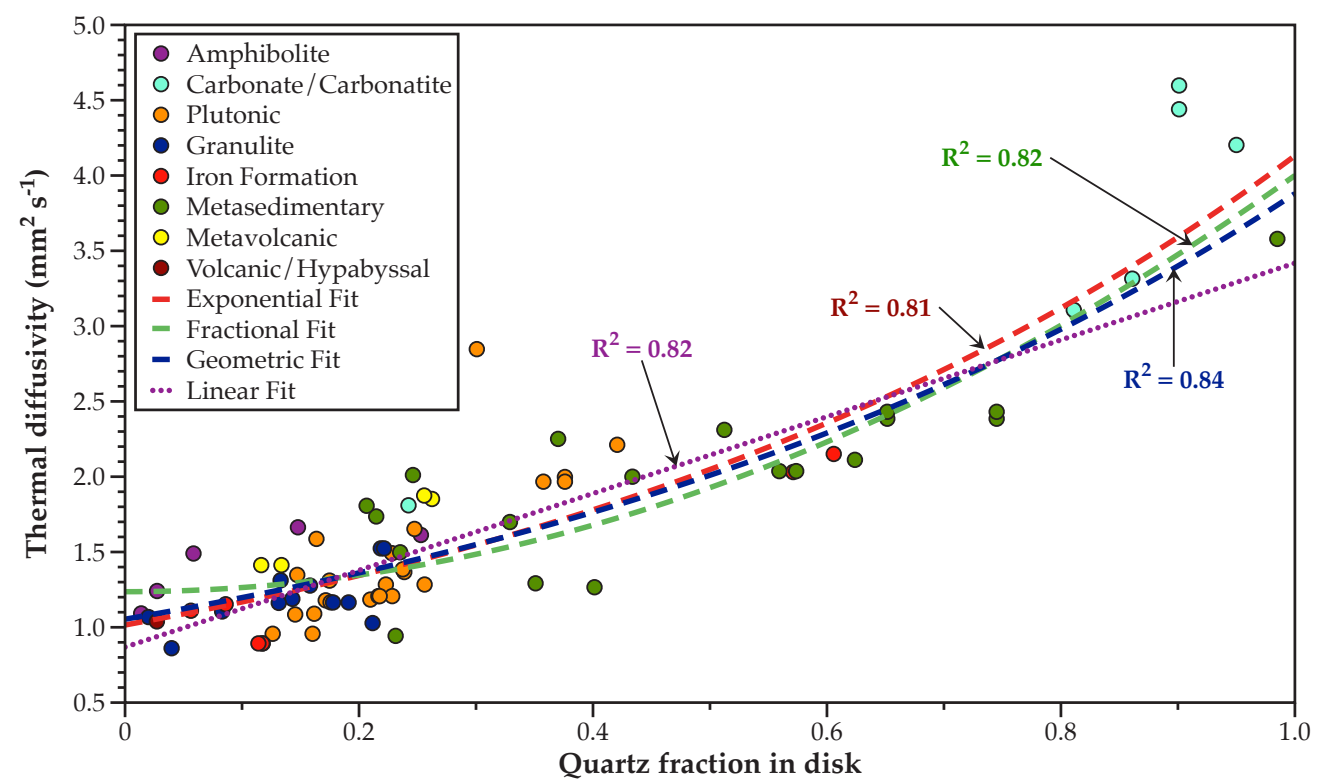

Figure 3-12) Plagioclase $D$ subtracted from measured thermal diffusivity compared to fraction of quartz in LFA disk for 86 samples. For clarity, only fits in which sample points are limited to those within 2 standard deviations of the fit are presented. For the exponential fit, this is 74 points $(\mathrm{RMSE}=0.199), 80$ points for the Fractional fit $(\mathrm{RMSE}=0.265)$, and 81 points the Linear fit $(\mathrm{RMSE}=0.381)$. Samples without plagioclase are included at very-high quartz fractions to more-tightly constrain the quartz-rich side of the figure. 
which are included to provide an upper limit). Factoring-in matrix $D$ improves the fits considerably, with $\mathrm{R}^{2}$ as high as 0.92 (Fractional fit). In this case, the Geometric and Fractional fits produce similar results, but the Exponential and Linear fits had noticeably poorer fits $\left(\mathrm{R}^{2}=0.74\right.$ and 0.81 respectively).

\subsubsection{Matrix-subtracted thermal diffusivity fits}

The above comparison, however, does not account for the abundance of plagioclase in the matrix, other than excluding samples with low plagioclase fractions. In order to account for variations in plagioclase abundance, figure 3-13 compares quartz fraction in the disk to measured D with weighted plagioclase subtracted, according to the formula: $\mathrm{D}_{\text {plag }}($ rock $)=\mathrm{D}_{\text {plag }}\left(\mathrm{An}_{\mathrm{x}}\right)^{\mathrm{Xplag}}$, which is similar in form to the Geometric Model 39. This comparison, if correct, should intersect the $D_{\text {mea }}-D_{\text {plag }}$ axis near zero if no other phases influence the $D$ of the disk and the plagioclase $D$ is accurately calculated. Additionally, because plagioclase tends to be the lowest- $D$ (major) component of most intermediate and felsic rocks, samples should plot above 0 if the relationship is robust. Indeed, when samples with no (visible) anisotropy, and no clear disk heterogeneity are included, the fitting parameters improve, with $\mathrm{R}^{2}=0.91$ for the Fractional fit, and $\mathrm{R}^{2}=$ 0.95 for the Geometric fit. In both cases, the fitting line intersects the ordinate axis between 0 and $0.2 \mathrm{~mm}^{2} \mathrm{~s}^{-1}$, with the Fractional fit forced through 0 if no constant is included in the fit.

The remaining deviation is likely due to the effects of phases other than quartz and feldspar within the disks. When samples with high abundances of amphibole, and garnet the fit of the Fractional $\left(\mathrm{R}^{2}=0.97\right.$ with constant, 0.95 without constant $)$ and 


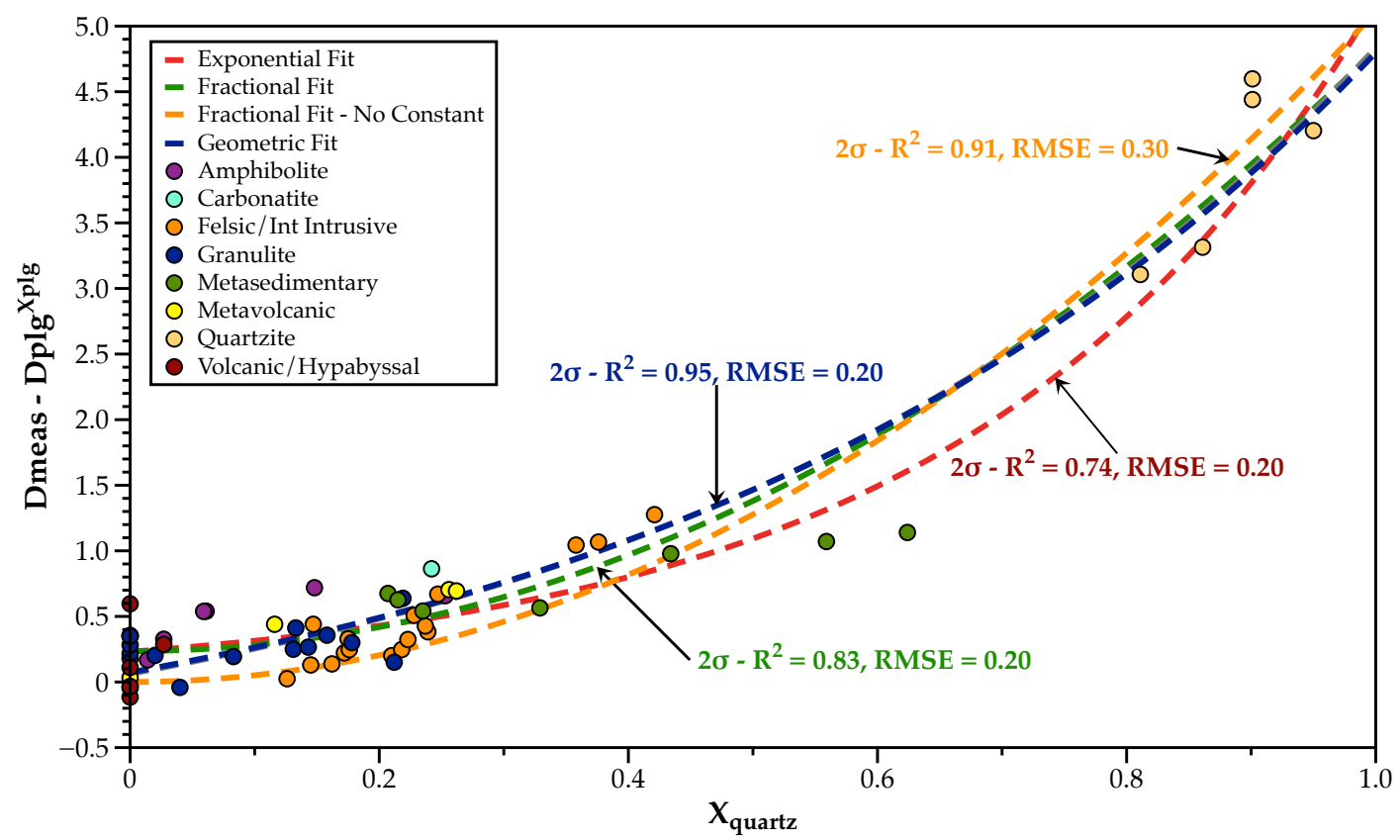

Figure 3-13) Fitting methods for weighted plagioclase subtracted measured thermal diffusivity compared to fraction of quartz in the LFA disk. Note that $\mathrm{X}_{\mathrm{qtz}}$ is fraction of quartz in the LFA disk, $\mathrm{D}_{\text {meas }}$ is the measured thermal diffusivity in $\mathrm{mm}^{2} \mathrm{~s}^{-1}, \mathrm{D}_{\mathrm{plg}}$ is modeled plagioclase thermal diffusivity, and $\mathrm{X}_{\mathrm{plg}}$ is fraction of plagioclase in disk.

Geometric $\left(\mathrm{R}^{2}=0.96\right)$ models improve, and the Geometric fit to approaches 0 along the ordinate, reducing spread in individual values to $<0.25 \mathrm{~mm}^{2} \mathrm{~s}^{-1}$. Furthermore, both fits intersect the ordinate at $100 \%$ quartz with values between 4.7 and $5.0 \mathrm{~mm}^{2} \mathrm{~s}^{-1}$, close to the directionally-averaged $D$ of quartz (4.87-5.35 $\mathrm{mm}^{2} \mathrm{~s}^{-1}$ depending on averaging method).

\subsubsection{Two equations for thermal diffusivity of plagioclase-quartz mixtures at ambient temperatures}

These results can be used to calculate $D$ for strongly plagioclase- and quartz-rich rocks if the plagioclase composition is known. By combining the two axis parameters with the fits, the following equations result: 
$D_{\text {rock }}=D_{\text {plag }} X_{\text {plag }}+\left(\mathrm{X}_{\text {qtz }} / 46000\right)^{2}+0.603$

Equation 3-10.

and

$\mathrm{D}_{\text {rock }}=\mathrm{D}_{\text {plag }} \mathrm{Xplag}+5.8020^{\mathrm{Xqtz}}-0.966$

Equation 3-11.

where $D_{\text {rock }}$ is the calculated thermal diffusivity of the rock $\left(\right.$ in $\left.\mathrm{mm}^{2} \mathrm{~s}^{-1}\right), D_{\text {plag }}$ is the calculated $D$ of plagioclase at a specified Anorthite content, and $X_{\text {plag }}$ and $X_{q t z}$ are the volumetric fractions of plagioclase and quartz respectively. Application of these equations requires knowledge of the $D$ of plagioclase at a specific composition (see chapter 4)

\subsubsection{A Broader approach to matrix-subtracted thermal diffusivity}

This approach could be extended to rocks with different matrix and matrixmodifying phases as well. For example, for a marble with a matrix composed of calcite, and a matrix-modifying phase of dolomite, or a quartzite with quartz matrix, and matrixmodifying brine in pore space. However, specific equations for each would require sufficient samples to produce a trend along the independent variable composition (matrix-modifying phase). Furthermore, extending this approach to a matrix-modifying phase with a solid solution would require compensating for variations in $D$ of the matrixmodifying phase. The above equations are only applicable to plagioclase-quartz mixtures because insufficient sample numbers were available to provide confident fitting parameters for the equations if, for example, amphibole were the matrix phase. 


\subsection{CONCLUSIONS}

A number of underlying assumptions color the ability of researchers to analyze and assign appropriate thermal transport properties to rocks on the scale of the application in question. These assumptions lead to errors with magnitudes which are often unpredictable, and are driven by multi-modal variations in the composition and texture of rocks formed under natural conditions. The major assumptions examined in this paper were:

I) Measurements of thermal transport properties on samples on the $\mathrm{cm}$ to $\mathrm{mm}$ scale are not strongly affected by heterogeneity within the sample.

II) Common rock names such as "Granite", or "Basalt" are adequate to predict the thermal transport properties of a sample of such rock. For example, a sample of granite from the Andes will have the same thermal diffusivity, within reasonable error, as a sample of granite from the Alps.

III) Measurements of thermal transport properties of rocks at ambient, or nearambient temperatures are sufficient to predict these properties at elevated temperatures.

The first assumption introduces errors which approach $50 \%$ at ambient temperature as illustrated measurements of the thermal diffusivity of different slices of the same rock. For example, for the fairly homogeneous sample $16-28$, disk $D$ varied by up to $22 \%$ at ambient-temperature, and is largely driven by variations in minerals interacting with the laser pulse and analyzed by the detector. Further variation is often driven by one of two factors: layering within rocks on a scale the size of the sample being observed, or crystallographic preferred orientation inherent in the sample. These two sources of 
heterogeneity produced variations in $D$ of greater than $50 \%$ for samples of KB12 (Layering) and UP-3A (Preferred Orientation). Although methods with larger sample sizes may reduce some of this heterogeneity, analytical errors associated with these methods crop up which are not present in the LFA.

The second assumption also introduces strong error. For example, disks OM1a and OM3a of sample KB12 both qualify as tonalites under the IUGS classification scheme as a result of high proportions of plagioclase relative to orthoclase, but disk OM1a had a measured $D$ of $2.21 \mathrm{~mm}^{2} \mathrm{~s}^{-1}$ compared to $1.35 \mathrm{~mm}^{2} \mathrm{~s}^{-1}$ for disk OM3a. This discrepancy is likely a result of a large contrast in modal quartz content: $\sim 40 \%$ for OM1a and $15 \%$ for OM3a. Similar contrasts exist between different samples of rock with the same assigned names. For example, both samples $14-4 \mathrm{D}$ and KB12 qualify as tonalites as a whole, but the mean $D$ for $14-4 \mathrm{D}$ was $1.18 \mathrm{~mm}^{2} \mathrm{~s}^{-1}$ and the mean for $\mathrm{KB} 12$ was $1.52 \mathrm{~mm}^{2} \mathrm{~s}^{-1}$. This variation is not only a result of mean quartz content, but also of variations in composition of plagioclase - Plagioclase for $14-4 \mathrm{D}$ had a mean Anorthite content of $52 \%$ compared to $31 \%$ for $\mathrm{KB} 12$.

Finally, ambient-temperature $D$, and consequently, $k$ has a poor correlation with the decrease in $D$ or $k$ as temperature increases, and thus predicting $\mathrm{d} k / \mathrm{d} T$ by roomtemperature measurements of $k$ introduces an unpredictable, but potentially very large, degree of error at elevated temperatures. Models of the temperature-dependence of $k$ using ambient-T, or near-ambient-T measurements to predict high-temperature $k$ are inconsistent at best, and often have unpredictable error when compared to hightemperature measurements of $D$ used to calculate $k$. 
These drivers of variations in rock $D$ extend to the whole of the Earth's crust. Modest variations in mineralogy drive observable variations in the ability of rocks to conduct heat, and complex dependencies of mineral $\mathrm{d} D / \mathrm{d} T$. The Earth's crust contains enormous mineralogical, textural and compositional diversity which is a reflection of the complex, and long-lived Earth system. As a result, the variability shown in figure 3-1 is likely an understatement of the true variability of $D$ in the Earth's crust. Thus, in order to encapsulate 4 billion years of recorded rock history on Earth as reflected in rock $D$, we need a model which can encompass the major drivers in rock $D$ : Mineralogy, composition of minerals, rock fabric, porosity, temperature, pressure, and all the changes in a rock that could occur over its lifetime. Chapters 4 and 5 of this work examine these drivers in more detail, and lay the groundwork for developing such a model.

\section{REFERENCES CITED}

Afonso, J. \& Ranalli, G., 2004, Crustal and mantle strengths in continental lithosphere: is the jelly sandwich model obsolete?: Tectonophysics, v. 394, n. 3, pp.221-232.

Andrés, C., Álvarez, R., and Ordóñez, A., 2016, Estimation of thermal conductivity of rocks from their mineralogical composition (Asturian Coal Basin, NW Spain) for modelling purposes: Environmental Earth Sciences, v. 75, p. 1-10, DOI: 10.1007/s12665015-5037-8. 
Armstrong, J.T., 1995, CITZAF, a package of correction programs for the quantitative electron microbeam X-ray analysis of thick polished materials, thin films, and particles: Microbeam Analysis, v. 4, p. 177-200.

Ashwal, L.D., Morgan, P., Kelley, S.A., and Percival, J., 1987, Heat production in an Archean crustal profile and implications for heat flow and mobilization of heat producing elements: Earth and Planetary Science Letters, v. 85, p. 439-450.

Avard, G., and Whittington, A.G., 2012, Rheology of arc dacite lavas: Experimental determina- tion at low strain rates: Bulletin of Volcanology, v. 74, p. 1039-1056, https://doi.org/10.1007/s00445-012-0584-2.

Benn, K., and Kamber, B.S., 2009, In Situ U/Pb Granulite-Hosted Zircon Dates, Kapuskasing Structural Zone, Ontario: A Late Archean Large Igneous Province (LIP) as a Substrate for Juvenile Crust: The Journal of Geology, v. 117, n. 5, p. 519-541.

Birch, F., and Clark, H., 1940, The thermal conductivity of rocks and its dependence upon temperature and composition: American Journal of Science, v. 238, n. 8, p. 529-558

Blundy, J.D., and Annen, C.J., 2016, Crustal magmatic systems from the perspective of heat transfer: Elements, v. 12, p. 115-120. 
Branlund, J.M., and Hofmeister, A.M., 2007, Thermal diffusivity of quartz to $1,000^{\circ}$ C: effects of impurities and the $\alpha-\beta$ phase transition: Physics and Chemistry of Minerals, v. 34, n. 8, p.581-595.

Branlund, J.M., and Hofmeister, A.M., 2008, Factors affecting heat transfer in natural $\mathrm{SiO}_{2}$ solids: American Mineralogist, v. 93, p. 1620-1629.

Branlund, J.M. and Hofmeister, A.M., 2012, Heat transfer in plagioclase feldspars: American Mineralogist, v. 97, p. 1145-1154.

Bräuer, H., Dusza, L., and Schulz, B., 1992, New laser flash equipment LFA 427: Interceram, v. 41, p. 489-492.

Burov, E. \& Watts, A., 2006, The long-term strength of continental lithosphere: ' jelly sandwich' or‘ crème brûlée'?: GSA Today, v. 16, n. 1, p.4.

Carson, J.K., Lovatt, S.J., Tanner, D.J., and Cleland, A.C., 2005, Thermal conductivity bounds for isotropic, porous materials: International Journal of Heat and Mass Transfer, v. 48, p. 2150-2158, https://doi.org/10.1016/j.ijheatmasstransfer.2004.12.032. 
Chapman, D.S., Keho, T.H., Bauer, M.S., and Picard, M.D., 1984, Heat flow in the Uinta Basin determined from bottom hole temperature (BHT) data: Geophysics, v. 49, p. 453466, https:// doi.org/10.1190/1.1441680.

Clauser, C. \& Huenges, E., 1995, Thermal conductivity of rocks and minerals: Rock physics \& phase relations: A Handbook of Physical Constants, Volume 3: American Geophysical Union, Washington, D.C., http://onlinelibrary.wiley.com/doi/10.1029/RF003p0105/summary.

Criss, E.M., and Hofmeister, A.M., 2017, Isolating lattice from electronic contributions in thermal transport measurements of metals and alloys above ambient temperature and an adiabatic model: International Journal of Modern Physics B, v. 31, n. 14, 1750205. doi:10.1142/s0217979217502058.

Durham, W.B., Mirkovich, V.V., and Heard, H.C., 1987, Thermal diffusivity of igneous rocks at elevated pressure and temperature: Journal of Geophysical Research, v. 92, p. 11,615-11,634, https://doi.org/10.1029/JB092iB11p11615. 
Fei, Y., 1995, Thermal expansion: in Ahrens, T.J., ed. Mineral Physics and Crystallography: A Handbook of Physical Constants. Washington, DC, American Geophysical Union, p. 29-44, https://doi.org/10.1029/RF002p0029.

Fuchs, S., Schütz, F., Förster, H-J., and Förster, A., 2013, Evaluation of common mixing models for calculating bulk thermal conductivity of sedimentary rocks: Correction charts and new conversion equations: Geothermics, v. 47, p. 40-52.

Fuchs, S. Balling, N., and Förster, A., 2015, Calculation of thermal conductivity, thermal diffusivity and specific heat capacity of sedimentary rocks using petrophysical well logs: Geophysical Journal International, v. 203, p. 1977-2000, doi: 10.1093/gji/ggv403.

Funnell, R., Chapman, D., Allis, R., and Armstrong, P., 1996, Thermal state of the Taranaki Basin, New Zealand: Journal of Geophysical Research, v. 101, p. 25,19725,215, https://doi.org/10 .1029/96JB01341.

Hantschel, T., and Kauerauf, A.I., 2009, Fundamentals of Basin and Petroleum Systems Modeling: Dordrecht, Springer, 475 p. 
Henderson, J.B., Hagemann, L., and Blumm, J., 1998a, Development of SRM 8420 series electro- lytic iron a thermal diffusivity standard: Netzsch Applications Laboratory Thermophysical Properties Section Report I-9E, 11 p.

Henderson, J.B., Giblin, F., Blumm, J., and Hagemann, L., 1998b, SRM 1460 series as a thermal diffusivity standard for laser flash instruments: International Journal of Thermophysics, v. 19, p. 1647-1656, https://doi.org/10.1007/BF03344916.

Hofmeister, A.M., 2006, Thermal diffusivity of garnets at high temperature: Physics and Chemistry of Minerals, v. 33, n. 1, p.45-62. Available at: http://link.springer.com/10.1007/s00269-005-0056-8.

Hofmeister, A.M., 2007, Pressure dependence of thermal transport properties: Proceedings of the National Academy of Sciences of the United States of America, v. 104, p. 9192-9197, https://doi.org/10.1073/pnas.0610734104.

Hofmeister, A.M., 2019, Measurements, Mechanisms, and Models of Heat Transport. $1^{\text {st }}$ Ed., Elsevier, 440 p.

Hofmeister, A.M., and Pertermann, M., 2008, Thermal diffusivity of clinopyroxenes at elevated temperature: European Journal of Mineralogy, v. 20, p. 537-549. 
Hofmeister, A.M., and Branlund, J.M., 2015, Thermal Conductivity of the Earth: Treatise on Geophysics, pp.583-608. Available at: http://dx.doi.org/10.1016/B978-0-444-538024.00047-6.

Hofmeister, A.M. and Carpenter, P.K., 2015, Heat transport of micas: The Canadian Mineralogist, v. 53, p. 557-570, doi: 10.3749/canmin. 1400093

Hofmeister, A.M., Pertermann, M., and Branlund, J.M., 2007, Thermal conductivity of the Earth, in Price, G.D., ed., Treatise on Geophysics, Volume 2: Mineral Physics: Amsterdam, The Netherlands, Elsevier, p. 543-577, https://doi.org/10.1016/B978$\underline{044452748-6.00048-1 .}$

Hofmeister, A.M., Whittington, A.G. \& Pertermann, M., 2009, Transport properties of high albite crystals, near-endmember feldspar and pyroxene glasses, and their melts to high temperature: Contributions to Mineralogy and Petrology, v. 158, n. 3, p.381-400. Available at: http://link.springer.com/10.1007/s00410-009-0388-3.

Hofmeister, A.M., Dong, J-J., and Branlund, J.M., 2014, Thermal diffusivity of electrical insulators at high temperatures: Evidence for diffusion of bulk phonon-polaritons at 
infrared frequencies augmenting phonon heat conduction: Journal of Applied Physics, v. 115, 163517, doi:10.1063/1.4873295.

Kramers, J., Kreissig, K. \& Jones, M., 2001, Crustal heat production and style of metamorphism: a comparison between two Archean high grade provinces in the Limpopo Belt, southern Africa: Precambrian Research, v. 112, n. 1, p.149-163.

Lee, Y., and Deming, D., 1998, Evaluation of thermal conductivity temperature corrections applied in terrestrial heat flow studies: Journal of Geophysical Research, v. 103, n. B2, p. 2447-2454.

Liu, S., Feng, C., Wang, L. and Li, C., 2011, Measurement and analysis of thermal conductivity of rocks in the Tarim Basin, Northwest China: Acta Geologica Sinica, v. 85, n. 3 , p. $598-609$.

Maglić, K.D., and Taylor, R.E., 1992, The apparatus for thermal diffusivity measurement by the laser pulse method, in Maglić, K.D., Cezairliyan, A., and Peletsky, V.E., eds., Compendium of Thermophysical Property Measurement Methods, Volume 2: Recommended Measurement Techniques and Practices: New York, Plenum Press, p. 281-314, https://doi.org/10.1007/978 -1-4615-3286-6_10. 
Mehling, H., Hautzinger, G., Nilsson, O., Fricke, J., Hofmann, R., and Hahn, O., 1998, Thermal diffusivity of semitransparent materials determined by the laser-flash method applying a new mathematical model: International Journal of Thermophysics, v. 19, p. 941-949, https:// doi.org/10.1023/A:1022611527321.

Merriman, J.D. et al., 2013, Thermal transport properties of major Archean rock types to high temperature and implications for cratonic geotherms: Precambrian Research, v. 233, p.358-372. Available at: http://dx.doi.org/10.1016/j.precamres.2013.05.009.

Merriman, J.D., Hofmeister, A.M., Roy, D.J., and Whittington, A.G., 2018, Temperaturedependent thermal transport properties of carbonate minerals and rocks: Geosphere, v. 14, n. 4, p. 1961-1987, https://doi.org/10.1130/GES01581.1.

Miao, S.Q., Li, H.P., and Chen, G., 2014, Temperature dependence of thermal diffusivity, specific heat capacity, and thermal conductivity for several types of rocks: Journal of Thermal and Analytical Calorimetry, v. 115, p. 1057-1063, doi: 10.1007/s10973-013$3427-2$.

Nabelek, P. \& Liu, M., 2004, Petrologic and thermal constraints on the origin of leucogranites in collisional orogens: Transactions of the Royal Society of Edinburgh: Earth Sciences, v. 95, n. 1, p.73-85. 
Nabelek, P.I., Whittington, A.G., and Hofmeister, A.M., 2010, Strain heating as a mechanism for partial melting and ultrahigh temperature metamorphism in convergent orogens: Implications of temperature-dependent thermal diffusivity and rheology: Journal of Geophysical Research, v. 115, B12417, doi:10.1029/2010JB007727.

Nabelek, P.I., Hofmeister, A.M., and Whittington, A.G., 2012, The influence of temperature-dependent thermal diffusivity on the conductive cooling rates of plutons and temperature-time paths in contact aureoles: Earth and Planetary Science Letters, v. 317318, p. 157-164. doi: 10.1016/j.eps1.2011.11.009.

Pasquale, V., Verdoya, M., and Chiozzi, P., 2015, Measurement of rock thermal conductivity with a Transient Divided Bar: Geothermics, v. 53, p. 183-189.

Percival, J.A., and Card, K.D., 1983, Archean crust as revealed in the Kapuskasing uplift, Superior Province, Canada. Geology, v. 11, p. 323-326.

Percival, J.A., and West, G.F., 1994, The Kapuskasing uplift: a geological and geophysical synthesis: Canadian Journal of Earth Science, v. 31, p. 1256-1286. 
Percival, J.A., and Easton, R.M., 2007, Geology of the Canadian Shield in Ontario: An Update; Geological Survey of Canada, Open File 5511, Ontario Geological Survey, Available at: http://scholar.google.comjavascript:void(0).

Pertermann, M. \& Hofmeister, A.M., 2006, Thermal diffusivity of olivine-group minerals at high temperature: American Mineralogist, v. 91, n. 11, p.1747-1760. Available at: http://ammin.geoscienceworld.org/cgi/doi/10.2138/am.2006.2105.

Pertermann, M., Whittington, A.G., Hofmeister, A.M., Spera, F.J., and Zayak, J., 2008, Transport properties of low-sanidine single-crystals, glasses and melts at high temperature: Contributions to Mineralogy and Petrology, v. 155, p. 689-702, https://doi.org/10.1007/s00410-007 -0265-x.

Ray, L., Förster, H-J., Förster, A., Füchs, S., Naumann, R., and Appelt, O., 2015, Tracking the thermal properties of the lower continental crust: Measured versus calculated thermal conductivity of high-grade metamorphic rocks (Southern Granulite Province, India): Geothermics, v. 55, p. 138-149. doi:

10.1016/j.geothermics.2015.01.007.

Regenauer-Lieb, K., Weinberg, R. \& Rosenbaum, G., 2006, The effect of energy feedbacks on continental strength: Nature, v. 442, n. 7098, pp.67-70. 
Rietveld, H.M., 1968, A profile refinement method for nuclear and magnetic structures: Journal of Applied Crystallography, v. 2, p. 65-71, https://doi.org/10.1107/S0021889869006558.

Robertson, E.C., 1988, Thermal properties of rocks: United States Department of the Interior Geological Survey, Open-File Report 88-441, Reston, Virginia, p. 110.

Robie, R.A., and Hemingway, B.S., 1995, Thermodynamic properties of minerals and related substances at $298.15 \mathrm{~K}$ and 1 bar (105 pascals) pressure and at higher temperature: U.S. Geological Survey Bulletin 2131, 470 p.

Rollinson, H., 2007, Early Earth Systems: A Geochemical Approach: Blackwell Publishing, Malden, MA, 285 p.

Sass, J.H., Lachenbruch, A.H., Moses, T.H., Jr., and Morgan, P., 1992, Heat flow from a scientific research well at Cajon Pass, California: Journal of Geophysical Research, v. 97, p. 5017-5030, https://doi.org/10.1029/91JB01504.

Sawyer, E.W., Cesare, B., and Brown, M., 2011, When the Continental Crust Melts. Elements, v. 7, n. 4, p.229-234. Available at: http://elements.geoscienceworld.org/cgi/doi/10.2113/gselements.7.4.229. 
Smith, D.S., Fayette, S., Grandjean, S., Martin, C., Telle, R., and Tonnessen, T. 2003, Thermal resistance of grain boundaries in alumina ceramics and refractories: Journal of the American Ceramic Society, v. 86, p. 105-111, https://doi.org/10.1111/j.11512916.2003.tb03285.x.

Somerton, W.H., 1992, Thermal Properties and Temperature-Related Behavior of Rock/Fluid Systems: New York, Elsevier, 257 p.

Vosteen, H-D., and Schellschmidt, R., 2003, Influence of temperature on thermal conductivity, thermal capacity and thermal diffusivity for different types of rock: Physics and Chemistry of the Earth, v. 28, p. 499-509.

Vozár, L., and Hohenauer, W., 2003, Flash method of measuring the thermal diffusivity: A review: High Temperatures-High Pressures, v. 35-36, p. 253, https://doi.org/10.1068/htjr119.

Vozár, L., and Hohenauer, W., 2005, Uncertainty of thermal diffusivity measurements using the laser flash method: International Journal of Thermophysics, v. 26, p. 18991915, https://doi.org/10.1007/s10765-005-8604-5. 
Whittington, A.G., Hofmeister, A.M. \& Nabelek, P.I., 2009, Temperature-dependent thermal diffusivity of the Earth's crust and implications for magmatism: Nature, v. 458, n. 7236, pp.319-321. Available at:

http://www.nature.com/doifinder/10.1038/nature07818.

Yu, X. and Hofmeister, A.M., 2011, Thermal diffusivity of alkali and silver halide crystals as a function of temperature: Journal of Applied Physics, v. 109, 033516, doi: $10.1063 / 1.3544444$. 


\section{Chapter 4: A Model for Temperature-Dependent Thermal Diffusivity of Crystalline Rocks, Part II: Ambient- Temperatures and a New Model for Plagioclase}

\subsection{INTRODUCTION}

In the previous chapter, we presented a refined procedure for highly detailed characterization of slices of rock used in thermal diffusivity $(D)$ measurements. A combination of methods produced weight and volume fractions of phases within disks (XRD, optical analysis), provided compositional information about both individual phases, and the disk and sample as a whole (Electron Microprobe, bulk-rock ICP-OES, disk-specific EDS), estimated porosity for the bulk sample using contrasting measured densities (volumetric measurements, analytical mass balance, ethanol-based Archimedean density, multipycnometry), and provided textural information on both disks and broader samples (PLM, SEM backscatter images, microprobe images). Thermal diffusivity was measured using the Laser Flash Analysis method (LFA) on a suite of 122 disks at ambient-temperature and combined with previous measurements by Branlund and Hofmeister (2008), Merriman et al., (2013), Merriman et al. (2018), and Roy et al. (in review).

By examining multiple slices of the same sample, we showed that $D$ can vary strongly across the scale of a hand sample, with heterogeneity of up to $50 \%$. This heterogeneity is driven by several properties inherent rocks, including volumetric contrasts in major phase abundances, sample layering, preferred orientation of minerals, and coupled substitution of $\mathrm{NaSi} \Leftrightarrow \mathrm{CaAl}$ in plagioclase, which drives strong contrasts in $D$ of the mineral. Because quartz and the alkali and plagioclase feldspars are some of the 
most common rock-forming minerals, the abundances of these phases can be used to calculate disk $D$ at ambient- $T$ for samples with no other major rock-forming phases (eq. 3-10 and 3-11 Chapter 3). However, more complex models are needed to calculate rock $D$ for samples with different rock-forming phases. Furthermore, the $D$ of samples appears to vary in part with the composition of solid-solution phases, meaning a model is needed for $D$ of solid solutions that can interpolate between discrete measured $D$ values of phases such as plagioclase.

This chapter uses the $D$ measurements and characteristics found in chapter 3 to evaluate the effectiveness of calculating ambient-temperature $D$ from observable sample properties. In order to provide more accurate calculations, we present and evaluate three new models for interpolating plagioclase $D$ at between An contents not directly measured in the LFA. Sources of error for calculations are evaluated, and the influence of major properties of samples such as preferred orientation of minerals within the disk are discussed in detail. High-temperature calculations as well as applications for this model are discussed in chapter 5.

\subsection{MIXTURE THEORY FOR CONDUCTIVE HEAT FLOW}

Endmember models of thermal conduction can be described by analogy to electrical resistors. In rocks, the resistors are different phases within, such as minerals, glass, or a fluid trapped or moving through pore space. Crystals within a rock are arranged in quasi-random to orderly patterns (Saadatfar et al., 2005; Peternell and Kruhl, 2009; Heilbronner and Barrett, 2014). Analogous to electrical resistors arranged in parallel, if a rock is layered and has a strongly-oriented mineral fabric, heat may flow 

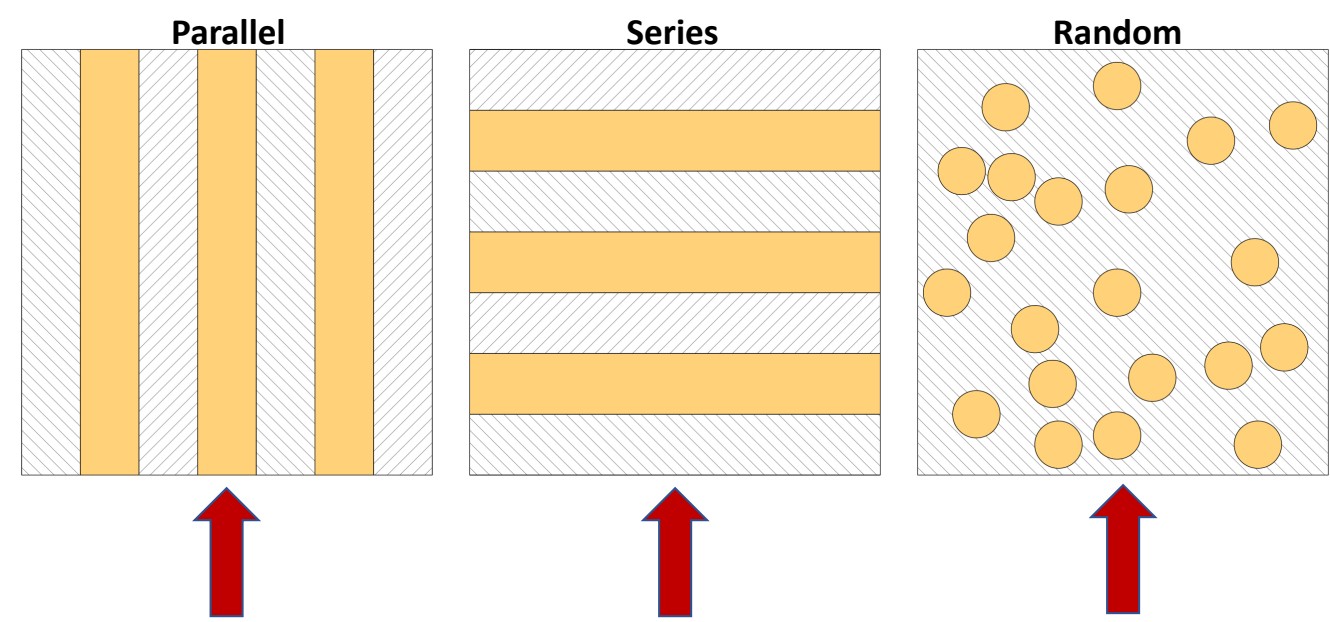

\section{Heat Flow Direction}

Figure 4-1) Simplified diagrams illustrating the endmember heat flow mixing models Resistors in Parallel (left), and Resistors in Series (middle), as well as randomly-distributed phases in a matrix (right). The yellow phase could be either the more conductive phase, or the more resistive phase. In the case of the Parallel model, both phases are mixed arithmetically, in the series model, harmonically, and multiple models exist for mixing of a randomly-distributed phase in a matrix, depending in part on the relative thermal conductivity of the matrix and distributed phase. See text for details and mathematical formulations.

continuously, taking a pathway parallel to mineral orientation (Fig. 4-1, left). This case produces the highest expected effective thermal conductivity (e.g. Berryman, 1995; Clauser and Huenges, 1995; Carson et al., 2005; Wang et al., 2006) as the rate of thermal energy traversing the system is proportional to the weighted (arithmetic) mean resistance of each phase:

$$
k_{\mathrm{bulk}}=k_{1} m_{1}+k_{2} m_{2} \ldots k_{n} m_{n}
$$


where $k_{b u l k}$ is the bulk thermal conductivity of the material, $m_{n}$ is the mode (relative volumetric abundance) of component $\mathrm{n}$, and $k_{n}$ is the thermal conductivity of the $\mathrm{n}^{\text {th }}$ component. This model is typically referred to as the parallel model $(P)$.

Conversely, if heat must flow perpendicular to layering, thermal energy is forced through each phase in sequence (Fig 4-1, middle). This lower expected limit is analogous to resistors arranged in series $(S)$ and is sometimes called the harmonic mean model.

$$
k_{\text {bulk }}=\frac{1}{\left(\frac{m_{1}}{k_{1}}+\frac{m_{2}}{k_{2}} \ldots \frac{m_{n}}{k_{n}}\right)}
$$

Equation 4-2.

A rock, however, is a complex three-dimensional material in which heat has multiple potential pathways. Although both purely-parallel and purely-series examples may occur naturally, strong alignment and continuous layering of minerals within a rock is rare in the crust (but possibly more common in the lower lithosphere (Fischer et al., 2010; Lee et al., 2011)). Because most minerals (and any pore space) are arranged in semi-random patterns, a model intermediate to the series and parallel models may be the best predictor of mineral mixing in rocks (Fig. 4-1, right). A number of mathematical equations have been proposed to account for this placement of minerals (For a more thorough review of these models, see Carson et al. (2005), Wang et al., (2008); Fuchs et al. (2013)). Additionally, in many cases one mineral is considerably more abundant than the remaining phases, which may create a quasi-continuous medium surrounded by many interspersed, less abundant phases, or short, but overall discontinuous pathways of the same mineral. 
The many intermediate mixing models that may apply to thermal conduction are too numerous to review here (e.g. see review in Wang et al., 2008), but some common examples are the Maxwell-Eucken models (ME-1 and ME-2), the Effective Mean Theory (EMT) model, and the Geometric (G) mean model. The ME models vary by the relative $k$ of the phases in the material. For a two-phase medium where the continuous phase has a lower $k$ than the dispersed phase, the ME-1 model assumes heat will travel through both the continuous and the dispersed phases.

Finally, a model based on the geometric mean of Pythagorean fame is often used as an intermediate model (Lichtenecker, 1924):

$$
k_{\text {bulk }}=k_{1}^{m_{1}} k_{2}^{m_{2}} \ldots k_{n}^{m_{n}}
$$

Equation 4-3.

Although the mathematical derivation of this model has no known physical basis, a number of studies have found good correlation between this model and observed $k$ measurements on polymineralic rocks (e.g. Woodside and Messmer (1961); Clauser and Huenges, 1995; Füchs et al., 2013; Ray et al., 2015). The lack of a physical basis for this model is concerning, however, and its effectiveness may be more coincidence resulting from a prediction of $k$ between that of the $P$ and $S$ models.

Although these models were generated for evaluating $k$, eq. 3-1 can be used in applying these to $D$ by substituting into each of the above equations. As an example, for a rock with $n$ components, a grain size of $L$, and a thermal storativity of $C$ (where $C=$ $\rho C_{P}$ ), the series equation becomes (Hofmeister, 2019): 


$$
\frac{L}{k_{b u l k}}=\frac{L_{n}^{2} C_{n}}{k_{n}} \sum \frac{1}{L_{n} C_{n}}=\sum \frac{L_{n}}{k_{n}}
$$

Equation 4-4.

where $L_{n}$ and $C_{n}$ from 1 to $\mathrm{n}=\mathrm{i}$ correspond to the length and storativity of the $\mathrm{i}^{\text {th }}$ components. This equation accounts for the length over which heat must travel, and the ability of the phases to store heat. Of note, for the equations for the $P, S$, and $G$ models, if the heat capacity and density of all major phases is similar, then the storativity can be neglected, and $D$ substituted directly into each for $k$.

Typically, evaluation of the various models to rocks focuses on high-contrast phases such as monomineralic sedimentary rocks with high pore fractions, where a continuous phase is composed of a material such as quartz or calcite, and the dispersed phase is pore space with a pore-filling fluid. Fluid compositions range from air ( $D \sim 16$ $\mathrm{mm}^{2} \mathrm{~s}^{-1}-$ Hofmeister and Criss, 2018), to water or brine, both of which have low thermal conductivity relative to most rock forming minerals $\left(\sim 0.14 \mathrm{~mm}^{2} \mathrm{~s}^{-1}\right.$ e.g. Ramires et al., 1995; He et al., 2006). Additionally, high porosity near the Earth's surface ( $10 \%$ by volume in the top several $\mathrm{km}$ for many sedimentary rocks) is expected to decrease rapidly with depth to $\sim 0.5-1 \%$ at $10 \mathrm{~km}$, and $\sim 0.1 \%$ to $0.01 \%$ near the Moho (Ingebritsen and Manning, 2003; Vitovtova et al., 2014). Thus high-porosity materials were not a primary focus of this project, although estimated porosity is included for each sample (see chapter 3), and some highly porous samples of limestone and quartzite are evaluated. 


\subsection{A NEW MODEL FOR THERMAL DIFFUSIVITY OF PLAGIOCLASE FELDSPARS}

The feldspars are the most abundant mineral group in the Earth's crust (Klein and Dutrow, 2008), the lunar highlands and highly abundant in lunar basalts (Wieczorek et al., 2006) as well as Mars (Milam et al., 2010), making up an estimated 50\% of surface rock material. Additionally, the plagioclase solid solution dominates this group of minerals, making up $\sim 80 \%$ of feldspars, and $40 \%$ of all minerals in the continental crust of Earth. Because of this, plagioclase likely provides a "baseline" thermal diffusivity for continental rocks on which secondary phases such as quartz increase bulk $D$. Additionally, plagioclase is a major component of oceanic crust.

Although the plagioclase series is simple in composition, resulting from the coupled substitution $\mathrm{CaAl} \Leftrightarrow \mathrm{NaSi}$, structural changes are a complex function of composition and temperature. As a result of the high abundance of plagioclase in crustal rocks, their near omnipresent abundance in our rock suite (see Chapter 3), and the potential for complex phase relations, it was necessary for us to develop a model for $D$ of plagioclase which could potentially incorporate both compositional and structural changes that have significant controls on plagioclase $D$. This section describes the models, and the benefits/drawbacks of the three different mixing models developed.

\subsubsection{Structural and compositional relationships in plagioclase feldspars}

Like the mineral quartz, which transforms from $\alpha$ to $\beta$ quartz at $\sim 846 \mathrm{~K}$ (Klein and Dutrow, 2008), the plagioclase solid solution has a different structure at elevated temperatures than at ambient temperatures (Figure 4-2). However, unlike quartz, these 


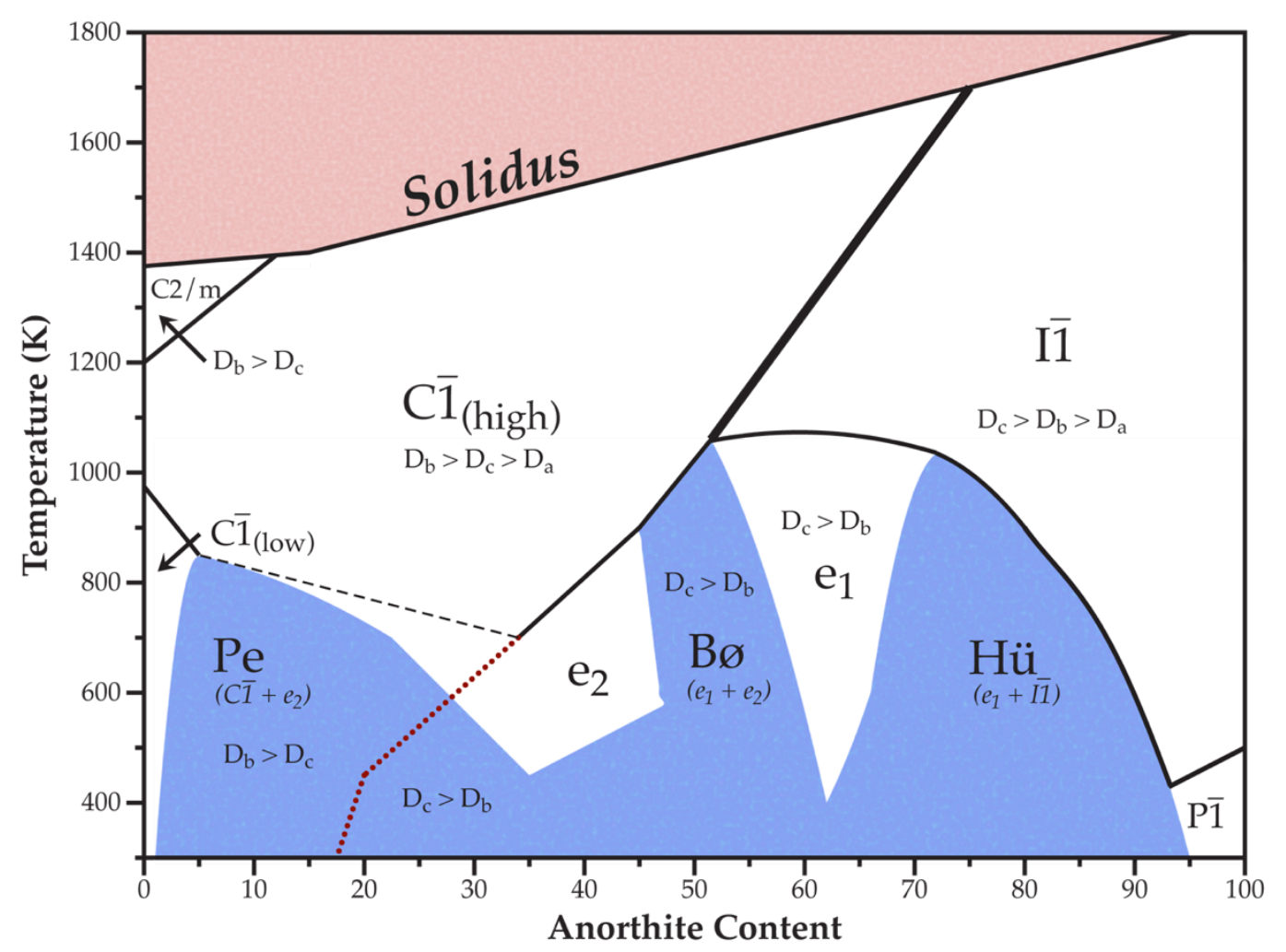

Figure 4-2) Plagioclase phase diagram including the implied relative $D$ values of orientations in stability fields. $D_{a}, D_{b}$, and $D_{c}$ refer to $D$ when heat flows along the $a-, b,-$ and c-axis respectively. Phase transformations cause structural changes which are reflected in the ability of the mineral to diffuse a thermal gradient. Modified from Branlund and Hofmeister, 2012; Parsons, 2010; and McConnell, 2008. Low temperature plagioclase structures display a combination of one of two structures: $C \overline{1}_{\text {low }}$ (triclinic) at the albite end, and $P \overline{1}$ (also triclinic) at the anorthite end. As Ca-content increases along the series, albite and anorthite in low-temperature plagioclase are thought to be immiscible, generating a series of complex terminology for combinations of albite and anorthite from Peristerite (Pe), combining $C \overline{1}_{\text {low }}$ and $e_{2}$, Bøgglid (Bø), combining $\mathrm{e}_{2}$ and $\mathrm{e}_{1}$, and Hüttenlocher $(H \ddot{u})$, combining $\mathrm{e}_{1}$ and the high-temperature phase $I \overline{1}$.

Ordering within plagioclase feldspars is highest at low temperature and purest endmember composition. This relationship holds for plagioclase formed above the transition from triclinic (low temperature) to monoclinic (high temperature) structures, including the $C \overline{1}_{\text {high }}$ structure for albite-rich compositions, $I \overline{1}$ structure for anorthite-rich 
compositions, and the rare, very-high temperature $(>1200 \mathrm{~K}) \mathrm{C} 2 / \mathrm{m}$ structure, which is observed only at near-endmember albite compositions (see Fig. 4-2). When a rock forms at elevated temperatures in one of these high-temperature fields, cooling rate controls what structure will persist to ambient temperature. Volcanic or hypabyssal material that extrudes or intrudes at high temperature and cools rapidly typically preserves hightemperature structures, whereas deeper plutonic or metamorphic feldspars that cool slowly are able to transform to low-temperature structures. Crucially, very slow-cooling materials facilitate full transformation of plagioclase at low temperature to immiscible albite and anorthite below $\sim 400^{\circ} \mathrm{C}$, with exsolution lamellae on a nanometer scale (Parsons, 2010). Furthermore, immiscibility textures are often only visible through the very-high magnification available through use of a Transmission Electron Microscope.

As a result, two plagioclase crystals formed at the same temperature, with nearly identical compositions can have strongly different structures, and consequently contain the potential for very different $D$ values.

\subsubsection{Thermal diffusivity and heat capacity of the plagioclase solid-solution}

Hofmeister et al. (2009) and Branlund and Hofmeister (2012) reported LFA measurements of the $D$ of nine plagioclase feldspar samples in up to three orientations. Average values calculated using eq. 4-2 are shown in figure 4-3. For sample FSU ( $\left.\mathrm{An}_{05}\right)$, the perpendicular orientation was modeled using the measured room-temperature value $\left(0.93 \mathrm{~mm}^{2} \mathrm{~s}^{-1}\right.$, compared to 1.27 and 1.10 for the [010] and [001] orientations) and the average $\mathrm{d} D / \mathrm{d} T$ trend of the [010] and [001] orientations. The resulting three-direction average for FSU displays a similar trend to sample FON ( $\left.\mathrm{An}_{19}\right)$, in which the 


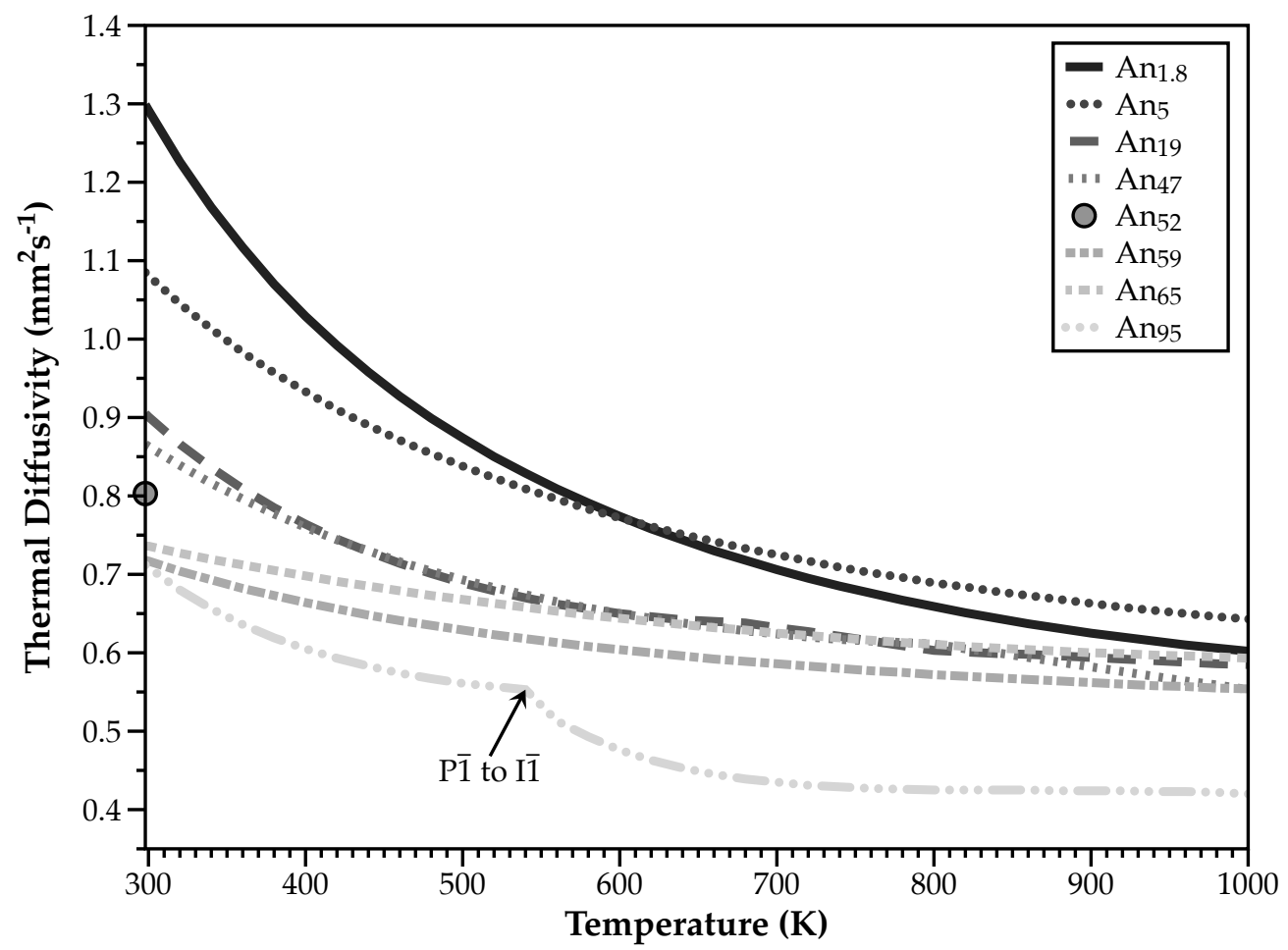

Figure 4-3) Thermal diffusivity of samples from Hofmeister et al., 2009 and Branlund and Hofmeister, 2012. Results shown are harmonic averages of available orientations. The transition to $C \overline{1}_{\text {high }}$ is barely visible as a modest change in slope in Albite-rich compositions near $700 \mathrm{~K}$. Measurements for Ans2 were limited to ambient-temperature. A strong change in $\mathrm{d} D / d T$ occurs for An95 near the $P \overline{1}$ to $I \overline{1}$ transition.

perpendicular orientation was also the slowest orientation measured.

For the suite of 8 samples, average $D$ of plagioclase varied from $\sim 1.3$ to $0.7 \mathrm{~mm}^{2}$ $\mathrm{s}^{-1}$ at ambient $T$, and all samples showed a decreasing $D$ with increasing $T$, with a concave-up trend. Overall, ambient $T$ thermal diffusivity decreases as Ca-content increases from $\mathrm{An}_{1.8}$ to $\mathrm{An}_{95}$ (Fig. 4-3). However, $\mathrm{d} D / \mathrm{d} T$ varied strongly between samples of different An-content, with measurements at high $T$ for the most Na-rich sample (Albite - $\mathrm{An}_{1.8}$ ) showing lower $D$ at high $T$ than the next-closest sample in composition (FSU - 
$A n_{05}$ ) or the much initially much lower $A n_{19}$. Furthermore, $\mathrm{d} D / \mathrm{d} T$ appears to be noticeably affected by some phase transitions shown in fig. 4-2, but not others.

The most extreme example of this is highlighted by sample FMA $\left(\mathrm{An}_{95}\right.$, fig. 4-3), which is best modeled by using different fitting parameters for temperatures below and above $\sim 540 \mathrm{~K}$, near the $P \overline{1}$ to $I \overline{1}$. As a whole, plagioclase feldspars have lower $D$ than most major rock-forming minerals, with the lowest reported values found at high temperature for Ca-rich $\mathrm{An}_{95}$ approaching those observed for silicic glasses and liquids (Hofmeister et al., 2016).

Although $D$ of plagioclase is apparently highly complex, $C_{P}$ of plagioclase is much simpler, with a reported $C_{P}$ of $0.77 \mathrm{Jg}^{-1} \mathrm{~K}^{-1}$ for albite, and $0.75 \mathrm{Jg}^{-1} \mathrm{~K}^{-1}$ for anorthite at 295K (Robie and Hemingway, 1995; Benisek et al., 2013). However, $\mathrm{d} C_{P} / \mathrm{d} T$ at high- $T$ appears to vary somewhat between volcanic and metamorphic anorthite (Fig. 2, Benisek et al., 2013), likely due to different ordering between $I \overline{1}$ and $P \overline{1}$ structures (Fig. 4-4).

Given the small differences in $C_{P}$ between the two endmembers we have assumed a linear change in $C_{P}$ between endmembers. Any error introduced by this assumption should be small relative to the larger variations in $D$. 


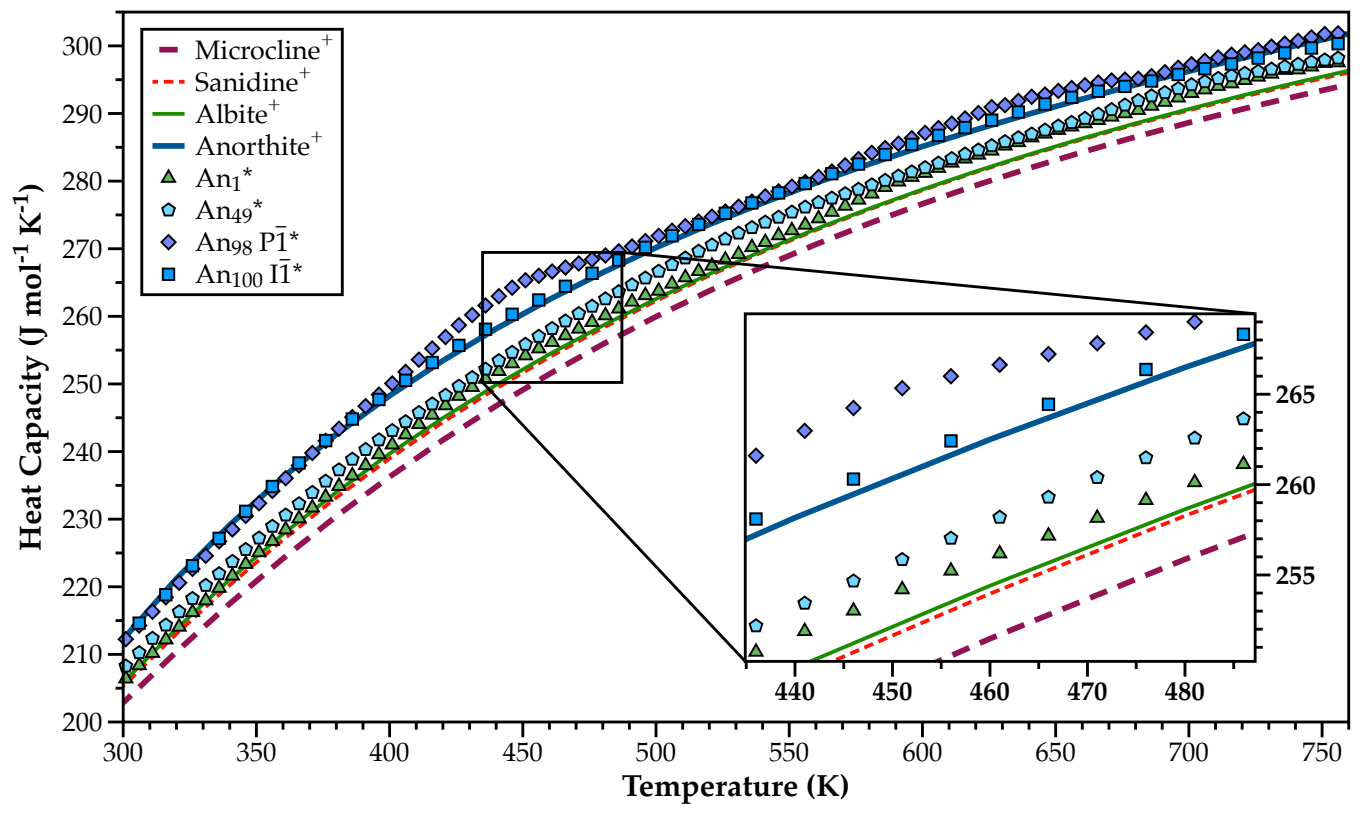

Figure 4-4) Heat capacity of various feldspars from ${ }^{+}$Robie and Hemingway (1995) and *Benisek et al.

(2013). Values from Robie and Hemingway (1995) are fits to experimental data (lines), whereas those from Benisek et al. (2013) are reported data points (available in supplementary materials). Heat capacity of $P \overline{1}$ An98 shows a change in slope near the temperature where $P \overline{1}$ phase transforms to I $\overline{1}$ phase (see Fig. 4-2), but this transformation is apparently absent from An100. Modest, but not insignificant differences in heat capacity due in part to structural differences between samples of similar composition are possible.

\subsubsection{Interpolation models for thermal diffusivity of the plagioclase solid solution}

Both $C_{P}$ and $\rho$ can be interpolated linearly between the end-member values, with relatively small uncertainties. The density of albite is $2.62 \mathrm{~g} \mathrm{~cm}^{-3}$ for both $C \overline{1}_{\text {low }}$ low and $C \overline{1}_{\text {high }}$ high, and the density of anorthite is $2.76 \mathrm{~g} \mathrm{~cm}^{-3}$ (Gaines et al., 1998). Thermal diffusivity shows more complex variations with composition (see Fig. 4-3, Fig. 4-5 below), so three approaches were used to interpolate plagioclase $D$ for compositions not measured in the LFA: 
L) A weighted linear model (Linear), in which $D$ was calculated based on linear interpolation between discrete measured compositions:

$$
D\left(\mathrm{X}_{\mathrm{An}}\right)=\mathrm{a}+\mathrm{b}^{*} \mathrm{X}_{\mathrm{An}}
$$

Equation 4-5.

where $\mathrm{a}$ and $\mathrm{b}$ are constants fitted for each interval, and $\mathrm{X}_{\mathrm{An}}$ is the anorthite content of the plagioclase being calculated.

P) A piecewise model (Piecewise):

$$
D\left(A n_{\mathrm{x}}\right)=\mathrm{c}+\mathrm{e} \mathrm{X}_{\mathrm{An}}+\mathrm{fX}_{\mathrm{An}}{ }^{-2}+\mathrm{gX}_{\mathrm{An}}{ }^{-1 / 2}
$$

Equation 4-6.

where $\mathrm{c}, \mathrm{e}, \mathrm{f}$, and $\mathrm{g}$ are fitting parameters, and $\mathrm{X}$ is anorthite content in percent. This equation was applied between three subsets of composition: Na-rich values $\left(\mathrm{An}_{1.8}\right.$ to An47), intermediate Ca-values ( $\mathrm{An}_{47}$ to $\left.\mathrm{An}_{64}\right)$ where coupled substitution changes plagioclase from $\mathrm{Si}$ - to $\mathrm{Al}$ - rich and measured values are highly complex, and $\mathrm{Ca}$-rich values $\left(\mathrm{An}_{64}\right.$ to $\left.\mathrm{An}_{95}\right)$.

A) An power-law function applied across the entire compositional range (All compositions):

$$
D\left(\mathrm{An}_{\mathrm{x}}\right)=\mathrm{hX}_{\mathrm{An}}{ }^{\mathrm{i}}+\mathrm{j} \mathrm{X}_{\mathrm{An}}
$$


Where $\mathrm{h}$ and $\mathrm{j}$ are fitting parameters. This model is called "All compositions" because it incorporates all measured values in the fit, rather than in between discrete, or subsets of measured An contents.

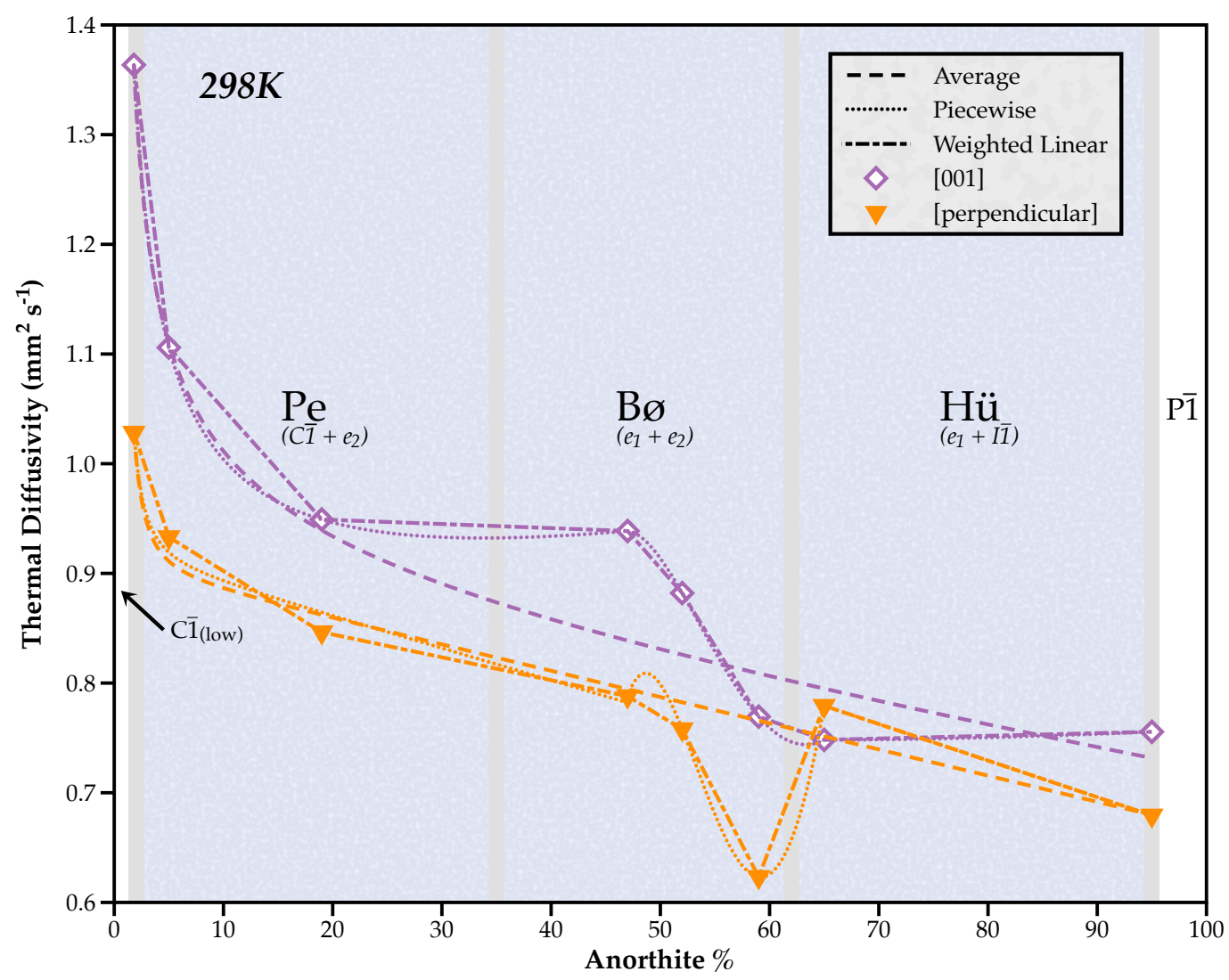

Figure 4-5) Two orientations showing displaying three interpolation models for plagioclase. The average model uses a single equation to fit all An values, the Piecewise models fits values from $\mathrm{An}_{1.8}$ to $\mathrm{An}_{47}, \mathrm{An}_{47}$ to $\mathrm{An}_{64}$, and $\mathrm{An}_{64}$ to $\mathrm{An}_{95}$ using separate equations, and the Weighted Linear model averages linearly between each point. Figure shows the stable plagioclase structures formed at $298 \mathrm{~K}$, not necessarily the phase present in samples measured by Branlund and Hofmeister (2012). Abbreviations explained in text and in Fig. 4-2 captions. Only orientations [001] and [perpendicular] (highest and lowest $D$ values at 298K) are presented for clarity. 
Figure 4-5 shows the results of each of these models at $298 \mathrm{~K}$ for the [001] and [perpendicular] orientations of each sample from Hofmeister et al. (2009), and Branlund and Hofmeister (2012). In general, the decrease in $D$ with increasing Ca- and Al- content is fit broadly by the "All" model, local, strong deviations occur at intermediate compositions (e.g. An 49 ), and the slow and fast orientation can occasionally reverse (c.f. [Perpendicular] and [001] at An64, Fig. 4-5). Although the model implies that pure anorthite should have lower $D$ than the highest-An sample measured (An95), disorder within samples is often a source of lower $D$ (e.g. Branlund and Hofmeister, 2012; Branlund and Hofmeister, 2008; Pertermann et al., 2008), and thus the exponential increase in $D$ between oligoclase and nearly-pure albite compositions could be mirrored somewhat at very high Ca-contents.

In the absence of two diverse sets of measurements for samples of the samecomposition with different starting structures (e.g. rapidly-cooled volcanic plagioclase and slowly-cooled magmatic or metamorphic plagioclase of the same composition) across the full series, the Average model presents the best compromise between the broader trend of decreasing $D$ with increasing Ca- content, and minimization of local variations of sample-specific origin. Figure 4-6 shows the average model only, at selected temperatures from $298 \mathrm{~K}$ to $1000 \mathrm{~K}$. All three measured orientations are shown, along with three calculations of the average for each composition: a harmonic average (modeled after eq. 4-2), corresponding to the "resistors in series" conductivity model, an arithmetic average, corresponding to the "resistors in parallel" model (based on eq. 4-1), and a geometric average (eq. 4-3). Fitting parameters for individual compositions 

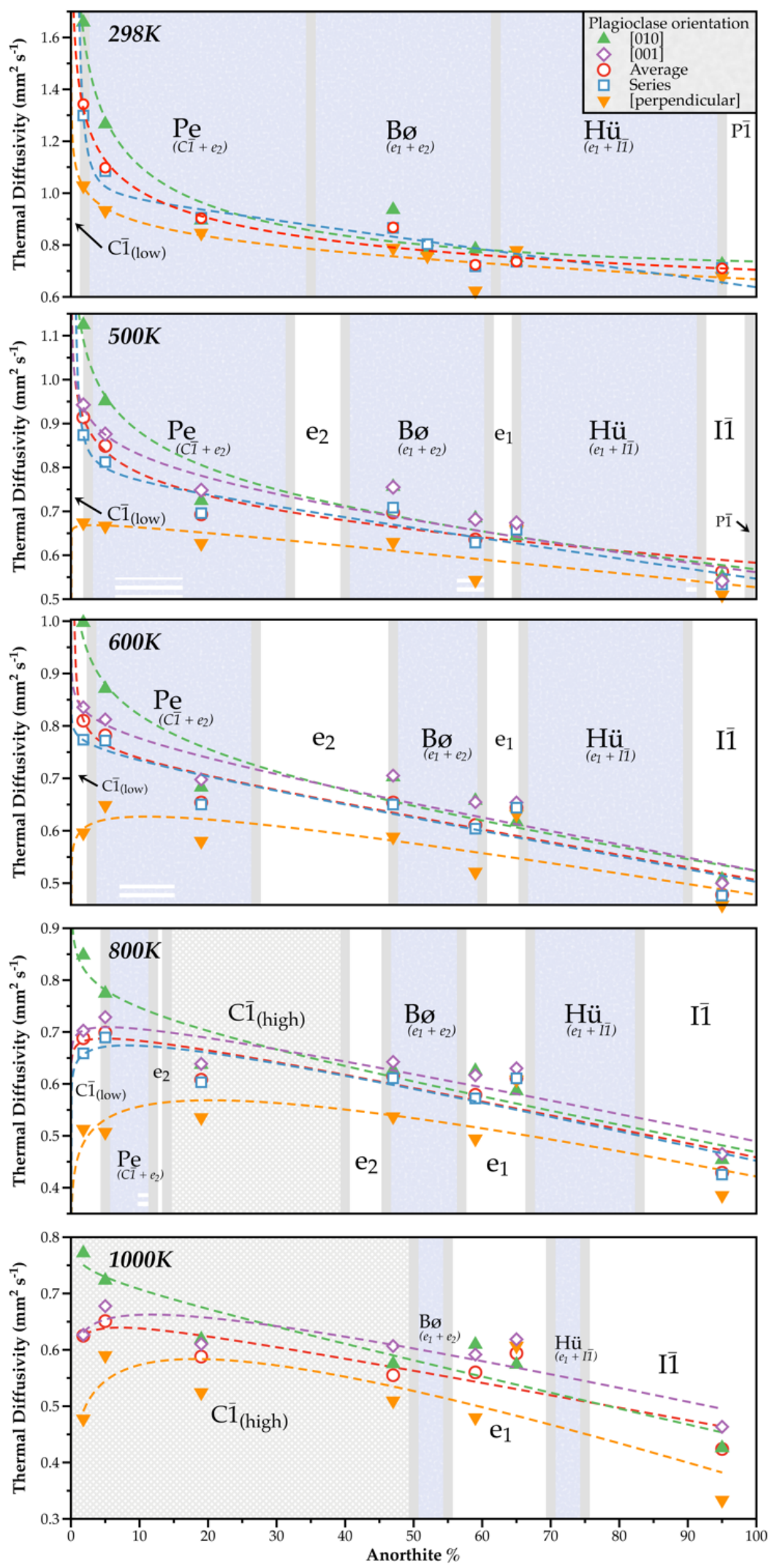

Figure 4-6) Measured

(triangles and diamonds) and averaged (circles and squares) plagioclase $D$ reported by Hofmeister et al., 2009 and

Branlund and Hofmeister

(2012) at discrete temperatures. Dashed lines represent the Average interpolation model (see text).

Grey, blue and white background denote different stable phases of plagioclase at a given temperature and anorthite content, which may not be reflected in measured $D$ due to sluggish kinetics. At low temperature, highly albitic compositions produce the highest $D$ plagioclase, but elevated temperatures likely cause structural changes that change relative $D$, not only between compositions, but also between fast and slow orientations of the same composition (c.f. $\mathrm{An}_{47}$ at $298 \mathrm{~K}$ and $1000 \mathrm{~K})$. Note the scale changes between panels. 
are included in the Excel spreadsheet [RockCalculator] under the "MinParams" tab, in the online supplementary material (appendix 2). Fitting parameters for all three plagioclase models are presented there as well.

\subsubsection{Equations for thermal diffusivity of plagioclase at ambient temperature}

Application of the three plagioclase models described above to calculation of thermal diffusivity of rocks at ambient temperature (chapter 3 ) requires an equation for interpolating $D$ between measured compositions of plagioclase. For elevated temperature applications (part III), individual equations are available for predicting $D$ across relevant lithospheric temperatures. Presentation of the three averaging methods for three plagioclase models is available in the supplementary material. However, for first-order application to ambient temperature, the following equation produces the simplest results that are closest to measured values for samples with no preferred orientation (see section 7):

Parallel: $D\left(\mathrm{An}_{\mathrm{x}}\right)=1.43 * \mathrm{An}_{\mathrm{x}}{ }^{-0.15}+\mathrm{An}_{\mathrm{x}} * 9.94 * 10^{-5}$

Equation 4-7.

Where $\mathrm{An}_{\mathrm{x}}$ is the anorthite content of the plagioclase in question. This equation is the Pythagorean average of orientations using the Average model described above. 


\subsection{DIRECT CALCULATION OF THE THERMAL DIFFUSIVITY OF ROCKS AT AMBIENT CONDITIONS}

Although the plagioclase-quartz mixtures discussed in chapter 3 appear to be well reproduced by equations 3-11 and 3-12, these results were achieved by isolating disks with only minor accessory and trace phases. This was possible because the two major phases had a well-characterized relationship between composition and $D$. In the larger suite, a number of samples lacked a single dominant phase, and had low modal quartz. Equations 3-11 and 3-12 do not work well samples with abundant secondary or minor minerals, nor will they work for rocks composed of other major phases. To this end, we have created a spreadsheet [RockCalculator_v5.3.5], which compares the results of measured disk $D$ to calculated disk $D$. RockCalculator solves for both $k$ and $D$ using equations 4-1 through 4-3. This spreadsheet incorporates results from all three plagioclase models discussed in part I, and the broader database of $D$ results measured using the LFA over the last 15 years, compiled in Hofmeister (2019).

\subsubsection{The RockCalculator Spreadsheet}

RockCalculator requires the following inputs: measured $D$, temperature (in $\mathrm{K}$ ), weight fraction of up to six phases, and phase names which are consistent with the database located in the "MinParams" tab. Results are produced automatically by first recalculating the volume fraction of each phase using published mineral densities (Gaines et al., 1998). For solid-solutions, linear variations in density between end-members are 
assumed. Although strictly incorrect, this assumption produces only small error for most phases, because contrasts in density between endmembers is typically small (e.g. the density of pure albite is $2.63 \mathrm{gcm}^{-3}$ compared to $2.75 \mathrm{gcm}^{-3}$ for anorthite). Heat capacity is calculated for each phase using equation 3-2 and published values for minerals (from Robie and Hemingway, 1995 unless otherwise stated), and then combined using the arithmetic mean.

Thermal diffusivity is then calculated using published values assigned to each phase by the user. All minerals which have anisotropic thermal diffusivity or conductivity require assumptions about how the mineral is oriented within the sample. For example, for a sample with no mineral fabric composed of plagioclase $\left(\mathrm{An}_{25}\right)$ and quartz, calculation requires the user to choose how the two orientations of quartz (heat flow into the [100] face or [001] face) will be averaged: arithmetically (analogous to resisters in parallel), harmonically (resisters in series), or using the geometric mean. To avoid confusion with the mixing models described in section 4-3, we will refer to these averaging methods as the Arithmetic average, the Harmonic average, and the Pythagorean average respectively. For phases with small differences in $D$ between orientations, all these methods will produce similar results. For example, at 295K, calcite $D$ is $1.64 \mathrm{~mm}^{2} \mathrm{~s}^{-1}$ and $1.60 \mathrm{~mm}^{2} \mathrm{~s}^{-1}$ parallel and perpendicular to the c-axis respectively (Merriman et al., 2018). However, for highly anisotropic minerals (e.g. quartz [100] $\left.3.60 \mathrm{~mm}^{2} \mathrm{~s}^{-1},[001]-7.097 \mathrm{~mm}^{2} \mathrm{~s}^{-1}\right)$, these different averaging methods produce much stronger contrasts between means (e.g. for quartz, the Arithmetic mean $=5.35 \mathrm{~mm}^{2} \mathrm{~s}^{-1}$, the Harmonic mean $=4.77 \mathrm{~mm}^{2} \mathrm{~s}^{-1}$, and the Pythagorean mean $=5.05 \mathrm{~mm}^{2} \mathrm{~s}^{-1}$ ) 
With the above calculations, the spreadsheet can produce a $\rho, C_{P}$, and $D$ for each phase, which in turn is used to calculate $k$ for the bulk rock according to the models described in section 3 above.

\subsubsection{Example Results}

\subsubsection{Sample 16-36}

To explore the analysis process, we present detailed results for two samples with analysis performed on multiple slices. The first sample, 16-36, is primarily a quartzfeldspar mixture in which six disks were measured in the LFA. The average abundance of major phases within the disks was $\sim 60 \%$ plagioclase, $20 \%$ quartz, and $10 \%$ microcline by weight, and included the accessory phase biotite, and trace phases apatite, and titanite. However, high and low values of $75.7 \%$ and $54.9 \%$ for plagioclase, and $25.6 \%$ and $14.5 \%$ for quartz were calculated from XRD and optical analysis in different disks. Probe results revealed an average An content of $17.5 \pm 1.2 \mathrm{~mol} \%(2 \sigma)$ in plagioclase, with potassium-dominated microcline containing less than $4 \mathrm{~mol} \% \mathrm{Na}$. Mixing calculations were performed using all three plagioclase models, all three orientation-averaging models, a variation in mean An content of $\pm 1 \mathrm{~mol} \%$, and alternating between data for either intermediate or maximum microcline, and biotite or phlogopite (Hofmeister and Carpenter, 2015).

To evaluate the effectiveness of calculations, we used the ratio of calculated $D$ $\left(D_{\text {calc }}\right)$ to measured $D\left(D_{\text {meas }}\right)$, which indicates the relative error, rather than the absolute difference between $D_{\text {calc }}$ and $D_{\text {meas. }}$. For ambient- $T$ measurements of sample 16-36 and 
using the geometric $(G)$ method (between 295.18 and $296.65 \mathrm{~K}$ ), the mean $D_{\text {calc }} / D_{\text {meas }}$ ranged from $1.02 \pm 0.05$ to $1.07 \pm 0.05$ for models P-An19 - geometric and Biotite-average respectively. Results for the Parallel and Series models are less consistent with measured $D$. The Parallel $D_{\text {calc }} / D_{\text {meas }}(P)$ ranged from $1.35 \pm 0.05$, to $1.39 \pm 0.05$, and the series $(S)$ from $0.82 \pm 0.07$ to $0.93 \pm 0.06$ for the same mineral models as above. This trend of high $P$ and low $S$ is similar for nearly all samples measured.

For all three plagioclase models, a slightly high value relative to measured probe compositions of $\mathrm{An}_{19}$ produced the most similar $D_{\text {calc }}$ to $D_{\text {meas }}$. However, the Piecewise plagioclase model had the lowest error: an $\sim 0.5 \%$ departure from measured $D$. All calculations have results within $\sim 10 \%$ of measured values, and the best results $\left(\right.$ Piecewise- $\mathrm{An}_{19}$ ) have a calculated individual disk variance of $-8.1 \%, 6.2 \%,-1.7 \%, 2.8 \%$, $0.1 \%$, and $2.4 \%$ (figure $4-7$ ). For consistency, when multiple disks of the same sample were measured, the same phase parameters are used for each disk under the assumption that mineral compositions and structures are unlikely to vary significantly between different slices. However, as is discussed in the following section, this assumption is not always valid. Although specific An contents produce better results for isolated disks, the results shown above and in the figures that follow are for those inputs which produce the most consistent results between all disks of the same sample.

\subsubsection{Sample 16-28}

Sample 16-28 is another feldspar-quartz mixture with both alkali and plagioclase feldspars, and minor phyllosilicates. Microprobe analysis of plagioclase feldspars on a 1" round produced three plagioclase compositions ranging from nearly pure albite 

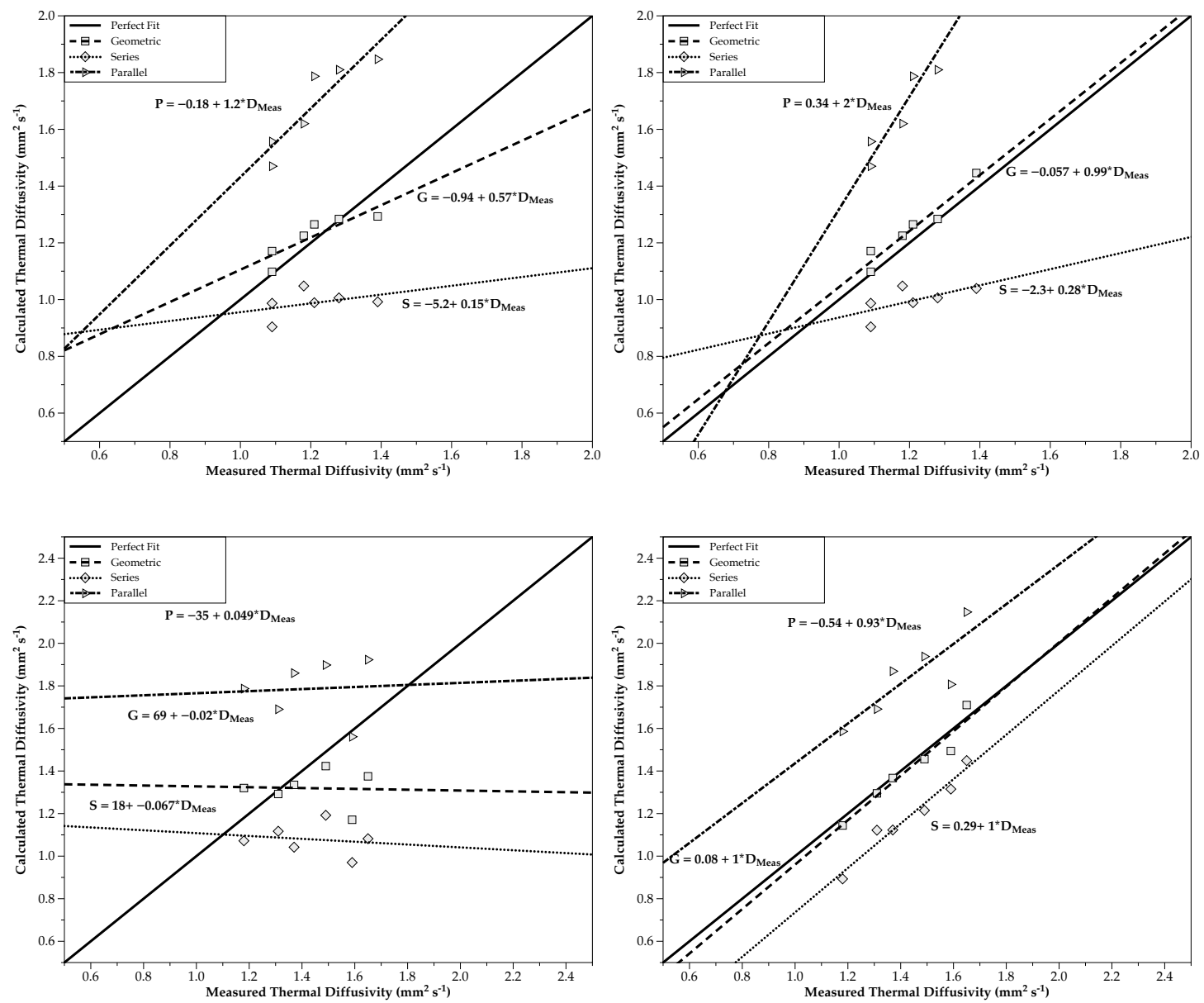

Figure 4-7) Ratio of measured to calculated $D$ for samples $16-36$ (A and $\mathrm{B}$ ) and $16-28$ (C and D). A and C are based on XRD analysis for the entire disk, whereas panels B and D are based only on the center $0.5 \mathrm{~cm}$ of the disk, which interacts with the LFA spot. 16-36 - In addition to an improved slope for the G model ( 0.99 compared to 0.57 ), goodness of fit parameters $\mathrm{R}^{2}$ and RMSE improve from 0.75 and 0.04 respectively for the initial fit, to 0.94 and 0.03 for the corrected fit. 16-28 - Two sets of errors lead to the poor trends observed in $\mathrm{C}$ : variation in plagioclase composition of $\sim 17 \% \mathrm{~mol} \mathrm{Ca}$, and heterogeneity between the full disk mineral composition, and the center $0.5 \mathrm{~cm}$ measured in the LFA. See text for further discussion. Correction of the above sources of errors produces a much stronger fit (B), with an $\mathrm{R}^{2}$ OF 0.93 , RMSE OF 0.06 for the G fit, compared to 0.002 and 0.096 for the same fit parameters prior to correction. Similar contrasts and fit parameters occur for the $\mathrm{P}$ and $\mathrm{S}$ models. 
$\left(\mathrm{An}_{1.7} \mathrm{Ab}_{98.0} \mathrm{Or}_{0.3}\right)$ to $\left(\mathrm{An}_{9.1} \mathrm{Ab}_{90.4} \mathrm{Or}_{0.5}\right)$ to oligoclase $\left(\mathrm{An}_{19.9} \mathrm{Ab}_{79.2} \mathrm{Or}_{0.8}\right)$. Microcline was again Na-poor ( Or $_{96.5)}$, but unlike 16-36, disks of 16-28 had considerable chlorite content, which was slightly Fe-rich (chamosite $55 \%$, clinochlore $44 \%$ by mol).

Considering the potential for three plagioclase feldspars detected by the probe, calculating $D$ required evaluating the five LFA disks with all three compositions. Measured $D$ ranged from 1.18 to $1.65 \mathrm{~mm}^{2} \mathrm{~s}^{-1}$, despite only modest variations in quartz and plagioclase abundances reported by the XRD: Plagioclase: $60.3-74.7 \mathrm{wt} \%$; quartz: 17.5-24.7 wt\%. XRD could not be used to determine variations in plagioclase composition between disks, because the feldspars do not have a dominant peak in diffraction patterns, and variations between different compositions are subtle.

Using the endmember approach in calculating $D$ and $k$, an input of $A_{02}$ for plagioclase produced calculated $D$ values that were high compared to measured values by up to $36 \%$ for all but one sample (Figure 4-7). However, both an intermediate plagioclase value $\left(\mathrm{An}_{11}\right)$ and a maximum anorthite value $\left(\mathrm{An}_{19}\right)$ reproduce measured $D$ values within $5 \%$ total error for the sample. A higher Ca-content would be more consistent with the relative abundance of $\mathrm{CaO}$ to $\mathrm{Na}_{2} \mathrm{O}$ reported by ICP-OES (1.4 vs. $5.1 \mathrm{wt} \%$ respectively, table 3-3) as no other major phases should be significant repositories of these elements. For four of the five disks imaged in the SEM (disk c2d1 was not included in SEM analysis), EDS produced detectable $\mathrm{Ca}$ and $\mathrm{Na}$ content in plagioclase grains. However, alteration in some grains of plagioclase is clear from PLM images (Figure 3-2), and in some images, more pervasive closer to grain boundaries. Some of the bimodal compositions reported by the probe could, therefore, be a result of variable amounts of low-temperature alteration within plagioclase grains, as some totals are consistent with 
the presence of water or $\mathrm{OH}^{-}$in hydrous alteration products such as muscovite or chlorite.

In particular, EDS illustrated very low concentrations of $\mathrm{Ca}$ for most plagioclase grains of

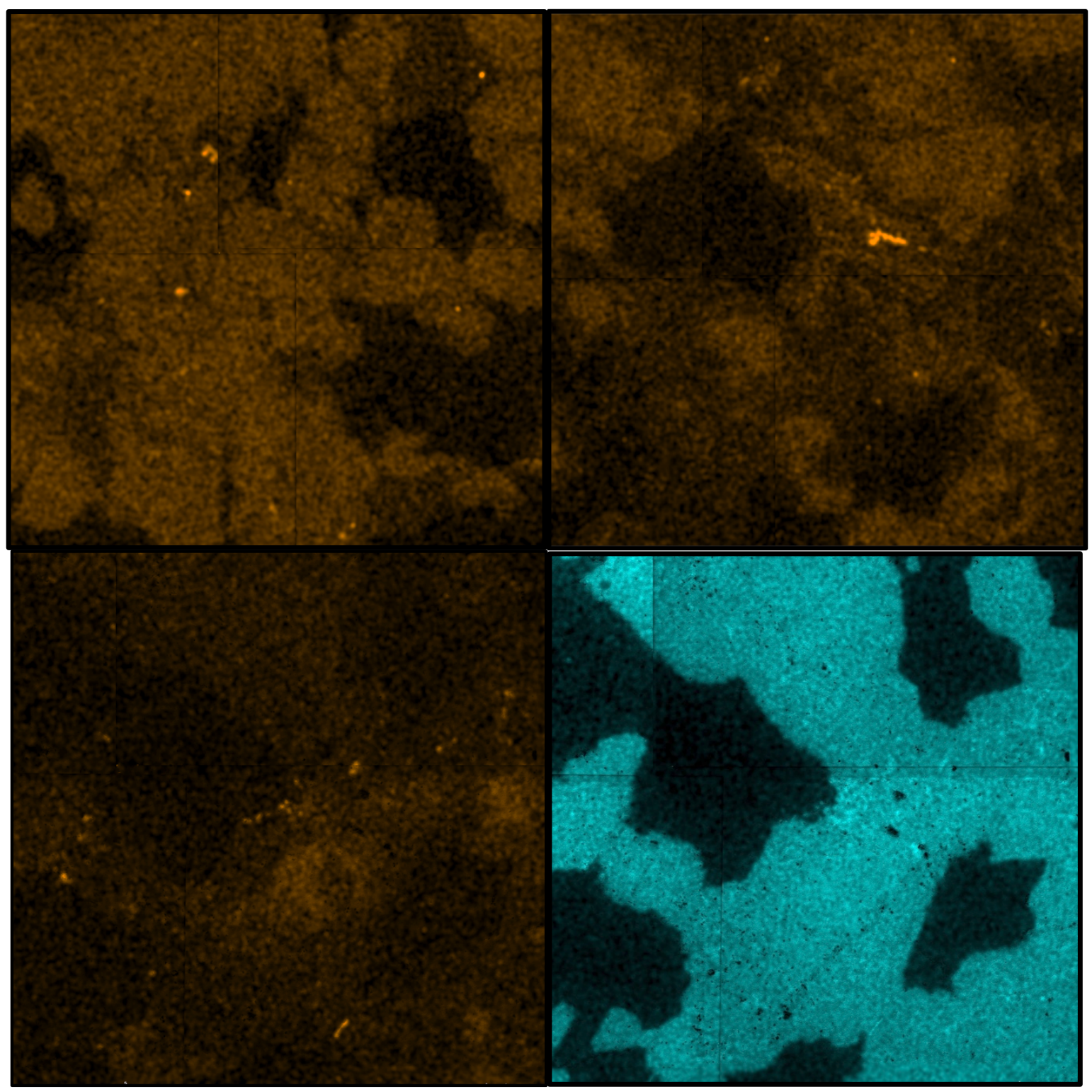

Figure 4-8) EDS maps of Ca content of disks c1d1 (upper left), c8d1 (upper right), and c4d2 (bottom left), with matching $\mathrm{Al}$ content for $\mathrm{c} 4 \mathrm{~d} 2$ (bottom right). Maps illustrate variability within-sample of $\mathrm{Ca}$ in plagioclase from $\sim \mathrm{An}_{19}(\mathrm{c} 1 \mathrm{~d} 1)$, to nearly-pure albite (c4d2). The $\mathrm{Al}$ map is for reference of plagioclase surfaces in $\mathrm{c} 4 \mathrm{~d} 2$. A minor microcline grain is located in the center and indicated by slightly higher $\mathrm{Al}$ and $\mathrm{Ca}$ content. Black zones are typically quartz. An content likely reduced by fluid-induced retrogression preferentially concentrated in plagioclase. 
disk c4d2 (fig. 4-8), consistent with the measured, nearly albitic composition in the probe.

As a whole, the measured $D$ of the six disks of sample 16-28 are well-reproduced by using $\mathrm{An}_{19}$ for plagioclase with the exception of disks c4d2 and c1d1, which align better with $\mathrm{An}_{02}$. The phases intermediate microcline (Roy et al., in review), sodic diopside (Hofmeister and Pertermann, 2008), biotite and muscovite (Hofmeister and Carpenter, 2015), and chlorite (Hofmeister, 2019) with orientations averaged by arithmetic mean produced a mean $G$ of $1.019 \pm 0.067$ (Fig. 4-7). Using geometricallyaveraged orientations produced a negligibly-different $G(0.993 \pm 0.068)$.

\subsubsection{Phyllosilicate averaging methods}

For the above results, biotite, chlorite, and muscovite were averaged using the series method, rather than arithmetic, or geometric means. Despite small contents of these phases in disks ( $<5 \%$ by volume for most disks), the method of averaging platy minerals appears to have a strong influence on calculated $D$ and $k$. For example, using the arithmetic mean for biotite and muscovite-P raises the mean $G$ for the six disks of 16-28 to $1.065( \pm 0.08)$, with all disk ratios above 1.00 . This effect is similar for all samples that contain platy minerals as phases qualifying as secondary in abundance or higher, and likely results from the high contrast in $D$ between orientations of platy minerals: e.g. $D$ of biotite is $1.34 \mathrm{~mm}^{2} \mathrm{~s}^{-1}$ and $0.12 \mathrm{~mm}^{2} \mathrm{~s}^{-1}$ if heat flows parallel to or perpendicular to cleavage respectively (Hofmeister and Carpenter, 2015).

\subsubsection{Optical corrections to XRD}


Detailed optical analysis was available for all disks of sample 16-36 and all but one disk of 16-28. These images include EDS and backscatter on one side of the disk, PLM images of alternate cuts of the sample, and binoscope images of both sides of the disks with a magnification of $\sim 2-5 \mathrm{x}$. Of note, the detector for the LFA measures $D$ on an area which is determined by the aperture of a graphite cover placed over the sample prior to analysis. For all samples in this work, this aperture was set to a diameter of $0.5 \mathrm{~cm}$, which limits the analysis to the center of the disk. However, XRD measurement was performed for most samples on a fully-mixed powder of the whole disk. On the scales analyzed here, some heterogeneity between the full disk and the center is reasonable, particularly for layered samples, or coarser-grained samples.

Closer examination of the optical images for samples 16-36 and 16-28 suggested modest contrasts in the abundance of major phases between the full disk, and the center analyzed by the LFA for disks c1d3 (16-36) and c8d1 (16-28). For example, XRD reported $65.8 \%$ plagioclase, $23.7 \%$ quartz, $5.3 \%$ biotite, and $4.9 \%$ microcline by weight for disk c1d3 (16-36). By layering binoscope images over EDS maps in Adobe Photoshop, we were able to differentiate between plagioclase and quartz in areas of the binoscope images that were not covered by EDS. This provided sufficient textural information on each phase to calculate the abundance of all major phases in the full disk, and thus the distribution of phases on both sides of the disk. Isolating the center of the disks and using the analysis tool in Adobe Photoshop produced a mean abundance of 

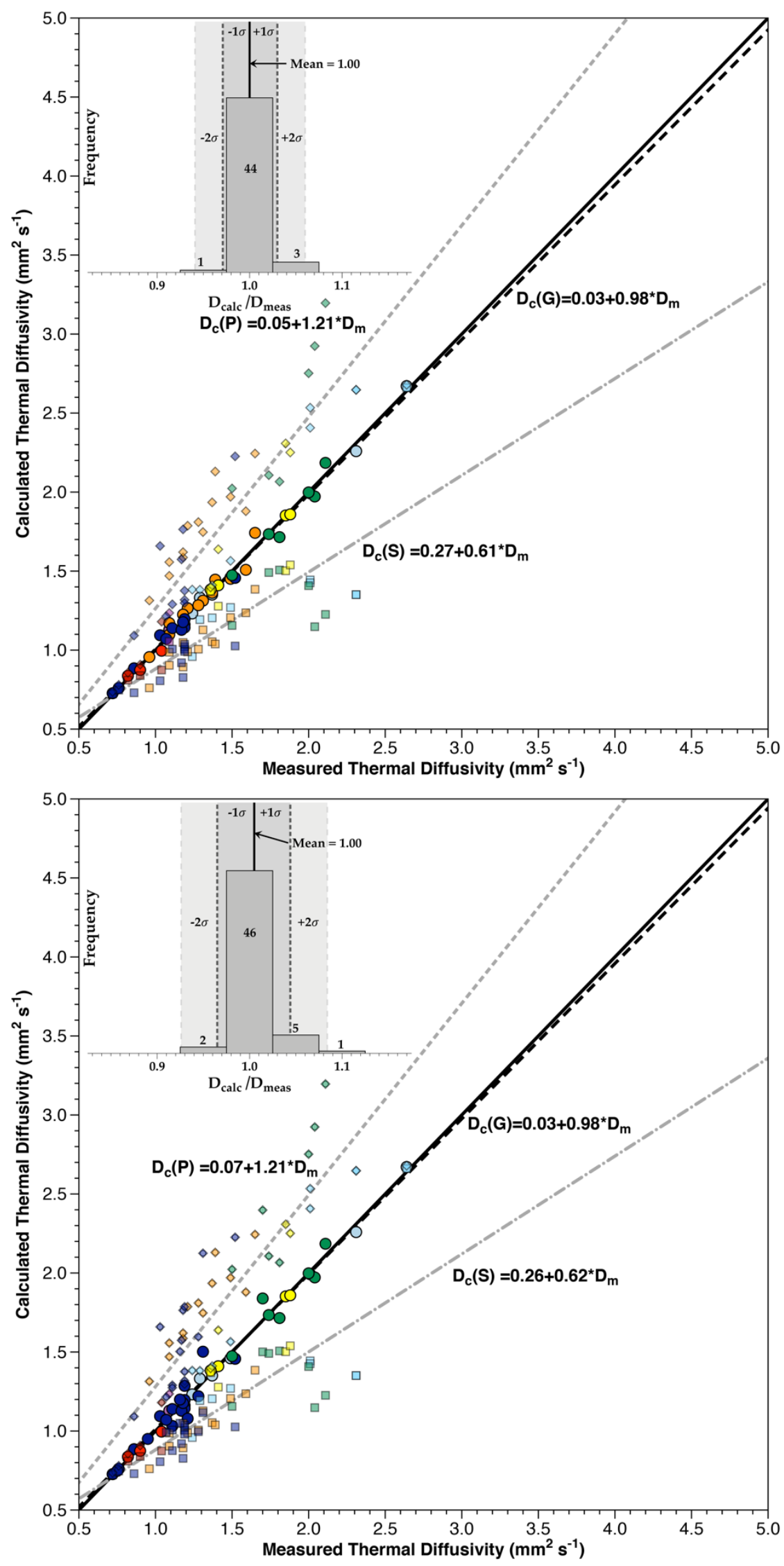

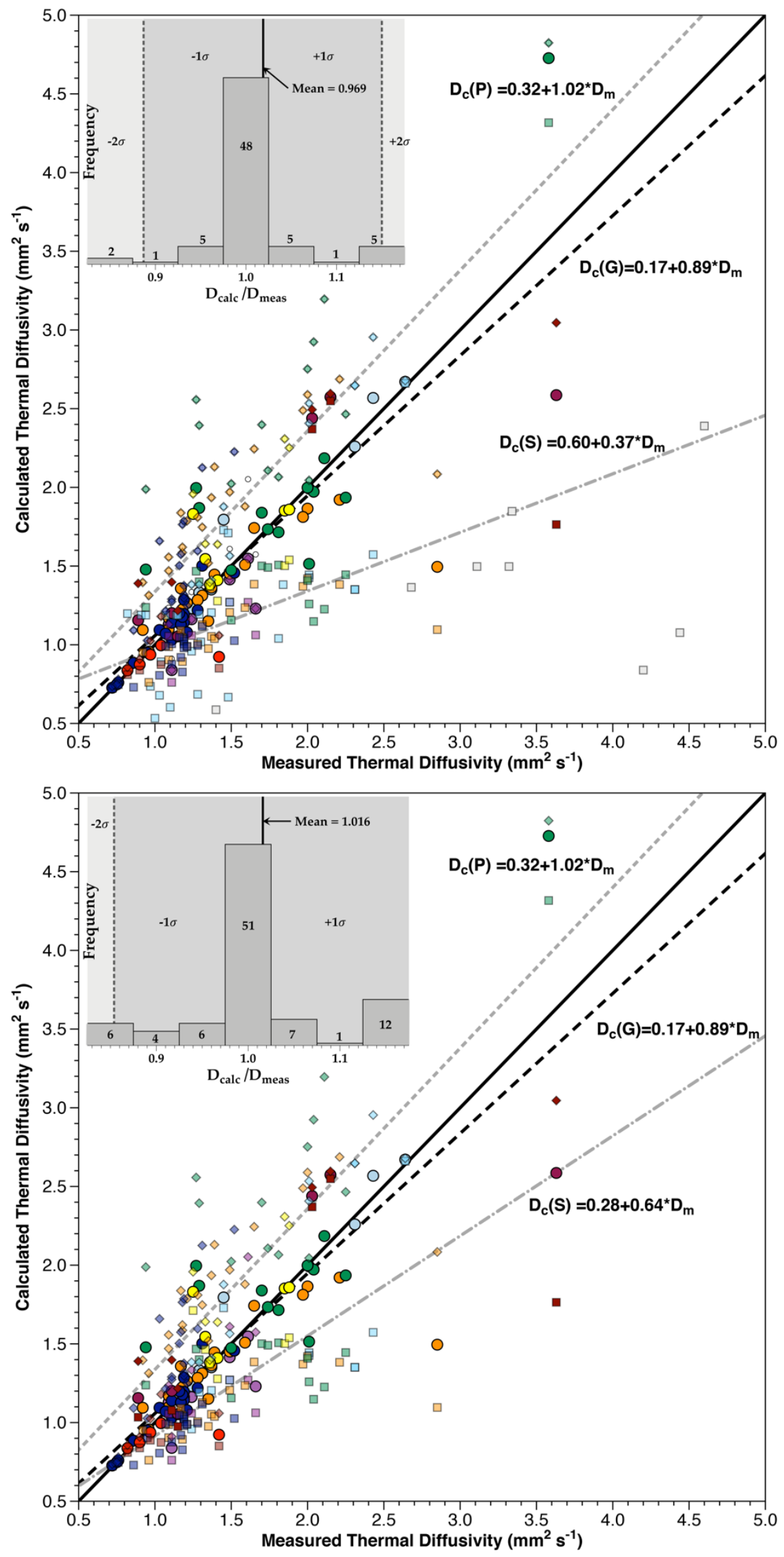

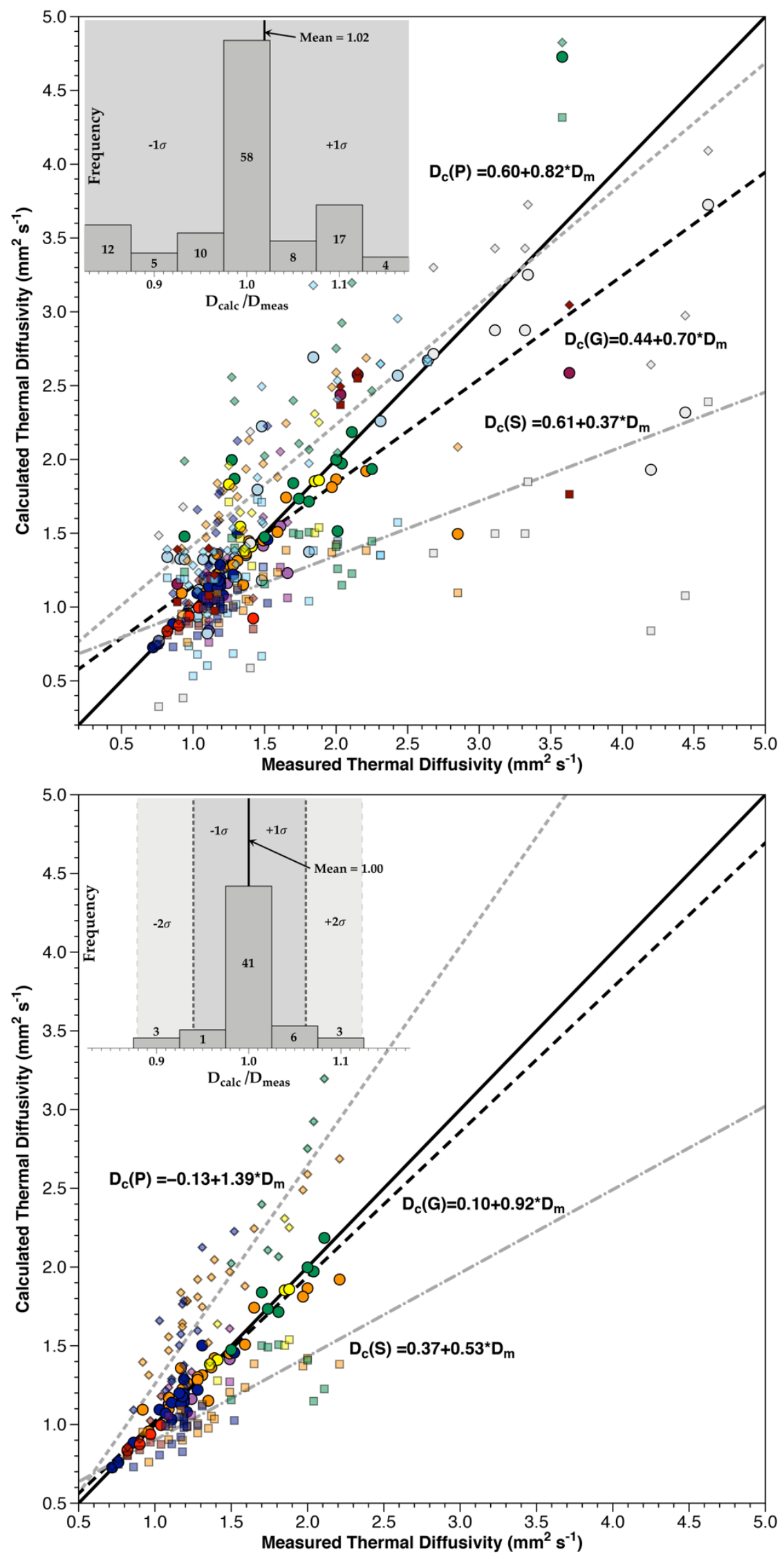
Figure 4-9) Comparison of results for calculated $\left(D_{c}\right)$ and measured $\left(D_{m}\right)$ by removal/addition of samples as discussed in section 4.4. Each figure shows results for the Parallel (P, diamonds), Geometric (G, circles) and Series (S, squares) models along with fits a linear. See figure 3-1 for color scheme, and note the change in scale between A-D and E-F. A) Best results. B) Effects of adding samples with less thorough characterization of disks. C) Effects of adding samples with mineral orientation anisotropy. D) Effects of adding samples with porosity higher than $1 \%$. E) The full suite of 122 disks: effects of adding samples with major phases without LFA data. F) A narrow suite of 58 samples with plagioclase as the first or second most abundant phase.

$53.5 \%$ plagioclase, $30.5 \%$ quartz, $9.9 \%$ microcline, and $6.1 \%$ biotite between the two sides. When this result is used in place of XRD data for the disk, $G$ increases to 1.04 compared to the previous 0.933 . Similarly, using optically-calculated abundances for disk c8d1 (16-28) decreased $G$ from 1.14 to 0.97 . The effects on the fits for the full samples of both is shown in figure 4-7, and most importantly includes a decrease in standard deviations when combined with An-content corrections from 0.07 to 0.04 for $16-28$ and 0.05 to 0.03 for $16-36$.

TABLE 4-1. SUITE LINEAR FITTING PARAMETERS

\begin{tabular}{lcccc}
\hline \hline Suite (fig panel) & Number of Disks & $P-R^{2}$ (RMSE) & $G-R^{2}$ (RMSE) & $S-R^{2}$ (RMSE) \\
\hline Best Results (A) & 48 & $0.84(0.24)$ & $0.99(0.04)$ & $0.71(0.18)$ \\
No Anisotropy (B) & 67 & $0.71(0.30)$ & $0.83(0.16)$ & $0.63(0.18)$ \\
Mineral Pref. Or. (C) & 79 & $0.72(0.36)$ & $0.69(0.37)$ & $0.54(0.34)$ \\
No Porosity (D) & 87 & $0.73(0.35)$ & $0.75(0.29)$ & $0.53(0.34)$ \\
Full Suite (E) & 122 & $0.71(0.41)$ & $0.69(0.36)$ & $0.34(0.40)$ \\
Plagioclase-Dom. (F) & 58 & $0.85(0.21)$ & $0.95(0.08)$ & $0.75(0.11)$ \\
\hline Note: Fitting parameters for linear equation for suites described in text. See Figure 4-9. \\
\multicolumn{4}{l}{ Mineral Pref. Or. - Suite including disks with mineral preferred orientation } \\
Plagioclase-Dom. - Suite of only disks that are dominated by plagioclase. \\
\hline
\end{tabular}




\subsubsection{Calculations of $D$ and $k$ by suite}

This section examines results for the full suite of rocks. Because of the number of samples, and the wide variety of samples included, these results are divided into multiple subsets, which will be described in turn from the narrowest set, to the full suite.

\subsubsection{Narrow, well-characterized suite}

This subset includes 48 disks from 23 samples. Included disks have the highestquality characterization including EDS and backscatter images of one side, binoscope images of both sides, XRD of the powdered disk, as well as containing minor or no measurable porosity, and no clear evidence for mineral preferred orientation or fabrics on the disk. Using the $G$ method, the $D_{\text {calculated }} / D_{\text {measured }}$ ratio for the suite is $1.00 \pm 0.03$. This $1 \sigma$ uncertainty is within the $3-5 \%$ analytical uncertainty of the LFA at ambient temperature.

As will be a common theme for calculated results, the $S$ and $P$ methods do not reproduce measured $D$ as well as the $G$ method (Figure 4-9). For this subset, the mean $S$ was $0.82 \pm 0.11$ and $P$ was $1.25 \pm 0.16$ (Table $4-1)$. Furthermore, the slope of $D_{\text {calc }} / D_{\text {meas }}$, which should ideally be 1.0 , was 1.2 for $P$ and 0.65 for the $S$ method. It would be tempting to assign these slope values as characteristic of Parallel and Series results for a well-characterized sample set given similar results for later subsets, but it is much more likely that these slopes are a reflection of the anisotropy inherent in the major rockforming minerals which make up the suite. Other suites of quartz-feldspar mixtures may have similar slopes in $D_{\text {calc }} / D_{\text {meas }}$ space, but rocks composed of minerals with different 
anisotropy characteristics between orientations would likely have noticeably different slopes.

Every sample in this suite has well-characterized $D$ for every major phase. These samples are all dominated by plagioclase, quartz, calcite, dolomite or an olivine composition previously measured directly in the LFA (Fo92, Pertermann and Hofmeister, 2006). Each of these phases have either simple compositions which can be characterized through a small set of carefully-selected samples (e.g. quartz, calcite, etc.), or a solid solution with fairly-predictable relationships between composition and $D$ (e.g. plagioclase). Once samples with complex solid-solutions such as amphibole, or phases with uncharacterized $D$ are added, calculations of ambient- $D$, and consequently, $k$, have higher .

\subsubsection{Disk Mineral Heterogeneity}

Some uncertainty likely results from the heterogeneity in distributions between the full disk measured using XRD, and the spot measured by the LFA. Most disks with obvious heterogeneity also had phases that were difficult to distinguish without the assistance of EDS maps. As a result, image analysis of these disks was limited to the side that was mapped with EDS, and we could not place as high of confidence in abundances measured optically as with XRD results for the full disk.

This subset includes all samples from the previous set, as well as six samples with heterogeneity which could not be corrected for using optical methods. Addition of samples with know errors illustrates the effects of controls on $D$ that can easily be missed. Figure 4-9 (B) shows a marginal increase in uncertainty associated with these 
additional samples: $G$ increases from 1.00 to 1.01 , with an increase in the standard deviation from 0.03 to 0.04 . The primary driver of this increased uncertainty is the five disks of sample 14-5B, a sample with layering on the disk scale, which have a $\mathrm{G}$ ranging from 0.93 to 1.15 . Figure 4-10 illustrates some of the heterogeneity between the center (black circle) and the wider disk. Quartz grains (green here as a result of layering with EDS) are concentrated to one side of the disk, whereas pyroxenes (light and dark blue) dominate the other side of the disk. Plagioclase (pale violet) and biotite (dark green) are

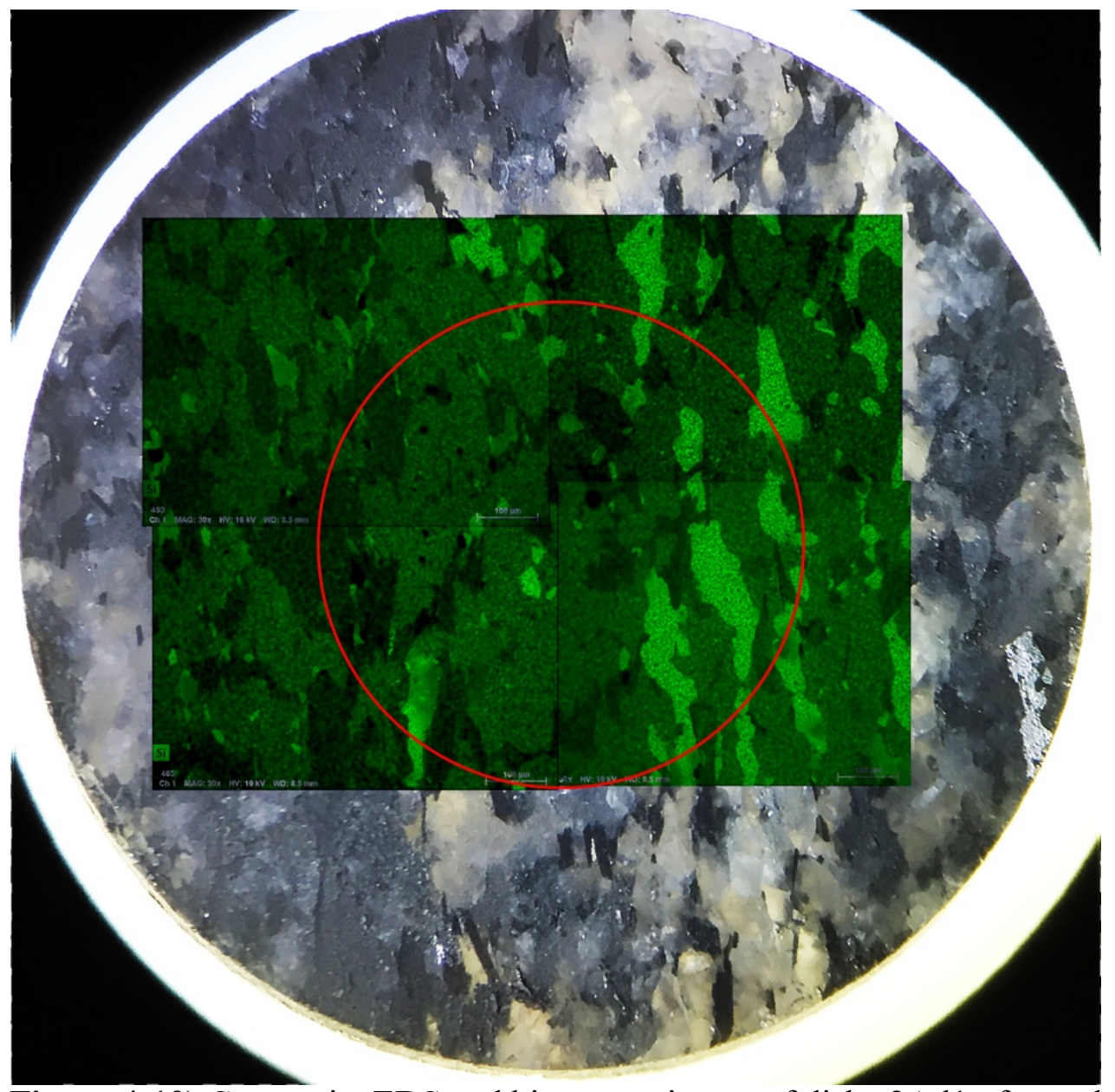

Figure 4-10) Composite EDS and binoscope image of disk c2Ad1 of sample 14-5B. Red circle is the approximate area analyzed by the LFA. Bright green grains are quartz, dark green plagioclase, and black grains amphibole or biotite. Approximate diameter of the disk is $1.1 \mathrm{~cm}$. 
evenly distributed throughout, but in the center, the result is likely a smaller abundance of quartz under analysis in the LFA than the disk as a whole. As a consequence, the calculator modestly underestimates the measured disk $D\left(D_{\text {calc }} / D_{\text {meas }}(G)=0.93\right)$.

\subsubsection{Mineral Shape and Crystal Preferred Orientation}

A number of disks displayed evidence of a crystallographic preferred orientation, sometimes in the form of aligned, elongate minerals such as biotite or amphibole. The strength of this anisotropy varied from modest alignment of amphibole and biotite laths in both disks of sample Acasta, to near-perfect alignment of all micas in heavily micaceous samples from the Upper Peninsula (UP-3A) and Swayze Greenstone Belt (1639). In total, 14 disks had evidence of a preferred orientation likely to influence calculations of $D$.

The effect of anisotropy on calculations ranged from modest: three disks of sample KB12 had $D_{\text {cald }} / D_{\text {meas }}(G)$ of $0.92,1.17$, and 1.19), to extreme: disks of sample UP-3A cut parallel and perpendicular to foliation with nearly-identical mineral abundances produced measured $D$ 's of 2.01 and $0.94 \mathrm{~mm}^{2} \mathrm{~s}^{-1}$ respectively. For calculation of $D$, resulting $G s$ are 0.75 (parallel disk) and 1.57 (perpendicular disk). Similar results were produced for three disks of sample 16-39, with $D_{\text {calc }} / D_{\text {meas }}(G)$ of 0.86 for parallel cut $\mathrm{c} 1 \mathrm{~d} 1$, and 1.45 and 1.58 for perpendicular cut $\mathrm{c} 2 \mathrm{~d} 1$ and $\mathrm{c} 2 \mathrm{~d} 2$.

Corrections of anisotropy effects on calculations is discussed in detail in section 4.4.3.7. However, uncorrected results add significant deviation to the suite as illustrated 
by figure 4-9 (C). With the samples from the previous suites included, 67 disks are shown in this figure, which produce a mean $D_{\text {calc }} / D_{\text {meas }}(G)$ of 1.00 , but a higher standard deviation of 0.07 compared to the two previous subsets.

\subsubsection{Poor characterization}

This subset includes samples with two separate sources of uncertainty: the first is disks with insufficient optical evidence to corroborate disk features with measured properties or whole disk XRD. These disks were missing EDS maps and/or binoscope images. The resulting mismatch in $D_{\text {calc }} / D_{\text {meas }}$ ranged from insignificant: (1.00 for sample KB10ab R\#2), to extreme (0.53 for sample KB12 R\#1).

The second source of uncertainty was secondary or major phases for which $D$ measurements are unavailable. This was particularly important for sample 16-15, a carbonate-bearing BIF containing the major phases siderite and pyrrhotite, for which $D$ data are unavailable. It is less important for samples such as $16-13$, which contains 2.1 wt.\% clinozoisite.

Twenty disks met these criteria, which, when added to the previous subset did not dramatically alter mean $G(1.02)$ but increased the standard deviation more than two-fold to 0.16 (figure 4-9, d). For samples with missing mineral data, the offending phase was either ignored if minor (e.g. 16-13) or replaced with measurements of related phases.

\subsubsection{High porosity reduction}

A number of porous samples were characterized and measured, but excluded from the subsets described above. Porosity was estimated using a combination of methods as 
described in chapter 3 , but pore space, like mineralogy, varies within disks cut from the same sample. Limitations in disk density measurements prevented direct characterization of porosity within disks (see Methods, chapter 3). Porosity is expected to exert a strong influence on bulk thermal transport characteristics, due to the insulating nature of most pore-filling fluids, including air and water (e.g. Branlund and Hofmeister, 2008).

Figure 4-11 shows 18 samples which had either measured porosity or was a sample which is likely to have porosity (e.g. limestone), and the corresponding porosity required to produce that measured $D$ for each sample if pore space was filled with pure water. Although some samples have a calculated porosity similar to measured porosity, others show no correlation between the porosity measured for the bulk sample, and that

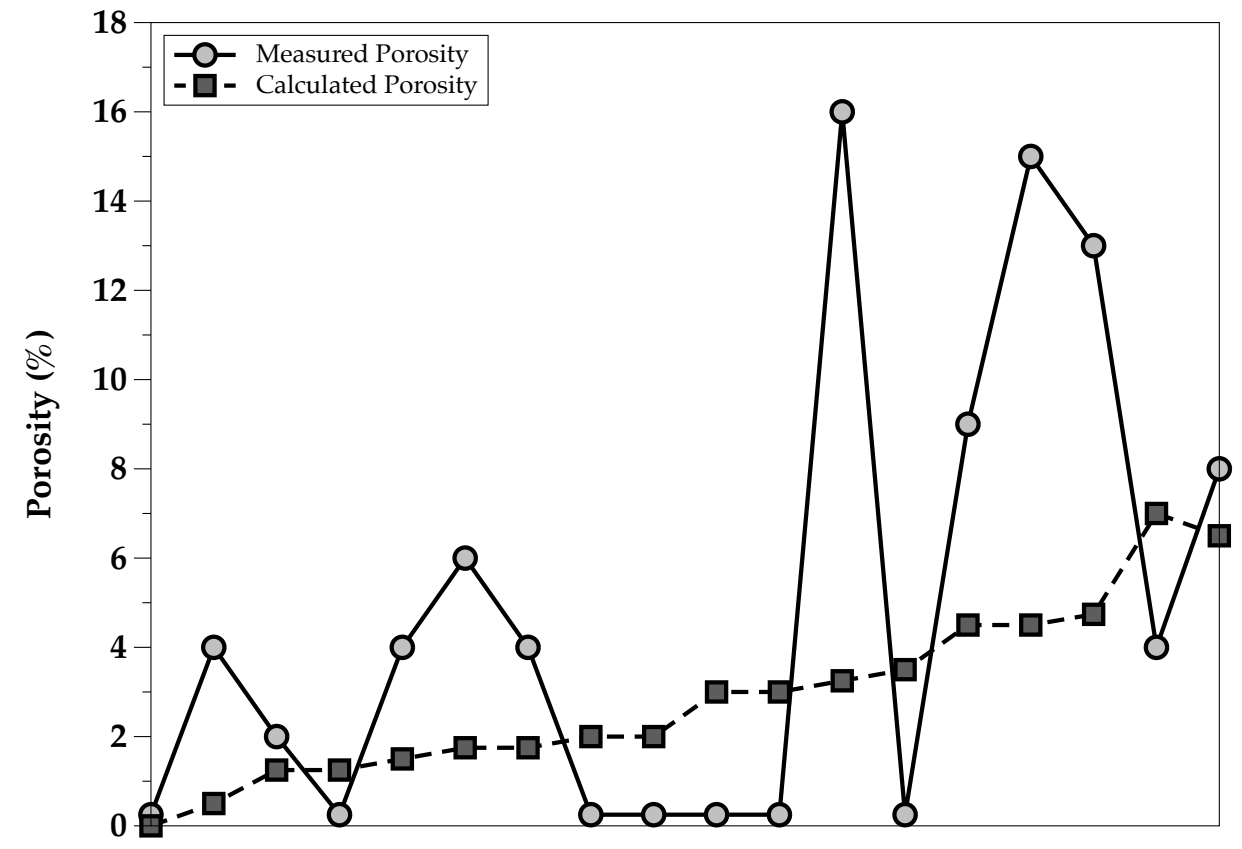

Figure 4-11) Comparison of porosity measured for bulk samples and porosity calculated assuming all mismatch between measured and calculated D is due to water-filled porosity. The x-axis is spaced according to discrete samples and has no physical meaning other than samples are plotted in increasing calculated porosity from left to right. 
estimated from disk $D$. Without a more robust method for determining pore space directly in disks, and better characterized fluid compositions and transport properties for them, highly porous samples have higher uncertainty in calculated $D$ and, consequently, $k$.

\subsubsection{Full Suite}

When high porosity samples were added to the full suite, a total of 122 disks had calculated $D$ which could be compared to measured $D$. Figure 4-9 shows the results for these calculations and frequency diagrams for $G$. The resulting mean $D_{\text {cald }} / D_{\text {meas }}$ was $1.02 \pm 0.20$. The mean is within $2 \%$ of an ideal fit, indicating an accurate model, but the standard deviation of 0.2 reflects low precision, illustrated in the frequency distribution of $D_{\text {cald }} D_{\text {meas. }}$. The high variance for these samples suggests poor characterization, rather than an issue with the model because of the reasons described above. Considering only the best characterized, least porous, most isotropic samples produces much better results, and for all subsets, the best results are achieved by calculating $D$ using the geometric mean (with one exception described below). In the full suite, this is still the case, where the mean $P$ is $1.25 \pm 0.26, G$ is $1.02 \pm 0.20$, and $S$ is $0.81 \pm 0.23$. Similarly, the slopes and intercepts in $D_{\text {calc }} / D_{\text {meas }}$ space are (overall) closer to 1.00 for the $G$ method than the $P$ and $S$ methods (Fig 4-9).

\subsubsection{Modelling Anisotropy}

As discussed in section 5.3.3, crystallographic and shape preferred orientation for samples appears to influence $D$ for several samples. Five disks in particular displayed strong alignment of micaceous phases, and when cut parallel and perpendicular to foliation, produced high anisotropy factors. For example, for sample 16-39, 3 disks were 
measured in the LFA, with one cut such that the laser heats a face cut perpendicular to layering, and two cut parallel to layering (c2d1 and c2d2). Figure 3-6 shows alignment of grains (A). Alignment of platy minerals is clearly visible in the image, suggesting that heat flowing into this face will flow along cleavage planes. Conversely, for the two disks of core 2, flat surfaces of platy minerals are visible in backscatter, which indicates heat must cross each phase in turn. Despite minor variations of quantities of minerals between disks (e.g. 37\% quartz for disk c1d1, and 37\% and 40\% quartz for disks c2d1 and c2d2), $D$ at ambient $T$ varied from $2.25 \mathrm{~mm}^{2} \mathrm{~s}^{-1}$ for disk c1d1, to 1.29 and $1.27 \mathrm{~mm}^{2} \mathrm{~s}^{-1}$ for disks $\mathrm{c} 2 \mathrm{~d} 1$ and $\mathrm{c} 2 \mathrm{~d} 2$ respectively. This translates to an anisotropy factor of 1.75 . Similarly, parallel (c1d1 PA) and perpendicular (c1d1 PE) cuts of sample UP-3A produced an anisotropy ratio of $\sim 2.1$.

This anisotropy causes problems in calculating $D$ using the $G$ model as described in section 5.3.3. Calculations for perpendicular cuts are too high by an average of 53\%, whereas parallel cuts are too low by an average of $20 \%$. However, calculations using the $\mathrm{P}$ and S models produce much more consistent results. For example, for sample 16-39 the S of disks c2d1 and $\mathrm{c} 2 \mathrm{~d} 2$ was 0.96 and 1.03, compared to a G of 1.45 and 1.59 respectively. The parallel cut is slightly over-estimated by the P model (1.14), but a slight improvement over the underestimated $G$ of 0.82 . Similarly, the S and P models produce excellent results for the perpendicular and parallel cuts of disk UP-3A (1.01 and 1.00 respectively). These results suggest that strong alignment of grains can produce pathways for heat that mimic the resistors in series and resistors in parallel models (section 3), but results for other samples with suspected porosity are less convincing. For example, KB09a and KB09c were cut parallel and perpendicular to lineation with resulting $D$ 
measurements displaying a modest contrast of $1.49 \mathrm{~mm}^{2} \mathrm{~s}^{-1}$ and $1.24 \mathrm{~mm}^{2} \mathrm{~s}^{-1}$ respectively (Merriman et al., 2013). However, once mineralogy is accounted for, $G$ is nearly identical for both $(0.95$ and 0.94$)$, and only a slightly improved predictor of $D$ than the P model (1.08 both disks). Mineralogy is more likely the culprit in this case, as actinolite is the dominant phase for KB09a and Plagioclase for KB09c. Sample KB12 produced two disks which have $D$ that is better reproduced by the $S$ model than the G model (disks c1d1 and c2d1), but the four remaining disks of this sample are all better predicted by the G model. This means that some alignment of grains may be influencing the disks mentioned above, but overall, most disks of this sample have either insufficient foliation, or foliation on a scale larger than the area analyzed by the LFA.

\subsubsection{Evaluation of the three plagioclase models}

Resulting fits for a special subset of disks which contain abundant plagioclase are shown in figure 4-9 (x). This subset of 58 disks does not include those with strong errors such as a high amount of anisotropy or heterogeneity. Results are similar to the more restricted subsets described above, with a mean $G$ of $1.00 \pm 0.06(1 \mathrm{~s})$, which is a much lower standard deviation than for $P$ or $S$ models ( 0.17 and 0.10 respectively). However, these samples include calculations using all three plagioclase models described in section 4.3. To evaluate the effectiveness of each model (Average, Piecewise, and Linear), the plagioclase-rich subset was also evaluated as a whole, using each plagioclase model in turn. Mean values and deviations are statistically the same for all three recalculations as the above results: $D_{\text {cald }} / D_{\text {meas }}(G)=1.01 \pm 0.07$ for the Average model, $1.00 \pm 0.07$ for the 
Piecewise, and $1.01 \pm 0.07$ for the Linear model respectively. However, each model works best for certain subsets of samples along the plagioclase series and also for likely slowlycooled and quickly-cooled samples.

Along the plagioclase solid solution, the models differ most at a few specific ranges of An values: below $\sim 1.5 \mathrm{~mol} \%$, near $\mathrm{An}_{19}$, in the intermediate range of $\sim \mathrm{An}_{45}$ to $\mathrm{An}_{64}$, and at values above $\mathrm{An}_{95}$, where results are unconstrained by directly-measured higher anorthite contents on mineral samples. For the low An-regions $\left(<\mathrm{An}_{10}\right)$, the average model works best, except in the single case of sample 16-16, which had a measured An content of $0.5 \mathrm{~mol} \%$. This is likely a result of the exponential increase in $D$ predicted by the equation used for this model (see Fig. 4-5). For this sample, both the Piecewise and Linear models produce robust results, but the Piecewise model struggles to reproduce measured values in the range $\sim \mathrm{An}_{02}$ to $\mathrm{An}_{05}$. Despite higher error near $\mathrm{An}_{19}$, where both samples 16-36 and 16-28 reside, all three models produced broadly similar calculations.

In the intermediate range, the Linear model overestimates $D$ by an average of 10\% compared to the Average and Piecewise models (Fig. 4-6). Above $80 \mathrm{~mol} \%$ An, all three models produce acceptable results, but the Piecewise and Linear models produce slightly better results, whereas the Average model underestimates $D$ by $3-4 \%$.

Finally, the small uncertainty in fits for the $\mathrm{G}$ method is a consequence, in part, of varying inputs in mineral composition within reasonable error for compositions measured with the electron microprobe. In most cases, we allowed a variation in An content of no 
more than $1 \mathrm{~mol} \%$ from the mean, but allowing the An content to be $2-3 \%$ higher $^{6}$ than that measured by the microprobe still produced results within the analytical error of the LFA $\left(D_{\text {cald }} / D_{\text {meas }}(G)=0.98 \pm 0.07\right.$ compared to $1.00 \pm 0.06$ for the unbiased results $)$. A notable exception occurs at very low An contents, however. The average $D_{\text {cald }} / D_{\text {meas }}(G)$ for the unbiased calculations of the 8 disks with an An content $<6 \%$ was 0.99 , but increasing An content by 2 mol\% decreased $G$ to 0.90 , with all samples having resulting $\mathrm{G}$ values below 1.00, and all samples with An content $<5$ having $G$ values below 0.94 . Note that biasing the samples $2-3 \%$ lower than compositions measured in the probe would requires multiple samples to have negative $\mathrm{Ca}$-contents.

This suggests that modest uncertainty of a few percent An content for most plagioclase compositions is not a concern, with the notable exception of highly Na-rich plagioclase. Regardless, for accurately reproducing $D$ or $k$ at ambient temperature, composition of the major minerals must be characterized within a few $\%$ of the actual value, and simple optical examination using, for example, the Michel-Levy method, may be insufficient unless a broad result is all that is required for the application.

\subsection{CONCLUSIONS}

Uncertainty in rock $D$ and $k$ is driven in part by heterogeneity within different sections of the same rock. On the scale of the LFA sample, this heterogeneity is enough to drive misconceptions about the accuracy of the method when attempting to reproduce

\footnotetext{
${ }^{6}$ Biasing sample plagioclase compositions 2-3\% lower than those measured by the probe would requires multiple samples to have negative $\mathrm{Ca}$-contents.
} 
results using different slices of a sample of rock. However, careful characterization of all features that may influence the ability of a rock to conduct heat can account for any issues in reproducibility between different slices of the same sample. Much like internal heat production, strong heterogeneity within rocks extends to different samples with common designations such as "tonalite" or "amphibolite". These rock names, however, do not serve well in predicting rock thermal transport properties because variations in mineralogy and composition, particularly in quartz or olivine content, can lead to strong contrasts in the ability of the rock to conduct heat (c.f. Fig 3-1).

Uncertainty is partially driven by variations in the ability of rock-forming minerals to conduct heat, particularly minerals with complex solid-solutions. Because plagioclase is the most abundant mineral in the Earth's crust, we created three models for interpolating the thermal transport properties of compositions not directly measured in the LFA using existing measurements of various compositions along the Albite-Anorthite solution. Of these three models, the Piecewise model produces calculated transport properties closest to measured values, but the Average model is nearly as effective, and these differences may be heavily influenced by the inclusion of more slowly-cooled samples than quickly-cooled volcanic rocks in the suite. We tentatively recommend using the Average model for rapidly-cooled rocks where high-temperature plagioclase phases are preserved, and the Piecewise model for slowly-cooled rocks in which plagioclase is able to overcome kinetic barriers to low-temperature phase transformations.

For very low Ca-contents (below $\sim \mathrm{An}_{1.5}$ ), the Average model produces highly erroneous results, and should not be used. These models could be improved using additional direct measurements on minerals in the plagioclase solid solution, particularly 
at the extremes of $\mathrm{Ca}$ and $\mathrm{Na}$ contents because high-Na content $\left(<\sim \mathrm{An}_{10}\right)$ is associated with rapid changes in ambient- $\mathrm{T}$ thermal diffusivity with composition, and high-Ca contents $\left(>\mathrm{An}_{0.95}\right)$ have not been directly measured in the LFA. Discretization of hightemperature plagioclase and low-temperature plagioclase as separate solid solutions (c.f. Fig 4-2), as well as additional measurements on rapidly-cooled rocks (if porosity can be accurately accounted for) would also improve these models.

For the rocks analyzed $D$ is best calculated using the geometric (G) method (eq. 4-3). This result is non-controversial for $k$ of rocks (e.g. Berryman, 1995; Clauser and Huenges, 1995; Fuchs et al., 2013; Rey et al., 2015; Andrés et al., 2016), and the results presented here show that it also extends to $D$. Although the best results for this work were attained by effectively isolating smaller suites of samples, the broad suite, which includes a much more diverse set of rocks, is still best reproduced by the G method.

So why then does the $\mathrm{G}$ method best reproduce measured $D$ in our samples, and in other studies? Because no measurement (even point-source methods) measures a single spot in a sample. The LFA method is unique in that the area measured is controllable, but in this study we used an aperture diameter of $0.5 \mathrm{~cm}$. This means that in all but the coarsest-grained samples, measurements incorporate multiple "stacks" of minerals, each producing their own results in series. The geometric method may merely be a convenient middle-ground which is approximating the likelihood of a given phonon (or photon) encountering a phase or orientation of phase within that measurement area. This is beyond the scope of this work but could be tested by varying the spot size within a large enough set of samples, and to much narrower apertures than the minimum grain size of a given sample. Detailed results would likely require mapping the placement and 
orientations of minerals within the disk grain-by-grain. From a practical perspective, this means that bulk-sample aggregations of highly thermally anisotropic minerals such as the phyllosilicates are more likely to be reproduced by the harmonic mean. This was the case in all the results described in the discussion, where using the Arithmetic or Pythagorean mean for orientations of highly platy minerals resulted in higher calculated $D$ than measured.

Variability in the ability of a rock to conduct heat in different orientations is the subject of focus for workers evaluating lithospheric mantle dynamics, rapidly crystallizing lava flows (Shore and Fowler 1999) and upper crustal sedimentary basins (e.g. Fuchs et al. 2015). Although our sample suite was not selected in mind to evaluate anisotropy, several samples had strongly anisotropic $D$ based on the orientation of the sample cut. For these samples, disks with heat flowing across layers of platy minerals are best modeled using the $\mathrm{S}$ method, rather than the $\mathrm{G}$ method, and those with heat flowing along cleavage planes of platy minerals are best modeled using the $\mathrm{P}$ method. However, further research is needed, with a focus on a larger suite of anisotropic samples. Less strongly anisotropic samples did not produce clear correlation with the appropriate methods described above, and future work should focus on determining the amount of preferred orientation required to produce anisotropy, as well which phases are more likely to produce anisotropy in the bulk rock.

However, for the bulk of rock found within the continental crust and lithosphere, we are confident that if all major minerals have well-characterized thermal transport properties (particularly $D$ ), and any major textural issues such as anisotropy, very finegrained rocks, or porosity are accounted for, then $D$, and consequently $k$, can be 
accurately calculated to within $\sim 5 \%$ at ambient temperature. Future work should focus on building strong models for the $D, C_{P}$, and $\rho$ of major rock-forming minerals with complex solid-solutions (such as amphibole) and improving the database for lesscommon minerals for specialized applications such as heat flow models in ore-forming systems.

\section{REFERENCES CITED}

Andrés, C., Álvarez, R., and Ordóñez, A., 2016, Estimation of thermal conductivity of rocks from their mineralogical composition (Asturian Coal Basin, NW Spain) for modelling purposes: Environmental Earth Sciences, v. 75, p. 1-10; doi: 10.1007/s12665015-5037-8.

Benisek, A., Dachs, E., and Carpenter, M.A., 2013, Heat capacity and entropy of low structural state plagioclases: Physics and Chemistry of Minerals, v. 40, p. 167-173, doi:10.1007/s00269-012-0556-2.

Berryman, J.G., 1995, Mixture Theories for Rock Properties, In: Rock Physics and Phase Relations: A Handbook of Physical Constants, AGU Reference Shelf 3, American Geophysical Union, p. 205-228

Branlund, J.M., and Hofmeister, A.M., 2008, Factors affecting heat transfer in natural $\mathrm{SiO}_{2}$ solids: American Mineralogist, v. 93, p. 1620-1629. 
Branlund, J.M. and Hofmeister, A.M., 2012, Heat transfer in plagioclase feldspars: American Mineralogist, v. 97, p. 1145-1154.

Carson, J.K., Lovatt, S.J., Tanner, D.J., and Cleland, A.C., 2005, Thermal conductivity bounds for isotropic, porous materials: International Journal of Heat and Mass Transfer, v. 48, p. 2150-2158, https://doi.org/10.1016/j.ijheatmasstransfer.2004.12.032.

Clauser, C. \& Huenges, E., 1995, Thermal conductivity of rocks and minerals: Rock physics \& phase relations: A Handbook of Physical Constants, Volume 3: American Geophysical Union, Washington, D.C., http://onlinelibrary.wiley.com/doi/10.1029/RF003p0105/summary.

Fischer, K.M., Ford, H.A., Abt, D.L., Rychert, C.A., 2010, The LithosphereAsthenosphere Boundary: Annual Reviews in Earth and Planetary Sciences, v. 38, p. 551-75, doi:http:/ 10.1146/annurev-earth-040809-152438

Fuchs, S., Schütz, F., Förster, H-J., and Förster, A., 2013, Evaluation of common mixing models for calculating bulk thermal conductivity of sedimentary rocks: Correction charts and new conversion equations. Geothermics, v. 47, p. 40-52. 
Füchs, S. Balling, N., and Förster, A., 2015, Calculation of thermal conductivity, thermal diffusivity and specific heat capacity of sedimentary rocks using petrophysical well logs: Geophysical Journal International, v. 203, p. 1977-2000, doi: 10.1093/gji/ggv403.

He, X. M., Fowler, A., Toner, M., 2006, Water Activity and Mobility in Solutions of Glycerol and Small Molecular Weight Sugars: Implication for Cryo- and Lyopreservation: Journal of Applied Physics, v. 100, n. 7, p. 074702.

https://doi.org/10.1063/1.2336304

Heilbronner, R., and Barrett, S., 2014, Image Analysis in Earth Sciences: Microstructures and Textures of Earth Materials: Springer, Heidelberg, 521p.

Hofmeister, A.M., 2019, Measurements, Mechanisms, and Models of Heat Transport. $1^{\text {st }}$ Edition: Elsevier, 440 p.

Hofmeister, A.M., and Pertermann, M., 2008, Thermal diffusivity of clinopyroxenes at elevated temperature: European Journal of Mineralogy, v. 20, p. 537-549.

Hofmeister, A.M., and Criss, E.M., 2018, How Properties that Distinguish Solids from Fluids and Constraints of Spherical Geometry Suppress Lower Mantle Convection, 
Journal of Earth Science, v. 29, n. 1, p. 1-20, doi:https://doi.or/10.1007/s12583-017$0819-4$

Hofmeister, A.M., Whittington, A.G. and Pertermann, M., 2009, Transport properties of high albite crystals, near-endmember feldspar and pyroxene glasses, and their melts to high temperature: Contributions to Mineralogy and Petrology, v. 158, n. 3, p.381-400. Available at: http://link.springer.com/10.1007/s00410-009-0388-3.

Hofmeister, A. M., Sehlke, A., Avard, G., et al., 2016, Transport Properties of Glassy and Molten Lavas as a Function of Temperature and Composition: Journal of Volcanology and Geothermal Research, v. 327, p. 330-348, https://doi.org/10.13039/100000001

Ingebritsen S.E., and Manning C.E., 2003, Implications of crustal permeability for fluid movement between terrestrial fluid reservoirs: Journal of Geochemical Exploration, v. 78-79, p. 1-6.

Klein, C., and Dutrow, B., 2008, The $23^{\text {rd }}$ Edition of the Manual of Mineral Science: John Wiley \& Sons, Inc., Hoboken, New Jersey, p. 271. 
Lee, C-T. A., Luffi, P., and Chin, E.J., 2011, Building and Destroying Continental Mantle: Annual Review of Earth and Planetary Sciences, v. 39, p. 59-90.

Lichtenecker, K., 1924, Der elektrische Leitungswiderstand künstlicher und natürlicher Aggregate, v. 25: Physikalische Zeitschrift, p. 169-181, p. 193-204, and p. 226-233.

McConnell, J.D.C., 2008, The origin and characteristics of the incommensurate structures in the plagioclase feldspars: The Canadian Mineralogist, v. 46, p. 1389-1400.

Merriman, J.D. et al., 2013, Thermal transport properties of major Archean rock types to high temperature and implications for cratonic geotherms: Precambrian Research, v. 233, p.358-372. Available at: http://dx.doi.org/10.1016/j.precamres.2013.05.009.

Merriman, J.D., Hofmeister, A.M., Roy, D.J., and Whittington, A.G., 2018, Temperaturedependent thermal transport properties of carbonate minerals and rocks: Geosphere, v. 14, n. 4, p. 1961-1987, https://doi.org/10.1130/GES01581.1.

Milam, K.A., McSween, H.Y., Moersch, J., and Christensen, P.R., 2010, Distribution and variation of plagioclase compositions on Mars: Journal of Geophysical Research, v. 115, E09004, doi:10.1029/2009JE003495. 
Parsons, I., 2010, Feldspars defined and described: a pair of posters publish by the Mineralogical Society, Sources and supporting information: Mineralogical Magazine, v. 74, p. 529-551.

Pertermann, M. \& Hofmeister, A.M., 2006, Thermal diffusivity of olivine-group minerals at high temperature: American Mineralogist, v. 91, v. 11, p.1747-1760. Available at: http://ammin.geoscienceworld.org/cgi/doi/10.2138/am.2006.2105.

Pertermann, M., Whittington, A.G., Hofmeister, A.M., Spera, F.J., and Zayak, J., 2008, Transport properties of low-sanidine single-crystals, glasses and melts at high temperature: Contributions to Mineralogy and Petrology, v. 155, p. 689-702, https://doi.org/10.1007/s00410-007 -0265-x.

Ramires, M.L.V., Nieto de Castro, C.A., Nagasaka, Y., Nagashima, A., Assael, M.J., and Wakeham, W.A., 1995, Standard Reference Data for the Thermal Conductivity of Water, Journal of Physical and Chemical Reference Data, v. 24, p. 1377, doi:10.1063/1.555963.

Ray, L., Förster, H-J., Förster, A., Fuchs, S., Naumann, R., and Appelt, O., 2015, Tracking the thermal properties of the lower continental crust: Measured versus calculated thermal conductivity of high-grade metamorphic rocks (Southern Granulite Province, India): Geothermics, v. 55, p. 138-149. doi:10.1016/j.geothermics.2015.01.007. 
Ray, L., Förster, H-J., Förster, A., Fuchs, S., Naumann, R., and Appelt, O., 2015, Tracking the thermal properties of the lower continental crust: Measured versus calculated thermal conductivity of high-grade metamorphic rocks (Southern Granulite Province, India): Geothermics, v. 55, p. 138-149, http://dx.doi.org/10.1016/j.geothermics.2015.01.007

Robie, R.A., and Hemingway, B.S., 1995, Thermodynamic properties of minerals and related substances at $298.15 \mathrm{~K}$ and 1 bar (105 pascals) pressure and at higher temperature: U.S. Geological Survey Bulletin 2131, 470 p.

Roy, D., Merriman, J.D., Whittington, A.G., and Hofmeister, A.M., in review. Thermal properties of carbonatite and anorthosite from the Superior Province, Ontario, and implications for non-magmatic thermal effects of intrusions. Submitted to: Canadian Journal of Earth Sciences, March 13, 2019.

Saadatfar, M., Turner, M.L., Arns, C.H., Averdunk, H., Senden, T.J., Sheppard, A.P., Sok, R.M., Pinczewski, W.V., Kelly, J., and Knackstedt, M.A., 2005, Rock fabric and texture from digital core analysis: SPWLA $46^{\text {th }}$ Annual Logging Symposium, June 26-29, 2005. 
Shore, M., and Fowler, A.D., 1999, The origin of spinifex texture in komatiites: Nature, v. 397, p. 691-694.

Vitovtova, V.M., Shmonov, V.M., and Zharikov, A.V., 2014, The porosity trend and pore sizes of the rocks in the continental crust of the Earth: Evidence from experimental data on permeability: Physics of the Solid Earth, v. 50, n. 5, p. 593-602, doi:10.1134/S1069351314040181.

Wang, J., Carson, J.K., North, M.F., and Cleland, D.J., 2006, A new approach to modelling the effective thermal conductivity of heterogeneous materials: International Journal of Heat and Mass Transfer, v. 49, p. 3075-3083.

Wieczorek, M.A., et al., 2006, The constitution and structure of the lunar interior, Reviews in Mineralogy and Geochemistry, v. 60, p. 221-364, doi:10.2138/rmg.2006.60.3.

Woodside, W., and Messmer, J., 1961, Thermal conductivity of porous media II. Consolidated rocks: Journal of Applied Physics, v. 32, pp. 1699-1706. 


\section{Chapter 5: A Model for Thermal Diffusivity of Crystalline Rocks, Part III: Modeling High-Temperature Thermal Diffusivity}

\subsection{INTRODUCTION}

In chapters 2-4 of this work, we presented data from a suite of 122 disks, from 55 different rock samples, measured using the Laser Flash Analysis (LFA) method. Chapter 2 explored thermal diffusivity $(D)$, heat capacity $\left(C_{P}\right)$, density $(\rho)$, and resulting thermal conductivity $(k)$ of carbonate minerals and rocks, and illustrated the effects of using temperature-dependent thermal transport properties when modeling the thermal structure of an idealized, simplified sedimentary basin. Chapter 3 described the characterization methods used to identify specific disk characteristics that may affect measured $D$. Characterization included X-Ray Diffraction (XRD) results for LFA disks, optical analysis using Polarizing Light Microscopy (PLM) and binocular microscope images, Scanning Electron Microscopy (SEM) backscatter electron and Energy-Dispersive X-ray Spectroscopy (EDS) mapping of disks, electron microprobe analysis (EMPA) of mineral compositions, and density measurements on bulk samples. Chapter 3 also contains thermal diffusivity data measured by LFA at both ambient, and elevated temperatures. Simple mineral-thermal diffusivity relationships were analyzed, and two equations for calculating rock $D$ for simple plagioclase-quartz mixtures at ambient temperatures were presented (Eqs. 3-10 and 3-11). However, these equations require knowledge of the $D$ of the specific plagioclase composition within the rock, and do not work for more complex mineral mixtures. 
Chapter 4 addressed these issues by developing a model for interpolating $D$ of plagioclase compositions not directly measured using the LFA. Using this model, and the database of mineral $D$ presented by Hofmeister (2019), we calculated $D\left(D_{\text {calc }}\right)$ for the suite and compared the predicted values at ambient temperature to measurements of $D$ $\left(D_{\text {meas }}\right)$ in chapter 3 . Accurate modeling requires thorough sample characterization including modal mineralogy and mineral composition. For samples with significant pore fraction, internal layering, shape- or crystal-preferred orientation of minerals, or lack of sample cohesion, calculated $D_{\text {calc }}$ can differ from $D_{\text {meas }}$ by up to a factor of two. We concluded that of the three mixing models examined, the Parallel model (P), the Series model (S), and the Geometric model (G), the G model was the most effective in reproducing $D_{\text {meas }}$ for most disks at ambient temperature.

However, as discussed in chapters 1-3, thermal transport properties of minerals are temperature-dependent, with $D$ of individual minerals decreasing by as much as an order of magnitude between ambient temperature and lower crustal / uppermost mantle temperatures (e.g. Diamond, figure 1-1). The question remains, if well-characterized disk $D$ of rocks can be calculated to within analytical uncertainty of the LFA at ambient $T$, will the same results be achieved at elevated temperatures?

This chapter explores using the RockCalculator Microsoft Excel(C) spreadsheet to calculate high-temperature thermal transport properties of 55 samples in our suite, which were previously measured above ambient $T$ conditions. These calculations are used to test the effectiveness of the three plagioclase interpolation models found in Chapter 4 to high temperature (e.g. Figure 4-6), and to evaluate if the G model still the best one at high temperature. Finally, additional sources of experimental error are discussed. 


\subsection{THEORETICAL HIGH-TEMPERATURE MINERAL MIXING}

Consider the hypothetical mixture of the two minerals plagioclase ( $\mathrm{An}_{19}-$ Fit to Primary Data (PR) - Branlund and Hofmeister, 2012) and quartz (Pythagorean average Branlund and Hofmeister, 2007) shown in figure 5-1. At ambient temperatures, these two minerals have distinctly different $D$ values of $\sim 5.2 \mathrm{~mm}^{2} \mathrm{~s}^{-1}$ (Quartz) and $0.95 \mathrm{~mm}^{2} \mathrm{~s}^{-1}$ (Plagioclase), a difference of a factor of 5 . The mixture produces distinctly different

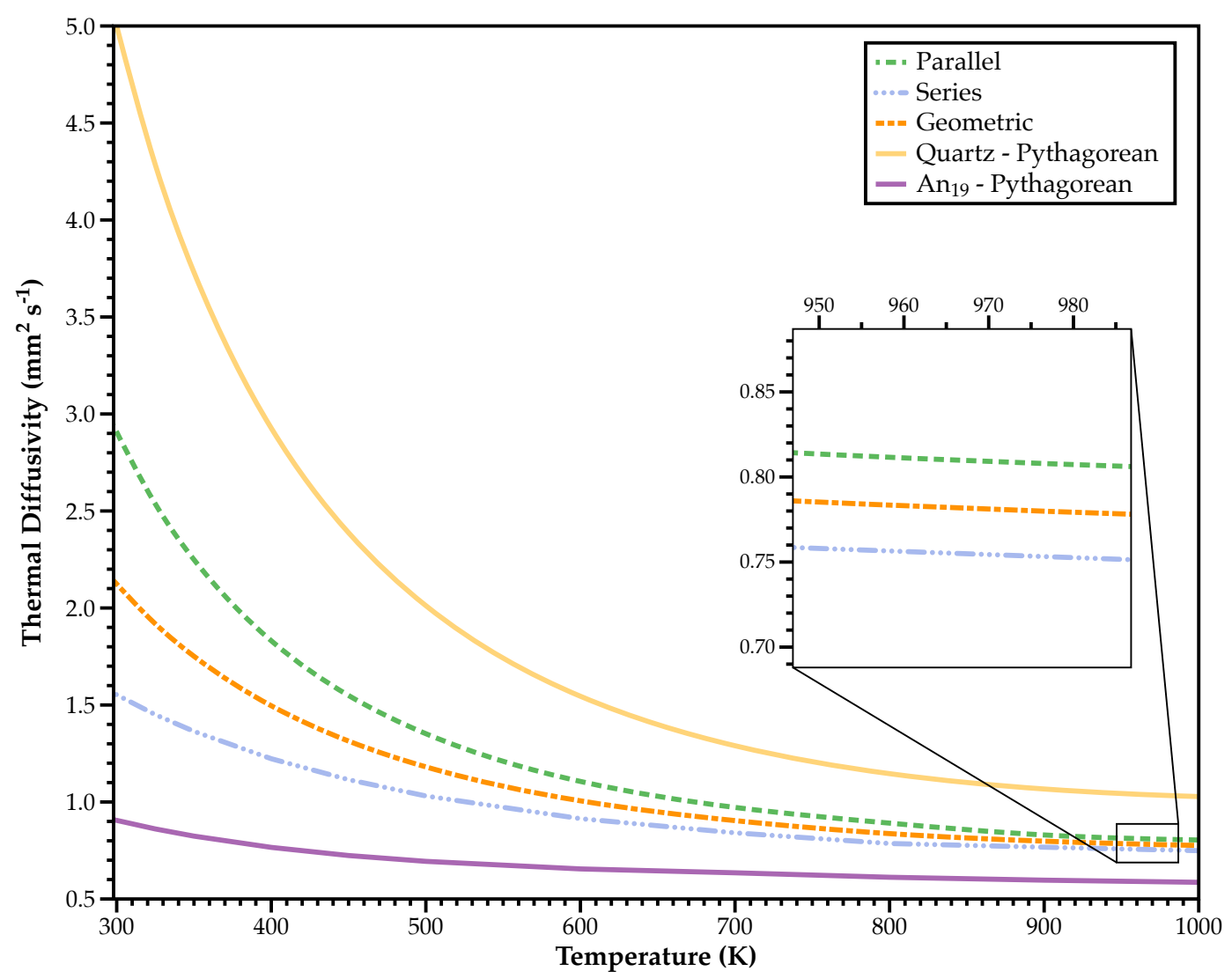

Figure 5-1) A theoretical mixture of 50-50 quartz and plagioclase. Data for both quartz (Branlund and Hofmeister, 2007), and plagioclase ( $\mathrm{An}_{19}$, Branlund and Hofmeister, 2012) are Pythagorean (Geometric) means. See Chapter 4 for description of mixing models. 
results depending upon the mixing method considered: $\sim 2.9 \mathrm{~mm}^{2} \mathrm{~s}^{-1}$ for the Parallel model (Eq. 4-1), $1.6 \mathrm{~mm}^{2} \mathrm{~s}^{-1}$ for the Series model, and $2.1 \mathrm{~mm}^{2} \mathrm{~s}^{-1}$ for the Geometric model. However, as temperature increases, the contrast in $D$ between quartz and plagioclase decreases to approximately a factor of 3 at $400 \mathrm{~K}$, and less than a factor of 2 at $1000 \mathrm{~K}$. As a consequence, predicted $D$ of the mixture varies less between mixing models at elevated temperatures.

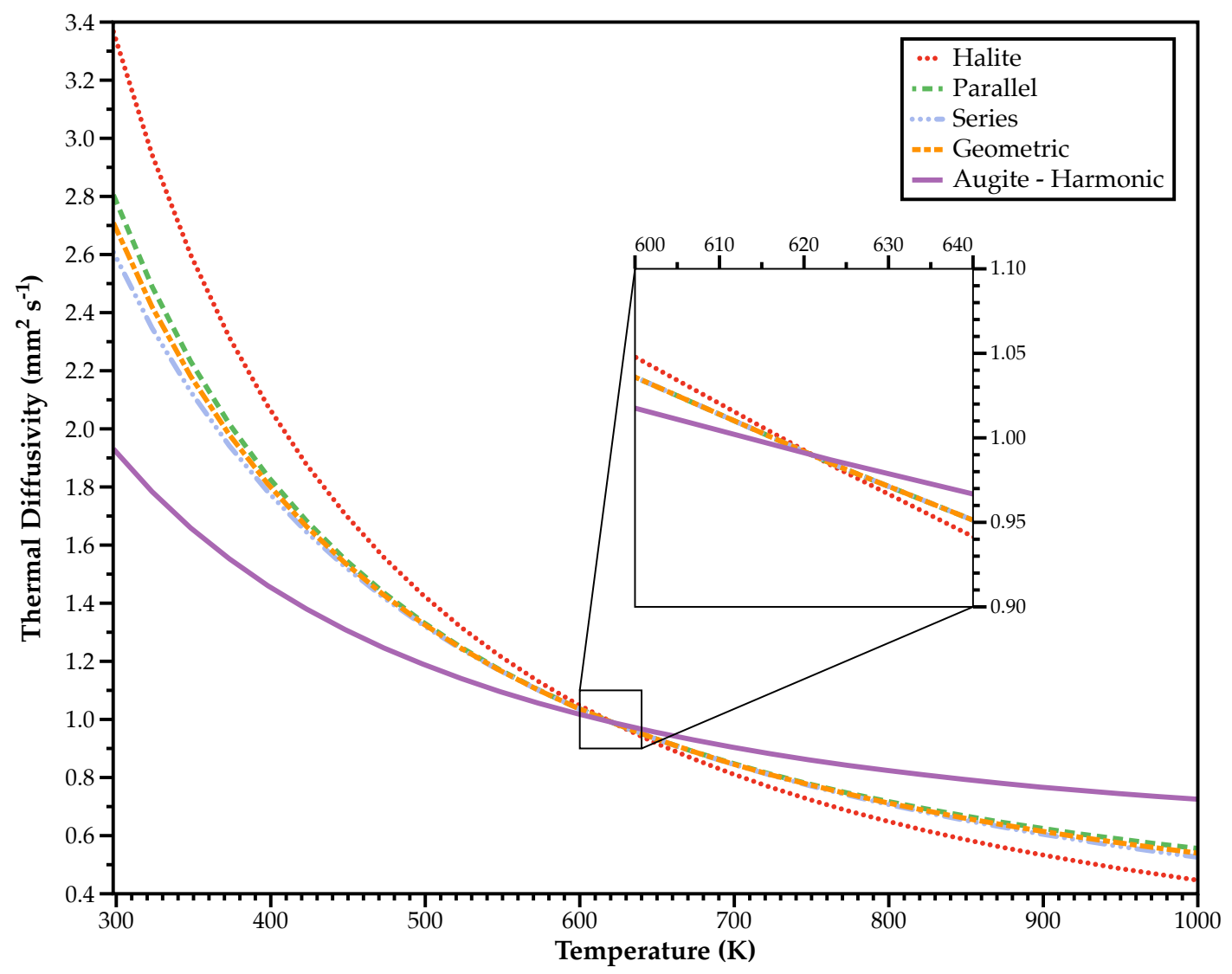

Figure 5-2) A 50-50 mixture of Augite (Hofmeister and Pertermann, 2008) and Halite (Yu and Hofmeister, 2011) using the Pythagorean mean for augite. Halite is thermally isotropic.

High contrasts between mixing models for the case in figure 5-1 are a result of the factor of 5 difference between the two minerals. If two minerals with fairly similar $D s$ are mixed, however, it becomes more difficult to determine which mixing model is best. 
Figure 5-2 shows a hypothetical mixture of augite (Hofmeister and Pertermann, 2008) and halite (Yu and Hofmeister, 2011). In this case, high $D$ for both phases at ambient temperature results in only modest differences between different mixing models at ambient-temperature. Additionally, because halite and augite have distinctly different $\mathrm{d} D / \mathrm{d} T$ resulting from different contributions of diffusive radiative transfer (see Chapter 1 , and $\mathrm{Yu}$ and Hofmeister, 2011), D is identical for both phases at $620 \mathrm{~K}$. This means that determining the best mixing model for this hypothetical sample would be difficult because the peak contrast between models is only $\sim 0.2 \mathrm{~mm}^{2} \mathrm{~s}^{-1}$ (Parallel and Series models, ambient $T$ ), or $<10 \%$ of the measured $D$. This is close to the analytical error of the LFA at ambient $T(5 \%$, Criss and Hofmeister, 2017).

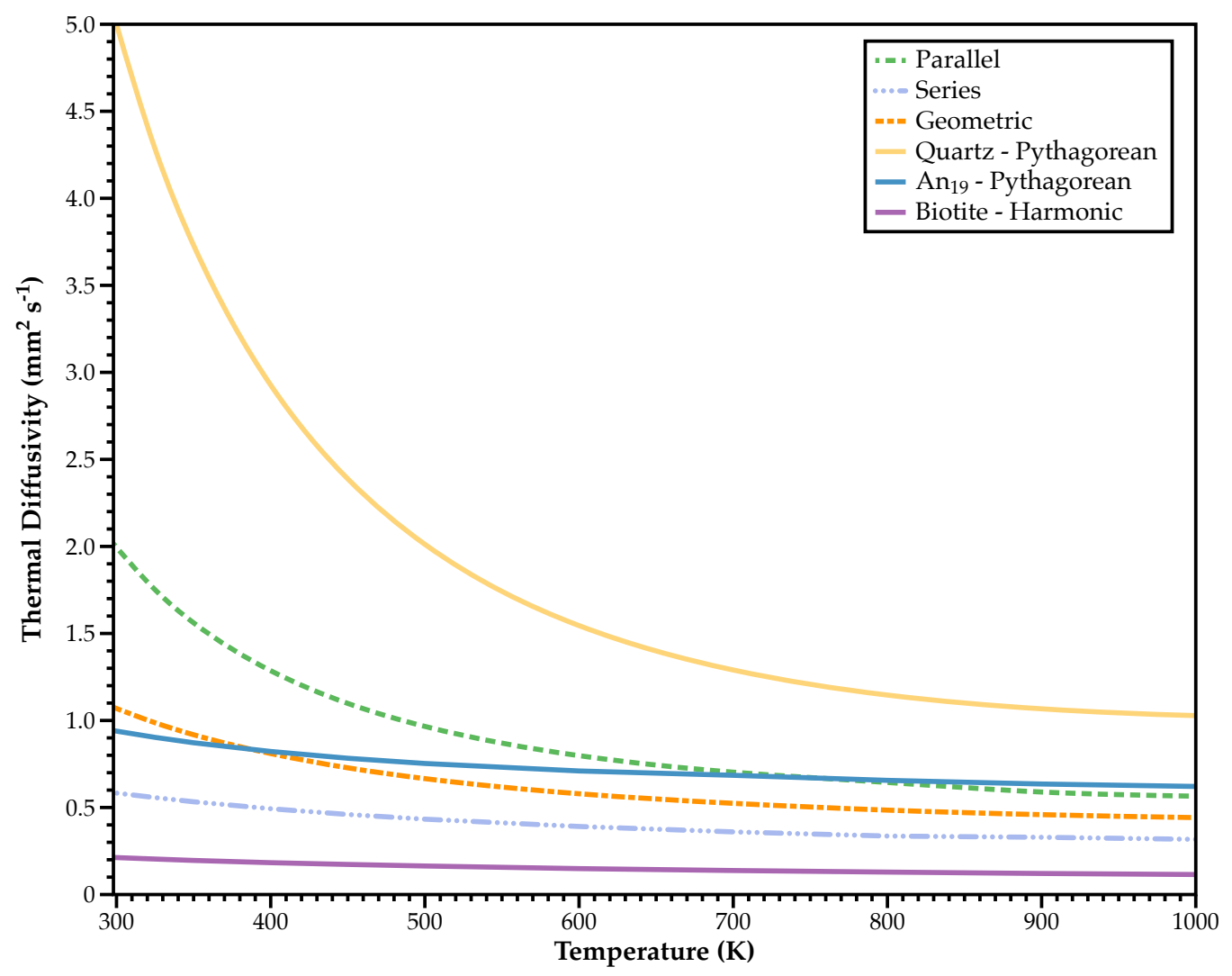

Figure 5-3) Theoretical mixing of equal parts quartz, plagioclase ( $\left.\mathrm{An}_{19}\right)$, and biotite to high temperature. Compare to predicted contrasts by mixing models in figure 5-2. See text for references. 
Furthermore, as temperature increases, lower analytical error for the LFA ( $\sim 2 \%$ at $\sim 500 \mathrm{~K}$ ) is counterbalanced by even lower expected differences between models ( $<2 \%$ at $400 \mathrm{~K}$, decreasing to no difference at $620 \mathrm{~K}$ ). High contrasts between predicted $D$ for all three mixing models is expected to persist to $1000 \mathrm{~K}$, assuming the sample can survive heating without confining pressure

Thus, differentiating between the best mixing model to use at high temperature requires us to examine materials with phases that have high contrasts in $D$ across a wide temperature range. Figure 5-3 shows a more complex example. Here quartz, plagioclase $\left(\mathrm{An}_{19}\right)$ and biotite (Harmonic average of sample Biotite-P, Hofmeister and Carpenter, 2015) are mixed in equal proportions. Recall that measurements at ambient $T$ of samples with biotite were best reproduced using the Harmonic average (see Chapter 4). These three phases have very different $D$ values, and as a consequence, a factor of $\sim 4$ difference exists in $D$ calculated at ambient $T$, between the $\mathrm{P}$ and $\mathrm{S}$ models. Furthermore, although differences between $D$ of the phases decreases as temperature increases, enough contrast exists to preserve detectable differences in $D$ between models to $1000 \mathrm{~K}$. For example, the G model predicts a $D$ of $0.44 \mathrm{~mm}^{2} \mathrm{~s}^{-1}$ at $1000 \mathrm{~K}$, and the $\mathrm{S}$ model a $D$ of $0.31 \mathrm{~mm}^{2} \mathrm{~s}^{-1}$, which is well within the analytical error of the LFA.

Crucially, none of the mixing models described in Chapter 4, or any other model available in the literature (e.g. the M-E or EMT models, see descriptions in Chapter 4 or equations in Wang et al., 2008) predicts that $D$ would decrease below that of the most insulating phase within the sample. Previous workers have suggested that grain boundaries have an inherent thermal resistance that causes the measured $k$ or $D$ of a rock to be lower than predicted values from mixing models (e.g. Smith et al., 2003). 
According to this hypothesis, the thermal resistance generated by crossing grain boundaries is directly proportional to the number of grain boundaries over a given length (see Eq. 9, Branlund and Hofmeister, 2008). However, work by Branlund and Hofmeister (2008) on quartzites with grain sizes from $<1 \mu \mathrm{m}$ to $0.42 \mathrm{~mm}$ found that any discrepancy between expected and measured $D$ for samples with grain-sizes $<\sim 1 \mu \mathrm{m}$ could be accounted for by reasonable variations in porosity or $D$ of a pore-filling fluid. Therefore, for most of the samples studied here, grain-boundary resistance (if a real effect) should have little or no influence on $D$, because grain sizes of the suite are typically much higher than $1 \mu \mathrm{m}$ (Table 3-1).

\subsection{COMPARING CALCULATED AND MEASURED THERMAL DIFUSIVITY AT HIGH TEMPERATURES}

\subsubsection{The High Temperature Suite}

The measured and fitted $D$ for 15 of the 32 samples analyzed in this section are shown in figure 5-4. Samples include a quartzite (UP-7A), a quartz-rich metadolomite (UP-7B), metasedimentary rocks rich in phyllosilicate minerals (UP-3A PA and PE, 1614, 16-17), low-grade metavolcanics rocks (16-03, 16-14, 16-16, AW04, TF07 [Runs 1 and 2]), two BIFs (AW16, 16-44), hypabyssal and volcanic rocks (AW15x, AW20 [Runs 1 and 2], ED22), mid-crustal plutonic rocks (AW21, 16-28, 16-36), upper-amphibolite facies metavolcanics and metasedimentary rocks (Acasta B [Runs 1 and 2], KB08c1, KB09a1 and c1, KB10ab [run \#2], KB11ab [run \#1], KB12ab [Run \#1], KB13ab, 
KB14x, 14-4D s1c3, 14-5B c1d1) and two anorthosites (Shawmere and Stillwater). High temperature measurements for these samples were first reported by Merriman et al. (2013), Merriman et al. (2018), Roy et al. (in review), and in Chapter 3.

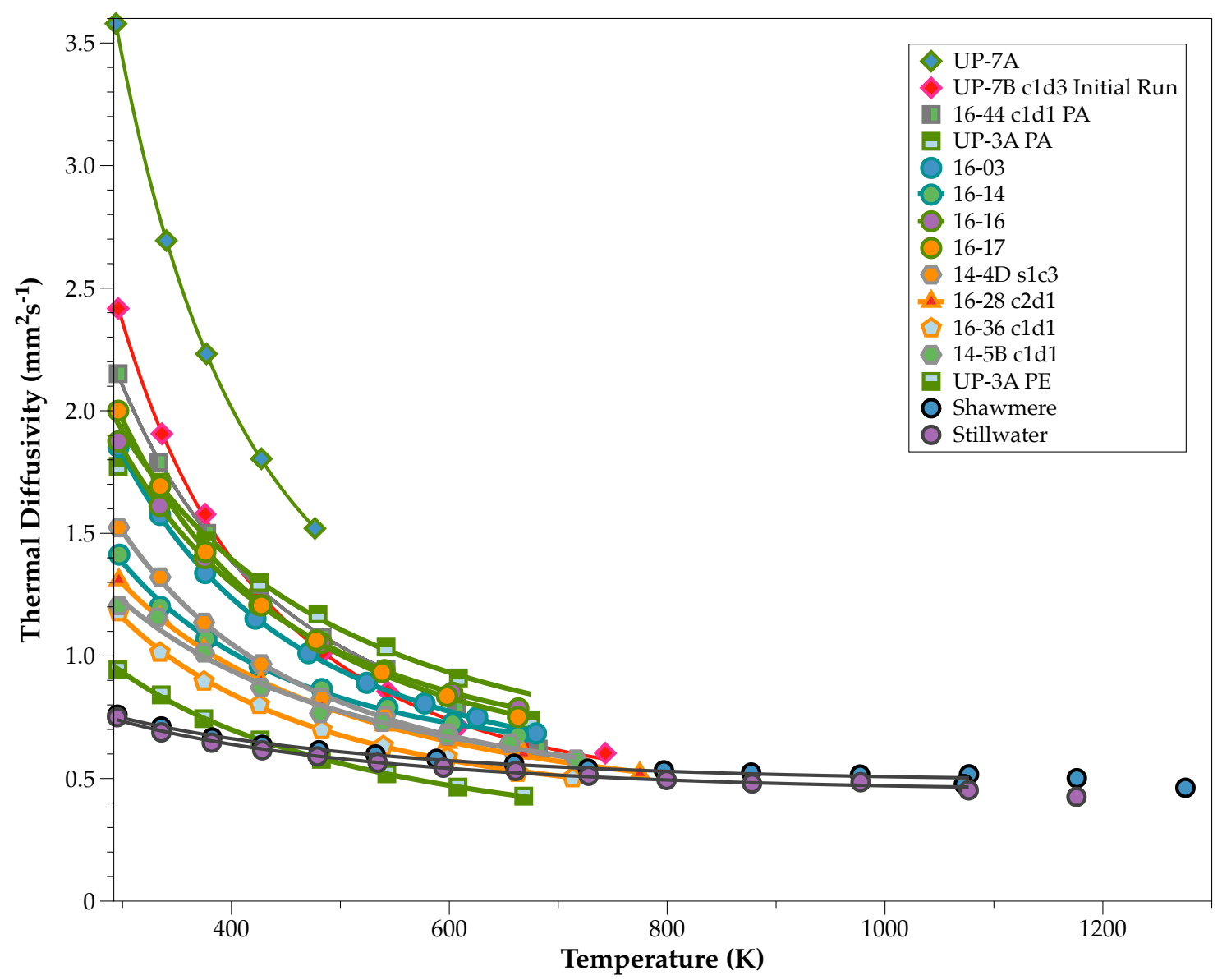

Figure 5-4) High temperature results for samples analyzed in this chapter. Symbols are points measured by the LFA, and lines are fits to the measurements. See figure 3-1 for line color legend. Samples are from Chapter 3, as well as Merriman et al., 2013, Merriman et al., 2018, and Roy et al., in review. Measurements on cooling, and some measurements near peak temperatures, were not included in fits (see publications for details and rationale).

Thermal diffusivity calculations were performed using the RockCalculator spreadsheet described in Chapters 3 and 4. At elevated temperatures, the RockCalculator 
spreadsheet automatically switches between inputs for minerals with phase changes at elevated temperature (e.g. the quartz $\alpha-\beta$ transition, Branlund and Hofmeister, 2007) and calculates mineral volume fractions from weight fractions using published density values for minerals (Gaines et al., 1998), but does not account for variations in density resulting from thermal expansion of minerals (Fei, 1995).

\subsubsection{Analysis of Calculated $D$}

For most samples it is adequate to evaluate the effectiveness of calculations by using the ratio of $D_{\text {calc }} / D_{\text {meas, }}$ similar to results for ambient temperature reported in Chapter 4. Most sample results fell into one of three categories:

I) samples with $D_{\text {meas }}$ reproduced by $D_{\text {calc }}$ to within $5-10 \%$ maximum error across measured temperatures (Figure 5-5),

II) samples with good agreement between $D_{\text {meas }}$ and $D_{\text {calc }}$ at ambient temperature, but wide departures ( $>10 \%$ difference) at elevated temperatures, III) and samples which were poorly reproduced at ambient temperature but for which analysis at high temperature provides some insight into the cause of the error.

Examples of each of the above follows. 


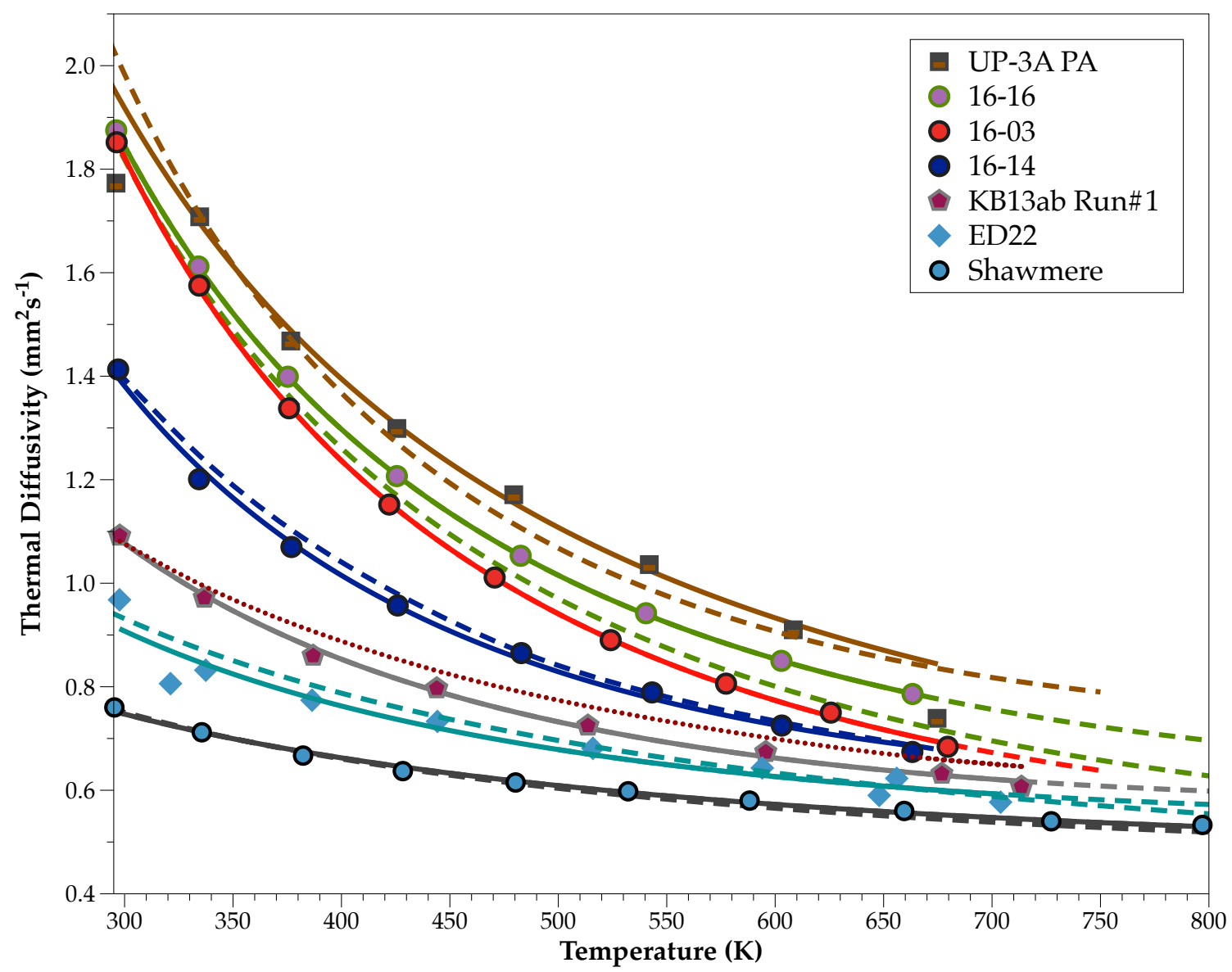

Figure 5-5) Measured (symbols), fitted (solid lines), and calculated (dashed and dotted lines) for seven samples with calculated $D$ within $5 \%$ of measured $D$ for most of the temperatures measured in the LFA.

\subsubsection{Sample 16-03}

Sample 16-03 falls into category I above. This sample is a low-grade silicified metavolcanic rock with albitic plagioclase $(30 \%)$, quartz $(26 \%)$, chlorite $(24 \%)$, calcite (13\%), and muscovite (7\%). The sample was measured to $\sim 680 \mathrm{~K}$ with $D$ that ranged from $1.85 \mathrm{~mm}^{2} \mathrm{~s}^{-1}$ at ambient $T$, to $0.68 \mathrm{~mm}^{2} \mathrm{~s}^{-1}$ at $680 \mathrm{~K}$. Calculated $D$ (G model) reproduced measured $D$ to within $4 \%$ for all temperatures (Figure 5-5) with a slightly increasing overprediction starting near $\sim 375 \mathrm{~K}$. Similar to theoretical calculations shown 
in figures 5-1 and 5-3, strong variations in predicted $D$ were produced by the $\mathrm{P}$ and $\mathrm{S}$ models (dashed and dotted lines respectively, Fig. 5-6) at ambient temperature (20-25\%),

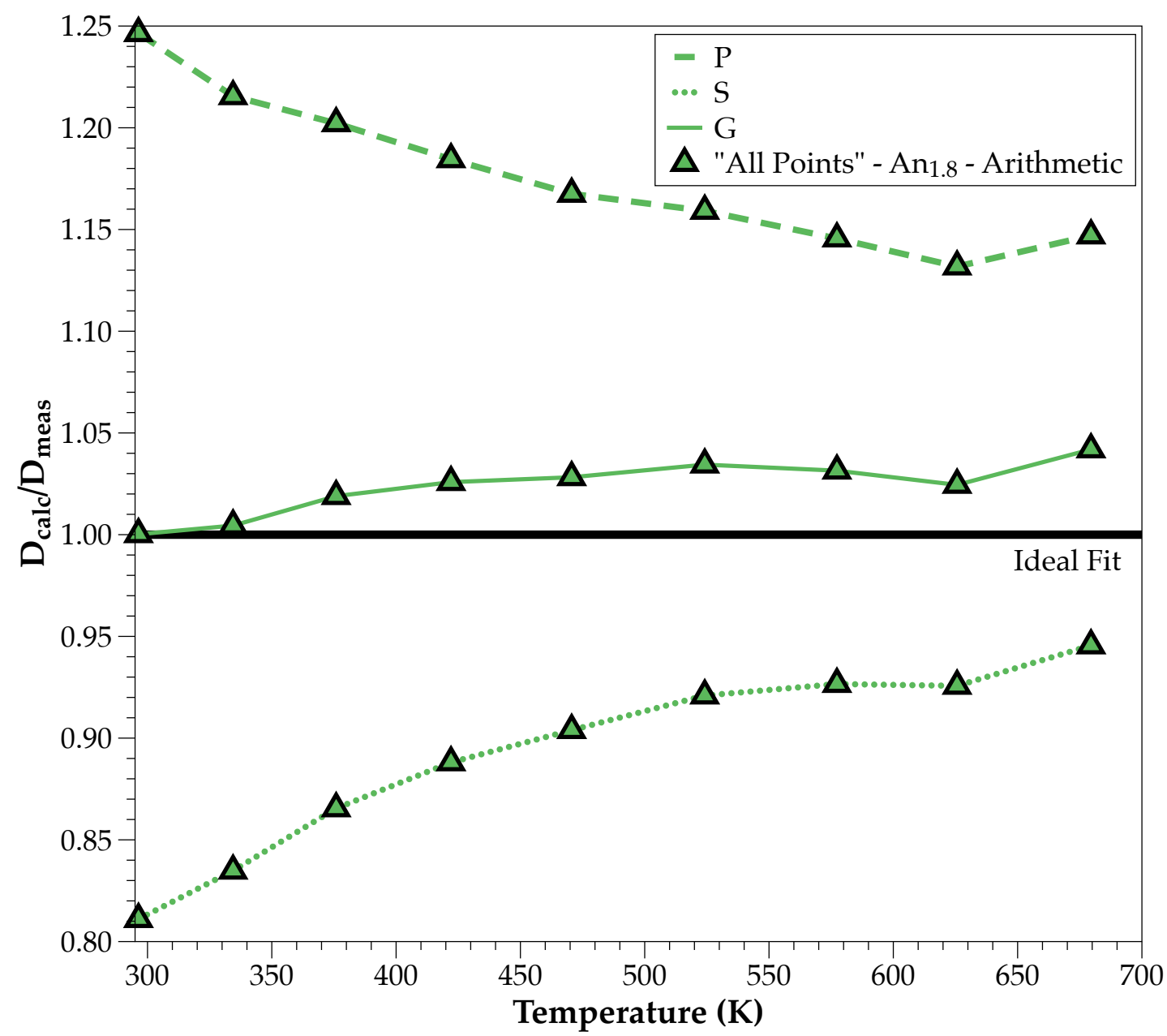

Figure 5-6) Calculated $\left(D_{\text {calc }}\right)$ compared to measured $\left(D_{\text {meas }}\right)$ thermal diffusivity ratio for sample 16-03 across measured temperatures. The "All Points" plagioclase model using the Arithmetic mean was used to calculate plagioclase $D$ within the sample. See figure 5-7 for additional phase descriptions and proportions.

with decreasing contrasts as temperature increases. This pattern of decreasing $D_{\text {calc }} / D_{\text {meas }}$ for the $\mathrm{P}$ model and increasing $D_{\text {calc }} / D_{\text {meas }}$ for the $\mathrm{S}$ model as temperature increases was repeated for all samples that were well reproduced using the RockCalculator spreadsheet. 


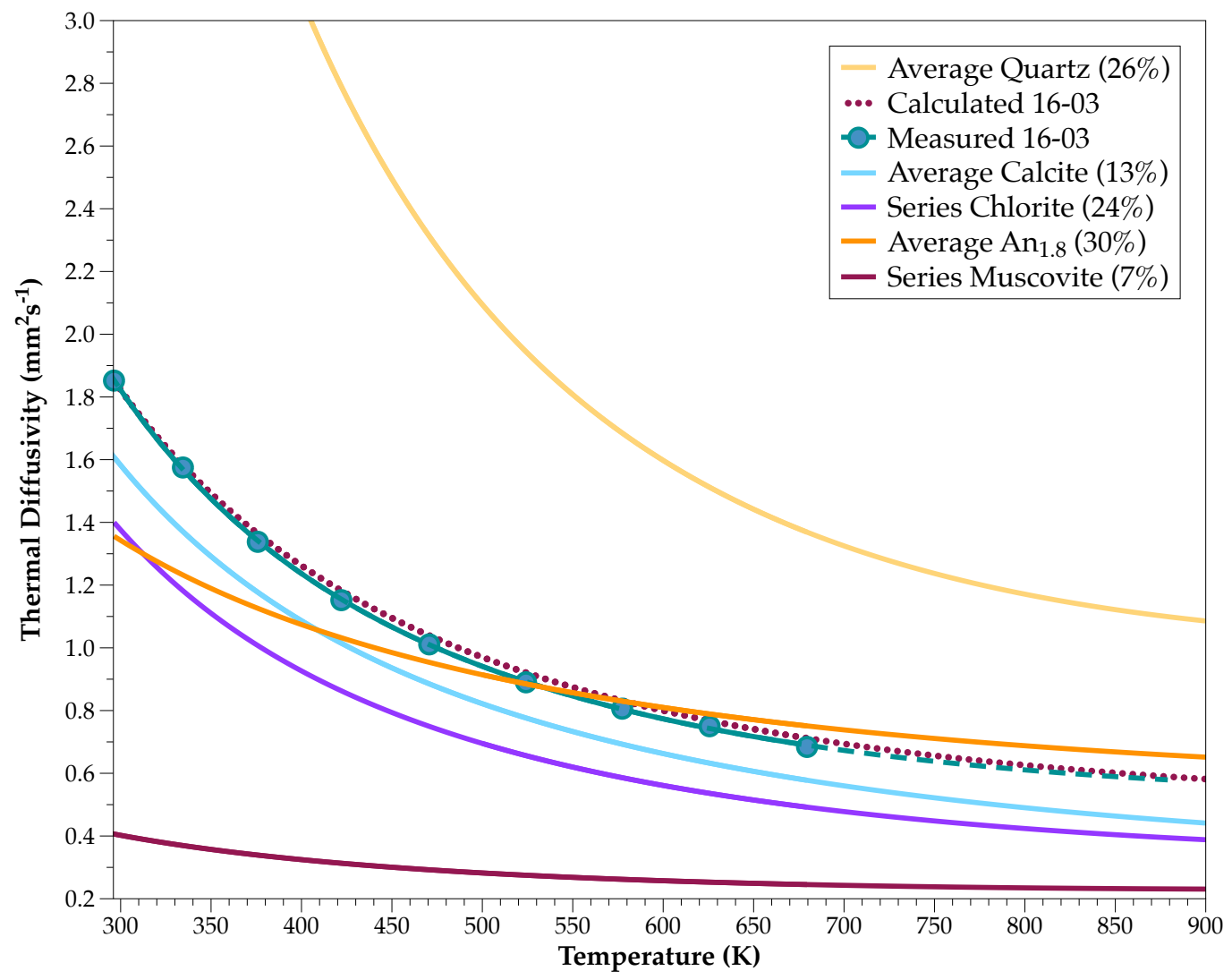

Figure 5-7) Measured and calculated $D$ (G model) for sample 16-03 along with the major phases reported by XRD. The dashed blue line extending from the measured fit of $16-03$ is a predicted $D$ at temperatures above those measured in the LFA using equation 3-4. Values for quartz are from Branlund and Hofmeister (2007), calcite - Merriman et al. (2018), chlorite - Hofmeister (2019), and muscovite - Hofmeister and Carpenter (2015). The plagioclase $D$ was calculated using the "All Points" model (Chapter 4). See text for discussion.

Figure 5-7 shows the calculated and measured $D$ along with the $D$ of the major constituent phases reported by XRD (Chapter 3). As is expected, calculated and measured values fall below the highest $D$ phase (quartz) and above the lowest $D$ phase (muscovite) across the full range of measured $T$. 


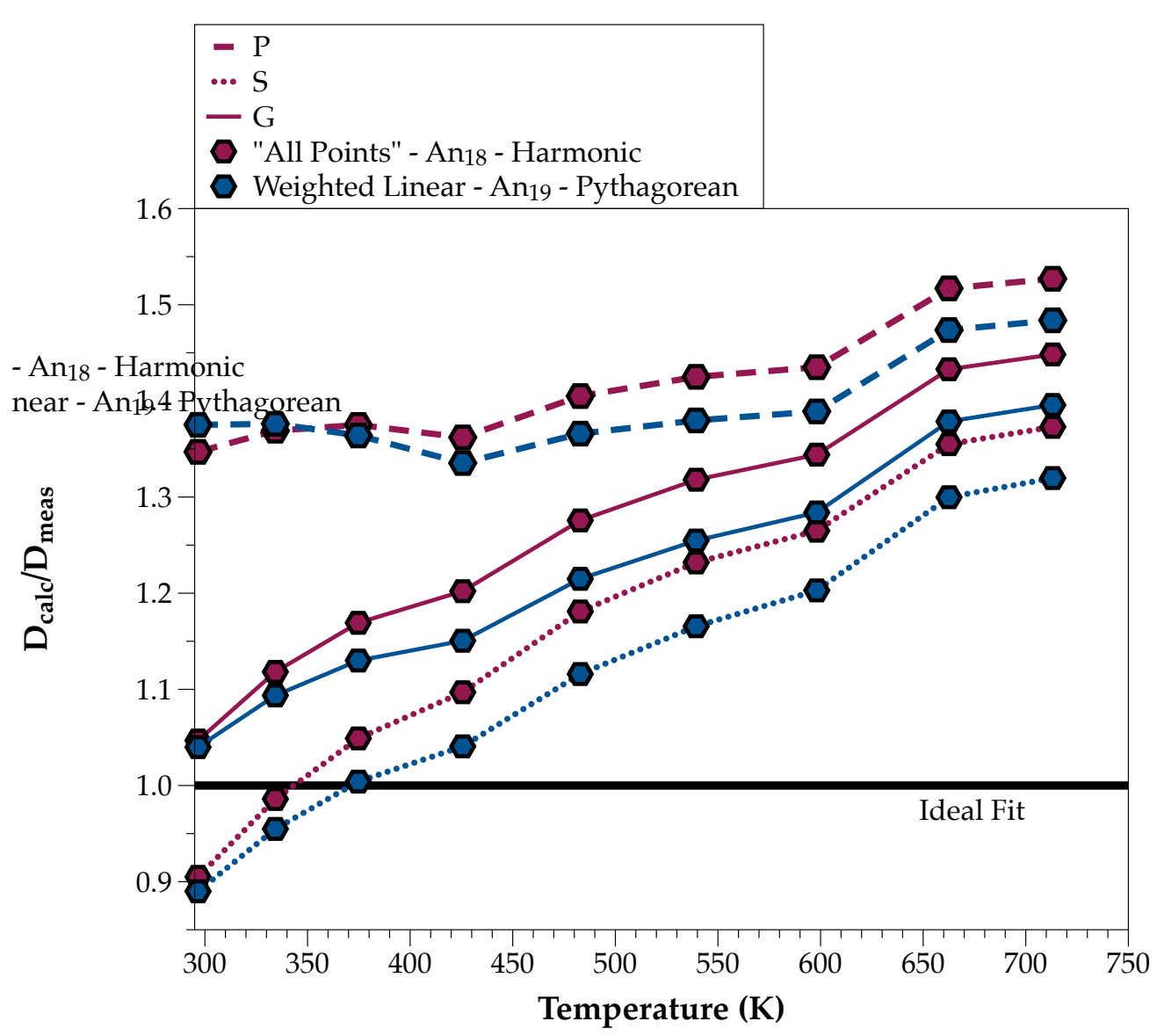

Figure 5-8) Calculated $\left(D_{\text {calc }}\right)$ compared to measured $\left(D_{\text {meas }}\right)$ thermal diffusivity ratio for sample 16-36 across measured temperatures. Two calculations are presented, one in which the "All Points" plagioclase model was used, and one for which the Weighted Linear plagioclase model was used. See text for discussion and Figure 5-8 for additional mineral information.

This sample falls in category II (section 5.3.2 above). At room temperature, calculated $D$ was within $4 \%$ of measured $D$, and the sample was composed of common phases with well-characterized $D$ : $\mathrm{An}_{18}$, quartz, microcline, and biotite. Additionally, the sample was not heated above the quartz $\alpha-\beta$ transition (see section 5.3.3), reaching a 
maximum temperature of $713 \mathrm{~K}$. However, unlike sample $16-03$ above, $D_{\text {calc }} / D_{\text {meas }}(\mathrm{G}$ model $)$ increases across all measured temperatures (Figure 5-8). Furthermore, results for $D_{\text {calc }} / D_{\text {meas }}$ of the $\mathrm{P}$ and $\mathrm{S}$ models both increase as temperature increases. Varying plagioclase models, or using fits to primary data from Branlund and Hofmeister (2012) produced similar slopes within reasonable An contents (c.f. blue and maroon lines, Fig. 5-8).

Examining the measurements in the context of the $D$ of minerals found in the sample illustrates the magnitude of the error in calculations (Figure 5-9). Initially, measured $D$ is above the most abundant phase in the sample (blue line, $\mathrm{An}_{18}$ ), but near $500 \mathrm{~K} D$ drops below $\mathrm{An}_{18}$, and continues to decrease faster than all phases except quartz (yellow line). At maximum temperature, $D_{\text {meas }}$ is below all phases in the sample except biotite. Given biotite makes up $\sim 1 \%$ (by weight) of the disk, it is unlikely that this lower$D$ phase is the source of the higher $\mathrm{d} D / \mathrm{d} T$ of the sample than is predicted. Most samples in category II have $D_{\text {calc }} / D_{\text {meas }}$ for both the G and $\mathrm{S}$ models with a positive slope similar to figure 5-8, and many include P results with positive slopes as well.

\subsubsection{Sample AW20 Run \#1}

This sample, measured by Merriman et al. (2013), falls in category III above. No results for calculations produced from measured XRD results were within 35\% of the measured disk $D$ at ambient temperature. Thermal diffusivity predicted by the RockCalculator spreadsheet decreases less with increasing temperature than measured 


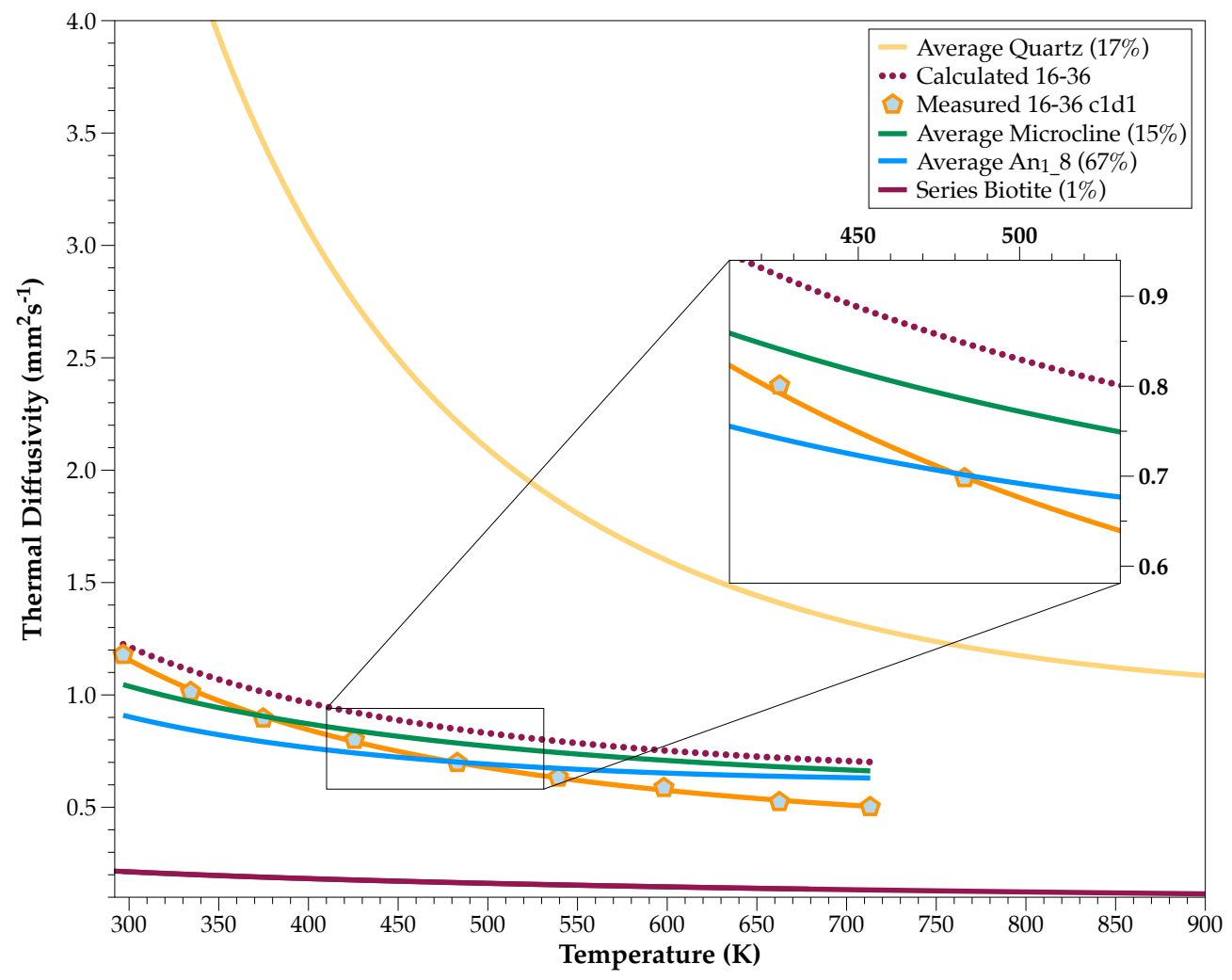

Figure 5-9) Measured and calculated $D$ (G model) for sample 16-36 disc c3d1 compared with minerals found within the disk. Values for quartz are from Branlund and Hofmeister (2007), microcline, intermediate - unpublished, discussed in Chapter 3 and biotite - Hofmeister and Carpenter (2015). The plagioclase $D$ was calculated using the "All Points" model (Chapter 4). See text for discussion.

values (Figure 5-10). Furthermore, slopes of all models increase strongly across the quartz $\alpha-\beta$ transition, and measurements taken on cooling were much lower than initial values on heating.

This sample was heated to very high temperature $(1471 \mathrm{~K})$ prior to the identification of potential sample stability issues for samples heated above $\sim 850 \mathrm{~K}$ without confining pressure (Merriman et al., 2013). Furthermore, the sample was warped and the graphite coating flaked off upon removal from the measurement chamber of the 


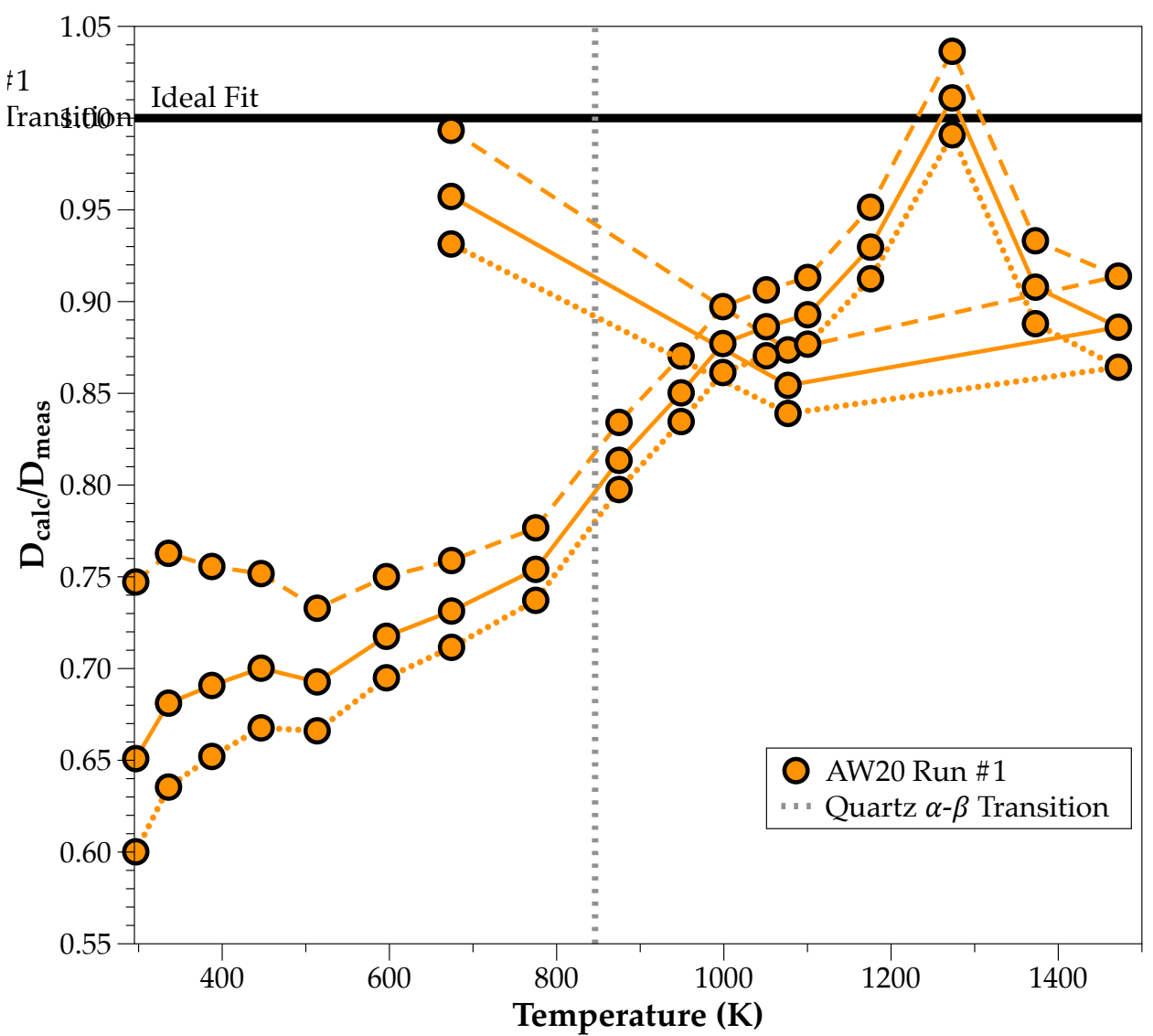

Figure 5-10) Calculated $\left(D_{\text {calc }}\right)$ compared to measured $\left(D_{\text {meas }}\right)$ thermal diffusivity ratio for sample AW20 Run \#1 (Merriman et al., 2013) across measured temperatures. Dashed lines are for the P model, solid lines the G model, and dotted lines the S model. Measurements were taken on cooling (endpoints just below the "Ideal Fit" line near $700 \mathrm{~K}$ ) which were much lower than those taken on heating.

LFA. Compared to a second disk sample AW20 (run \#3), cut from the same core, mineralogy reported by XRD was noticeably different: Runs \#1 and \#3 were both dominated by plagioclase ( $75 \%$ and $64 \%$ by weight respectively), run $\# 3$ has a large amount of hydrous phases - actinolite (12\%), chlorite (6\%), and biotite ( $2 \%)$, whereas run \#3 had enstatite (12\%), augite (8\%), and microcline (5\%). Calculated results for run $\# 3$ were all within $10 \%$ of measured $D$, and the maximum temperature for the disk were a much more modest $824 \mathrm{~K}$. Given the extreme temperature that run \#1 was exposed to, the 
change in the slopes of $D_{\text {calc }} / D_{\text {meas }}$ of all models above $800 \mathrm{~K}$, and cooling measurements that were much lower than those on heating, it is likely the XRD reported for this sample is not representative of the composition and abundances of phases in the disk prior to heating. Breakdown of hydrous phases such as biotite leading to a loss of sample cohesion is the likely cause.

\subsubsection{Full high-temperature suite}

For the full suite of high temperature samples, 14 samples had $D_{\text {calc }} / D_{\text {meas }}$ within \pm 0.1 of 1.0 . For the remaining 18 samples, three (Acasta Run \#1, KB09c1, KB1 1ab) had relatively flat slopes for $D_{\text {calc }} / D_{\text {meas }}$ over the interval of $\sim 290-500 \mathrm{~K}$ and increasing slopes thereafter (e.g. Fig. 5-11b \& c). Nine had initial $D_{\text {calc }} / D_{\text {meas }}$ values outside the interval 0.9-1.1. And seven had $D_{\text {calc }} / D_{\text {meas }}$ values near 1.0 at ambient temperature, but steep slopes at elevated temperatures similar to sample 16-36. Mean error at maximum temperature for all samples was $14 \%$, but crucially, 23 of the 32 samples had lower $D$ at maximum temperature than projected by calculations, and 22 samples had overall positive $D_{\text {calc }} / D_{\text {meas }}$ slopes (outside $\sim 2-5 \%$ analytical error), indicating that overall, high-temperature rock measurements tend toward lower $D$ than expected on the 
basis of mineralogy alone.

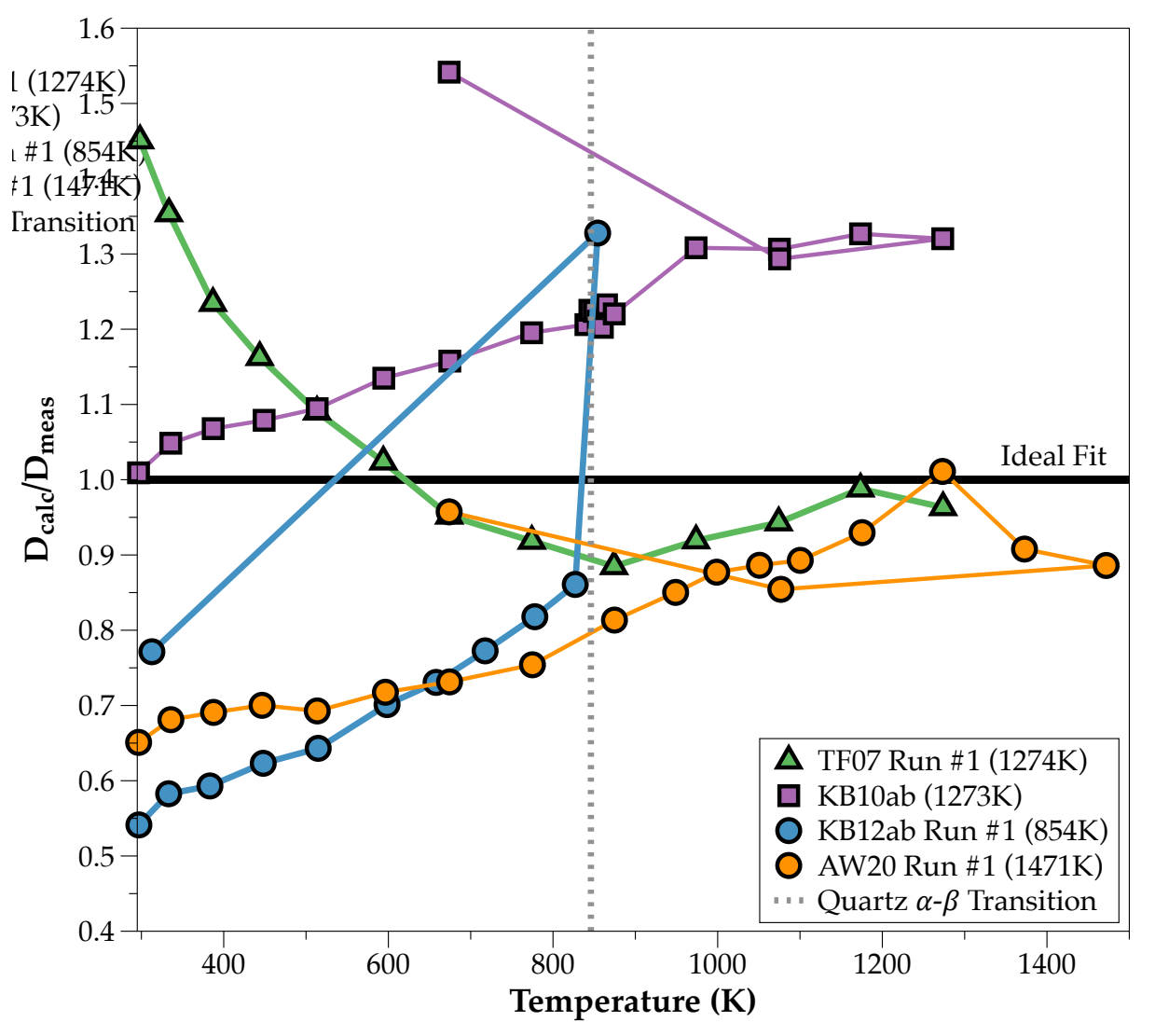

Figure 5-11) $D_{\text {calc }} / D_{\text {meas }}(\mathrm{G}$ model) of four samples from Merriman et al. 2013. These samples were heated to higher temperatures than most of the suite described at the beginning of section 5.3. Potential sources of error are described in section 5.3.3.

\subsubsection{Additional potential sources of measurement error}

A clear correlation exists between samples measured to temperatures above $\sim 800$ $\mathrm{K}$ and poor high-temperature $D_{\text {calc }} / D_{\text {meas }}$ (e.g. Figure 5-10). Of the 10 samples measured above $800 \mathrm{~K}$, only sample AW20 Run\#3 and the anorthosites Shawmere and Stillwater had measured $D$ that was well reproduced using the RockCalculator spreadsheet. For samples that cross the quartz $\alpha-\beta$ transition and contain more than trace quantities of 
quartz, abrupt changes in volume of quartz are a possible source. An abrupt displacive transformation occurs in quartz at $846 \mathrm{~K}( \pm 1-2 \mathrm{~K})$ with a linear expansion of $\sim 0.5 \%$ and slight change in density (c.f. Figs. 12.5 a \& b pg. 271, Klein and Dutrow, 2007). The transformation is fully reversible. Of the few samples measured above $846 \mathrm{~K}$, samples contained detectible quantities of quartz: UP-7B (Fig. 5.11c), KB09c (Fig. 5.11a), KB10ab (Fig. 5-10), KB11ab, and KB12ab (Fig. 5-10). All of these samples show changes in slopes of $\mathrm{d} D / \mathrm{d} T$ across the $\alpha-\beta$ transition, and commensurate increases in $D_{\text {cald }} / D_{\text {meas. }}$ Furthermore, for samples KB11ab and KB12ab, which had large quantities of quartz ( $\sim 19 \%$ and $30 \%$ by weight), the increase in $D_{\text {calc }} / D_{\text {meas }}$ over the transition was proportionally high: $\sim 15 \%$ for KB11ab, and $60 \%$ for KB12ab. Despite both samples being heated only slightly above $846 \mathrm{~K}$, irreversible changes in the disks are suggested by lower measured $D$ on cooling than heating.

A theme of lower $D$ measured on cooling is present in most samples measured to high $T$. Figure 5.11 shows $D_{\text {calc }} / D_{\text {meas }}$ for three samples in which cooling measurements did not reproduce heating measurements. In figure 5-11a, sample KB09c is predicted within $\sim 5 \%$ of measured values using the $\mathrm{G}$ method to $\sim 600 \mathrm{~K}$, but heating past $1200 \mathrm{~K}$ appears to irreversibly alter the disk as calculations on cooling are as much as $90 \%$ higher than measured values. Despite peak measurement temperatures lower than those discussed above, Acasta Run \#1 (Fig. 5-11b) also had measurements on cooling that were lower than predicted by calculations. A similar process appears to have occurred for sample UP-7A (Fig. 5-11c), which was initially heated to $\sim 800 \mathrm{~K}$ and cooled, the graphite coating removed and a fresh coating applied, and then reheated to $\sim 1250 \mathrm{~K}$. Initial ambient $T$ measurements on reheating were not only $25 \%$ lower, but a subsequent 

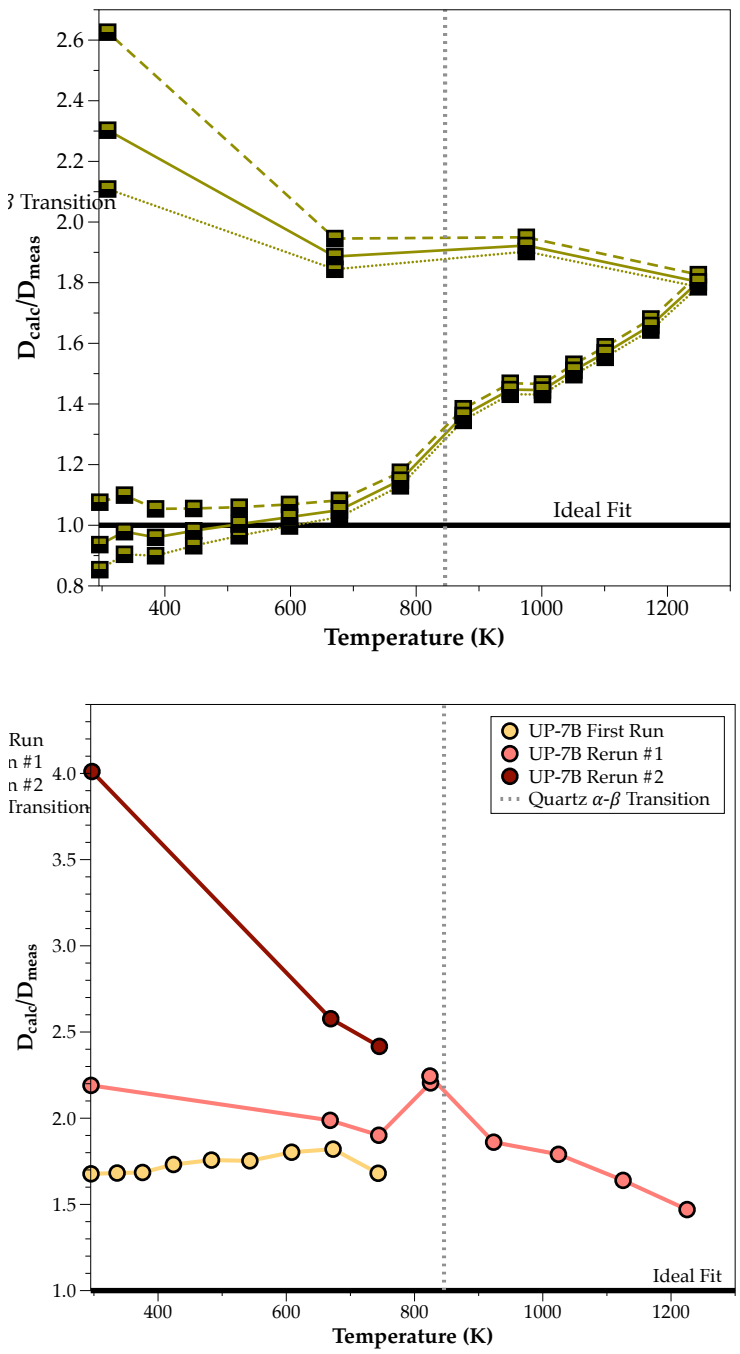

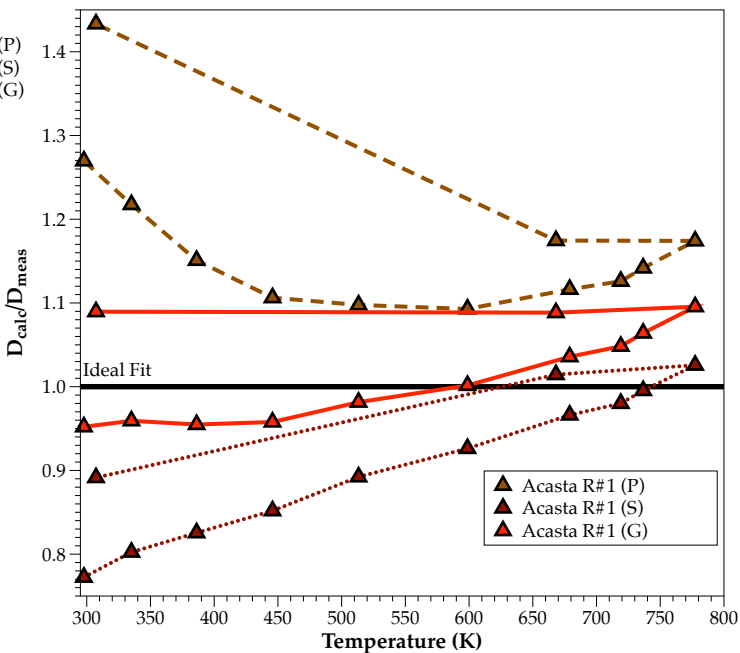

Figure 5.11) $D_{\text {calc }} / D_{\text {meas }}$ for three samples which did not produce $D$ measurements on cooling similar to those during heating. (A) KB09c, (B) Acasta Run \#1, and (C)

UP-7B had results which indicate irreversible changes in the disk upon heating. Dashed lines indicate the P model, dotted, the S model, and solid lines the G model.

Calculations for sample UP-7B are for the G model only.

This disk was heated to high temperature several times (see text). Disks KB09c and Acasta Run \#1 were originally measured by Merriman et al. (2013).

third run on the same disk lowered ambient $T$ thermal diffusivity again. It is likely, given a mineralogy of quartz and dolomite, that breakdown of dolomite $\left(\mathrm{CaMg}\left(\mathrm{CO}_{3}\right)_{2}\right)$ occurred progressively during heating. This is supported by XRD results for the disk after heating, which indicated quartz, periclase $(\mathrm{MgO})$, portlandite $\left(\mathrm{Ca}(\mathrm{OH})_{2}\right)$ and lime $(\mathrm{CaO})$, but no dolomite, despite $\sim 49 \%$ dolomite (by wt) for an adjacent cut of the same sample (UP-7B c1d1). This may also be the cause of the poor $D_{\text {calc }} / D_{\text {meas }}$ for the sample. Values calculated for figure 5-11c were made by recalculating the original dolomite content of 
the disk, but the weight fractions of the above breakdown products do not balance, and it is likely considerable mass was lost.

Although most samples in our suite did not include carbonate minerals, ten samples had steeper $\mathrm{d} D / \mathrm{d} T$ than projected by the RockCalculator, compared to two with lower $\mathrm{d} D / \mathrm{d} T$ than expected. The latter samples are both disks of komatiite TF07 (green line, Fig. 5-10), and this error is likely a result of chlorite in the sample that is more much more Mg-rich than that measured by Hofmeister (2019).

However, the ten samples with steeper $\mathrm{d} D / \mathrm{d} T$ than predicted all fall under category II (section 5.3.2): immediate departure of calculated $D$ from measured $D$ at temperatures above ambient. Branlund and Hofmeister (2008) found similar results for porous quartzites, suggesting that differential expansion of grains, combined with cracks generated during heating could create secondary porosity within the samples during measurements. Although the samples in this work are generally very low-porosity materials (Chapter 3), during decompression, rocks may expand, opening new cracks which can be filled with water or other fluids (Parnell, 2002; Akker et al. 2018). Water is notable for, amongst other characteristics, its high coefficient of thermal expansion at low temperatures (e.g. Kell, 1975) and can be metastable in a liquid form at atmospheric pressure at temperatures up to $325^{\circ} \mathrm{C}$ (Chukanov and Skr 1971). Combined with differential expansion of grains, pore water, however minor, could cause samples to expand during heating in the LFA. Because measured $D$ is proportional to the square of the thickness of the sample (Eq. 1-4), minor expansion of the LFA disk would result in higher error in reported $D$. Furthermore, if pore pressure is sufficient to cause the sample 
to dehydrate, cracking of samples would generate permanent air on grain boundaries, lowering the ability of the sample to conduct heat.

\subsection{CONCLUSIONS}

Mixing of mineral thermal diffusivity in a rock produces a complex, but predictable bulk rock $D$ that behaves according to established mixing models (Chapter 4$)$. At ambient temperature, most rocks $D$ can be calculated using the Geometric model (Eq. 4-3), with the possible exception of samples in which grains are aligned in strong layers. These results appear to extend to rocks at high temperature, where differences between $D$ of minerals are typically smaller (e.g. Figs. 5-1 to 5-3). For the suite of 32 rocks included in this chapter, all but 3 had $D_{\text {calc }} / D_{\text {meas }}$ closest to 1.00 across the widest range of temperatures using the Geometric model.

However, only 14 of the 32 samples analyzed in this chapter had $D$ s which could be predicted from measured disk properties. For samples with strong errors (peak error $>$ $\sim 10 \%$ ), no strong correlation between disk characteristics was found. Samples in this category range from deep-crustal upper-amphibolite facies metamorphic rocks (e.g. 145B), to chloritized ultramafic rocks (e.g. AW04) and simple quartz-dolomite mixtures (UP-7B). Although some issues likely arise for samples which have been heated above the stability range at atmospheric pressure of phases within them such as abrupt changes in volume associated with the quartz $\alpha-\beta$ transition, most of the samples with strong errors at elevated temperature were not heated past this temperature $(846 \mathrm{~K})$.

Errors in characterization of abundances and composition of phases within the disk are likely responsible for some of the poor results as described for ambient $T$ results 
in Chapter 4, but many disks had ambient $T$ calculations within the 5\% analytical error of the LFA, simple mineralogy with phases that have well-characterized $D$, but a strong positive slope in $D_{\text {calc }} / D_{\text {meas }}$ space.

The number of samples analyzed here, along with the (apparent) random nature of this error prevents us from making any definitive conclusions about the source of errors. However, it is unlikely that these results are representative of the true behavior of these samples at high temperature because rock $D$ often drops below the $D$ of most insulating phase in the sample. Furthermore, grain-boundary resistance is also an unlikely culprit because samples with this error span nearly the full-range of measured grain sizes (Table 3-1), and grain-boundary resistance should increase with the density of grains.

Until definitive evidence is available to prove otherwise, we conclude that many high-temperature rock measurements have the potential for a complex series of experimental errors resulting in reversible and/or irreversible changes to the sample during heating. Some possibilities include differential expansion of grains during heating, rapid expansion of trapped water in minor pore space, abrupt changes in quartz density across the quartz $\alpha-\beta$ transition, and the breakdown of hydrous phases such as biotite or amphibole during heating. Some of these issues could be reduced or eliminated by applying pressure during heating (e.g. differential expansion, hydrous phase breakdown), but others are not strongly affected by applied pressure, and would be present in measurements using any technique.

Furthermore, without having available calculated rock $D$ to high temperature to compare to measured $D$ for polycrystalline samples, it may be difficult to distinguish between samples that have a higher amount of experimental error than expected, and 
those that do not. We therefore conclude that calculating rock $D$ at elevated temperatures, from modal mineralogy and published single-crystal data mixed with the $\mathrm{G}$ method, is the best approach to establishing the ability of lithospheric rocks to conduct heat.

\section{REFERENCES CITED}

Akker, I.V., Kaufmann, J.K, Desbois, G., Klaver, J., Urai, J.L., Berger, A., and Herwegh, M., 2018. Multiscale porosity changes along the pro- and retrograde deformation path: an example from Alpine slates. Solid Earth, vol. 9, pp. 1141-1156, https://doi.org/10.5194/se-9-1141-2018.

Branlund, J.M., and Hofmeister, A.M., 2007, Thermal diffusivity of quartz to $1,000^{\circ} \mathrm{C}$ : Effects of impurities and the $\alpha-\beta$ transition: Physics and Chemistry of Minerals, v. 34, p. 581-595, https://doi.org/10.1007/s00269-007-0173-7.

Branlund, J.M., and Hofmeister, A.M., 2008. Factors affecting heat transfer in natural $\mathrm{SiO}_{2}$ solids. American Mineralogist, v. 93, pp. 1620-1629.

Branlund, J.M., and Hofmeister, A.M., 2012, Heat transfer in plagioclase feldspars: The American Mineralogist, v. 97, p. 1145-1154, https://doi.org/10.2138/am.2012.3986.

Bräuer, H., Dusza, L., and Schulz, B., 1992, New laser flash equipment LFA 427: Interceram, v. 41, p. 489-492. 
Chukanov, V.N., and Skripov, V.P., 1971. Spezifische Volumina vom überhitzten Wasser. Teplofiz. Vys. Temp., Vol. 9, p. 1071. English translation: High Temp., Vol. 9, p. 978.

Criss, E.M., and Hofmeister, A.M., 2017. Isolating lattice from electronic contributions in thermal transport measurements of metals and alloys above ambient temperature and an adiabatic model. International Journal of Modern Physics B, vol. 31, no. 14, 1750205 (75p.), doi: 10.1142/S0217979217502058

Fei, Y., 1995, Thermal expansion, in Ahrens, T.J., ed., Mineral Physics and Crystallography: A Handbook of Physical Constants: Washington, DC, American Geophysical Union, p. 29-44, https://doi.org/10.1029/RF002p0029.

Gaines, R.V., Skinner, H.C.W, Foord, E.E., Mason, B., and Rosenzweig, A., 1998. Dana's New Mineralogy, 8th Ed., John Wiley \& Sons, Inc., New York, 1819 p.

Hofmeister, A.M., 2019. Measurements, Mechanisms, and Models of Heat Transport. $1^{\text {st }}$ Ed., Elsevier, 440 p.

Hofmeister, A.M., and Perterman, M., 2008, Thermal diffusivity of clinopyroxenes at elevated temperature: European Journal of Mineralogy, v. 20, p. 537-549. 
Hofmeister, A.M. and Carpenter, P.K., 2015. Heat transport of micas. The Canadian Mineralogist, vol. 53, pp. 557-570, doi: 10.3749/canmin.1400093

Kell, G.S., 1975. Density, Thermal Expansivity, and Compressibility of Liquid Water from $0^{\circ}$ to $150^{\circ} \mathrm{C}$ : Correlations and Tables for Atmospheric Pressure and Saturation Reviewed and Expressed on 1968 Temperature Scale. Journal of Chemical and Engineering Data, Vol. 20, No. 1, pp. 97-105.

Klein, C., and Dutrow, B., 2008. The $23^{\text {rd }}$ Edition of the Manual of Mineral Science, John Wiley \& Sons, Inc., Hoboken, New Jersey, p. 271.

Merriman, J.D., Whittington, A.G., Hofmeister, A.M., Nabelek, P.I., and Benn, K., 2013, Thermal transport properties of major Archean rock types to high temperature and implications for cratonic geotherms: Precambrian Research, v. 233, p. 358-372, https://doi.org/10.1016/j .precamres.2013.05.009.

Merriman, J.D., Hofmeister, A.M., Roy, D.J., and Whittington, A.G., 2018. Temperaturedependent thermal transport properties of carbonate minerals and rocks. Geosphere, v. 14, no. 4, p. 1961-1987, https://doi.org/10.1130/GES01581.1.

Parnell, P., 2002. Diagenesis and fluid flow in response to uplift and exhumation. In: Doré, A.G., Cartwright, J.A., Stoker, M.S., Turner, J.P. and White, N. Exhumation of the 
North Atlantic Margin: Timing, Mechanism and Implications for Petroleum Exploration. Geological Society, London, Special Publications, 196, pp. 433-446.

Roy, D., Merriman, J.D., Whittington, A.G., and Hofmeister, A.M., in review. Thermal properties of carbonatite and anorthosite from the Superior Province, Ontario, and implications for non-magmatic thermal effects of intrusions. Submitted to: Canadian Journal of Earth Sciences, March 13, 2019.

Smith, D.S., Fayette, S., Grandjean, S., Martin, C., Telle, R., and Tonnessen, T. 2003, Thermal resistance of grain boundaries in alumina ceramics and refractories: Journal of the American Ceramic Society, v. 86, p. 105-111, https://doi.org/10.1111/i.11512916.2003.tb03285.x.

Wang, J., Carson, J.K., North, M.F., and Cleland, D.J., 2008. A new structural model of effective thermal conductivity for heterogeneous materials with co-continuous phases. International Journal of Heat and Mass Transfer, vol. 51, pp. 2389, doi:10.1016/j.ijheatmasstransfer.2007.08.028

Yu, X. and Hofmeister, A.M., 2011. Thermal diffusivity of alkali and silver halide crystals as a function of temperature. Journal of Applied Physics, v. 109, 033516, doi: $10.1063 / 1.3544444$. 


\section{Chapter 6: Conclusions, Applications, and Suggestions for Future Research}

\subsection{Conclusions}

Because a rock is a complex mixture of materials and textural features, multiple physical and chemical properties combine to determine the ability of a rock to conduct heat. The thermal transport properties, thermal diffusivity $(D)$, thermal conductivity $(k)$, heat capacity $C_{P}$, and density $(\rho)$ are related through equation $1-1$, and for a rock, are a product of many of the same properties. Of these, mineralogy has the clearest influence on bulk rock $D$. For example, in carbonate rocks, bulk-rock $D$ is generally a consequence of whether the rock is dominated by low- $D$ calcite or higher- $D$ dolomite, but variations in proportions of other sedimentary minerals (detrital or organic in nature) add an additional layer of complexity.

For the broader family of rocks found on Earth, the suite of 55 rock samples examined in this work show that the relative abundance of high- $D$ or low- $D$ minerals correlates strongly with the ability of those rocks to conduct heat at ambient temperatures. Slices of rocks which are rich in the high- $D$ mineral quartz tend towards higher disk $D$, such that the relationship can be predicted to a confidence similar to the analytical error of the Laser Flash Analysis (LFA) method (e.g. Eqs. 3-10 \& 3-11). Similar relationships likely exist for rocks without quartz, but insufficient number of samples were available to generate fitting parameters similar to those for the above equations.

Mineral $D$ is itself controlled by structure of the mineral, the volume of the unit cell, and the mass of cations that compose it. For example, the composite mineral 
dolomite has a thermal diffusivity that is effectively the weighted average of the pure $\mathrm{Ca}$ and $\mathrm{Mg}$ carbonate minerals calcite and magnesite. The trends may be simple enough to predict mineral $D$ for compositions which fall between endmembers for solid solutions (e.g. figure 2-11(A)), at least for (compositionally) simple solid solutions such as olivine.

More complex mineral solutions require more complex models, as is shown by the plagioclase solution. Although simple chemically, the coupled substitution of $\mathrm{NaSi}$ $\Leftrightarrow \mathrm{CaAl}$ creates more complex structural changes that influence mineral $D$. The relationship, unlike what is suggested by mixing of the carbonates, creates a non-linear change in $D$ with composition (e.g. Fig. 4-5). Additional complexity is added to the model when considering mineral anisotropy, and changes in the ability of a mineral to conduct heat with temperature (e.g. Figs. 3-2B and 4-6). Many minerals such as plagioclase or quartz are anisotropic both structurally, and with respect to $D$. Although mineral $\rho$ and $C_{P}$ do not vary by mineral orientation, both $D$ and $k$ do. Furthermore, as temperature increases, most mineral $D$ decreases, a relationship that is extended to rocks (e.g. Fig 3-1).

Because the complex structural relationships for the plagioclase solution extend to high $T$, we created a model to calculate plagioclase $D$, and consequently $k$. Measurements of $D$ at ambient temperature for plagioclase-rich rocks with An contents not directly measured in the LFA were effectively reproduced by calculated $D$ using one of the three plagioclase interpolation models as discussed in chapters 3 and 4. Furthermore, most of the high $T$ measurements for rocks that were effectively calculated using the RockCalculator spreadsheet included plagioclase as an important component (e.g. Figs. 5-6 \& 5-8). It should also be noted that many of the samples with strong errors included 
plagioclase as the most abundant phase (e.g. sample 16-36, Fig. 5-7, sample AW20, Fig. $5-10)$

However, anorthosites may be the best measure for the effectiveness of the plagioclase calculator at ambient and elevated temperature, because these rocks are nearly-pure mixtures of plagioclase, usually cooled at slow rates and deep depths facilitating growth of large crystals and equilibration of mineral composition (e.g. Arndt, 2013; Scoates, 2000). Calculated $D$ for the Shawmere anorthosite reproduced measured $D$ values to within $3 \%$ for the temperature range $\sim 300-1200 \mathrm{~K}$, where decomposition of minor amphiboles and epidote is suggested by a sudden drop in the measured $D$, lower values on cooling, and flaking of the graphite coating. Similar results were found for the Stillwater anorthosite, with higher uncertainty due to a lack of sample-specific probe data. This, combined with results for other plagioclase-rich rocks above suggests the plagioclase model is not a major driver of variation between $D_{\text {calc }}$ and $D_{\text {meas }}$. We tentatively recommend using the "All Points" plagioclase model for rapidly-cooled rocks where high-temperature plagioclase phases are preserved, and the Piecewise model for slowly-cooled rocks, but both models are effective in the range $\mathrm{An}_{0.5}$ to An95.

Additional variation is often driven by several factors, including layering within LFA disks (heterogeneity), crystallographic or shape-preferred orientation (anisotropy), and porosity. Careful characterization of the first two of these factors can compensate for any issues in reproducibility between different slices of the same sample, and produce accurate calculations of rock $D$ at low $T$ (e.g. Fig. 4-9A), but more work is needed to characterize $D$ of pore-filling fluids. Disk-specific data for pore fraction was unavailable, 
although porosity is unlikely to be a significant factor affecting $D$ for the crystalline rock suite we chose to study.

Additionally, a few samples were available which contained visible anisotropy. For these samples, disks with heat flowing across layers of platy minerals is effectively calculated using the Series model (Eq. 4-2.), and disks with heat flowing along cleavage planes of platy minerals are best modeled using the Parallel method (Eq. 4-1). This is in contrast to the majority of samples, which were best calculated at ambient to high temperature using the Geometric method (Eq. 4-3). However, successful reproduction of measured $D$ for rocks at high temperature was more elusive, in part because many samples displayed $D_{\text {meas }}$ near-, or lower-than that of the lowest- $D$ major phase identified by XRD (e.g., Fig. 5-8). Less than $50 \%$ of the samples analyzed to high temperature had $D_{\text {calc }} / D_{\text {meas }}$ within $10 \%$ of 1.00 across the full range of temperatures analyzed, and no characteristic was found in common between all disks that could explain these errors.

A number of these errors likely arise because samples have been heated above the stability range of phases within the disks at atmospheric pressure, with possible effects ranging from rapid expansion of trapped water in microfractures generated during decompression, abrupt changes in quartz density across the quartz $\alpha-\beta$ transition, the breakdown of hydrous phases during heating, and differential expansion of mineral grains creating separation along grain boundaries. It is unlikely that these results are indicative of natural behavior when a rock is heated in the lithosphere under confining pressure.

Until a definitive source is identified for this error, we recommend calculating rock $D$, even if measured $D$ is available for the sample, as the calculated $D$ provides a 
check on whether (apparently) random experimental error has occurred during measurement. Furthermore, measurements for single-crystal mineral samples are free of most of the possible sources of error discussed above, and for the few that are present (e.g. dehydration of micas), simpler $\mathrm{d} D / \mathrm{d} T$ and equation 3-4 allow extrapolation of measured data to higher temperatures. The RockCalculator spreadsheet provides a preliminary new tool for calculating the ability of a rock to conduct heat from constituent properties, which will facilitate new avenues of research for geoscientists working with heat flow. In the final sections of this chapter, we discuss some of these possible new applications, and suggest future directions for research which will could improve the RockCalculator, the measurement of thermal diffusivity using the LFA technique, and improve our understanding of controls on and behavior of heat flow within rocks.

\subsection{APPLICATIONS}

\subsubsection{Using Bulk Rock Compositions and Phase Equilibrium Modeling Software to Predict Changes in Rock Thermal Transport Properties}

Using temperature-dependent thermal transport properties of rocks in place of a single, invariant value can have moderate-to-strong effects on models for the geothermal gradient (e.g. Whittington et al., 2009; Merriman et al., 2013), be an essential part of the feedback mechanism behind strain heating leading to ultrahigh temperature metamorphism (Nabelek et al., 2010), and, when not incorporated in models for 
thermochronologically-constrained exhumation, can lead to an underestimation of the exhumation rate (Braun et al., 2016). Furthermore, inclusion of temperature-dependent thermal diffusivity $(D(T))$ into models of the cooling of plutons and sills can extend the time these bodies remain above the solidus by up to a factor of five (Nabelek et al., 2012). If higher temperatures and longer residence times can be achieved using $D(T)$ in numerical models ${ }^{7}$, what effect might metamorphism have on the ability of a rock to conduct heat?

The RockCalculator spreadsheet can be used to provide clues. Table 6-1 shows the chemical composition of three samples of migmatite 16-35 collected near the Ivanhoe Lake Fault Zone which separates the mid- and upper-crustal rocks of the Swayze greenstone belt from lower-crustal rocks exposed in the Kapuskasing Structural Zone (see Chapter 3 and Percival and West (1995) for more information). Using the software package Theriak-Domino (De Capitani, and Petrakakis, 2010), mineral proportions were calculated at $\sim 5 \mathrm{~km}$ intervals of increasing lithostatic pressure along a geothermal gradient modeled from a purely conductive lithosphere with heat producing element

TABLE 6-1: WEIGHT PERCENT OXIDES IN SAMPLES OF MIGMATITE 16-35

\begin{tabular}{|l|ccccccc|}
\hline \hline Sample & $\mathbf{S i O}_{2}$ & $\mathbf{A l}_{2} \mathbf{O}_{3}$ & $\mathbf{F e}_{2} \mathbf{O}_{3}$ & $\mathbf{M g O}$ & $\mathbf{C a O}$ & $\mathbf{N a}_{2} \mathbf{O}$ & $\mathbf{K}_{2} \mathbf{O}$ \\
\hline Leucosome & 75.9 & 13.3 & 2.2 & 0.3 & 3.5 & 3.6 & 0.6 \\
Melanosome & 54.5 & 14.9 & 11.9 & 4.5 & 8 & 2.8 & 0.9 \\
Bulk Rock & 61.8 & 14.5 & 8.9 & 3.2 & 6.6 & 3 & 0.9 \\
\hline
\end{tabular}

\footnotetext{
${ }^{7}$ Adding temperature-dependent thermal diffusivity does not result in higher temperatures in all numerical models of common lithospheric processes. Nabelek et al. (2012) noted that using $D(T)$ in place of a single, invariant $D$ of $1 \mathrm{~mm}^{2} \mathrm{~s}^{-1}$ for a model of contact metamorphism by a basaltic sill and granitic pluton reduced peak temperatures but extended the time the center of the sill remained above the solidus by a factor of three.
} 


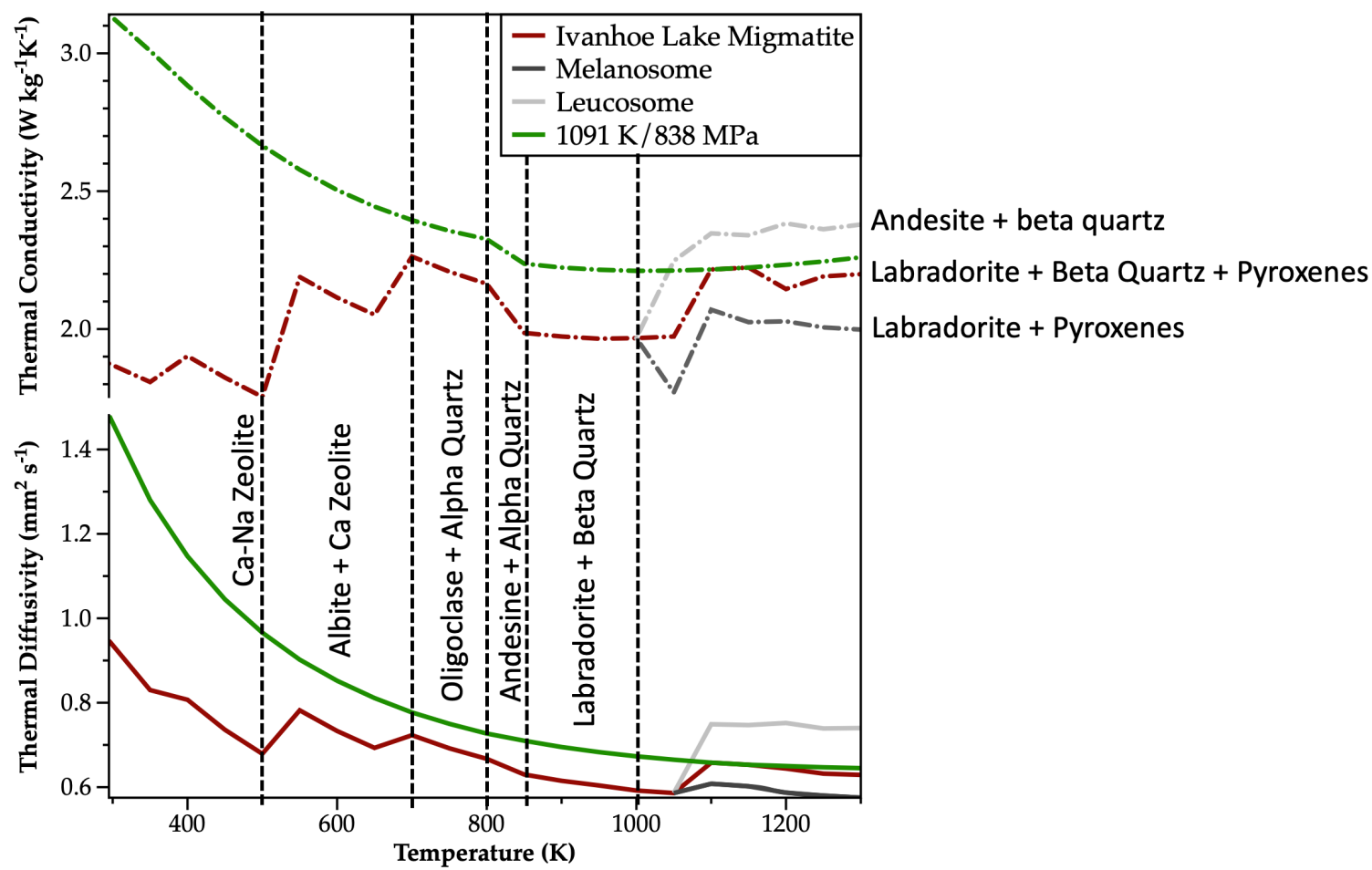

Figure 6-1) Calculated $D(T)$ and $k(T)$ for mineral assemblages derived from bulk chemical analysis in

Table 6-1. See text for details on calculations. Dashed lines indicate boundaries between the major assemblages at discrete stages along the geothermal gradient described in the text. Note the decrease in $k$ near $850 \mathrm{~K}$ for the green line (stable mineral assemblage across the full temperature range) and red line (variable mineral assemblage across temperature calculated using Theriak-Domino) is a result of an abrupt change in $C_{P}$ for quartz in the samples across the $\alpha-\beta$ transition.

concentrations back-calculated to the late Archean ${ }^{8}$.

Figure 6-1 shows the resulting thermal conductivity (lower) and thermal diffusivity (upper) calculated using the RockCalculator spreadsheet for a sample with the

\footnotetext{
${ }^{8}$ Thermal modeling performed using the finite-difference numerical modeling software Lithoheat (Nabelek et al., 2010), and the crustal structure and temperature-dependent thermal transport properties described in Chapter 3 from Merriman et al. (2013). Lithospheric thickness was set to $100 \mathrm{~km}$, and a basal thermal boundary condition of $1300^{\circ} \mathrm{C}$ used.
} 
full composition of the Ivanhoe Lake Migmatite (ILM) 16-35 ("Bulk Rock", table 6-1). The green lines represent calculated $D(T)$ and $k(T)$ for the peak metamorphic assemblage of minerals at estimated peak metamorphic assemblage along the modeled geothermal gradient. Calculated $D(T)$ and $k(T)$ are broadly similar to measurements for high-grade metamorphic rocks from the Kapuskasing Structural Zone (e.g. sample 14-4D, figure 39B), with a $D$ of $\sim 1.5 \mathrm{~mm}^{2} \mathrm{~s}^{-1}$ at $300 \mathrm{~K}$ decreasing to $\sim 0.8 \mathrm{~mm}^{2} \mathrm{~s}^{-1}$ at $700 \mathrm{~K}$, and $<0.7 \mathrm{~mm}^{2}$ $\mathrm{s}^{-1}$ near peak metamorphic conditions.

It is likely, however, that this sample had a more complex history prior to migmatization that included deposition or intrusion at shallower depths, and a prograde metamorphic path with previous metamorphic events. The red lines in figure 6-1(A \& B) show several $D$ and $k$ results for mineral assemblages derived from the bulk sample composition in table 6-1 at $5 \mathrm{~km}$ intervals along the geothermal gradient discussed above. The red line ILM $D$ is much lower across the range of temperatures shown than the green line ILM $D$. This is a result of changes in composition and abundance of major phases within the sample as predicted by Theriak-Domino (Figure 6-1B). Amphibolites of the $\mathrm{KSZ}$ are estimated to undergo partial melting beginning at $\sim 800^{\circ} \mathrm{C}$ (Hartel and Pattison, 1996, Pattison et al., 2003), and we use this boundary temperature to project the change in thermal transport properties for the full ILM sample (red line), the melanosome (dark grey line), and the leucosome (light grey line) that result from migmatization. The effects of this process on the local geology are partially dependent upon how much and how far melt derived from anatexis migrates in the crust, but the higher- $D$ leucosome, if recrystallized preferentially after rising to shallower depths in the crust, could cause the 
crust to have a higher ability to conduct heat because of much higher proportions of quartz in the leucosome than in the melanosome.

\subsubsection{Using XRD to Calculate Thermal Transport Properties of Rocks on Other}

\section{Planets}

A more than 20-year effort to miniaturize an X-Ray Diffractometer (XRD) resulted in the inclusion of the CheMin XRD in the Mars Curiosity Rover's onboard scientific toolset (Downs, 2015). Analysis of aeolian deposits at Rocknest (Blake et al., 2013), and sandstone collected from the Gale Crater (Bish et al., 2013) produced the first measurements of mineral proportions and compositions of solid solution minerals within sedimentary material collected off the surface of Earth. Table 6-2 shows results for both sampling efforts, with compositional information for plagioclase and pyroxene.

\begin{tabular}{|c|c|c|c|c|c|c|c|c|c|c|}
\hline \multicolumn{11}{|c|}{ TABLE 6-2: WEIGHT PERCENT OF MAJOR PHASES FROM MARTIAN SEDIMENTS } \\
\hline Locality & Plagioclase & Pyroxene & Olivine & Kspar & Magneite & Clay & Quartz & Hematite & Ilmenite & Amorphous Material \\
\hline Rocknest & 41 & 28 & 22 & 1 & 2 & - & 1 & 1 & 1 & - \\
\hline Gale Crater & - & 33 & - & 15 & 10 & 8 & & & & 20 \\
\hline
\end{tabular}

Using RockCalculator to calculate the thermal diffusivity of the sediment source for the Rocknest aeolian deposits produced an estimated $k$ of $\sim 3.1 \mathrm{~W} \mathrm{~m}^{-1} \mathrm{~K}^{-1}$ and $D$ of 1.3 $\mathrm{mm}^{-2} \mathrm{~s}^{-1}$ at $300 \mathrm{~K}$, dropping to $2.4 \mathrm{~W} \mathrm{~m}^{-1} \mathrm{~K}^{-1}$ and $0.7 \mathrm{~mm}^{2} \mathrm{~s}^{-1}$ at $1000 \mathrm{~K}$. Although atmospheric temperatures on Mars are much colder than $300 \mathrm{~K}$, measurements for thermal transport properties of minerals at temperatures below $300 \mathrm{~K}$ are sparse. However, if Eq. 3-4 can effectively extrapolate thermal diffusivity to temperatures above those measured in the LFA, and the same mechanisms of heat flow (primarily vibrational 
diffusion with minimal radiative transfer, see Chapter 1), then extrapolation to lower temperatures is theoretically possible. In the case of the above composition, calculated $D$ at a Martian surface temperature of $\sim 200 \mathrm{~K}^{9}$ (Hartmann, 2005) is $\sim 1.8 \mathrm{~mm}^{2} \mathrm{~s}^{-1}$.

Advances in probe sampling techniques and XRD analysis extended to probes sent to other terrestrial bodies within the solar system could use future iterations of the RockCalculator which include low-temperature measurements of minerals found on these bodies to calculate the ability of crustal rocks to conduct heat. This would create new possibilities for exploring how terrestrial planets and moons of the solar system cooled following formation.

\subsection{SUGGESTIONS FOR FURTHER RESEARCH IN THERMAL TRANSPORT PROPERTIES}

Development of the RockCalculator required the creation of a plagioclase interpolation model. Because many common rock-forming minerals are also solid solutions, successful application of the calculator to the broad range of possible rock compositions in the Earth's lithosphere (and other terrestrial planets) would require development of interpolation models for these other solutions. Important mineral solutions include the pyroxenes, alkali feldspars, amphiboles, olivine, chlorite, and garnet. Work is underway for additional measurements for alkali feldspars, but preliminary results suggest without the more complex coupled substitution described at the beginning of this chapter, and similar accounting for the similar masses of the cations

\footnotetext{
${ }^{9}$ Martian temperatures differ significantly across its surface. Polar temperatures can be as low as $\sim 150 \mathrm{~K}$, but daytime equatorial highs peak near $300 \mathrm{~K}$ during the summer. See infographic at:

https://mars.nasa.gov/allaboutmars/facts/\#?c=inspace\&s=distance
} 
$\mathrm{Na}$ and $\mathrm{K}$, phase changes in alkali feldspars are more likely to account for differences in measured $D$ between samples than compositional variation. However, other solutions such as olivine, with high contrasts in cation masses are likely to vary more with composition (Pertermann and Hofmeister, 2006) and require additional samples to fully develop interpolation models.

The plagioclase model, however complex, would also benefit from additional sample measurements, particularly at near-endmember compositions (e.g. pure albite, anorthite), and at An contents above 60, where only two samples were included in Branlund and Hofmeister (2012). Additionally, discrete suites of samples in which information on the plagioclase structure inherent in the minerals prior to measurement is available (e.g. high temperature plagioclase or low temperature plagioclase, Fig. 4-2) would improve the model predictions.

Further work on minerals should also include measurements at temperatures lower than ambient conditions, measurement of less common minerals which are important components of ore-forming systems (e.g. sulfides such as galena or pyrite), or evaporites (e.g. gypsum, anhydrite), and application of geometric principles to determine if mineral orientation averaging methods (e.g. Arithmetic, Harmonic, or Pythagorean) should be performed based on ratios of lengths of mineral orientations.

Work on rock $D$ measurements should continue, particularly to address three important issues discussed in detail in this dissertation:

I) the source and nature of possible errors in high-temperature rock measurements II) whether the scale of observation influences the mixing model that works best in calculating rock $D$ 
III) expansion of measurements for samples with heterogeneity or crystal preferred orientation

Issue I could be addressed by measuring multiple slices rock to high temperature in a dilatometer to track changes in length of disks during heating, or by measurement of the internal structure of disks prior-to and following LFA measurements using an X-ray microscope. Issue II could be examined by varying the spot size of samples in the LFA, ideally to apertures lower than the grain size of the sample. Application of sample maps also collected with an X-ray microscope would aid in determining the mineral in the pathway of heat during LFA measurement. Issue III may be as simple as creating collecting and developing a large sample suite of rocks with the potential for thermal anisotropy and collecting LFA data and characterizing samples using the techniques described in this work.

Finally, improvements in the instrumentation and design of the LFA could greatly improve both data for minerals and rocks. The LFA equipment used in this work has a detector sensitivity that is lowest at ambient temperature. Improving detector sensitivity at low temperatures would reduce uncertainty in calculations of rock $D$ and facilitate measurement of thicker samples. Loss of heat out the sides of samples reduces the ability of the software algorithm to detect peak height in the $T-t$ curve, and heat loss grows with sample thickness. Improved detector sensitivity may also be necessary for measuring mineral and rock $D$ at temperatures below ambient. Application of a technique for measuring sample thicknesses in the LFA during heating would also greatly improve the measurements produced by the technique. Monitoring of expansion or contraction of samples during heating or cooling could be incorporated into measurements and reduce 
quasi-random errors associated with length changes of samples during heating (see Eq. 1$4)$.

\section{REFERENCES CITED}

Arndt, N., 2013. The formation of massif anorthosite: Petrology in reverse. Geoscience Frontiers, vol. 4, pp. 195-198.

Bish, D.L., Blake, D.F., Vaniman, D.T., et al., 2013. X-ray Diffraction Results from Mars Science Laboratory: Mineralogy of Rocknest at Gale Crater. Science, vol. 341 (6153), 1238932. doi:10.1126/science. 1238932

Blake, D.F., et al., 2013. Curiosity at Gale Crater, Mars: characterization and analysis of the Rocknest sand shadow. Science, vol. 341, doi: 10.1126/science.123905

Branlund, J.M., and Hofmeister, A.M., 2012, Heat transfer in plagioclase feldspars: The American Mineralogist, v. 97, p. 1145-1154, https://doi.org/10.2138/am.2012.3986.

Braun, J., Stippich, C., and Glasmacher, U.A., 2016. The effect of variability in rock thermal conductivity on exhumation rate estimates from thermochronological data. Tectonophysics, vol. 690, pp. 288-297. 
De Capitani, C., and Petrakakis, K., 2010. The computation of equilibrium assemblate diagrams with the Theriak/Domino software. American Mineralogist, vol. 95, pp. 10061016

Downs, R.T., 2015. Determining Mineralogy on Mars with the CheMin X-Ray Diffractometer. Elements, vol. 11, pp. 45-50.

Hartel, T.H.D., and Pattison, D.R.M., 1996. Genesis of the Kapuskasing (Ontario) migmatitic mafic granulites by dehydration melting of amphibolite: the importance of quartz to reaction progress. Journal of Metamorphic Geology, vol. 14, 591-611.

Hartmann, W.K., 2005. Moons and Planets. $5^{\text {th }}$ ed. Brooks/Cole-Thomson Learning, Belmont, CA, $428 \mathrm{p}$.

Merriman, J.D., Whittington, A.G., Hofmeister, A.M., Nabelek, P.I., and Benn, K., 2013, Thermal transport properties of major Archean rock types to high temperature and implications for cratonic geotherms: Precambrian Research, v. 233, p. 358-372, https://doi.org/10.1016/j .precamres.2013.05.009.

Nabelek, P.I., Whittington, A.G., and Hofmeister, A.M., 2010. Strain heating as a mechanism for partial melting and ultrahigh temperature metamorphism in convergen orogens: Implications of temperature-dependent thermal diffusivity and rheology. Journal of Geophysical Research, v. 115, B12417, doi:10.1029/2010JB007727. 
Nabelek, P.I., Hofmeister, A.M., and Whittington, A.G., 2012. The influence of temperature-dependent thermal diffusivity on the conductive cooling rates of plutons and temperature-time paths in contact aureoles. Earth and Planetary Science Letters, v. 317318, pp. 157-164. doi: 10.1016/j.epsl.2011.11.009.

Pattison, D.R.M., Chacko, T., Farquhar, J., and McFarlane, C.R.M., 2003. Temperatures of Granulite-facies Metamorphism: Constraints from Experimental Phase Equilibria and Thermobarometry Corrected for Retrograde Exchange. Journal of Petrology, vol. 44, no. 5, pp. 867-900.

Percival, J.A., and West, G.F., 1994. The Kapuskasing uplift: a geological and geophysical synthesis. Can. J. Earth Sci., v. 31, pp. 1256-1286.

Pertermann, M., and Hofmeister, A.M., 2006, Thermal diffusivity of olivine-group minerals at high temperature: The American Mineralogist, v. 91, p. 1747-1760, https://doi.org/10.2138/am.2006.2105.

Scoates, J.S., 2000. The Plagioclase-Magma Density Paradox Re-examined and the Crystallization of Proterozoic Anorthosites. Journal of Petrology, vol. 41, no. 5, pp. 627649. 
Whittington, A.G., Hofmeister, A.M. \& Nabelek, P.I., 2009. Temperature-dependent thermal diffusivity of the Earth's crust and implications for magmatism. Nature, 458(7236), pp.319-321. Available at:

http://www.nature.com/doifinder/10.1038/nature07818. 
Jesse Merriman is a native Missourian, and unapologetic Montessori kid from Weatherby Lake, Missouri. He was born the son professional educators Paula and Larry Merriman, and the grandson of the founders of Clay Platte Montessori School and the Missouri Montessori Association Shirley Plath and Charles Plath on his mother's side, and the former personal mechanic of General George S. Patton Donald Merriman and professional mother and grandmother Virginia Merriman on his father's side. Following a brief stint in a punk band while peddling cancer sticks and liquid atmospheric alteration fuel in the early 2000s, he received a Bachelor of Science in Geology from the University of Missouri-Kansas City in May, 2009. He followed this in May of 2011 with a Master of Science degree from the University of Missouri-Columbia, with a thesis on temperature-dependent thermal transport properties of Archean rocks and implications for the triggering of dome-and-keel structures within the Archean crust. He is an advocate of mental health issues, and the identification of and early treatment for invisible learning disorders. A love of hiking, biking, and photography, as well as summers spent in the Rocky Mountains as a child instilled a passion for understanding the origins of terrestrial structures and processes. 